U.S. GEOLOGICAL SURVEY

\title{
WATER-QUALITY DATA FOR LANDFILLS, HILLSBOROUGH COUNTY, FLORIDA, JANUARY 1974-OCTOBER 1977
}

OPEN-FILE REPORT 78-820

Prepared in cooperation with HILLSBOROUGH COUNTY, FLORIDA 
UNITED STATES

DEPARTMENT OF THE INTERIOR

GEOLOGICAL SURVEY

WATER-QUALITY DATA FOR LANDFILLS, HILLSBOROUGH COUNTY, FLORIDA, JANUARY 1974-OCTOBER 1977

By Mario Fernandez, Jr., and Robin R. Hallbourg

Open-File Report 78-820

Prepared in cooperation with

HILLSBOROUGH COUNTY, FLORIDA

Ta11ahassee, Florida 


\section{UNITED STATES DEPARTMENT OF THE INTERIOR \\ CECIL D. ANDRUS, Secretary}

GEOLOGICAL SURVEY

H. William Menard, Director

For additional information write to:

U.S. Geological Survey

Water Resources Division

325 John Knox Road, Suite F-240

Tallahassee, Florida 32303 


\section{CONTENTS}

Page

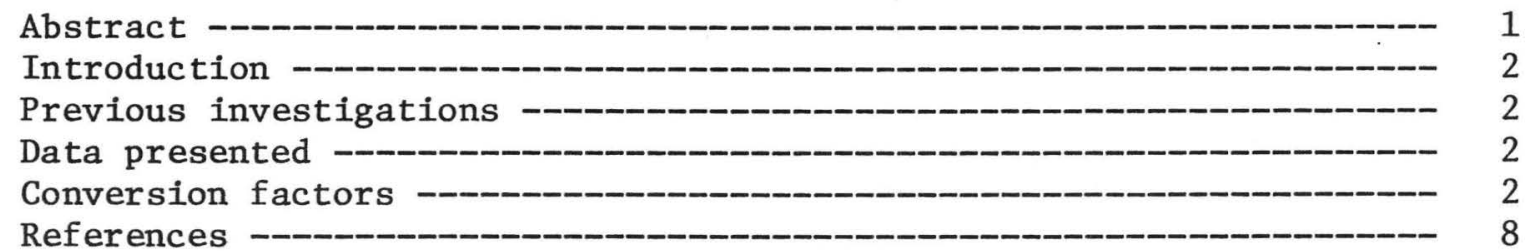

ILLUSTRATIONS

Page

Figures 1-5. Maps showing locations of:

1. Hillsborough County landfills - 3

2. Monitoring wells in Rocky Creek landfill ------ 4

3. Monitoring wells in Eureka Springs landfill --- 5

4. Monitoring we1ls in Gibsonton landfill ------- 6

5. Monitoring wells in Ruskin landfill -------- 7

TABLES

Page

Table 1. Description of wells - 9

2. Geologic logs of selected wel1s --_-_- 11

3. Chemical and bacteriological analyses for ground- and surface-water samples from the Rocky Creek landfill --- 14

4. Chemical and bacteriological analyses for ground- and surface-water samples from the Eureka Springs landfi11

5. Chemical and bacteriological analyses for ground- and surface-water samples from the Gibsonton landfill ----- 90

6. Chemical and bacteriological analyses for ground- and surface-water samples from the Ruskin landfill -------- 102 


\title{
WATER-QUALITY DATA FOR LANDFILLS, HILLSBOROUGH COUNTY, FLORIDA, JANUARY 1974-OCTOBER 1977
}

\author{
By Mario Fernandez, Jr., and Robin R. Hallbourg
}

\begin{abstract}
Periodic water-quality data were collected at four landfills in Hillsborough County from January 1974 through October 1977. Water samples were analyzed for nitrogen and phosphorus species, cations, trace metals, chloride, specific conductance, chemical oxygen demand, biological oxygen demand, and coliforms. Select ground-water samples were analyzed for herbicide and pesticide. Results of chemical and bacteriological analysis from four landfills are presented as basic data. Geologic logs and well descriptions are presented for wells drilled at the landfills after January 1974.
\end{abstract}




\section{INTRODUCTION}

Ground water in and near a landfill site can become contaminated by leachate from the fill material. Anticipating possible degradation of ground water, the Hillsborough County Commission entered, into a cooperative investigation with the U.S. Geological Survey to determine landfill effects on ground-water quality. The investigation began in May 1969 at the Eureka Springs landfill. The study was later expanded to include three other landfills: Rocky Creek (August 1969), Gibsonton and Ruskin (February 1974) landfills (fig. 1).

The purpose of this report is to present available well records, geologic logs of wells and surface- and ground-water quality data co1lected between January 1974 and October 1977 for planning purposes. This report will provide a base for a subsequent interpretive water-quality report.

Water samples were collected periodically from wells and selected surface-water sites at the four landfills. Specific conductance and $\mathrm{pH}$ were determined in the field. Sodium, potassium, calcium, magnesium, chloride, trace metals, chemical and biochemical oxygen demands, coliform, select herbicides and pesticides, and nitrogen and phosphorus species were determined in the laboratory.

\section{PREVIOUS INVESTIGATIONS}

Hydrologic factors affecting the utilization of land in Hillsborough - County were presented in a map by Stewart and Hanan (1970). Stewart and Duerr (1973) described hydrologic and geologic factors that are to be considered in landfill operations.

\section{DATA PRESENTED}

This report lists water-quality analyses of water samples collected January 1974 through October 1977 from wells and surface-water sites in and near four landfills operated by Hillsborough County (tables 3-6). Included are landfill locations (figs. 1-5), description of wells drilled during January 1974 through October 1977 (table 1), and geologic logs of selected wells drilled during this period (table 2). All water samples were analyzed in U.S. Geological Survey laboratories.

\section{CONVERSION FACTORS}

The inch-pound units used in this report can be converted to equivalent SI (metric) units as follows:

Multiply inch-pound unit

inch (in.)

foot $(\mathrm{ft})$
By

$$
\begin{aligned}
& 2.54 \times 10 \\
& 3.05 \times 10^{-10}
\end{aligned}
$$

To obtain SI (metric) unit millimeter (mm) meter (m) 


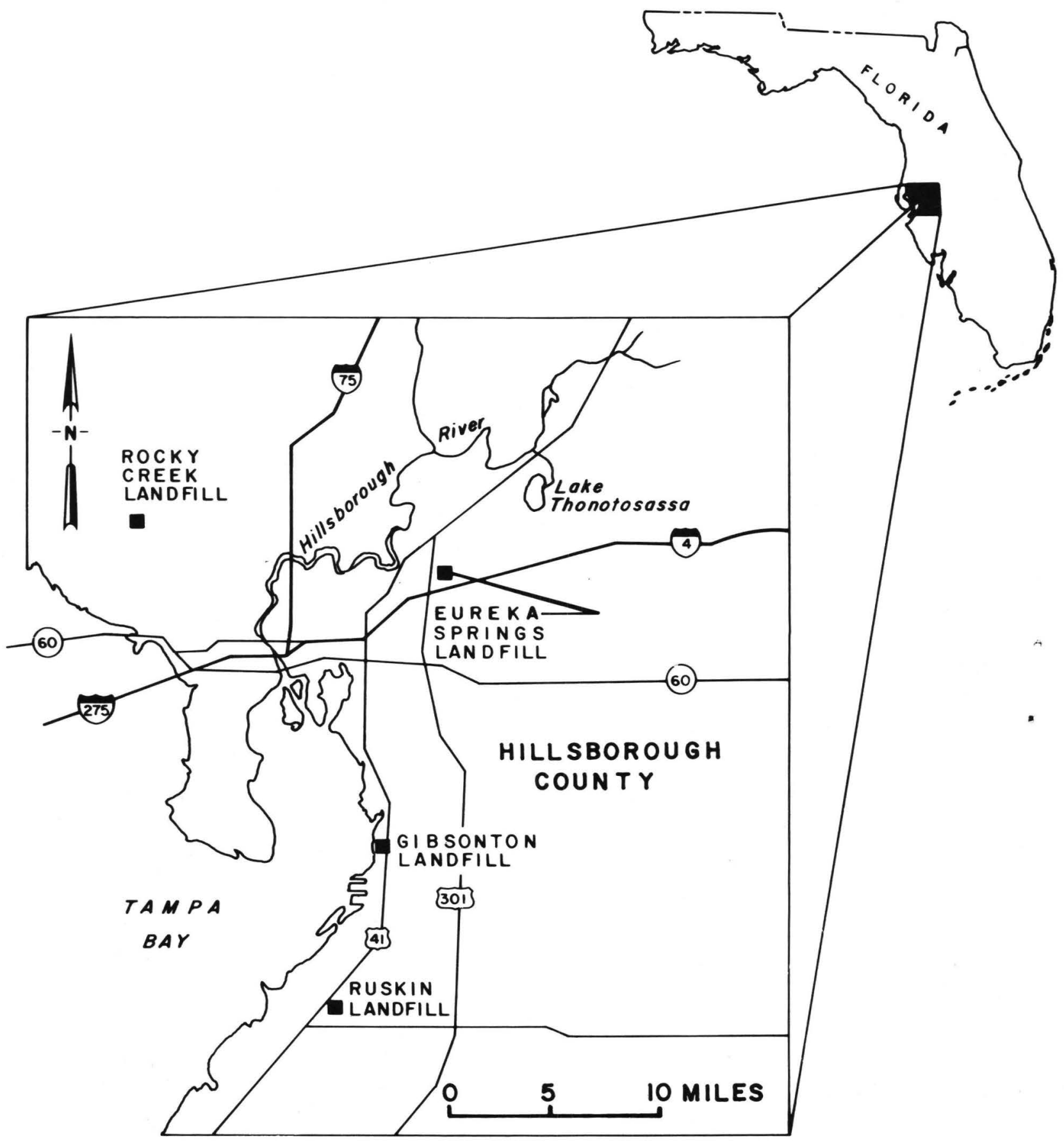

Figure 1.--Location of Hillsborough County landfills. 


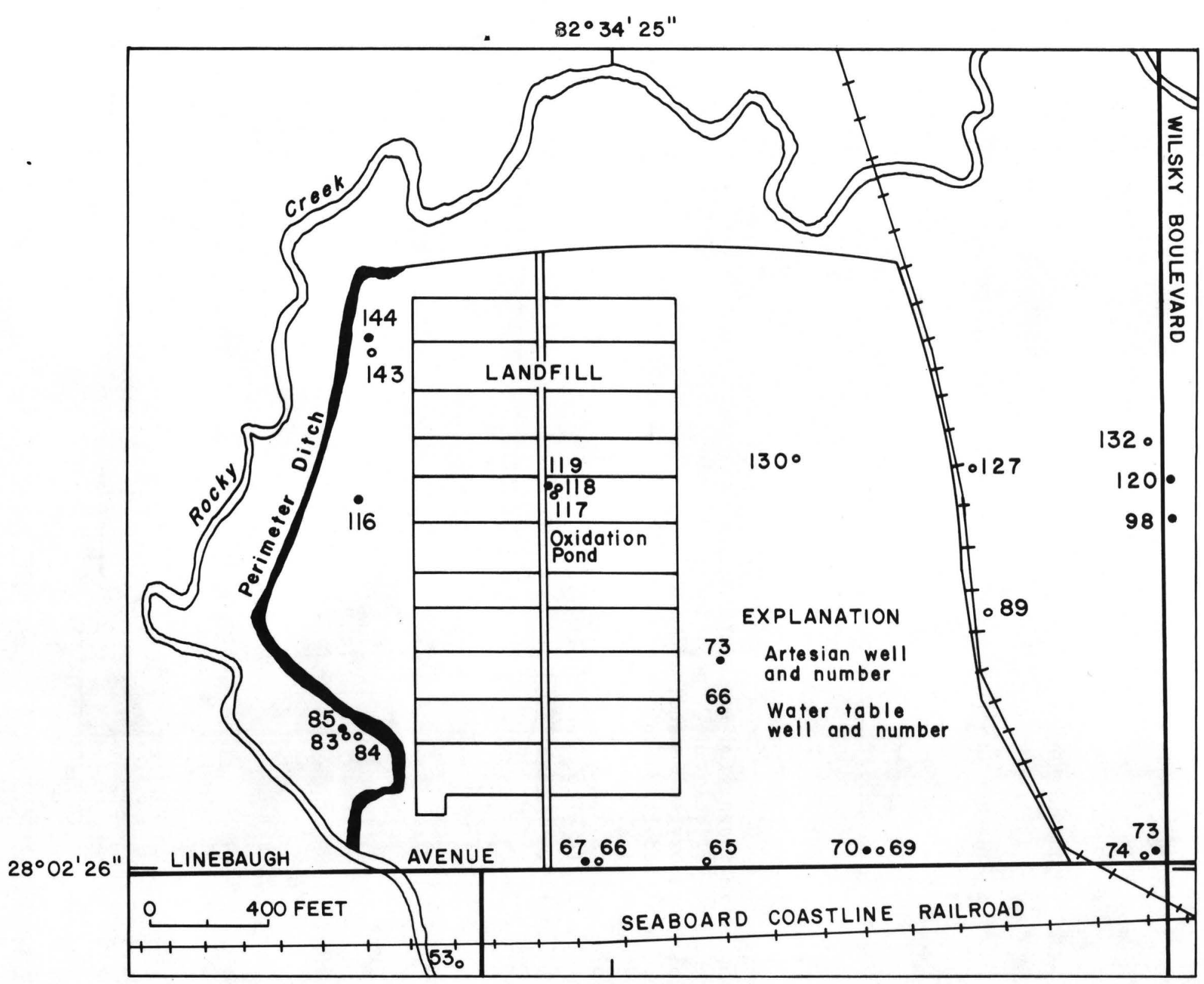

Figure 2.--Location of monitoring wells in Rocky Creek landfill. 


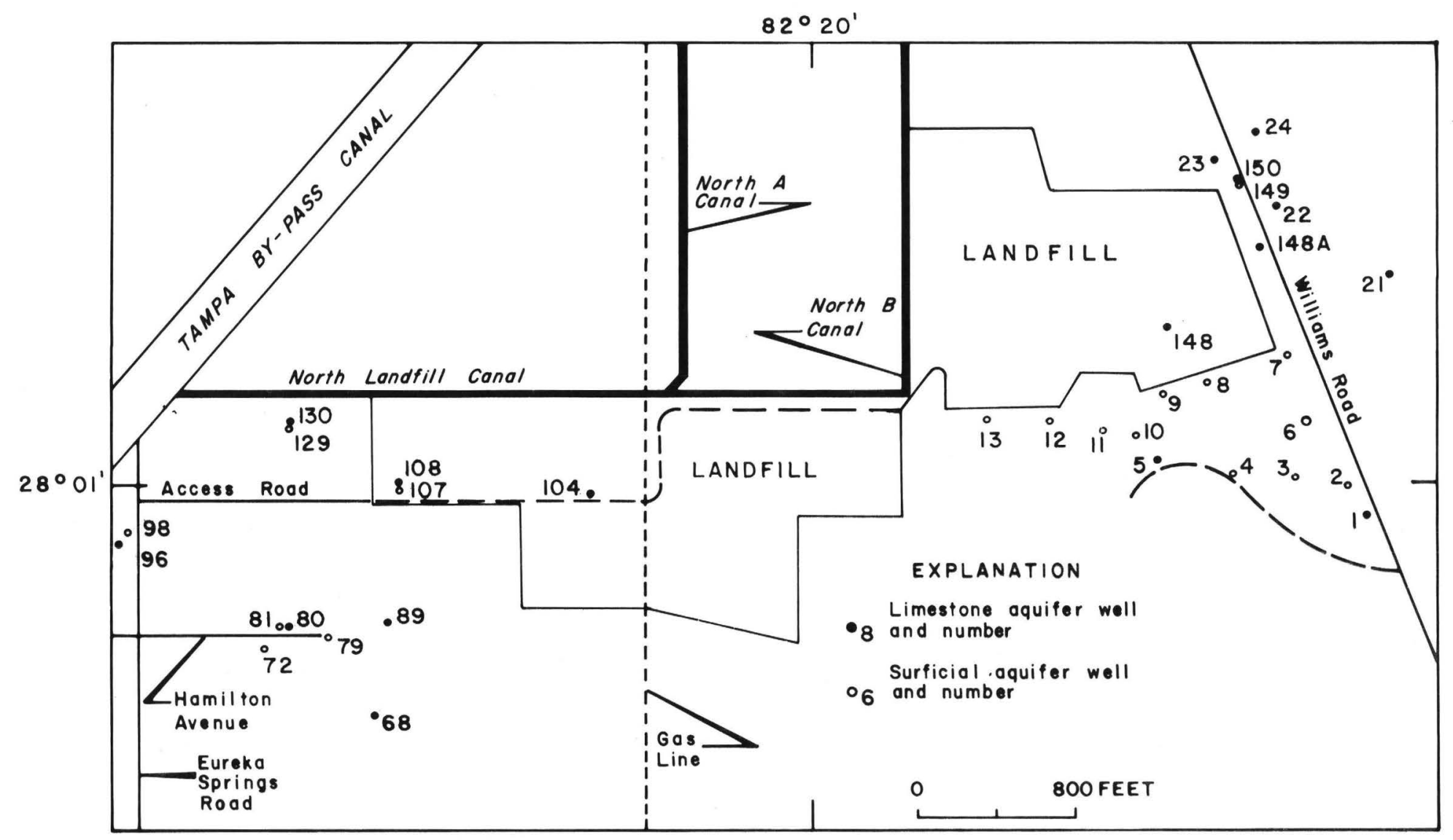

Figure 3.--Location of monitoring wells in Eureka Springs landfill. 


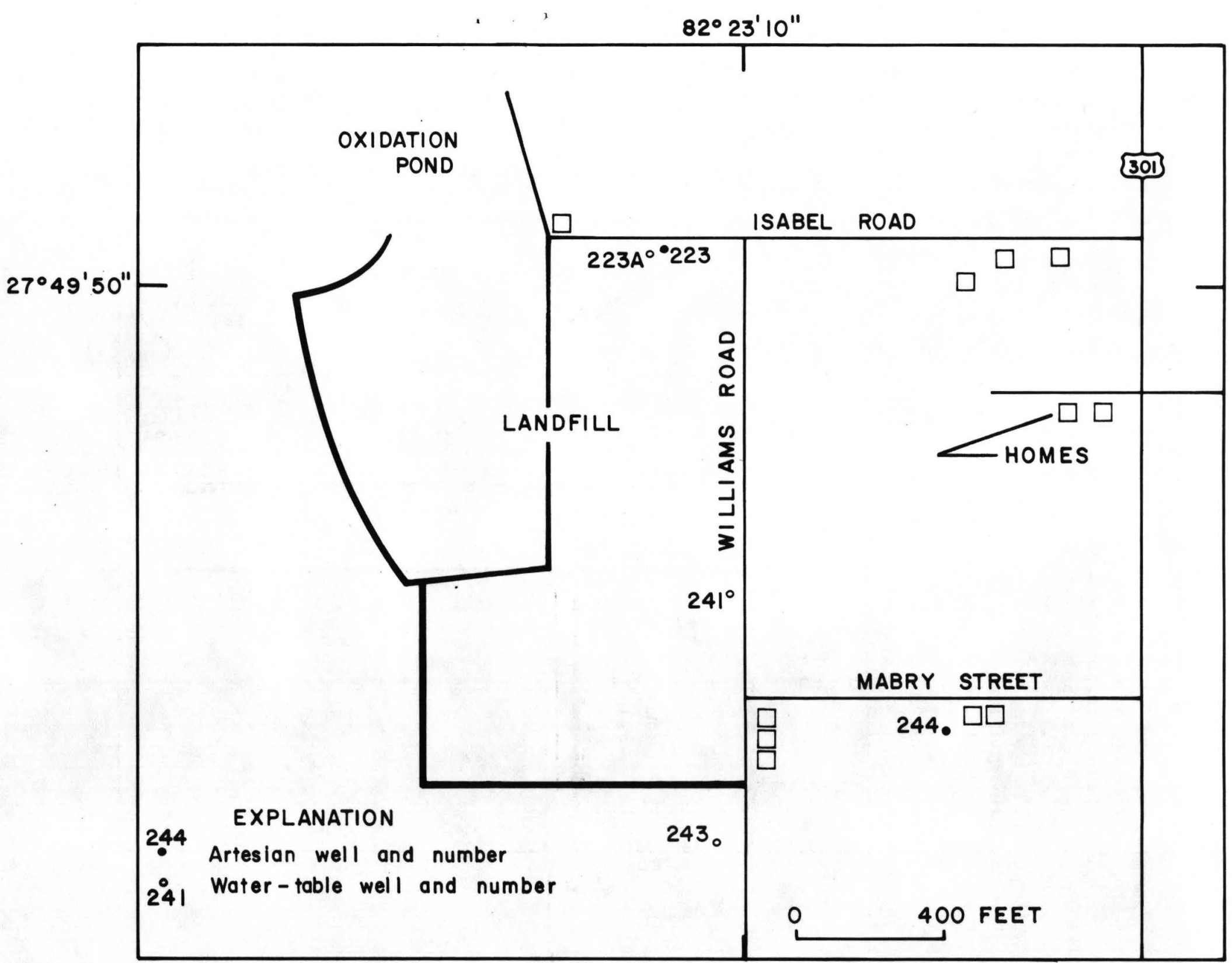

Figure 4.--Location of monitoring wells in Gibsonton landfill. 


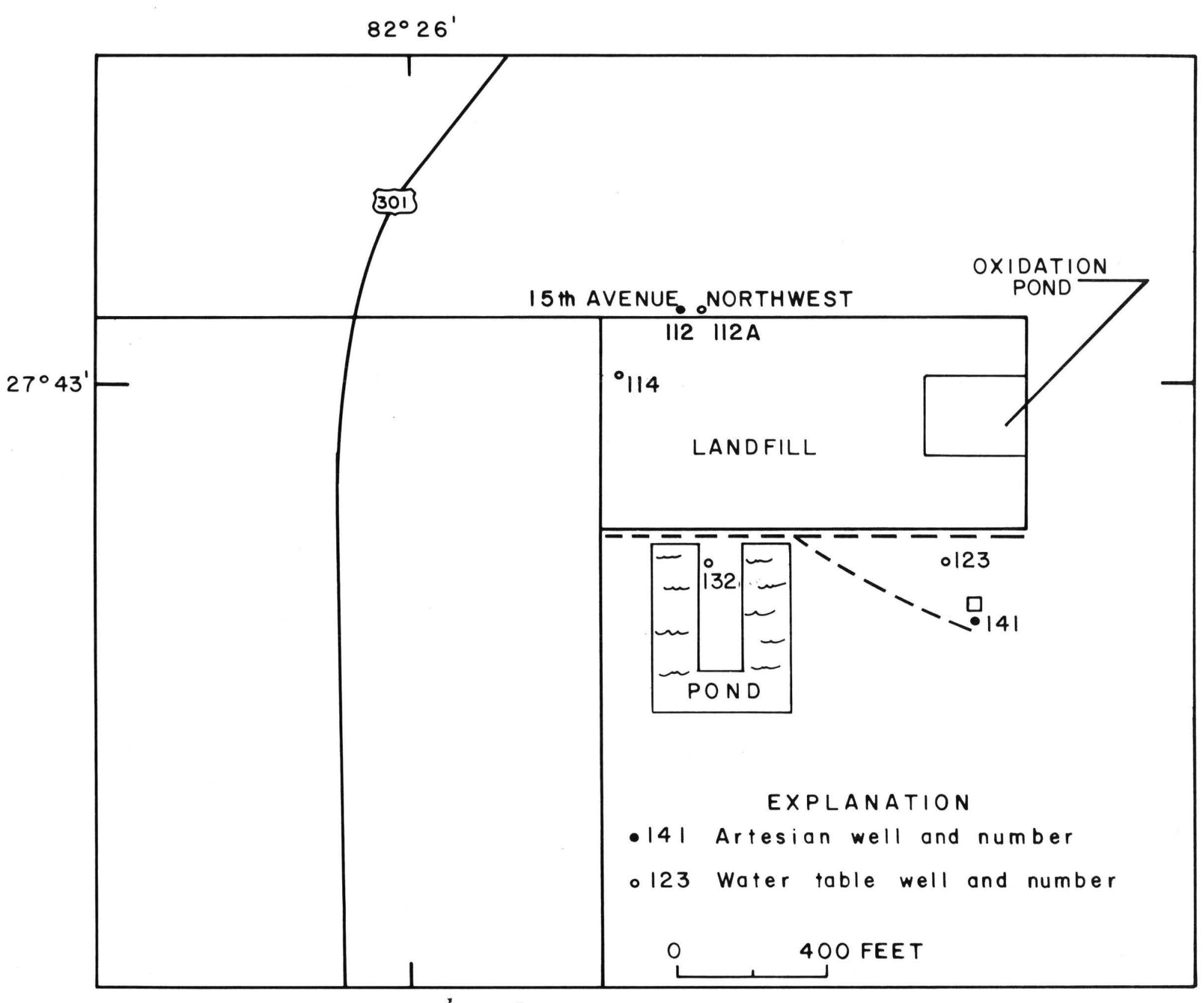

Figure 5.--Location of monitoring wells in Ruskin landfill. 


\section{REFERENCES}

Stewart, J. W., and Duerr, A. D., 1973, Hydrologic and geologic considerations for solid-waste disposal in west-central Florida: U.S. Geological Survey Water-Resources Investigations 50-73.

Stewart, J. W., and Hanan, R. V., 1970, Hydrologic factors affecting the utilization of land for sanitary landfills in northern Hillsborough County, Florida: Florida Bureau of Geology Map Series 39. 
Table 1.--Description of wells

We11 number: We11 locations are shown in respective landfill maps, figures 2-5.

Station number: Left of decimal point is latitude and longitude, right of decimal point is sequence number.

Date drilled: Month and year.

Aquifer: A, artesian; WT, water table.

Well depth: Depth cased plus screen length, in feet below land surface.

Depth cased: Feet below land surface.

Casing diameter: 2 inches.

Screen length: All screens are attached to the bottom of casing, length in feet.

Screen diameter: 2 inches.

\begin{tabular}{c|c|c|c|c|c|c}
\hline $\begin{array}{c}\text { Wel1 } \\
\text { number }\end{array}$ & $\begin{array}{l}\text { Station } \\
\text { number }\end{array}$ & $\begin{array}{c}\text { Date } \\
\text { drilled }\end{array}$ & Aquifer & $\begin{array}{l}\text { Well } \\
\text { depth }\end{array}$ & $\begin{array}{l}\text { Depth } \\
\text { cased }\end{array}$ & $\begin{array}{l}\text { Screen } \\
\text { length }\end{array}$ \\
\hline
\end{tabular}

EUREKA SPRINGS LANDFILL

$\begin{array}{rrrlllr}1 & 2800560821925.01 & 2-75 & \text { A } & 45 & 40 & 5 \\ 2 & 2800580821926.01 & 2-75 & \text { WT } & 15 & 10 & 5 \\ 3 & 2800580821929.01 & 2-75 & \text { WT } & 15 & 10 & 5 \\ 4 & 2800580821932.01 & 2-75 & \text { WT } & 15 & 10 & 5 \\ 5 & 2800590821936.01 & 2-75 & \text { A } & 70 & 60 & 10 \\ & & & & & & \\ 6 & 2801010821928.01 & 2-75 & \text { WT } & 18 & 11 & 7 \\ 7 & 2801949821930.01 & 2-75 & \text { WT } & 10.5 & 8.5 & 2 \\ 8 & 2801030821934.01 & 2-75 & \text { WT } & 11 & 6 & 5 \\ 9 & 2801929821936.01 & 2-75 & \text { WT } & 11 & 6 & 5 \\ 10 & 2801000821937.01 & 2-75 & \text { WT } & 8 & 4 & 4 \\ & & & & & & \\ 11 & 2801000821938.01 & 2-75 & \text { WT } & 8.5 & 3.5 & 5 \\ 12 & 2801010821944.01 & 2-75 & \text { WT } & 8.8 & 3.5 & 5.3 \\ 13 & 2801010821944.01 & 2-75 & \text { WT } & 8 & 3 & 5\end{array}$

GIBSONTON LANDFILL

$\begin{array}{lllllrl}223 & 2749520822312.01 & 1-74 & \text { A } & 42 & 37 & 5 \\ 223 A & 2749520822312.02 & 1-74 & \text { WT } & 17 & 12 & 5 \\ 241 & 274940822310.01 & 1-74 & \text { WT } & 16 & 11 & 5 \\ 243 & 2749340822311.01 & 1-74 & \text { WT } & 10 & 6 & 4\end{array}$


Table 1.--Description of we11s - continued

\begin{tabular}{|c|c|c|c|c|c|c|}
\hline $\begin{array}{c}\text { We11 } \\
\text { number }\end{array}$ & $\begin{array}{l}\text { Station } \\
\text { number }\end{array}$ & $\begin{array}{l}\text { Date } \\
\text { drilled }\end{array}$ & Aquifer & $\begin{array}{l}\text { We11 } \\
\text { depth }\end{array}$ & $\begin{array}{l}\text { Depth } \\
\text { cased }\end{array}$ & $\begin{array}{l}\text { Screen } \\
\text { length }\end{array}$ \\
\hline \multicolumn{7}{|c|}{ RUSKIN LANDFILL } \\
\hline 112 & 2743530822550.01 & $1-74$ & A & 47 & 42 & 5 \\
\hline $112 \mathrm{~A}$ & 2743530822550.02 & $1-74$ & WT & 13 & 8 & 5 \\
\hline 114 & 2743520822551.01 & $1-74$ & WT & 12 & 7 & 5 \\
\hline 123 & 2743460822542.01 & $1-74$ & WT & 13 & 8 & 5 \\
\hline 132 & 2743350822550.01 & $1-74$ & WT & 12 & 7 & 5 \\
\hline \multicolumn{7}{|c|}{ ROCKY CREEK LANDFILL } \\
\hline No new & ells were drilled & luring $\mathrm{Ja}$ & 1ary 1974 & and Oct & ber 197 & 7. \\
\hline
\end{tabular}


Table 2.--Geologic logs of selected wells

EUREKA SPRINGS LANDFILL

Material

Thickness

(ft)

Depth

(ft)

We11 number 1

Station number 2800560821925.01

Sand, fine, clayey, orange tan

10

10

Clay, orange tan, stiff

$5 \quad 15$

Clay, orange tan, stiff

$5 \quad 20$

Limestone, cherty

$19 \quad 39$

Limestone

6

45

Well number 2

Station number 2800580821926.01

Sand, fine, clayey, orange tan

15

Well number 3

Station number 2800580821924.01

Sand, fine, clayey, orange tan

Well number 4

Station number 2800580821932.01

Sand, fine, clayey, orange tan

Well number 5

Station number 2800590821936.01

Sand, fine, clayey, orange tan

Sand, fine, clayey, orange tan

5

Clay, orange tan, stiff

5

20

Clay, dark yellowish orange, alternating thin

layering of grayish blue green clay

Rock

Limestone

0.5

47.5

Limestone

22.5 
Table 2.--Geologic logs of selected wells - continued EUREKA SPRINGS LANDFILL - continued

\begin{tabular}{|c|c|c|}
\hline Material & $\begin{array}{l}\text { Thickness } \\
\text { (ft) }\end{array}$ & $\begin{array}{l}\text { Depth } \\
(\mathrm{ft})\end{array}$ \\
\hline \multicolumn{3}{|l|}{$\begin{array}{l}\text { We11 number } 6 \\
\text { Station number } 2801010821928.01\end{array}$} \\
\hline Sand, fine, clayey, orange tan & 18 & 18 \\
\hline \multicolumn{3}{|l|}{$\begin{array}{l}\text { We11 number } 7 \\
\text { Station number } 2801040821930.01\end{array}$} \\
\hline Sand, fine, clayey, orange tan & 10.5 & 10.5 \\
\hline $\begin{array}{l}\text { Well } \mathrm{r}, \quad 8 \\
\text { Static }\end{array}$ & & \\
\hline Sand, fine, clayey, orange tan & 11 & 11 \\
\hline \multicolumn{3}{|l|}{$\begin{array}{l}\text { Wel1 number } 10 \\
\text { Station number } 2801000821937.01\end{array}$} \\
\hline Sand, fine, clayey, orange tan & 8 & 8 \\
\hline \multicolumn{3}{|l|}{$\begin{array}{l}\text { We11 number } 12 \\
\text { Station number } 2801010821944.01\end{array}$} \\
\hline Sand, fine, clayey, orange tan & 8.8 & 8.8 \\
\hline \multicolumn{3}{|l|}{ GIBSONTON LANDFILL } \\
\hline Material & $\begin{array}{l}\text { Thickness } \\
\quad(\mathrm{ft})\end{array}$ & $\begin{array}{l}\text { Depth } \\
(\mathrm{ft})\end{array}$ \\
\hline \multicolumn{3}{|l|}{$\begin{array}{l}\text { We11 number } 223 \\
\text { Station number } 2749520822312.01\end{array}$} \\
\hline Sand, fine & 5 & 5 \\
\hline Sand, fine with shells & 7 & 12 \\
\hline Sand, medium with shells & 5 & 17 \\
\hline Sand, clayey & 5 & 22 \\
\hline Clay, sandy, traces of limestone chips & 10 & 32 \\
\hline Clay, limey with limestone chips & & 38 \\
\hline Clay, limey with limestone chips; unpermeable & 4 & 42 \\
\hline
\end{tabular}


Table 2.--Geologic logs of selected wells - continued

RUSKIN LANDFILL

\section{Material}

Thickness

(ft)

Depth

(ft)

We11 number 141

Station number 2743530822550.01

Sand, fine with she11s

Sand, fine to coarse, shell fragments

10

Clay, sandy, cohesive, fairly impermeable, some shell fragments

Clay, limey and 1imestone, alternating layers with hard lenses

Clay, limey and limestone, alternating layers with hard lenses

Limestone, hard

We11 number 123

Station number 2743460822542.01

Sand, fine

Limestone, soft

0.5

Sand, clayey, increasing with depth

9.5

We11 number 132

Station number 2743350822550.01

Sand, clayey, increasing with depth

Clay, sandy

We11 number 114

Station number 2743520822551.01

Sand, clayey, increasing with depth 
TABLE 3. CHEMICAL AND BACTERIOLOGICAL ANALYSES FOR GROUND- AND SURFACE-WATER SAMPLES FROM THE ROCKY CREEK LANDFILL

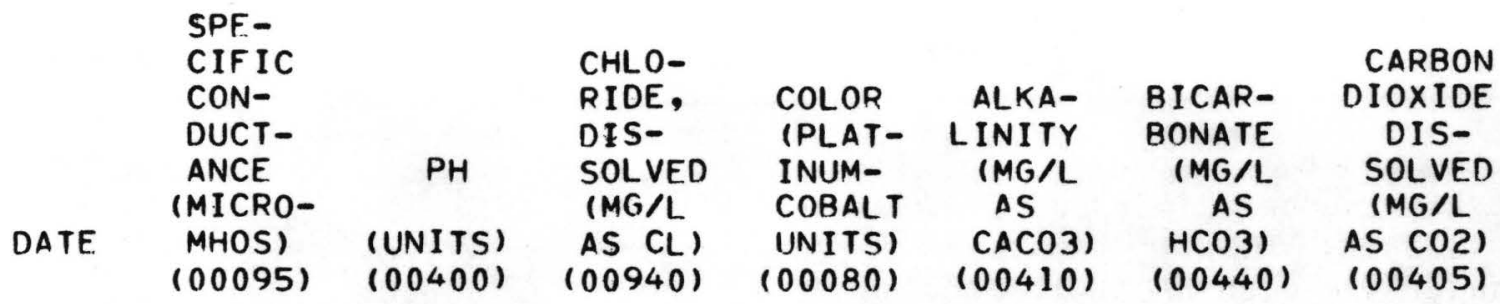

280221082342901 - ROCKY CREEK LF 53 (LAT 280221 LONG 0823429.01 )

\begin{tabular}{|c|c|c|c|c|c|c|c|}
\hline $21 \ldots$ & 383 & -- & 9.2 & -- & -- & -- & -- \\
\hline $\begin{array}{l}14 \\
A \cup G\end{array}$ & 380 & 7.4 & 10 & - & 189 & 231 & 15 \\
\hline $\begin{array}{l}28 \cdots \\
\text { JAN }, 1975\end{array}$ & 377 & 7.6 & $9: 9$ & -- & -- & -- & - \\
\hline $\begin{array}{l}27 \cdots \cdots \\
A P R\end{array}$ & 370 & 7.7 & 10 & -- & - & -- & -2 \\
\hline $\begin{array}{l}07 \\
\text { AUG }\end{array}$ & 391 & 7.5 & 12 & -- & -- & -- & -- \\
\hline $\begin{array}{l}20 \cdots \\
D E C\end{array}$ & 380 & 7.4 & 14 & 12 & -- & -- & -- \\
\hline $\begin{array}{l}09 \cdots \cdots \\
\text { APR } \because 1976\end{array}$ & 384 & 7.5 & 11 & -- & 189 & 230 & 12 \\
\hline $\begin{array}{l}14 \cdots \cdots \\
J U L\end{array}$ & 385 & 6.1 & 13 & 10 & $-\infty$ & -- & \\
\hline $\begin{array}{l}14 \cdots 1 \\
\text { MAY } 1977\end{array}$ & 420 & 7.6 & 11 & 10 & & - & \\
\hline $02 \ldots$ & 412 & $7 \cdot 2$ & 10 & $-\infty$ & & -- & \\
\hline
\end{tabular}

280226082342101 - ROCKY CREEK LF 65 (LAT 280226 LONG 0823421.01 )

\begin{tabular}{|c|c|c|c|c|c|c|c|}
\hline $\begin{array}{l}\text { AUE } \\
22 \ldots \cdots \\
D E C\end{array}$ & 138 & 6.2 & 1.0 & 900 & -- & -- & $-\infty$ \\
\hline $\begin{array}{l}09 \cdots 1 \\
\text { APR }, 1976\end{array}$ & 150 & 6.5 & 9.5 & 460 & 66 & 80 & 40 \\
\hline $\begin{array}{l}14 \ldots \ldots \\
\text { JUL }\end{array}$ & 188 & 5.9 & 12 & 580 & -- & -- & $-\infty$ \\
\hline $\begin{array}{l}14 \cdots \bullet \\
\text { MAY } 1977\end{array}$ & 387 & 7.0 & 22 & 250 & -- & -- & -- \\
\hline $05 \ldots$ & 370 & 6.3 & 18 & -- & -- & -- & $-\infty$ \\
\hline
\end{tabular}


TABLE 3. CHEMICAL AND BACTERIOLOGICAL ANALYSES FOR GROUND - AND SURFACE-WATER SAMPLES FROM THE ROCK CREEK LANDFILL - CONTINUED

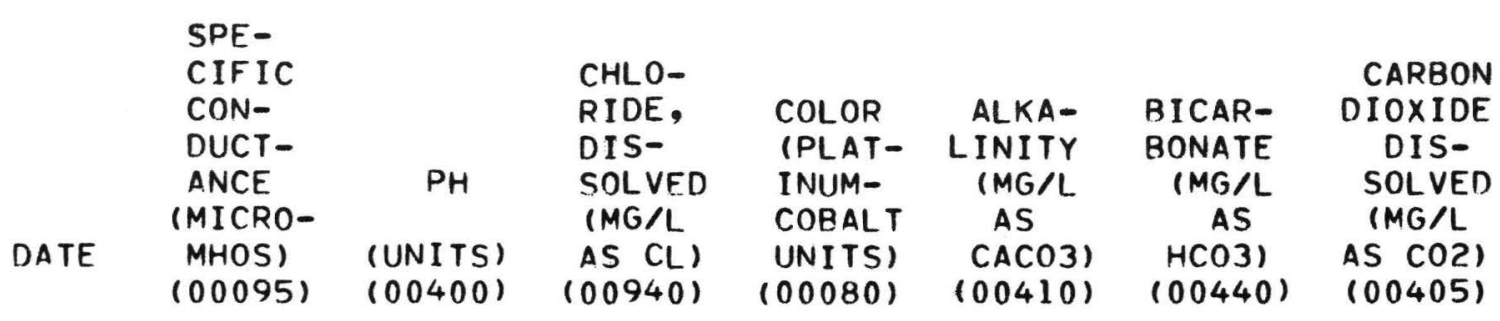

280226082342502 - ROCKY CREFK LF 66 (LAT 280226 LONG 0823425.02 )

\begin{tabular}{|c|c|c|c|c|c|c|c|}
\hline $\begin{array}{l}\text { AUG }, 1974 \\
28 \ldots . . \\
\text { JAN, } 1975\end{array}$ & 302 & 6.3 & 20 & -- & -- & -- & - \\
\hline $\begin{array}{l}27 \ldots \\
A P R\end{array}$ & 310 & 6.8 & 17 & -- & -- & -- & $\cdots$ \\
\hline $\begin{array}{l}03 \ldots \\
\text { AUG }\end{array}$ & 147 & -- & -- & -- & -- & -- & $-\alpha$ \\
\hline $\begin{array}{l}20 \cdots \\
D E C\end{array}$ & 268 & 6.5 & -- & 280 & -- & -- & $-\alpha$ \\
\hline $\begin{array}{l}08 \cdots \cdots \\
\text { APR } \because 1976\end{array}$ & 261 & 6.7 & 10 & -- & 115 & 140 & 45 \\
\hline $\begin{array}{l}16 \ldots \ldots \\
\text { JUL }\end{array}$ & 310 & -- & 14 & 140 & -- & -- & $-\infty$ \\
\hline $\begin{array}{l}15 \cdots \\
\text { OCT }\end{array}$ & 337 & 7.3 & 17 & 30 & -- & -- & \\
\hline $\begin{array}{l}06 \cdots \\
\text { MAY }: 1977\end{array}$ & 329 & 6.0 & 15 & -- & -- & -- & $-\infty$ \\
\hline $\begin{array}{l}05 \ldots \\
19 \ldots\end{array}$ & $\begin{array}{r}370 \\
2190\end{array}$ & $\begin{array}{l}6.5 \\
5.4\end{array}$ & 19 & $=$ & $=$ & $=-$ & \\
\hline
\end{tabular}

280226082342501 - ROCKY CREEK LF 67 (LAT 280226 LONG 0823425.01 )

\begin{tabular}{|c|c|c|c|c|c|c|c|}
\hline MAY & 386 & -- & 8.7 & -- & -- & -- & $-\infty$ \\
\hline $\begin{array}{l}10 \cdots \\
\text { APR }, 1976\end{array}$ & 384 & -- & 9.2 & - & -- & -- & - \\
\hline $\begin{array}{l}16 \cdots \cdots \\
\text { MAY } 1977\end{array}$ & 379 & 7.7 & 9.9 & 32 & -- & -- & \\
\hline $05 \ldots$ & 383 & 7.2 & 12 & - & -- & -- & \\
\hline
\end{tabular}


TABLE 3. CHEMICAL AND BACTERIOLOGICAL ANALYSES FOR GROUND- AND SURFACE-WATER SAMPLES FROM THE ROCKY CREEK LANDFILL - CONTINUED

\begin{tabular}{|c|c|c|c|c|c|c|c|}
\hline & $\begin{array}{l}\text { SPE- } \\
\text { CIF IC } \\
\text { CON- } \\
\text { DUCT- } \\
\text { ANCE } \\
\text { (MICRO- }\end{array}$ & $\mathrm{PH}$ & $\begin{array}{l}\text { CHLO- } \\
\text { RIDE, } \\
\text { DIS- } \\
\text { SOLVED } \\
\text { IMG/L }\end{array}$ & $\begin{array}{l}\text { COLOR } \\
\text { IPLAT- } \\
\text { INUM- } \\
\text { COBALT }\end{array}$ & $\begin{array}{l}\text { ALKA- } \\
\text { LINITY } \\
\text { IMG/L } \\
\text { AS }\end{array}$ & $\begin{array}{c}\text { BICAR- } \\
\text { BONATE } \\
\text { (MG/L } \\
\text { AS }\end{array}$ & $\begin{array}{c}\text { CARBON } \\
\text { DIOXIDE } \\
\text { DIS- } \\
\text { SOLVED } \\
\text { IMG/L }\end{array}$ \\
\hline DATE & $\begin{array}{l}\text { MHOS) } \\
(00095)\end{array}$ & $\begin{array}{l}\text { (UNITS) } \\
(00400)\end{array}$ & $\begin{array}{l}\text { AS CL) } \\
(00940)\end{array}$ & $\begin{array}{l}\text { UNITS) } \\
(00080)\end{array}$ & $\begin{array}{l}\text { (ACO3) } \\
(00410)\end{array}$ & $\begin{array}{c}\mathrm{HCO31} \\
(00440)\end{array}$ & $\begin{array}{l}\text { AS CO2) } \\
(00405)\end{array}$ \\
\hline
\end{tabular}

280226082341202 - ROCKY CREEK LF 69 (LAT 280226 LONG 0823412.02 )

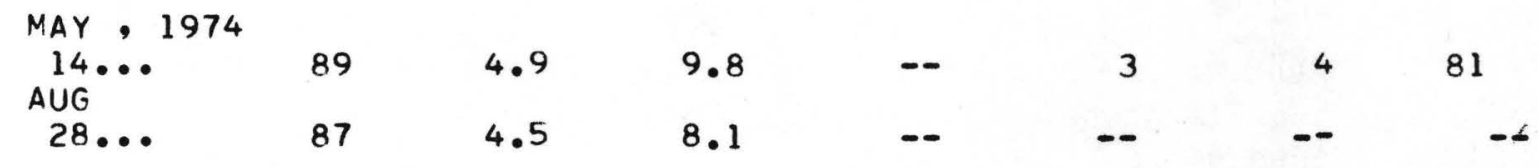

280226082341201 - ROCKY CREEK LF 70 (LAT 280226 LONG 0823412.01 )

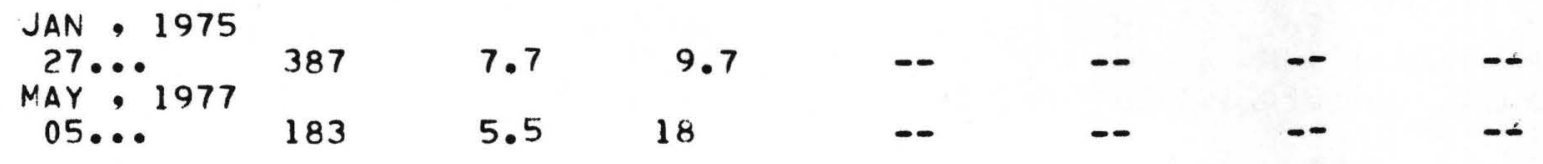

280228082335901 - ROCKY CREEK LF 73 (LAT 280228 LONG 0823359.01 )

JUL, 1976

$\begin{array}{lllllll}16 \ldots & 413 & 7.7 & 11 & 10 & \ldots & --\end{array}$ 
TABLE 3. CHEMICAL AND BACTERIOLOGICAL ANALYSES FOR GROUND- AND SURFACE-WATER SAMPLES FROM THE ROCKY CREEK LANDFILL - CONTINUED

\begin{tabular}{|c|c|c|c|c|c|c|c|}
\hline & $\begin{array}{l}\text { SPE- } \\
\text { CIFIC } \\
\text { CON- } \\
\text { DUCT- } \\
\text { ANCE } \\
\text { (MICRO- }\end{array}$ & $\mathrm{PH}$ & $\begin{array}{l}\text { CHLO- } \\
\text { RIDE, } \\
\text { DIS- } \\
\text { SOLVED } \\
\text { IMG/L }\end{array}$ & $\begin{array}{l}\text { COLOR } \\
\text { IPLAT- } \\
\text { INUM- } \\
\text { COBALT }\end{array}$ & $\begin{array}{l}\text { ALKA- } \\
\text { LINITY } \\
\text { IMG/L } \\
\text { AS }\end{array}$ & $\begin{array}{c}\text { BICAR- } \\
\text { BONATE } \\
\text { IMG/L } \\
\text { AS }\end{array}$ & $\begin{array}{c}\text { CARBON } \\
\text { DIOXIDE } \\
\text { DIS- } \\
\text { SOLVED } \\
\text { IMG/L }\end{array}$ \\
\hline & $\begin{array}{l}\text { MHOS }) \\
(00095)\end{array}$ & $\begin{array}{l}\text { (UNITS) } \\
(00400)\end{array}$ & $\begin{array}{c}\text { AS CL) } \\
(00940)\end{array}$ & $\begin{array}{l}\text { UNITS) } \\
(00080)\end{array}$ & $\begin{array}{l}\text { (ACO3) } \\
(00410)\end{array}$ & $\begin{array}{c}\mathrm{HCO} 31) \\
(00440)\end{array}$ & $\begin{array}{l}\text { AS CO2) } \\
(00405)\end{array}$ \\
\hline
\end{tabular}

280228082335902 - ROCKY CREEK LF 74 (LAT 280228 LONG 0823359.02 )

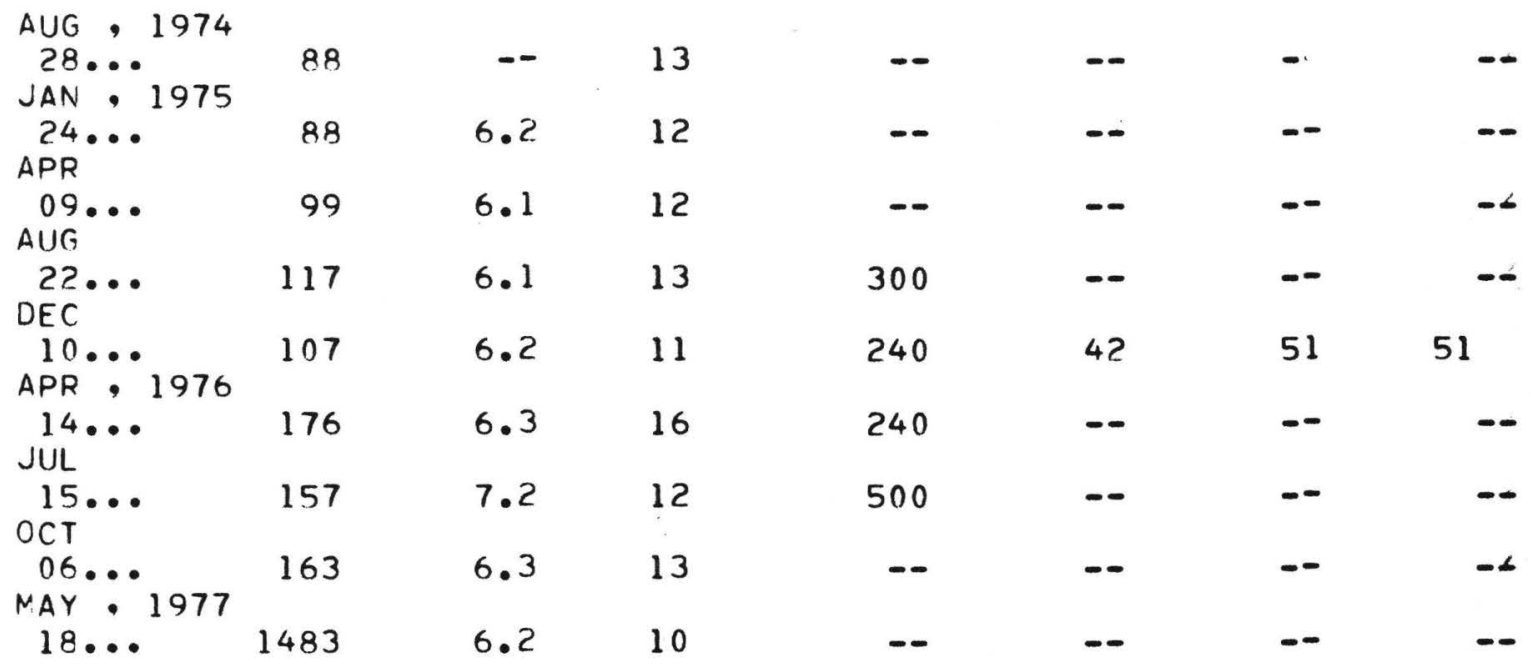

280231082343603 - ROCKY CREEK LF 83 (LAT 280231 LONG 0823436.03 )

\begin{tabular}{|c|c|c|c|}
\hline $\begin{array}{l}\text { FEB }: 1974 \\
21 \ldots \cdots \\
\text { MAY }\end{array}$ & 105 & -- & 11 \\
\hline $\begin{array}{l}14 \cdots \\
\text { JAN }, 1975\end{array}$ & 81 & -- & 13 \\
\hline $\begin{array}{l}28 \cdots \cdots \\
A P R \bullet 1976\end{array}$ & 337 & 7.6 & 7.7 \\
\hline $\begin{array}{l}15 \ldots \\
\text { OCT }\end{array}$ & 384 & 7.4 & 9.2 \\
\hline MAY $\because 1977$ & 370 & 7.0 & 8.6 \\
\hline $17 \ldots$ & 395 & 6.9 & 9.0 \\
\hline
\end{tabular}


TABLE 3. CHEMICAL AND BACTERIOLOGICAL ANALYSES FOR GROUND- AND SURFACE-WATER SAMPLES FROM THE ROCKY CREEK LANDFILL - CONTINUED

\begin{tabular}{|c|c|c|c|c|c|c|c|}
\hline & $\begin{array}{l}\text { SPE- } \\
\text { CIF IC } \\
\text { CON- } \\
\text { DUCT- } \\
\text { ANCE } \\
\text { (MICRO- }\end{array}$ & PH & $\begin{array}{l}\text { CHLO- } \\
\text { RIDE, } \\
\text { DIS- } \\
\text { SOLVED } \\
\text { IMG/L }\end{array}$ & $\begin{array}{l}\text { COLOR } \\
\text { IPLAT- } \\
\text { INUM- } \\
\text { COBALT }\end{array}$ & $\begin{array}{l}\text { ALKA- } \\
\text { LINITY } \\
\text { IMG/L } \\
\text { AS }\end{array}$ & $\begin{array}{c}\text { BICAR- } \\
\text { BONATE } \\
\text { IMG/L } \\
\text { AS }\end{array}$ & $\begin{array}{c}\text { CARBON } \\
\text { DIOXIDE } \\
\text { DIS- } \\
\text { SOLVED } \\
\text { IMG/L }\end{array}$ \\
\hline & $\begin{array}{l}\text { MHOS }) \\
(00095)\end{array}$ & $\begin{array}{l}\text { (UNITS) } \\
(00400)\end{array}$ & $\begin{array}{l}\text { AS CL) } \\
(00940)\end{array}$ & $\begin{array}{l}\text { UNITS) } \\
(00080)\end{array}$ & $\begin{array}{r}\text { (AC03) } \\
(00410)\end{array}$ & $\begin{array}{c}\mathrm{HCO31}) \\
(00440)\end{array}$ & $\begin{array}{l}\text { AS CO2) } \\
(00405)\end{array}$ \\
\hline
\end{tabular}

280231082343602 - ROCKY CREEK LF 84 (LAT 280231 LONG 0823436.02 )

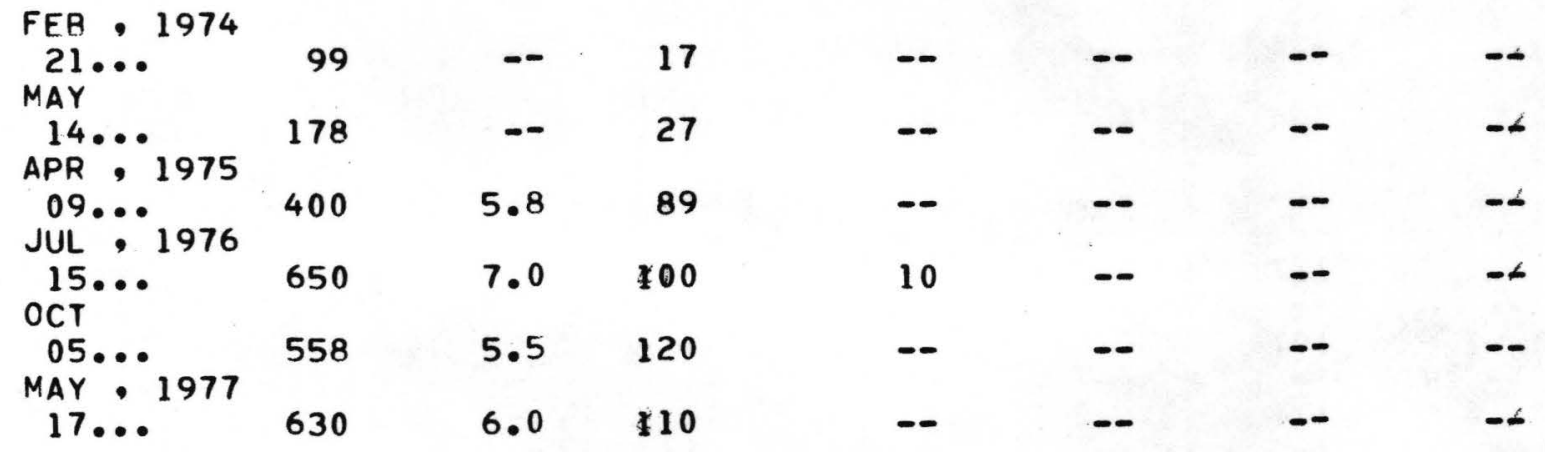

280231082343601 - ROCKY CREEK LF 85 (LAT 280231 LONG 0823436.01 )

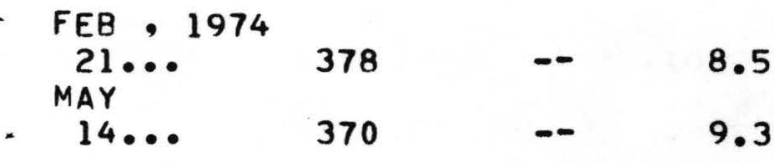

280233082340701 - ROCKY CREEK LF 89 (LAT 280233 LONG 0823407.01 )

\begin{tabular}{|c|c|c|c|c|c|c|c|}
\hline MAY & 152 & -- & 26 & -- & - & -- & $-\infty$ \\
\hline $\begin{array}{l}15 \cdots \cdots \\
\text { APR }, 1975\end{array}$ & 158 & -- & 24 & - & -- & -- & -2 \\
\hline $\begin{array}{l}09 \cdots \cdots 1976 \\
\text { JUL } 19\end{array}$ & 148 & 5.8 & 28 & -- & - & -- & \\
\hline $19 \ldots$ & 289 & 58 & & & & & \\
\hline
\end{tabular}


TABLE 3. CHEMICAL AND BACTERIOLOGICAL ANALYSES FOR GROUND- AND SURFACE-WATER SAMPLES FROM THE ROCKX CREEK LANDFILL - CONTTNTTER

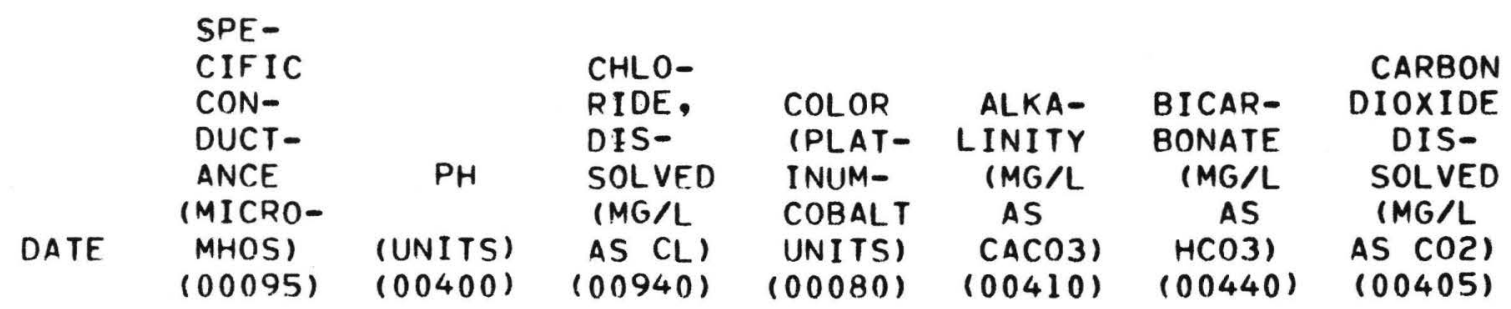

280235082335801 - ROCKY CREEK LF 98 (LAT 280235 LONG 0823358.01 )

\begin{tabular}{|c|c|c|c|c|c|c|c|}
\hline $\begin{array}{l}\text { MAY , } 1974 \\
15 \ldots \ldots \\
\text { AUG }\end{array}$ & 386 & -- & -- & -- & -- & -- & -4 \\
\hline $\begin{array}{l}30 \cdots \cdots \\
\text { JAN }, 1975\end{array}$ & 385 & 7.4 & 7.9 & -- & -- & -- & -- \\
\hline $\begin{array}{l}27 \\
A P R\end{array}$ & 374 & 7.6 & 7.9 & -- & -- & -- & -6 \\
\hline $\begin{array}{l}07 \cdots \\
A \cup G\end{array}$ & 380 & 7.4 & 8.7 & - & -- & -- & $-\infty$ \\
\hline $\begin{array}{l}20 \ldots \\
\text { DEC }\end{array}$ & 373 & 7.6 & 8.4 & 14 & -- & -- & $-\alpha$ \\
\hline $\begin{array}{l}\text { 09.. } \\
\text { APR }, 1976\end{array}$ & 380 & 7.3 & 9.0 & -- & 197 & 240 & 19 \\
\hline $\begin{array}{l}14 \cdots \cdots \\
\text { JUL. }\end{array}$ & 382 & 6.9 & 9.0 & 55 & -- & -- & $-\alpha$ \\
\hline $\begin{array}{l}14 \ldots \\
\text { MAY }, 1977\end{array}$ & 450 & 7.7 & 10 & 15 & $\cdots$ & -- & -4 \\
\hline $02 \ldots$ & 413 & 7.1 & 9.8 & -- & - & -- & -2 \\
\hline
\end{tabular}

280238082343201 - ROCKY CREEK LF 116 (LAT 280238 LONG 0823432.01 )

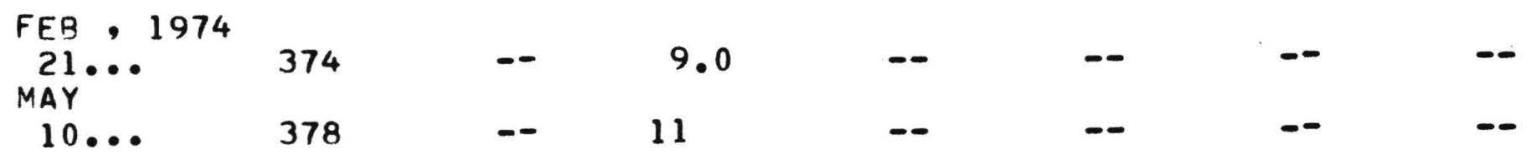

280238082342603 - ROCKY CREEK LF 117 (LAT 280238 LONG 0823426.03 )

OCT, 1976

06... $170 \quad 5.5 \quad 12$ 
TABLE 3. CHEMICAL AND BACTERIOLOGICAL ANALYSES FOR GROUND- AND SURFACE-WATER SAMPLES FROM THE ROCKY CREEK LANDF ILL - CONTINUED

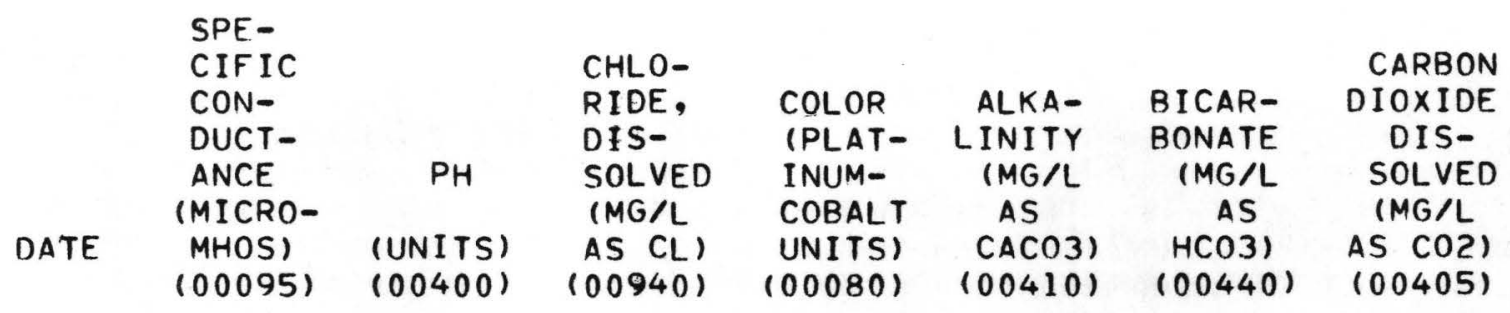

280238082342602 - ROCKY CREEK LF 118 (LAT 280238 LONG 0823426.02 )

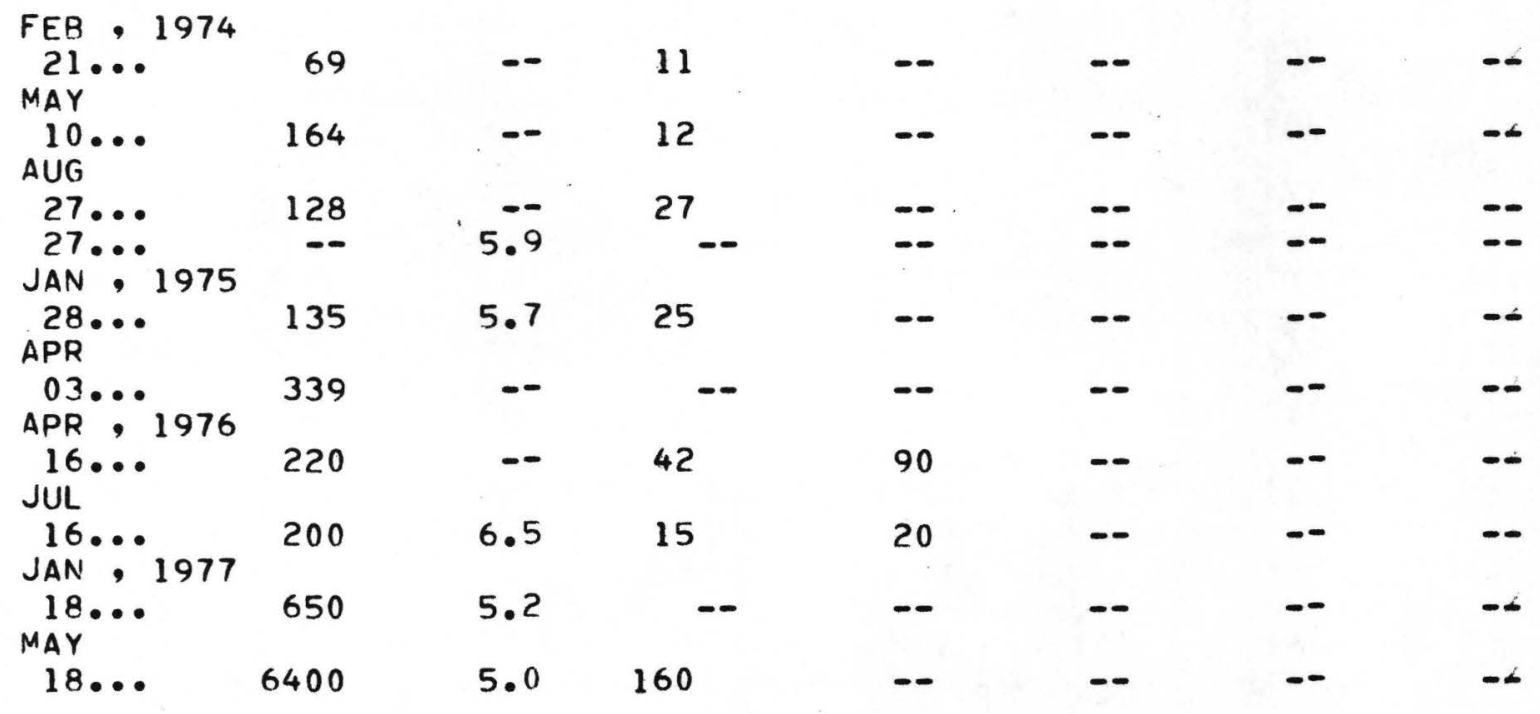

280238082342601 - ROCKY CREEK LF 119 (LAT 280238 LONG 0823426.01 )

\begin{tabular}{|c|c|c|c|}
\hline $\begin{array}{l}\text { MAY } 1974 \\
10 \ldots . . \\
\text { AUG }\end{array}$ & 399 & -- & 9.1 \\
\hline $\begin{array}{l}27 \cdots \cdots \\
\text { APR } \because 1975\end{array}$ & - & 8.1 & -- \\
\hline $\begin{array}{l}09 \\
\text { OCT } \because 1976\end{array}$ & 447 & 7.4 & 11 \\
\hline $\begin{array}{l}06 \cdots \cdots \\
\text { JAN }: 1977 \\
18 \ldots .\end{array}$ & 444 & 6.5 & 8.8 \\
\hline
\end{tabular}


TAELE 3. CHEMICAL AND BACTERIOLOGICAL ANALYSES FOR GROUND- AND SURFACE-WATER SAMPLES FROM THE POCKY CREEK LANDFILL - CONTINUED

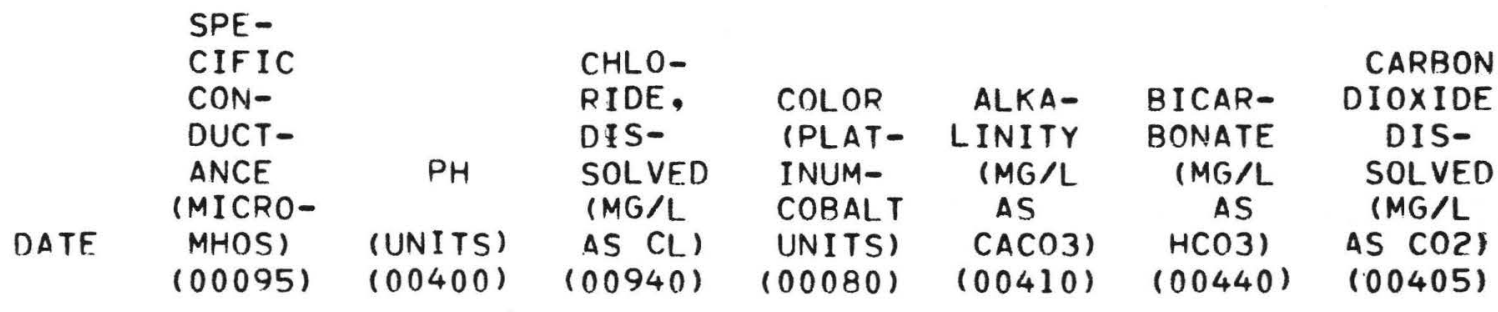

280238082335701 - ROCKY CREEK LF 120. (LAT 280238 LONG 0823357.01 )

\begin{tabular}{|c|c|c|c|c|c|c|c|}
\hline $\begin{array}{l}\text { FEB , } 1974 \\
21 \ldots \cdots \\
\text { MAY }\end{array}$ & 379 & -- & 8.4 & - & - & -- & -6 \\
\hline $\begin{array}{l}14 \ldots \\
A \cup G\end{array}$ & 410 & 7.6 & 19 & -- & 189 & 230 & 9.2 \\
\hline $\begin{array}{l}30 \cdots 1 \\
\text { JAN } 1975\end{array}$ & 379 & 7.8 & 7.6 & -- & -- & -- & -2 \\
\hline $\begin{array}{l}27 \ldots \\
\text { APR }\end{array}$ & 374 & 7.8 & 7.8 & -- & -- & -- & -2 \\
\hline $\begin{array}{l}08 \cdots \\
\text { AUG }\end{array}$ & 380 & -- & -- & -- & -- & -- & -6 \\
\hline $\begin{array}{l}22 \cdots \cdots \\
\text { DEC }\end{array}$ & 372 & 6.1 & 10 & 11 & -- & -- & - \\
\hline $\begin{array}{l}09 \bullet \bullet 1976 \\
A P R\end{array}$ & 377 & 7.2 & 8.6 & -- & 172 & 210 & 21 \\
\hline $\begin{array}{l}15 \cdots \cdots \\
\text { JUL }\end{array}$ & 373 & 7.2 & 8.6 & 9 & -- & -- & - \\
\hline $\begin{array}{l}14 \ldots \\
\text { OCT }\end{array}$ & 460 & 7.5 & 11 & 10 & -- & -- & $-\infty$ \\
\hline $\begin{array}{l}05 \bullet \bullet \\
\text { MAY }, 1977\end{array}$ & 400 & 6.5 & 9.0 & -- & -- & -- & -- \\
\hline $02 \ldots$ & 403 & 7.3 & 8.0 & -- & -- & -- & - \\
\hline
\end{tabular}

280240082340601 - ROCKY CREEK LF 127 (LAT 280240 LONG 0823406.01 )

FEB , 1974

$\begin{array}{lrrr}\text { 21... } & 62 & -- & 6.5 \\ \text { MAY } & & & \\ 15 \ldots . & 66 & -- & 7.8 \\ \text { JAN, } 1975 & & & \\ \text { 28... } & 144 & 5.4 & 33 \\ \begin{array}{l}\text { APR } \\ \text { O9... }\end{array} & 155 & -- & \ldots\end{array}$

280240082341201 - ROCKY CREEK LF 130 (LAT 280240 LONG 0823412.01 )

$\begin{array}{lrrr}\text { FEE , } 1974 & & & \\ 21 \ldots . . & 91 & -- & 7.0 \\ \text { AUG } & & & \\ 28 \ldots & 106 & 6.4 & 9.9\end{array}$


TABLE 3. CHEMICAL AND BACTERIOLOGICAL ANALYSES FOR GROUND- AND SURFACE-WATER SAMPLES FROM THE ROCKY CREEK LANDFILL - CONTINUED

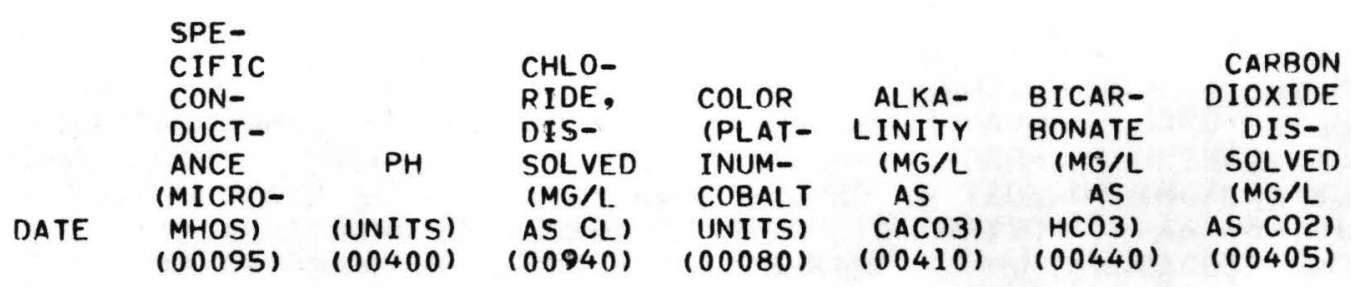

280240082335901 - ROCKY CREEK LF 132 (LAT 280240 LONG 0823359.01 )

$\begin{array}{llll}\begin{array}{l}\text { MAY , 1974 } \\ \text { 15... }\end{array} & 75 & -- & 12 \\ \text { AUG } & & & \\ \text { 30... } & 63 & 5.9 & 12 \\ \text { JAN, 1975 } & & & \\ \text { 27... } & 52 & 5.8 & 13\end{array}$

280242082343502 - ROCKY CREEK LF 143 (LAT 280242 LONG 0823435.02 )

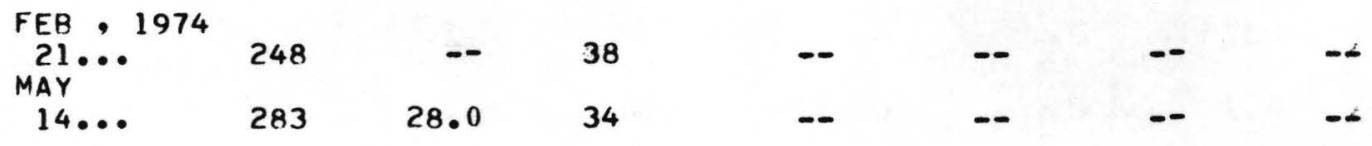

280242082343501 - ROCKY CREEK LF 144 (LAT 280242 LONG 0823435.01 )

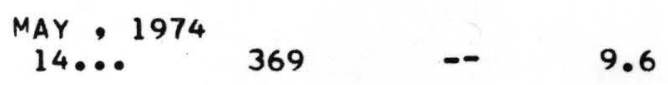

280227082341700 - ROCKY CREEK LF SE PERIMETER DITCH (LAT $2802 \quad 27$ LONG $082 \quad 34 \quad 17$ )

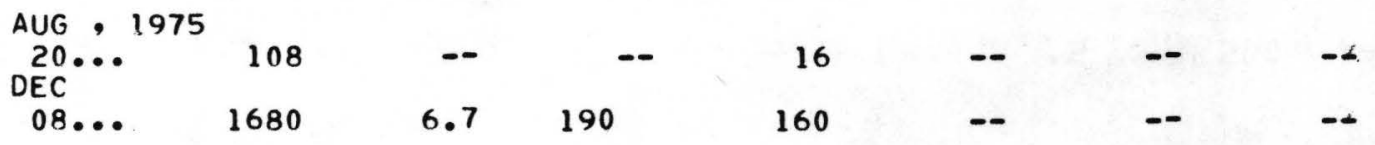

280235082342500 - ROCKY CREEK LF OXIDATION POND (LAT 280235 LONG 0823425 )

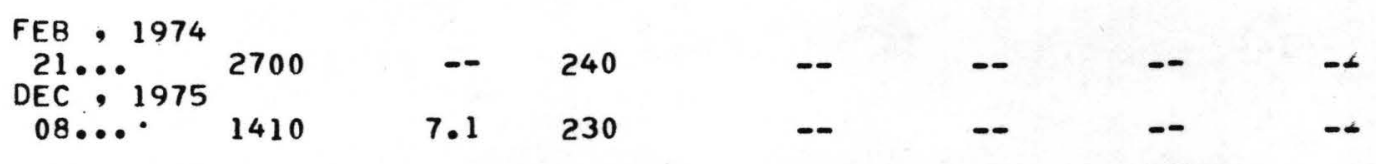


TABLE 3. CHEMICAL AND BACTERIOLIOGICAL ANALYSES FOR GROUND- AND SURFACE-WATER. SAMPLES FROM THE ROCKY CREEK LANDFILL - CONTINUED

\begin{tabular}{|c|c|c|c|c|c|c|c|}
\hline & $\begin{array}{l}\text { CALCIUM } \\
\text { DIS- } \\
\text { SOLVED } \\
\text { IMG/L }\end{array}$ & $\begin{array}{l}\text { MAGNE- } \\
\text { SIUM, } \\
\text { DIS- } \\
\text { SOLVED } \\
\text { (MG/L }\end{array}$ & $\begin{array}{l}\text { SODIUM, } \\
\text { DIS- } \\
\text { SOLVED } \\
\text { (MG/L. }\end{array}$ & $\begin{array}{l}\text { POTAS- } \\
\text { SIUM, } \\
\text { DIS- } \\
\text { SOLVED } \\
\text { (MG/L }\end{array}$ & $\begin{array}{c}\text { SODIUM } \\
\text { AD- } \\
\text { SORP- } \\
\text { TION } \\
\text { RATIO }\end{array}$ & $\begin{array}{l}\text { HARD- } \\
\text { NESS } \\
\text { IMG/L } \\
\text { AS }\end{array}$ & $\begin{array}{l}\text { HARD- } \\
\text { NESS, } \\
\text { NONCAR- } \\
\text { BONATE } \\
\text { IMG/L }\end{array}$ \\
\hline & $\begin{array}{l}\text { AS CA) } \\
(00915)\end{array}$ & $\begin{array}{r}4 S \text { MG }) \\
(00925)\end{array}$ & $\begin{array}{l}\text { AS NA) } \\
(00930)\end{array}$ & $\begin{array}{c}\text { AS K) } \\
(00935)\end{array}$ & $(00931)$ & $\begin{array}{r}\text { CACO3) } \\
(00900)\end{array}$ & $\begin{array}{r}\text { CAC03) } \\
(00902)\end{array}$ \\
\hline
\end{tabular}

280221082342901 - ROCKY CKEEK LF 53 (LAT 280221 LONG 0823429.01 )

\begin{tabular}{|c|c|c|c|c|c|c|c|}
\hline $\begin{array}{l}\text { FEB } 1974 \\
21 \cdots \cdots \\
\text { MAY }\end{array}$ & 66 & 3.6 & 7.4 & 1.0 & .2 & 180 & - \\
\hline $\begin{array}{l}14 \\
A U G\end{array}$ & 75 & 3.7 & 7.3 & .9 & .2 & 200 & 13 \\
\hline $\begin{array}{l}28 \cdots \\
\text { JAN } 1975\end{array}$ & 72 & 3.6 & 7.4 & $\cdot 8$ & .2 & 190 & -- \\
\hline $\begin{array}{l}27 \cdots \cdots \\
A P R\end{array}$ & 70 & 3.8 & 6.7 & .7 & .2 & 190 & -- \\
\hline $\begin{array}{l}07 \ldots \\
\text { AUG }\end{array}$ & 71 & 4.3 & 7.5 & .8 & .2 & 200 & \\
\hline$\stackrel{20 \cdots}{\mathrm{DEC}}$ & 66 & 4.0 & 7.6 & .8 & .2 & 180 & - \\
\hline APR $\because 1976$ & 66 & 4.4 & 8.2 & .9 & .3 & 180 & 0 \\
\hline $\begin{array}{l}14 \cdots \cdots \\
\text { MAY } 1977\end{array}$ & 70 & 4.1 & 7.0 & $\cdot 8$ & .2 & 190 & - \\
\hline $02 \ldots$ & 70 & 4.5 & 7.7 & .9 & .2 & 190 & - \\
\hline
\end{tabular}

280226082342101 - ROCKY CREEK LF 65 (LAT 280226 LONG 0823421.01 )

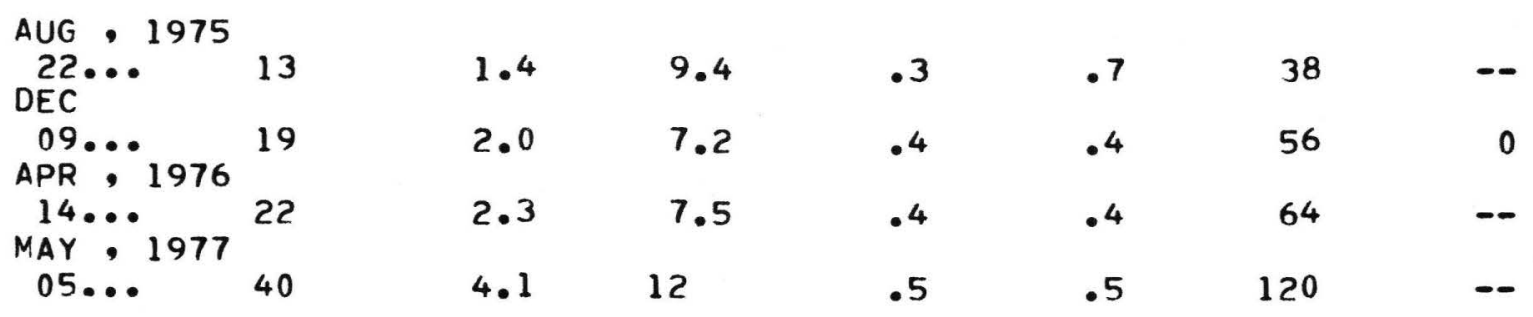


TABLE 3. CHEMICAL AND BACTERIOLOGICAL ANALYSES FOR GROUND- AND SURFACE-WATER SAMPLES FROM THE ROCKY CREEK LANDFILL - CONTINUED

\begin{tabular}{|c|c|c|c|c|c|c|c|}
\hline & $\begin{array}{l}\text { CALCIUM } \\
\text { DIS- } \\
\text { SOLVED } \\
\text { (MG/L }\end{array}$ & $\begin{array}{l}\text { MAGNE- } \\
\text { SIUM, } \\
\text { DIS- } \\
\text { SOLVED } \\
\text { (MG/L }\end{array}$ & $\begin{array}{l}\text { SODIUM, } \\
\text { DIS- } \\
\text { SOLVED } \\
\text { (MG/L }\end{array}$ & $\begin{array}{l}\text { POTAS- } \\
\text { SIUM, } \\
\text { DIS- } \\
\text { SOLVED } \\
\text { IMG/L }\end{array}$ & $\begin{array}{l}\text { SODIUM } \\
\text { AD- } \\
\text { SORP- } \\
\text { TION } \\
\text { RATIO }\end{array}$ & $\begin{array}{l}\text { HARD - } \\
\text { NESS } \\
\text { IMG/L } \\
\text { AS }\end{array}$ & $\begin{array}{l}\text { HARD- } \\
\text { NESS, } \\
\text { NONCAR- } \\
\text { BONATE } \\
\text { (MG/L }\end{array}$ \\
\hline DATE & $\begin{array}{l}\text { AS CA) } \\
(00915)\end{array}$ & $\begin{array}{l}\text { AS MG) } \\
(00925)\end{array}$ & $\begin{array}{l}\text { AS NA) } \\
(00930)\end{array}$ & $\begin{array}{c}\text { AS K) } \\
(00935)\end{array}$ & $(00931)$ & $\begin{array}{r}(\mathrm{CAC03}) \\
(00900)\end{array}$ & $\begin{array}{r}\text { CACO3) } \\
(00902)\end{array}$ \\
\hline
\end{tabular}

280226082342502 - ROCKY CREEK LF 66 (LAT $2802 \quad 26$ LONG 0823425.02 )

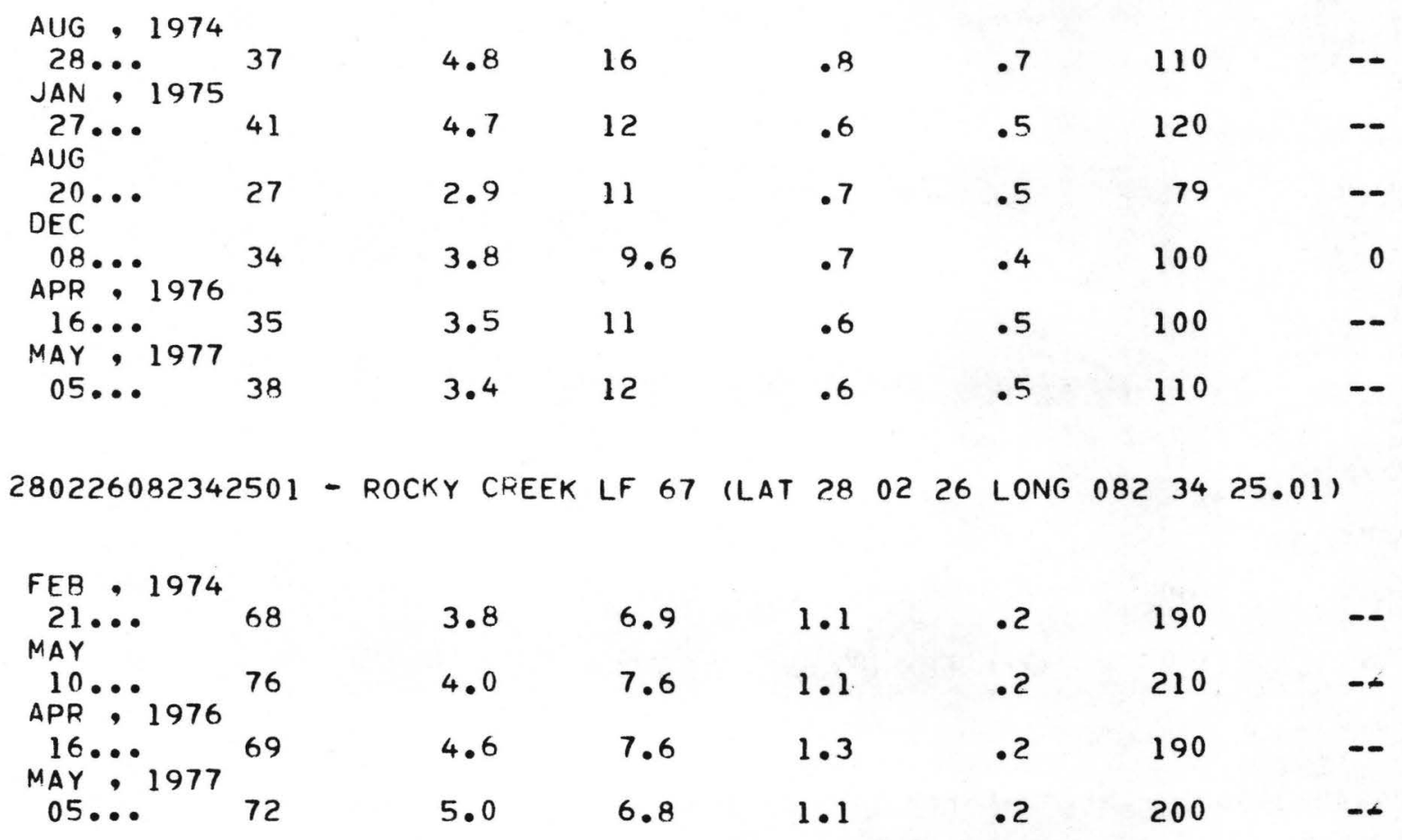

280226082341202 - ROCKY CREEK LF 69 (LAT 280226 LONG 0823412.02 )

$\begin{array}{llllllll}\begin{array}{l}\text { MAY } .1974 \\ \text { 14... }\end{array} & 5.6 & 2.4 & 5.1 & .2 & .5 & 24 & 21 \\ \begin{array}{l}\text { AUG } \\ 28 . .\end{array} & 3.6 & 2.1 & 6.4 & .4 & .7 & 18 & \ldots\end{array}$


TABLE 3. CHEMICAL AND BACTERIOLOGICAL ANALYSES FOR GROUND- AND SURFACE-WATER SAMPLES FROM THE ROCKY CREEK LANDFILL - CONTINUED

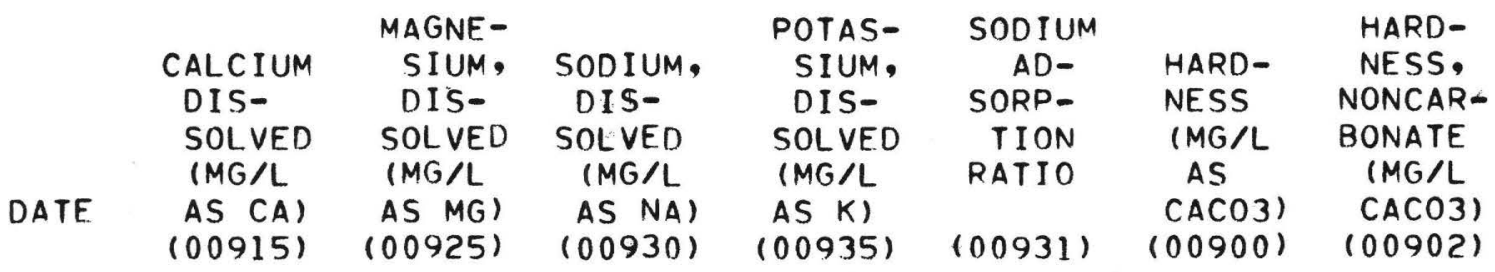

280226082341201 - ROCKY CREEK LF 70 (LAT 280226 LONG 0823412.01 )

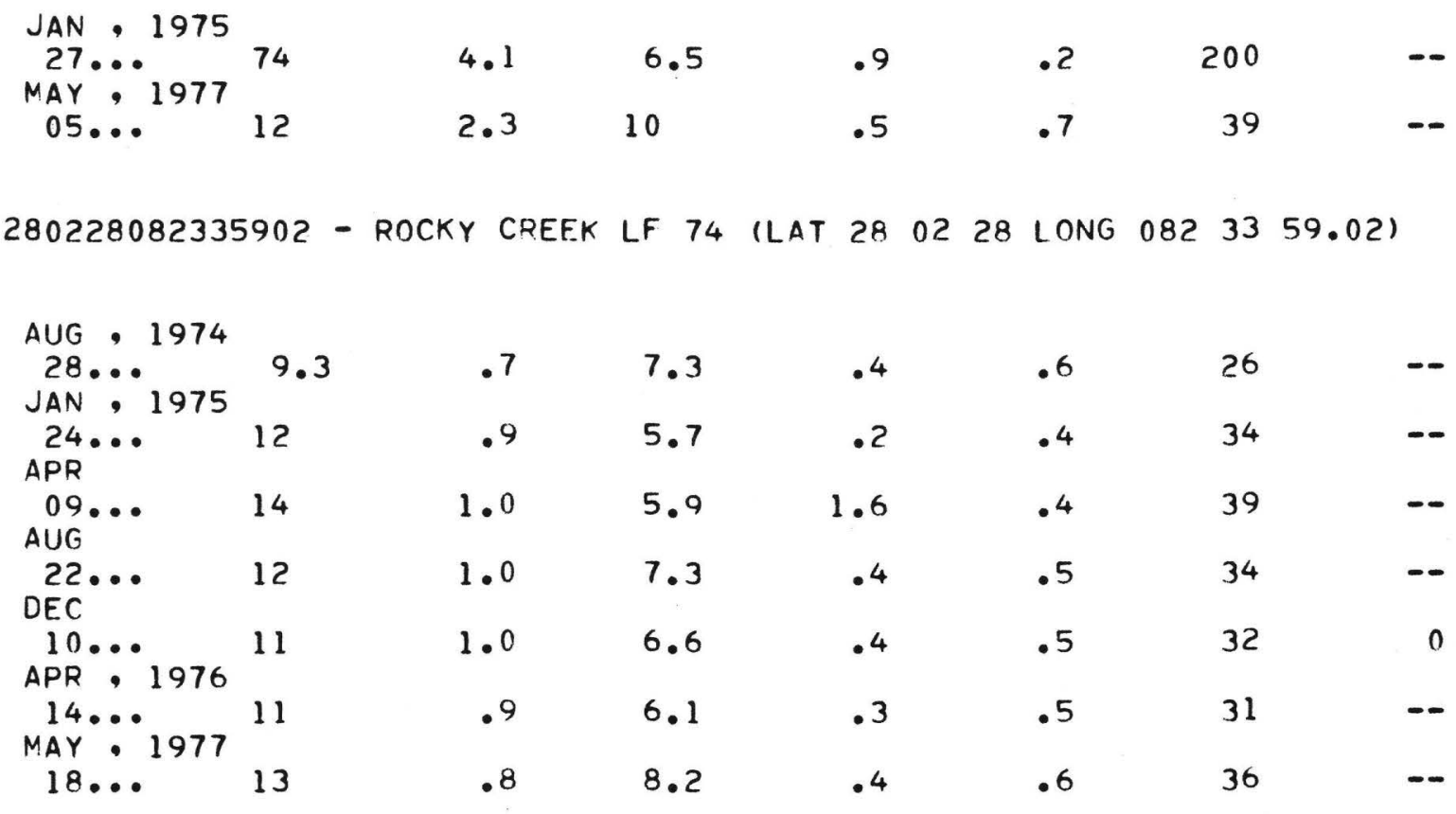


TABLE 3. CHEMICAL AND BACTERIOLIOGICAL ANALYSES FOR GROUND- AND SURFACE-WATER SAMPLES FROM THE ROCK* CREEK LANDFILL - CONTINUED

\begin{tabular}{|c|c|c|c|c|c|c|c|}
\hline & $\begin{array}{l}\text { CALCIUM } \\
\text { DIS- } \\
\text { SOLVED } \\
\text { IMG/L }\end{array}$ & $\begin{array}{l}\text { MAGNE- } \\
\text { SIUM, } \\
\text { DIS- } \\
\text { SOLVED } \\
\text { IMG/L }\end{array}$ & $\begin{array}{l}\text { SODIUM, } \\
\text { DIS- } \\
\text { SOLVED } \\
\text { (MG/L }\end{array}$ & $\begin{array}{l}\text { POTAS- } \\
\text { SIUM, } \\
\text { DIS- } \\
\text { SOLVED } \\
\text { (MG/L }\end{array}$ & $\begin{array}{l}\text { SODIUM } \\
\text { AD- } \\
\text { SORP- } \\
\text { TION } \\
\text { RATIO }\end{array}$ & $\begin{array}{l}\text { HARD - } \\
\text { NESS } \\
\text { IMG/L } \\
\text { AS }\end{array}$ & $\begin{array}{l}\text { HARD- } \\
\text { NESS, } \\
\text { NONCAR- } \\
\text { BONATE } \\
\text { IMG/L }\end{array}$ \\
\hline DATE & $\begin{array}{l}\text { AS CA) } \\
(00915)\end{array}$ & $\begin{array}{l}\text { AS MG }) \\
(00925)\end{array}$ & $\begin{array}{l}\text { AS NA) } \\
(00930)\end{array}$ & $\begin{array}{c}\text { AS K) } \\
(00935)\end{array}$ & $(00931)$ & $\begin{array}{r}\text { (ACO3) } \\
(00900)\end{array}$ & $\begin{array}{r}\text { CAC03) } \\
.(00902)\end{array}$ \\
\hline
\end{tabular}

280231082343603 - ROCKY CREEK LF 83 (LAT 280231 LONG 0823436.03 )

\begin{tabular}{|c|c|c|c|c|c|c|c|}
\hline $\begin{array}{l}\text { FEB , } 1974 \\
21 \ldots \ldots \\
\text { MAY }\end{array}$ & 7.4 & 1.1 & 7.1 & 1.5 & .6 & 23 & $\cdots$ \\
\hline 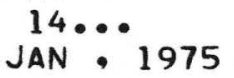 & 7.9 & 1.0 & 7.4 & 1.7 & .7 & 24 & -- \\
\hline $\begin{array}{l}28 \cdots \cdots \\
\text { APR }: 1976\end{array}$ & 62 & 4.1 & 6.0 & .7 & .2 & 170 & \\
\hline $\begin{array}{l}15 \cdots \cdots \\
\text { MAY } 1977\end{array}$ & 70 & 3.8 & 6.0 & .8 & .2 & 190 & \\
\hline $17 \ldots$ & 71 & 4.1 & 6.3 & .9 & .2 & 190 & \\
\hline
\end{tabular}

280231082343602 - ROCKY CREEK LF 84 (LAT 280231 LONG 0823436.02 )

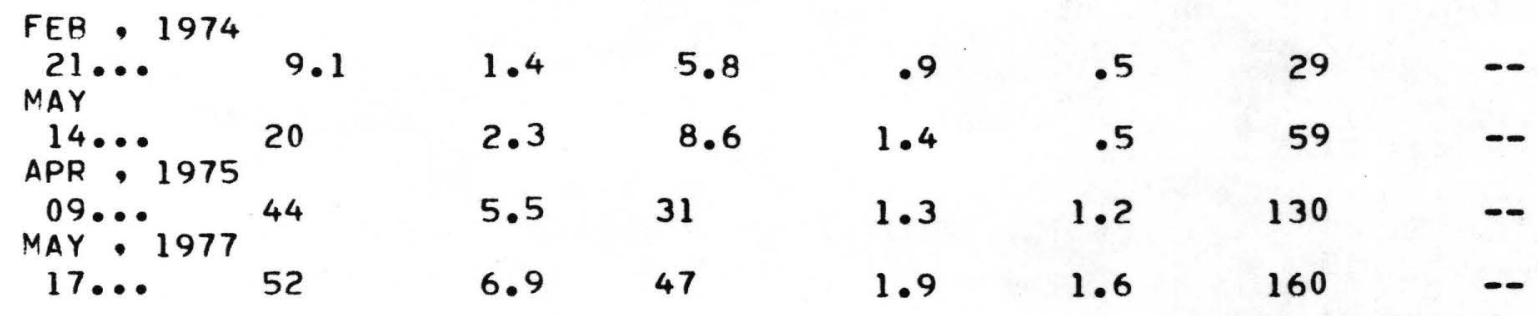

280231082343601 - ROCKY CREEK LF 85 (LAT 280231 LONG 0823436.01 )

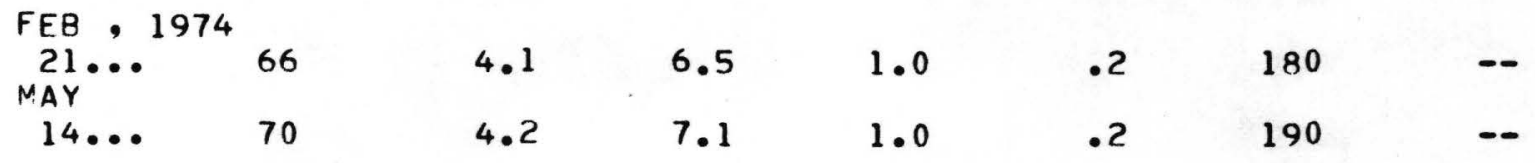


TABLE 3. CHEMICAL AND BACTERIOLOGICAL ANALYSES FOR GROUND- AND SURFACE-WATER SAMPLES FROM THE ROCKY CREEK LANDFILL - CONTINUED

$\begin{array}{ccccccc} & \text { MAGNE- } & & \text { POTAS- } & \text { SODIUM } & & \text { HARD- } \\ \text { CALCIUM } & \text { SIUM, } & \text { SODIUM, } & \text { SIUM, } & \text { AD- } & \text { HARD- } & \text { NESS, } \\ \text { DIS- } & \text { DIS- } & \text { DIS- } & \text { DIS- } & \text { SORP- } & \text { NESS } & \text { NONCAR- } \\ \text { SOLVED } & \text { SOLVED } & \text { SOLVED } & \text { SOLVEO } & \text { TION } & \text { (MG/L } & \text { BONATE } \\ (M G / L & (M G / L & (M G / L & (M G / L & \text { RATIO } & \text { AS } & \text { (MG/L } \\ \text { ASCA) } & \text { AS MG) } & \text { AS NA) } & \text { AS K }) & & \text { CACO3) } & \text { CACO3) } \\ (00915) & (00925) & (00930) & (00935) & (00931) & (00900) & (00902)\end{array}$

280233082340701 - ROCKY CREEK LF 89 (LAT 280233 LONG 0823407.01 )

\begin{tabular}{|c|c|c|c|c|c|c|c|}
\hline MAY & 10 & 2.6 & 12 & .9 & .9 & 36 & -- \\
\hline $\begin{array}{l}15 \cdots \cdots \\
\text { APR }, 1975\end{array}$ & 11 & 3.2 & 12 & 1.1 & - 8 & 41 & \\
\hline $09 \ldots$ & 8.5 & 2.6 & 12 & .4 & .9 & 32 & \\
\hline
\end{tabular}

280235082335801 - ROCKY CREEK LF 98 (LAT 280235 LONG 0823358.01 )

\begin{tabular}{|c|c|c|c|c|c|c|c|}
\hline $\begin{array}{l}\text { MAY } 1974 \\
15 \ldots . . \\
\text { AUG }\end{array}$ & 76 & -- & 6.8 & $\cdot 8$ & .2 & 210 & -- \\
\hline $\begin{array}{l}30 \cdots 1 \\
\text { JAN } 1975\end{array}$ & 73 & 3.8 & 7.0 & .7 & .2 & 200 & - \\
\hline $\begin{array}{l}27 \ldots \\
\text { APR }\end{array}$ & 71 & 4.1 & 6.3 & .7 & .2 & 190 & -- \\
\hline $\begin{array}{l}07 \cdots \\
A \cup G\end{array}$ & 71 & 4.0 & 6.4 & .7 & .2 & 190 & -- \\
\hline $\begin{array}{c}20 \cdots \\
\text { DEC }\end{array}$ & 66 & 3.5 & 6.6 & .7 & .2 & 180 & -- \\
\hline $\begin{array}{l}09 \cdots \cdots \\
\text { APR }, 1976\end{array}$ & 66 & 3.8 & 6.8 & .7 & .2 & 180 & 0 \\
\hline $\begin{array}{l}14 \ldots \\
\text { MAY }, 1977\end{array}$ & 72 & 3.7 & 6.5 & .7 & .2 & 200 & - \\
\hline $02 \ldots$ & 74 & 6.2 & 6.6 & .8 & .2 & 210 & $\cdots$ \\
\hline
\end{tabular}

280238082343201 - ROCKY CREEK LF 116 (LAT 280238 LONG 0823432.01 )

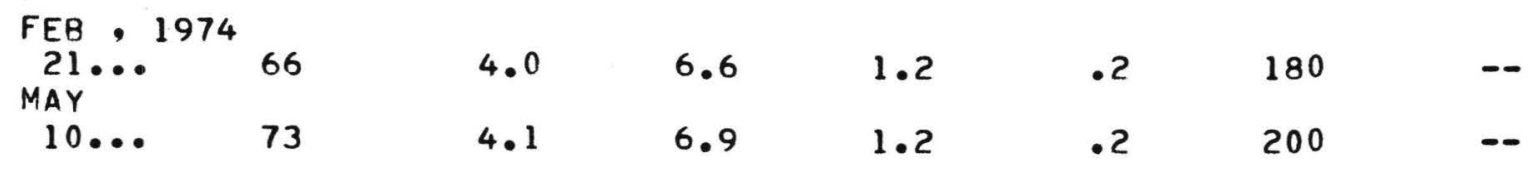


TABLE 3. CHEMICAL AND BACTERIOLOGICAL ANALYSES FOR GROUND- AND SURFACE-WATER SAMPLES FROM THE ROCKY CREEK LANDFILL - CONTINUED

$\begin{array}{ccccccc} & \text { MAGNE- } & & \text { POTAS- } & \text { SODIUM } & & \text { HARD- } \\ \text { CALCIUM } & \text { SIUM, } & \text { SODIUM, } & \text { SIUM, } & \text { AD- } & \text { HARD- } & \text { NESS, } \\ \text { DIS- } & \text { DIS- } & \text { DIS- } & \text { DIS- } & \text { SORP- } & \text { NESS } & \text { NONCAR- } \\ \text { SOLVED } & \text { SOLVED } & \text { SOLVED } & \text { SOLVED } & \text { TION } & \text { (MG/L } & \text { BONATE } \\ (M G / L & (M G / L & (M G / L & (M G / L & \text { RATIO } & \text { AS } & (M G / L \\ \text { ASCA) } & \text { AS MG) } & \text { AS NA) } & \text { AS K } & & \text { CACO3) } & \text { CACO3) } \\ (00915) & (00925) & (00930) & (00935) & (00931) & (00900) & (00902)\end{array}$

280238082342602 - ROCKY CREEK LF 118 (LAT 280238 LONG 0823426.02 )

FEB $\cdot 1974$

\begin{tabular}{|c|c|c|c|c|c|c|c|}
\hline $21 \cdots$ & 5.7 & 1.3 & 6.0 & .2 & .6 & 20 & - \\
\hline $\begin{array}{l}10 \cdots \\
\text { AUG }\end{array}$ & 28 & 2.2 & 6.9 & .5 & .3 & 79 & - \\
\hline $\begin{array}{l}27 \cdots \\
\text { JAN } \because 1975\end{array}$ & 8.9 & 2.4 & 7.4 & .0 & .6 & 32 & \\
\hline $\begin{array}{l}28 \cdots 1 \\
A P R\end{array} 1976$ & 10 & 2.5 & 7.0 & .1 & .5 & 35 & \\
\hline $\begin{array}{l}16 \cdots 1977 \\
\text { MAY } 197\end{array}$ & 10 & 3.4 & 15 & .2 & 1.0 & 39 & \\
\hline $18 \ldots$ & 39 & 17 & 44 & .4 & 1.5 & 170 & \\
\hline
\end{tabular}

280238082342601 - ROCKY CPEEK LF 119 (LAT 280238 LONG 0823426.01 )
MAY, 1974
$10 \ldots 77$
APR 1975
$09 \ldots 63$
3.2
8.3
1.6
.3
210
3.3
18
1.1
.6
170

280238082335701 - ROCKY CREEK LF 120 (LAT 280238 LONG 0823357.01 )

\begin{tabular}{|c|c|c|c|c|c|c|}
\hline $\begin{array}{l}\text { FEB , } 1974 \\
21 \ldots \\
\text { MAY }\end{array}$ & 68 & 3.8 & 7.0 & $\cdot 9$ & .2 & 190 \\
\hline $\begin{array}{l}14 \\
A \cup G\end{array}$ & 71 & 3.8 & 14 & .9 & .4 & 190 \\
\hline $\begin{array}{l}30 \cdots 1 \\
\text { JAN } 1975\end{array}$ & 70 & 6.8 & 6.5 & .7 & $\cdot 2$ & 200 \\
\hline $\begin{array}{l}27 \\
\text { AUG }\end{array}$ & 80 & 3.4 & 6.3 & .7 & .2 & 210 \\
\hline $\begin{array}{l}22 \\
D E C\end{array}$ & 67 & 3.6 & 7.0 & .7 & .2 & 180 \\
\hline $\begin{array}{l}09 \cdots \\
\text { APR }, 1976\end{array}$ & 68 & 3.9 & 7.3 & $\cdot 7$ & .2 & 190 \\
\hline $\begin{array}{l}15 \cdots \cdots \\
\text { MAY }: 1977\end{array}$ & 74 & 3.6 & 6.3 & .7 & .2 & 200 \\
\hline $02 \ldots$ & 2.4 & .1 & 100 & .1 & 17 & 6 \\
\hline
\end{tabular}


TABLE 3. CHEMICAL AND BACTERIOLOGICAL ANALYSES FOR GROUND- AND SURFACE-WATER SAMPLES FROM THE ROCKY CREEK LANDFILL - CONTINUED

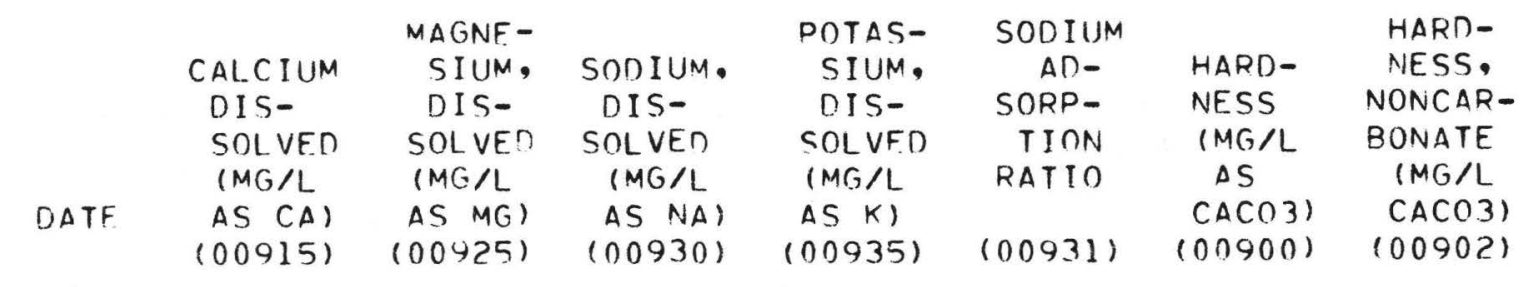

280240082340601 - ROCKY CKEEK LF 127 (LAT 280240 LONG 0823406.01 )

\begin{tabular}{|c|c|c|c|c|c|c|c|}
\hline $21 \ldots$ & 6.1 & .6 & 5.1 & .1 & .5 & 18 & -- \\
\hline MAY & & & & & & & \\
\hline $\begin{array}{l}15 \cdots \\
\text { JAN }, 1975\end{array}$ & 11 & .6 & 5.2 & .2 & .4 & 30 & \\
\hline $28 \ldots$ & 8.? & 3.8 & 17 & .7 & 1.2 & 36 & \\
\hline
\end{tabular}

280240082341201 - ROCKY CREEK LF 130 (LAT $280240 \quad$ LONG 0823412.01 )

$\begin{array}{llllllll}\text { FFP , } 1974 & & & & & \\ 21 \ldots & 8.3 & .7 & 8.7 & .3 & .8 & 24 & \ldots \\ \begin{array}{l}\text { AUG } \\ 28 \ldots\end{array} & 16 & .9 & 13 & 1.0 & .9 & 44 & \ldots\end{array}$

280240082335901 - ROCKY CREEK LF 132 (LAT 280240 LONG 0823359.01 )

\begin{tabular}{|c|c|c|c|c|c|c|c|}
\hline $15 \ldots$ & $1 ?$ & 1.1 & 6.4 & .3 & .5 & 35 & -- \\
\hline$A \cup G$ & & & & & & & \\
\hline $\begin{array}{l}30 \cdots 1975 \\
\text { JAN }\end{array}$ & $2 \cdot 9$ & .9 & 7.5 & $\cdot 2$ & 1.0 & 11 & \\
\hline $27 \ldots$ & 4.7 & .9 & 5.6 & .1 & .6 & 15 & \\
\hline
\end{tabular}

280242082343502 - ROCKY CREEK LF 143 (LAT 280242 LONG 0823435.02 )

$\begin{array}{llllllll}\text { FER , } 1974 & & & & & \\ 21 \ldots & 27 & 2.6 & 16 & .4 & .8 & 78 & - \\ \begin{array}{l}M A Y \\ 14 \ldots .\end{array} & 38 & 2.9 & 16 & .8 & .7 & 110 & \ldots\end{array}$

280242082343501 - ROCKY CREEK LF 144 (LAT 280242 LONG 0823435.01 )

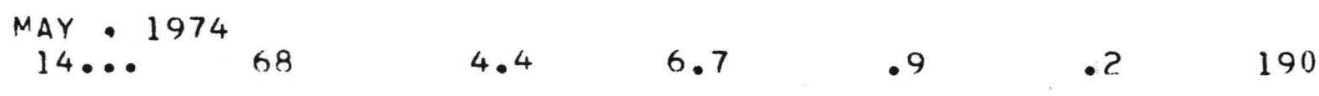

$0235 \cup 82342500$ - RDCKY CREEK LF OXIDATION POND (LAT $28 \quad 0235$ LONG $082 \quad 3425$ )

FEE $\cdot 1974$

$\begin{array}{lllllll}21 \ldots & 36 & 16 & 210 & 190 & 7.3 & 160\end{array}$


TABLE 3. CHEMICAL AND BACTERIOLOGICAL ANALYSES FOR GROUND- AND SURFACE-WATER SAMPLES FROM THE ROCKY CREEK LANDFILL - CONTINUED

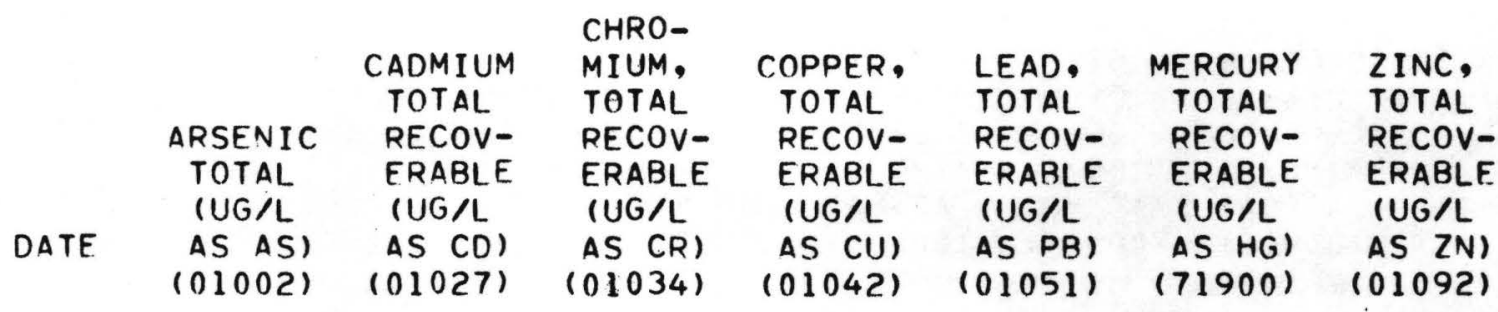

280221082342901 - ROCKY CREEK LF 53 (LAT 280221 LONG 0823429.01 )

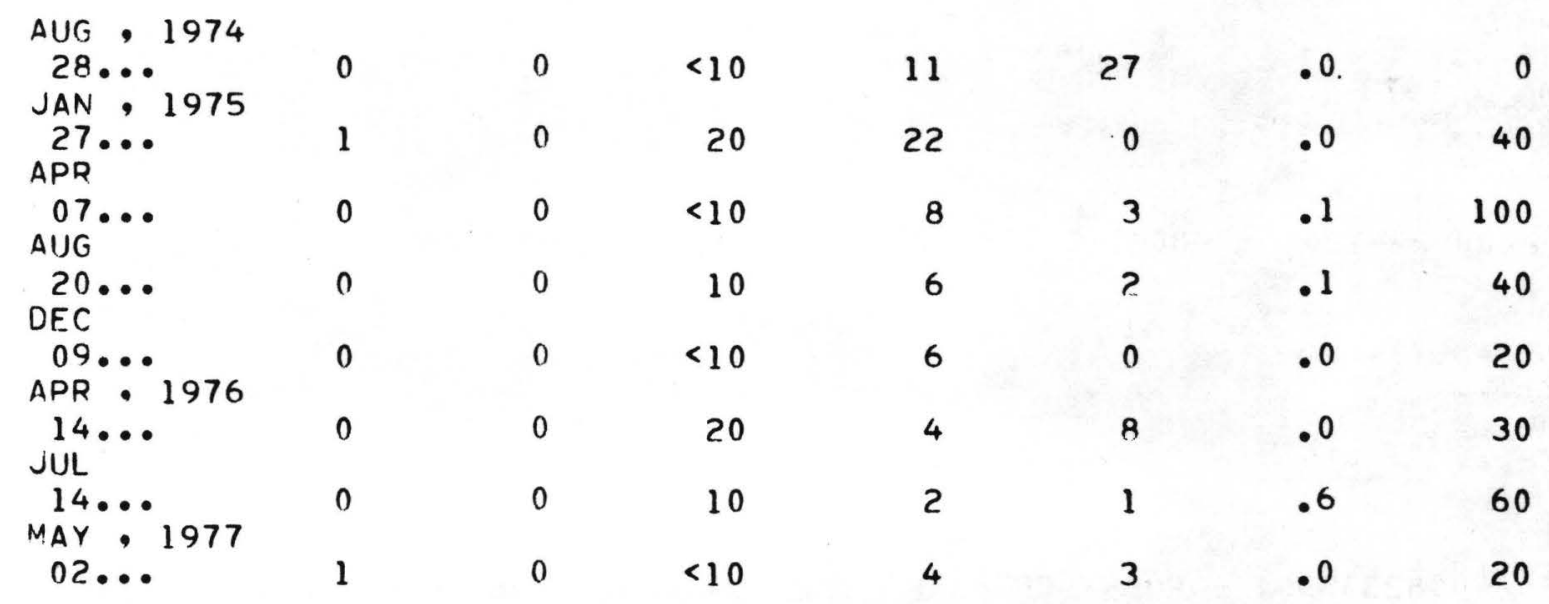

280226082342101 - ROCKY CREEK LF 65 (LAT 280226 LONG 0823421.01 )

\begin{tabular}{|c|c|c|c|c|c|c|c|}
\hline $\begin{array}{l}\text { AUE } \\
22 \ldots \\
\text { DEC }\end{array}$ & 1 & 0 & $<10$ & 10 & 8 & .6 & 1500 \\
\hline $\begin{array}{l}09 \cdots \cdots \\
\text { APR }, 1976\end{array}$ & 0 & 1 & 50 & 14 & 12 & .2 & 1200 \\
\hline $\begin{array}{l}14 \ldots \\
\text { JUL }\end{array}$ & 0 & 1 & 40 & 5 & 10 & .0 & 440 \\
\hline $\begin{array}{l}14 \ldots 1 \\
\text { MAY } 1977\end{array}$ & 2 & 2 & 20 & 15 & 17 & 1.0 & 1200 \\
\hline $05 \ldots$ & 1 & 0 & 10 & 7 & 22 & .0 & 1200 \\
\hline
\end{tabular}


TABLE 3. CHEMICAL AND BACTERIOLOGICAL ANALYSES FOR GROUND- AND SURFACE-WATER SAMPLES FROM THE ROCK CREEK LANDFILL - CONTINUED

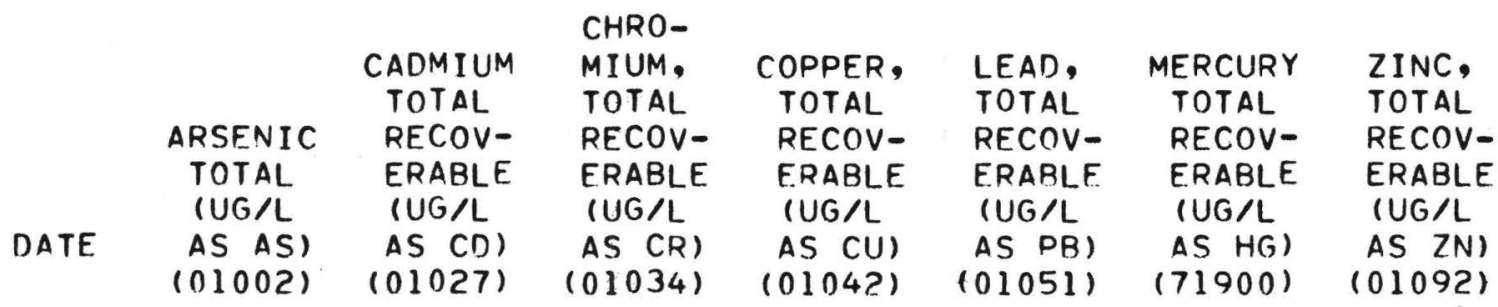

280226082342502 - ROCKY CREEK LF 66 (LAT $280226 \quad$ LONG 0823425.02 )

\begin{tabular}{|c|c|c|c|c|c|c|c|}
\hline $\begin{array}{l}\text { AUG } 1974 \\
28 \ldots . .\end{array}$ & 0 & 5 & $<10$ & 17 & 42 & .0 & 13000 \\
\hline $\begin{array}{l}\text { JAN } 1975 \\
27 \ldots \ldots \\
\text { AUG }\end{array}$ & 1 & 12 & 10 & 32 & 120 & .0 & 19000 \\
\hline $\begin{array}{l}20 \cdots \\
\text { DEC }\end{array}$ & 0 & 50 & $<10$ & 220 & 300 & .1 & 40 \\
\hline $\begin{array}{l}08 \cdots \cdots \\
\text { APR } 1976\end{array}$ & 0 & 9 & $<10$ & 22 & 54 & .2 & 2200 \\
\hline $\begin{array}{l}16 \cdots \cdots \\
J U L\end{array}$ & 1 & 62 & 10 & 140 & 820 & .0 & 31000 \\
\hline $\begin{array}{l}15 \\
\text { OCT }\end{array}$ & 1 & 17 & 20 & 120 & 490 & .2 & 20000 \\
\hline $\begin{array}{l}06 \cdots \cdots \\
\text { MAY } 1977\end{array}$ & 0 & 6 & 20 & 12 & 29 & .1 & 8600 \\
\hline $\begin{array}{l}05 \ldots \\
19 \ldots\end{array}$ & $\begin{array}{l}1 \\
1\end{array}$ & $\begin{array}{r}40 \\
0\end{array}$ & $\begin{array}{l}<10 \\
140\end{array}$ & $\begin{array}{l}53 \\
68\end{array}$ & $\begin{array}{l}300 \\
110\end{array}$ & .0 & $\begin{array}{r}14000 \\
70\end{array}$ \\
\hline
\end{tabular}

280226082342501 - ROCKY CREEK LF 67 (LAT 280226 LONG 0823425.01 )

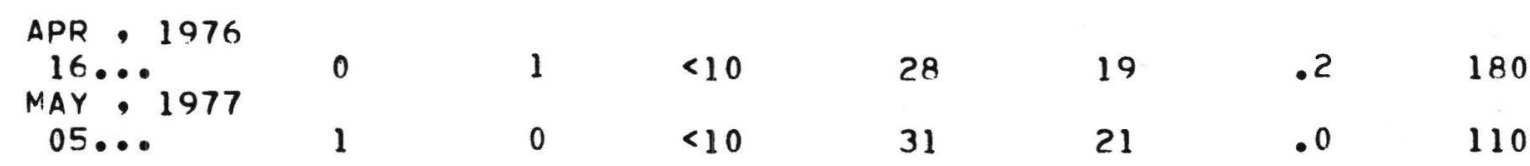

280226082341202 - ROCKY CREEK LF 69 (LAT 280226 LONG 0823412.02 )

AUG, 1974

$28 \ldots$

0

$<10$

14

21

. 3

50 
TABLE 3. CHEMICAL AND BACTERIOLOGICAL ANALYSES FOR GROUND- AND SURFACE-WATER SAMPLES FROM THE ROCKY CREEK LANDFILL - CONTINUED

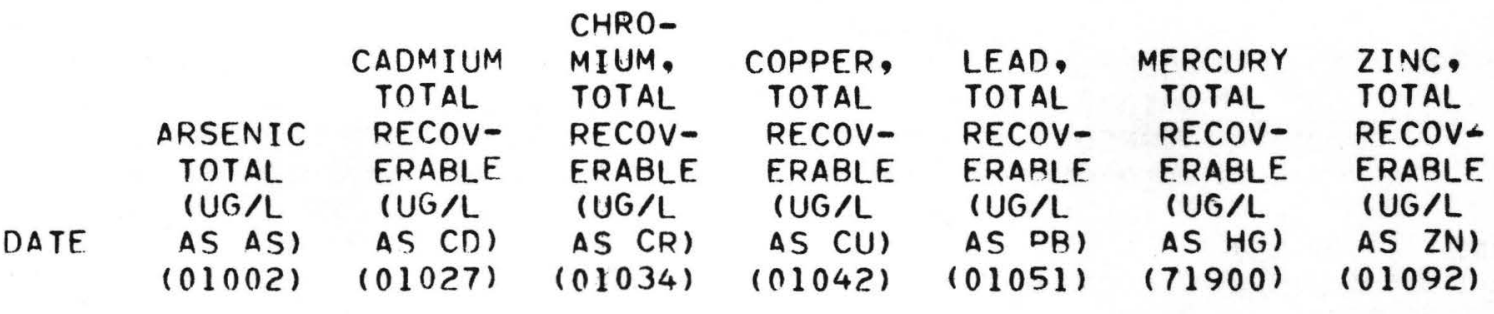

280226082341201 - ROCKY CREEK LF 70 (LAT 280226 LONG 0823412.01 )

\begin{tabular}{|c|c|c|c|c|c|c|}
\hline 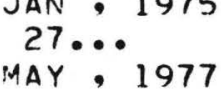 & 0 & 0 & $<10$ & 17 & 5 & .0 \\
\hline $05 \ldots$ & 2 & 0 & 60 & 14 & 33 & .2 \\
\hline
\end{tabular}

280228082335902 - ROCKY CREEK LF 74 (LAT 280228 LONG 0823359.02 )

\begin{tabular}{|c|c|c|c|c|c|c|c|}
\hline $\begin{array}{l}\text { AUG } 1974 \\
28 \cdots 1975 \\
\text { JAN } \because 1975\end{array}$ & 2 & 0 & 40 & 17 & 37 & .3 & 2500 \\
\hline $\begin{array}{l}24 \ldots \\
A P R\end{array}$ & 4 & 1 & 80 & 18 & 21 & .5 & 3400 \\
\hline$\stackrel{09}{\text { AUG }} \cdots$ & 2 & 2 & 20 & 16 & 27 & .2 & 1200 \\
\hline $\begin{array}{c}22 \\
\text { DEC }\end{array}$ & 1 & 0 & $<10$ & 23 & 22 & .2 & 1100 \\
\hline $\begin{array}{l}10 \cdots 1 \\
\text { APR }, 1976\end{array}$ & 1 & 0 & $<10$ & 5 & 5 & $\cdot 0$ & 300 \\
\hline $\operatorname{JUL}_{\text {JUL }}^{14 \ldots}$ & 1 & 1 & 30 & 7 & 17 & .0 & 900 \\
\hline OCT & 1 & 1 & 20 & 0 & 4 & .2 & 270 \\
\hline MAY $\because 1977$ & 1 & 0 & 50 & 4 & 14 & .0 & 170 \\
\hline $18 \ldots$ & 2 & 0 & 50 & 21 & 12 & .2 & 3700 \\
\hline
\end{tabular}


TABLE 3. CHEMICAL AND BACTERIOLOGICAL ANALYSES FOR GROUND- AND SURFACE-WATER SAMPLES FROM THE ROCKY CREEK LANDFILL - CONTINUED

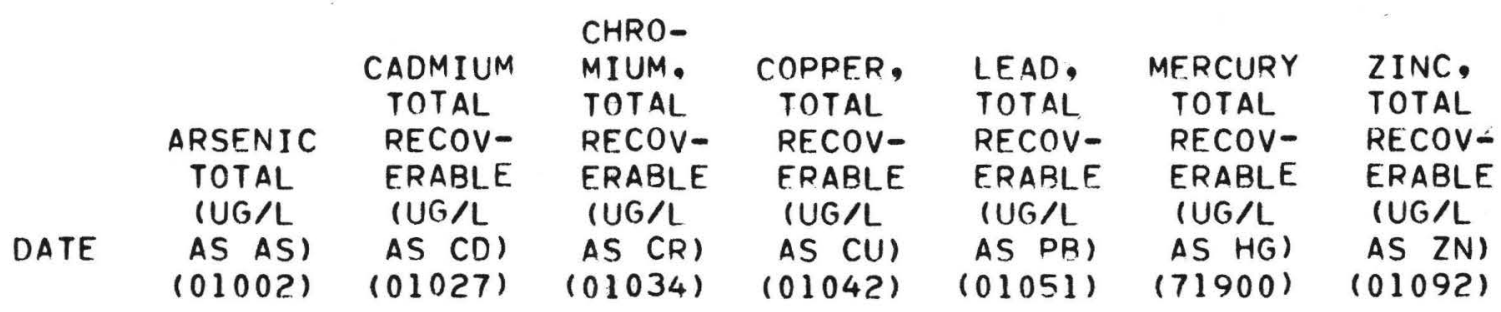

280231082343603 - ROCKY CREEK LF 83 (LAT 280231 LONG 0823436.03 )

\begin{tabular}{|c|c|c|c|c|c|c|c|}
\hline 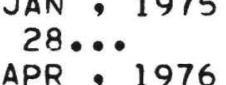 & 1 & 0 & 10 & 27 & 150 & .0 & 510 \\
\hline $\begin{array}{l}15 \ldots \\
O C T\end{array}$ & 0 & 0 & 20 & 2 & 9 & .0 & 10 \\
\hline MAY $\because 1977$ & 0 & 0 & 50 & 11 & 3 & .0 & \\
\hline $17 \ldots$ & 5 & 0 & 10 & 4 & 0 & 0 & \\
\hline
\end{tabular}

280231082343602 - ROCKY CREEK LF 84 (LAT 280231 LONG 0823436.02 )

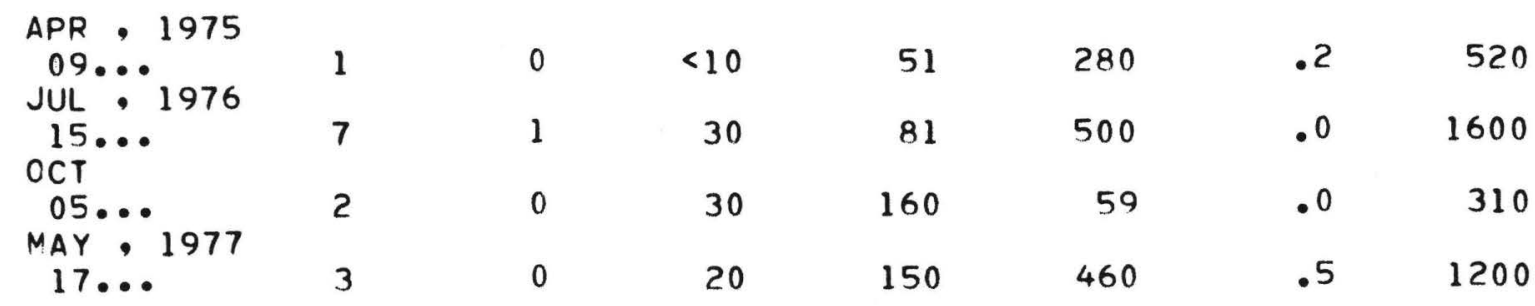

280233082340701 - ROCKY CREEK LF 89 (LAT 280233 LONG 0823407.01 )

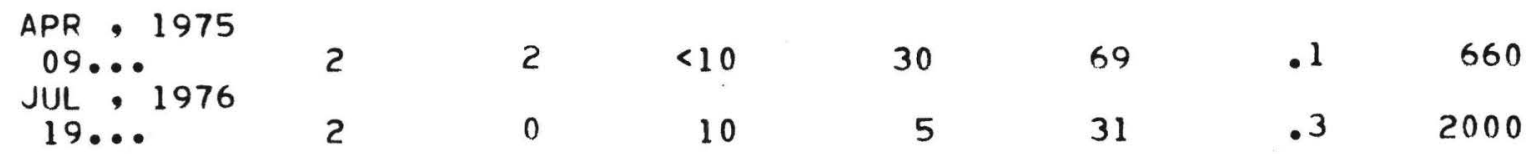


TABLE 3. CHEMICAL AND BACTERIOLOGICAL ANALYSES FOR GROUND- AND SURFACE-WATER SAMPLES FROM THE ROCKY CREEK LANDFILL - CONTINUED

\begin{tabular}{|c|c|c|c|c|c|c|c|}
\hline & $\begin{array}{c}\text { ARSENIC } \\
\text { TOTAL } \\
\text { IUG/L }\end{array}$ & $\begin{array}{l}\text { CADMIUM } \\
\text { TOTAL } \\
\text { RECOV- } \\
\text { ERABLE } \\
\text { IUG/L }\end{array}$ & $\begin{array}{l}\text { CHRO- } \\
\text { MIUM, } \\
\text { TOTAL } \\
\text { RECOV- } \\
\text { ERABLE } \\
\text { IUG/L }\end{array}$ & $\begin{array}{l}\text { COPPER, } \\
\text { TOTAL } \\
\text { RECOV- } \\
\text { ERABLE } \\
\text { IUG/L }\end{array}$ & $\begin{array}{l}\text { LEAD, } \\
\text { TOTAL } \\
\text { RECOV- } \\
\text { ERABLE } \\
\text { (UG/L }\end{array}$ & $\begin{array}{l}\text { MERCURY } \\
\text { TOTAL } \\
\text { RECOV- } \\
\text { ERABLE } \\
\text { IUG/L }\end{array}$ & $\begin{array}{l}\text { ZINC, } \\
\text { TOTAL } \\
\text { RECOV- } \\
\text { ERABLE } \\
\text { IUG/L }\end{array}$ \\
\hline DATE. & $\begin{array}{c}\text { AS AS) } \\
(01002)\end{array}$ & $\begin{array}{c}\text { AS CD }) \\
(01027)\end{array}$ & $\begin{array}{c}A S \text { CR }) \\
(01034)\end{array}$ & $\begin{array}{l}\text { AS CU) } \\
(01042)\end{array}$ & $\begin{array}{l}A S P B) \\
(01051)\end{array}$ & $\begin{array}{l}\text { AS HG) } \\
(71900)\end{array}$ & $\begin{array}{l}\text { AS ZN) } \\
(01092)\end{array}$ \\
\hline
\end{tabular}

280235082335801 - ROCKY CREEK LF 98 (LAT 280235 LONG 0823358.01 )

\begin{tabular}{|c|c|c|c|c|c|c|c|}
\hline $\begin{array}{l}\text { AUG } 1974 \\
30 \ldots \cdots\end{array}$ & 0 & 0 & $<10$ & 5 & 57 & .1 & 130 \\
\hline $\begin{array}{l}27 \ldots \\
A P R\end{array}$ & 0 & 0 & 10 & 34 & 0 & .0 & 230 \\
\hline $\begin{array}{l}07 \ldots \\
\text { AUG }\end{array}$ & 0 & 0 & $<10$ & 5 & 6 & .0 & 70 \\
\hline $\begin{array}{l}20 \cdots \\
D E C\end{array}$ & 0 & 0 & $<10$ & 5 & 7 & .1 & 220 \\
\hline $\begin{array}{l}09 \cdots \cdots 1976 \\
A P R \because 1970\end{array}$ & 0 & 0 & $<10$ & 15 & 12 & .1 & 320 \\
\hline $\operatorname{JUL}^{14 \ldots}$ & 0 & 0 & 10 & 11 & 8 & .0 & 230 \\
\hline $\begin{array}{l}14 \ldots \\
\text { MAY } 1977\end{array}$ & 0 & 0 & 20 & 0 & 0 & .7 & 120 \\
\hline $02 \ldots$ & 1 & 0 & $<10$ & 12 & 3 & .0 & 30 \\
\hline
\end{tabular}

280238082342603 - ROCKY CKEEK LF 117 (LAT 280238 LONG 0823426.03 )

OCT $\cdot 1976$

$\begin{array}{llllllll}06 \ldots & 1 & 0 & 40 & 33 & 0 & .1 & 360\end{array}$

280238082342602 - ROCKY CREEK LF 118 (LAT 280238 LONG 0823426.02 )

\begin{tabular}{|c|c|c|c|c|c|c|c|}
\hline $\begin{array}{l}\text { AUG } 1974 \\
27 \ldots . \\
\text { JAN, } 1975\end{array}$ & 0 & 0 & $<10$ & 12 & 46 & .2 & 1600 \\
\hline $\begin{array}{l}28 \cdots 1 \\
A P R \bullet 1976\end{array}$ & 0 & 0 & 10 & 21 & 0 & .0 & 1500 \\
\hline $\begin{array}{l}16 \cdots \cdots \\
\text { JUL }\end{array}$ & 1 & 3 & $<10$ & 1 & 15 & .0 & 450 \\
\hline $\begin{array}{l}16 \cdots \\
\text { MAY } 1977\end{array}$ & 0 & 1 & 30 & 7 & 8 & $\bullet 0$ & 1200 \\
\hline $18 \ldots$ & 2 & 0 & $<10$ & 9 & 2 & .5 & 310 \\
\hline
\end{tabular}

280238082342601 - ROCKY CREEK LF 119 (LAT 2R 0238 LONG 0823426.01 )

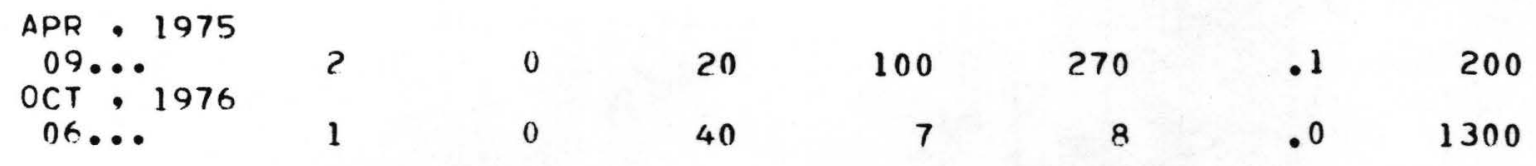


TABLE 3. CHEMICAL AND BACTERIOLOGICAL ANALYSES FOR GROUND- AND SURFACE-WATER SAMPLES FROM THE ROCKY CREEK LANDFILL - CONTINUED

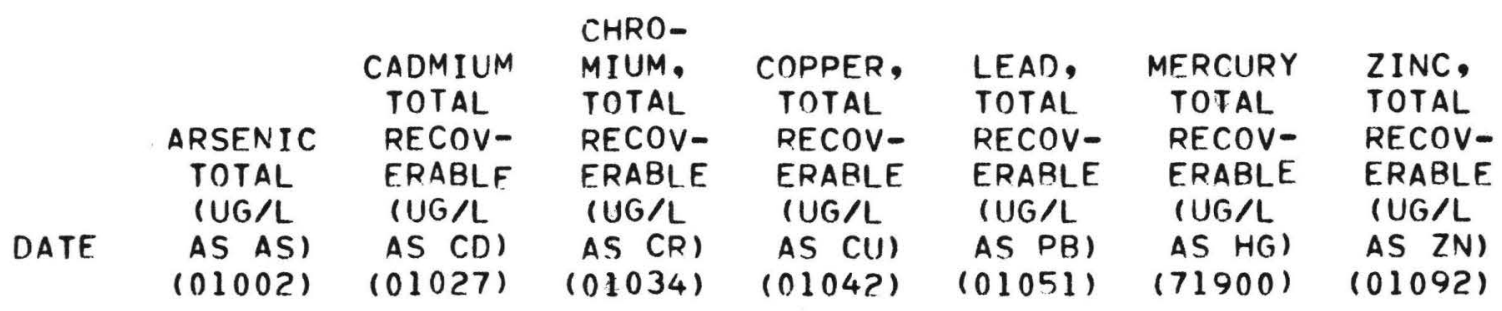

280238082335701 - ROCKY CREEK LF 120 (LAT 280238 LONG 0823357.01 )

\begin{tabular}{|c|c|c|c|c|c|c|c|}
\hline $\begin{array}{l}\text { AUE }, 1974 \\
30 \ldots .1975 \\
\text { JAN } 1975\end{array}$ & 1 & 1 & $<10$ & 3 & 55 & .2 & 100 \\
\hline $\begin{array}{l}27 \\
\text { AUG }\end{array}$ & 0 & 0 & 20 & 100 & 0 & .1 & 120 \\
\hline $\begin{array}{l}22 \ldots \\
D E C\end{array}$ & 0 & 0 & $<10$ & 66 & 6 & .2 & 90 \\
\hline $\begin{array}{l}\text { 09... } \\
\text { APR } 1976\end{array}$ & 0 & 0 & $<10$ & 50 & 5 & $\cdot 2$ & 140 \\
\hline $\begin{array}{l}15 \cdots \\
\text { JUL }\end{array}$ & 0 & 0 & 20 & 160 & 11 & .0 & 160 \\
\hline $\begin{array}{l}14 \ldots \\
\text { OCT }\end{array}$ & 0 & 1 & 20 & 39 & 8 & .0 & 200 \\
\hline $\begin{array}{l}05 \cdots \cdots \\
\text { MAY } 1977\end{array}$ & 0 & 0 & 50 & 27 & 16 & .0 & 280 \\
\hline $02 \ldots$ & 1 & 0 & 10 & 41 & 3 & .0 & 40 \\
\hline
\end{tabular}

280240082340601 - ROCKY CREEK LF 127 (LAT 280240 LONG 0823406.01 )
JAN, 1975
$\begin{array}{llllllll}28 \ldots & 4 & 1 & 50 & 48 & 150 & .6 & 110\end{array}$

280240082341201 - ROCKY CREEK LF 130 (LAT 280240 LONG 0823412.01 )
AUG , 1974
$\begin{array}{llllllll}28 \ldots & 2 & 1 & 100 & 83 & 120 & .7 & 100\end{array}$

280240082335901 - ROCKY CREEK LF 132 (LAT 280240 LONG 0823359.01 )

\begin{tabular}{|c|c|c|c|c|c|c|c|}
\hline JAN 1975 & 1 & 0 & 20 & 21 & 25 & .3 & 3100 \\
\hline $27 \ldots$ & 0 & 0 & 20 & 17 & 21 & .0 & 2100 \\
\hline
\end{tabular}


TABLE 3. CHEMICAL AND BACTERIOLOGICAL ANALYSES FOR GROUND- AND SURFACE-WATER SAMPLES FROM THE ROCKY CREEK LANDFILL - CONTINUED

\begin{tabular}{|c|c|c|c|c|c|c|c|c|c|c|}
\hline & $\begin{array}{l}\text { NITRO- } \\
\text { GEN, } \\
\text { ORGANIC } \\
\text { TOTAL } \\
\text { IMG/L }\end{array}$ & $\begin{array}{l}\text { NITRO- } \\
\text { GEN, } \\
\text { AMMONIA } \\
\text { DIS- } \\
\text { SOLVED } \\
\text { IMG/L }\end{array}$ & $\begin{array}{l}\text { NITRO- } \\
\text { GEN, } \\
\text { AMMONIA } \\
\text { TOTAL } \\
\text { IMG/L }\end{array}$ & $\begin{array}{l}\text { NITRO- } \\
\text { GEN, } \\
\text { NITRITE } \\
\text { DIS- } \\
\text { SOLVED } \\
\text { IMG/L }\end{array}$ & $\begin{array}{l}\text { NITRO- } \\
\text { GEN, } \\
\text { NITRITE } \\
\text { TOTAL } \\
\text { IMG/L }\end{array}$ & $\begin{array}{l}\text { NITRO- } \\
\text { GEN, } \\
\text { NITRATE } \\
\text { DIS- } \\
\text { SOLVED } \\
\text { IMG/L }\end{array}$ & $\begin{array}{l}\text { NITRO- } \\
\text { GEN, } \\
\text { NI TRATE } \\
\text { TOTAL } \\
\text { IMG/L }\end{array}$ & $\begin{array}{l}\text { PHOS- } \\
\text { PHORUS, } \\
\text { TOTAL } \\
\text { (MG/L }\end{array}$ & $\begin{array}{l}\text { PHOS- } \\
\text { PHORUS, } \\
\text { DIS- } \\
\text { SOL VED } \\
\text { (MG/L. }\end{array}$ & $\begin{array}{l}\text { PHOS- } \\
\text { PHORUS, } \\
\text { ORTHO, } \\
\text { DIS- } \\
\text { SOLVED } \\
\text { (MG/L }\end{array}$ \\
\hline ATE & $\begin{array}{l}\text { AS N) } \\
(00605)\end{array}$ & $\begin{array}{l}\text { AS N) } \\
(00608)\end{array}$ & $\begin{array}{l}\text { AS N) } \\
(00610)\end{array}$ & $\begin{array}{l}\text { AS N) } \\
(00613)\end{array}$ & $\begin{array}{l}\text { AS N) } \\
(00615)\end{array}$ & $\begin{array}{l}\text { AS N) } \\
(00618)\end{array}$ & $\begin{array}{c}\text { AS N) } \\
(00620)\end{array}$ & $\begin{array}{c}\text { AS P) } \\
(00665)\end{array}$ & $\begin{array}{c}\text { AS P) } \\
(00666)\end{array}$ & $\begin{array}{c}\text { AS P ) } \\
(00671)\end{array}$ \\
\hline
\end{tabular}

280221082342901 - ROCKY CREEK LF 53 (LAT 280221 LONG 0823429.01 )

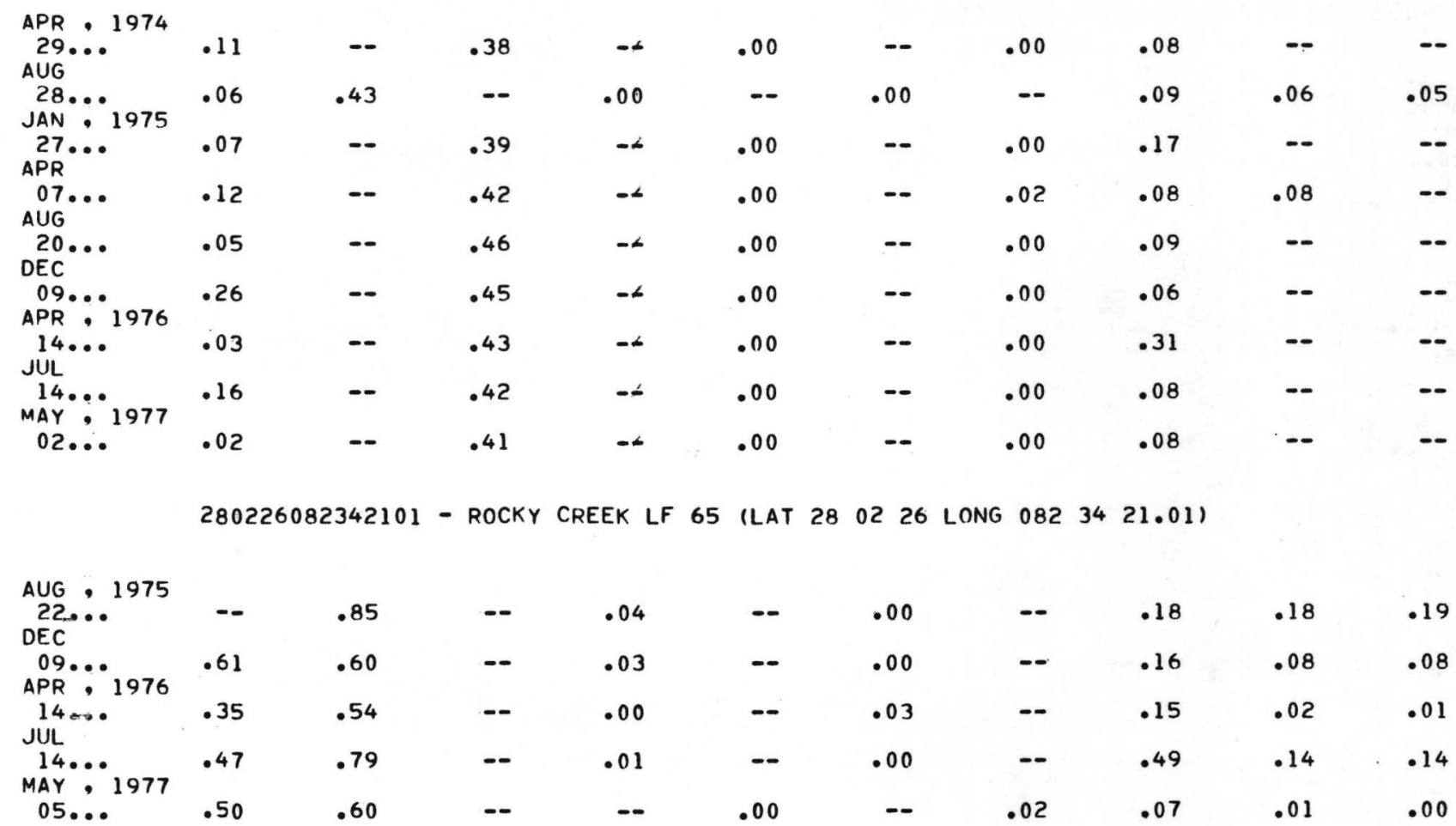


TABLE 3. CHEMICAL AND BACTERIOLOGICAL ANALYSES FOR GROUND- AND SURFACE-WATER SAMPLES FROM THE ROCKY CREEK LANDFILL - CONTINUED

\begin{tabular}{|c|c|c|c|c|c|c|c|c|c|c|}
\hline & $\begin{array}{l}\text { NITRO- } \\
\text { GEN, } \\
\text { ORGANIC } \\
\text { TOTAL } \\
\text { IMG/L }\end{array}$ & $\begin{array}{l}\text { NITRO- } \\
\text { GEN, } \\
\text { AMMONIA } \\
\text { DIS- } \\
\text { SOLVED } \\
\text { IMG/L. }\end{array}$ & $\begin{array}{l}\text { NITRO- } \\
\text { GEN, } \\
\text { AMMONIA } \\
\text { TOTAL } \\
\text { IMG/L }\end{array}$ & $\begin{array}{l}\text { NITRO- } \\
\text { GEN, } \\
\text { NITRITE } \\
\text { DIS- } \\
\text { SOLVED } \\
\text { (MG/L }\end{array}$ & $\begin{array}{l}\text { NITRO- } \\
\text { GEN, } \\
\text { NITRI TE } \\
\text { TOTAL } \\
\text { (MG/L }\end{array}$ & $\begin{array}{l}\text { NITRO- } \\
\text { GEN, } \\
\text { NITRATE } \\
\text { DIS- } \\
\text { SOLVED } \\
\text { (MG/L }\end{array}$ & $\begin{array}{l}\text { NITRO- } \\
\text { GEN, } \\
\text { NITRATE } \\
\text { TOTAL } \\
\text { (MG/L }\end{array}$ & $\begin{array}{l}\text { PHOS- } \\
\text { PHORUS, } \\
\text { TOTAL } \\
\text { (MG/L }\end{array}$ & $\begin{array}{l}\text { PHOS- } \\
\text { PHORUS, } \\
\text { DIS- } \\
\text { SOLVED } \\
\text { IMG/L }\end{array}$ & $\begin{array}{c}\text { PHOS- } \\
\text { PHORUS, } \\
\text { ORTHO, } \\
\text { DIS- } \\
\text { SOLVED } \\
\text { IMG/L }\end{array}$ \\
\hline DATE & $\begin{array}{l}\text { AS N) } \\
(00605)\end{array}$ & $\begin{array}{l}\text { AS N) } \\
(00608)\end{array}$ & $\begin{array}{l}\text { AS N) } \\
(00610)\end{array}$ & $\begin{array}{l}\Delta S N) \\
(00613)\end{array}$ & $\begin{array}{l}\text { AS N) } \\
(00615)\end{array}$ & $\begin{array}{c}\text { AS N) } \\
(00618)\end{array}$ & $\begin{array}{c}\text { AS N) } \\
(00620)\end{array}$ & $\begin{array}{c}\text { AS P) } \\
(00665)\end{array}$ & $\begin{array}{l}\text { AS P) } \\
(00666)\end{array}$ & $\begin{array}{c}\text { AS P) } \\
(00671)\end{array}$ \\
\hline
\end{tabular}

280226082342502 - ROCKY CREEK LF 66 (LAT 280226 LONG 0823425.02 )

\begin{tabular}{|c|c|c|c|c|c|c|c|c|c|c|}
\hline $\begin{array}{l}\text { AUG } \because 1974 \\
28 \ldots .1975 \\
\text { JAN } 1975\end{array}$ & .29 & .23 & -- & .00 & -- & .00 & -- & .03 & .01 & .01 \\
\hline $\begin{array}{l}27 \ldots \\
A P R\end{array}$ & $\cdot 35$ & .24 & -- & .02 & -- & .33 & -- & .11 & .09 & .00 \\
\hline $\begin{array}{l}03 \cdots \cdots \\
\text { AUG }\end{array}$ & .34 & .13 & -- & .00 & -- & .01 & -- & .19 & .03 & .01 \\
\hline $20 \cdots$ & .67 & -- & .46 & $-\infty$ & .01 & -- & .00 & .10 & -- & $\cdots$ \\
\hline $\begin{array}{l}08 \cdots \\
\text { APR }\end{array}$ & .43 & -- & .27 & $-\infty$ & .00 & - & .00 & .04 & - & -- \\
\hline $\begin{array}{l}16 \cdots \\
\text { JUL }\end{array}$ & .69 & .44 & -- & .00 & -- & .04 & -- & .14 & .04 & .03 \\
\hline MAY $\because 1977$ & .53 & .25 & -- & .00 & -- & .02 & -- & .13 & .03 & .03 \\
\hline $05 \ldots$ & .50 & .17 & -- & $-\infty$ & .00 & -- & .01 & .11 & .01 & .00 \\
\hline
\end{tabular}

280226082342501 - ROCKY CREEK LF 67 (LAT 280226 LONG 0823425.01 )

\begin{tabular}{|c|c|c|c|c|c|c|c|c|c|c|}
\hline MAY 1677 & .51 & .39 & - & .02 & - & .90 & -- & .08 & .03 & .01 \\
\hline $05 \ldots$ & .39 & .12 & -- & $-\alpha$ & .00 & - & .12 & .14 & .07 & .01 \\
\hline
\end{tabular}

280226082341202 - ROCKY CREEK LF 69 (LAT 280226 LONG 08234 12.02)

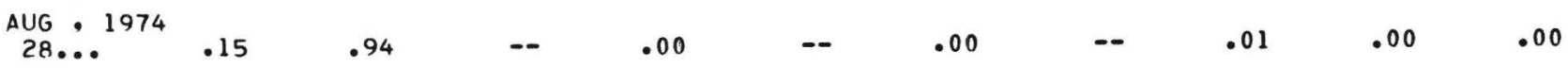

280226082341201 - ROCKY CREEK LF 70 (LAT 280226 LONG 0823412.01 )

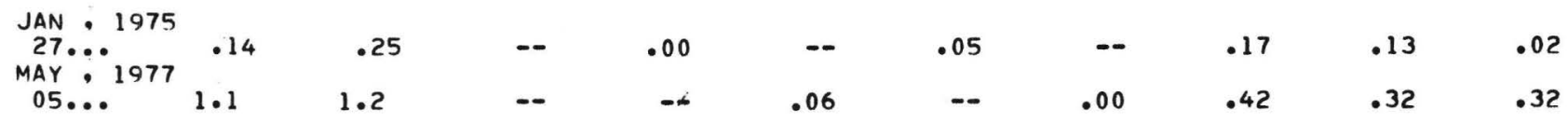


TABLE 3. CHEMICAL AND BACTERIOLOGICAL ANALYSES FOR GROUND- AND SURFACE-WATER SAMPLES FROM THE ROCKY CREEK LANDF ILL - CONTINUED

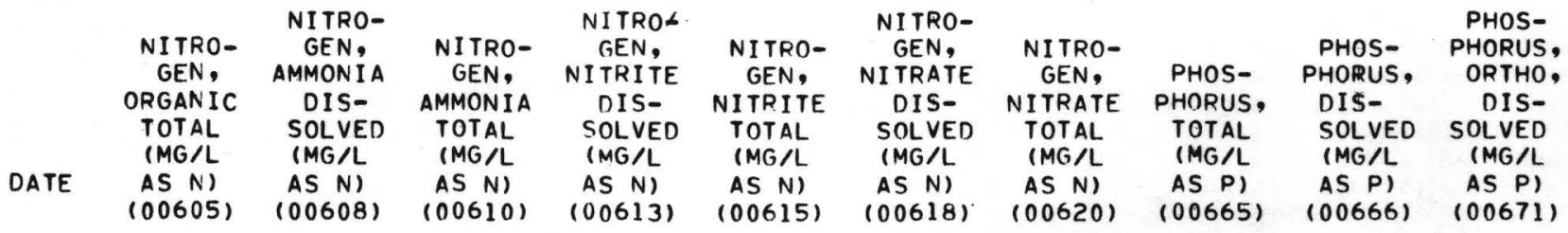

280228082335901 - ROCKY CREEK LF 73 (LAT 280228 LONG 0823359.01 )

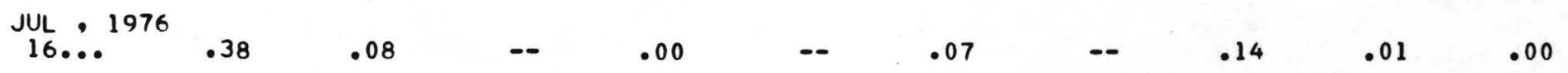

280228082335902 - ROCKY CREEK LF 74 (LAT 280228 LONG 0823359.02 )

APR, 1975

\begin{tabular}{|c|c|c|c|c|c|c|c|c|c|c|}
\hline $\begin{array}{l}09 \ldots \\
\text { AUG }\end{array}$ & .41 & .30 & -- & .00 & -- & .01 & -- & .37 & .04 & .00 \\
\hline $\begin{array}{l}10 \cdots \cdots \\
\text { APR } 1976\end{array}$ & .27 & -- & .43 & - & .02 & -- & .00 & .08 & $-\infty$ & - \\
\hline $\begin{array}{l}14 \ldots \ldots \\
\text { JUL }\end{array}$ & .29 & .33 & -- & .00 & -- & .01 & -- & .09 & .04 & .03 \\
\hline $\begin{array}{l}15 \cdots \cdots \\
\text { MAY } 1977\end{array}$ & .15 & - & .40 & -6 & . & -- & .00 & .07 & $\cdots$ & - \\
\hline
\end{tabular}

280231082343603 - ROCKY CREEK LF 83 (LAT 280231 LONG 0823436.03 )

JAN 1975

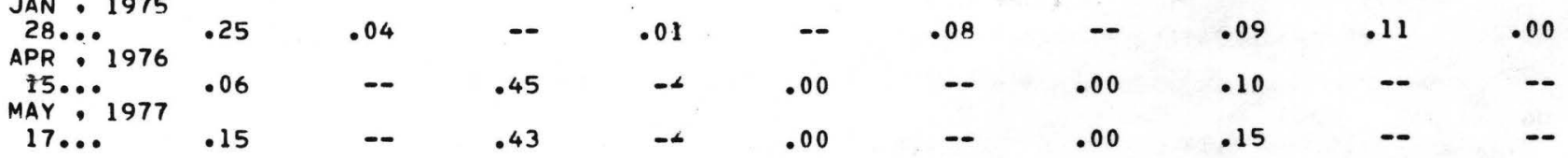

280231082343602 - ROCKY CREEK LF 84 (LAT 280231 LONG 0823436.02 )

\begin{tabular}{|c|c|c|c|c|c|c|c|c|c|c|}
\hline $\begin{array}{l}\text { APR , } 1975 \\
09 \ldots\end{array}$ & .68 & .26 & -- & .00 & -- & .01 & -- & .18 & .05 & .01 \\
\hline $\begin{array}{l}\text { JUL } 1976 \\
\text { MAY : } 1977\end{array}$ & 1.0 & .67 & - & .01 & -- & .01 & - & .18 & $\bullet 07$ & .06 \\
\hline
\end{tabular}


TABLE 3. CHEMICAL AND BACTERIOLOGICAL ANALYSES FOR GROUND- AND SURFACE-WATER SAMPLES FROM THE ROCK* CREEK LANDFILL - CONTINUED

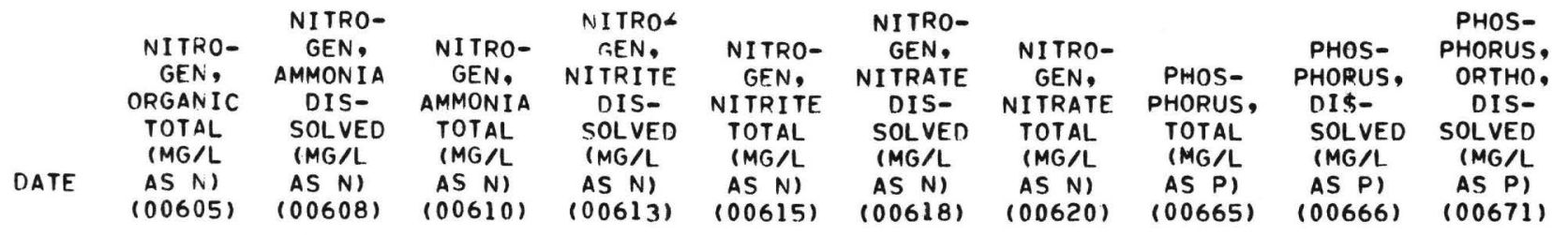

280233082340701 - ROCKY CREEK LF 89 (LAT 280233 LONG 0823407.01 )

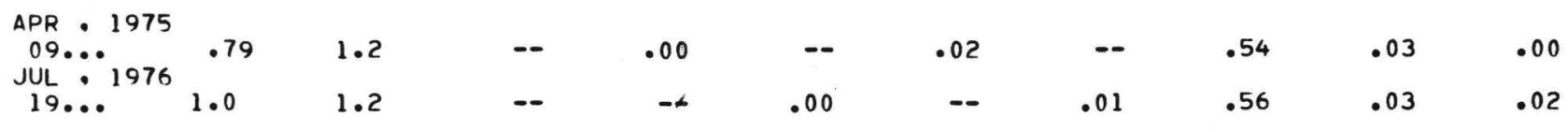

280235082335801 - ROCKY CREEK LF 98 (LAT 280235 LONG 0823358.01 )

\begin{tabular}{|c|c|c|c|c|c|c|c|c|c|c|}
\hline $\begin{array}{l}\text { AUG } 1974 \\
\text { 30 : } \\
\text { JAN } 1975\end{array}$ & $\cdot 32$ & -- & .29 & -2 & .00 & - & .00 & .10 & .09 & - \\
\hline $\begin{array}{l}27 \ldots \\
A P R\end{array}$ & .08 & .31 & -- & .00 & -- & .00 & -- & .18 & .11 & .01 \\
\hline $\begin{array}{l}20 \cdots \\
D E C\end{array}$ & .50 & -- & .35 & -- & .01 & - & .01 & .08 & - & - \\
\hline $\begin{array}{l}09 \cdots \\
\text { APR } \because 1976\end{array}$ & .80 & -- & .34 & $-\infty$ & .00 & - & .00 & .09 & -- & - \\
\hline $\begin{array}{l}14 \cdots 1 \\
\text { MAY } 1977\end{array}$ & .10 & -- & . 31 & -6 & .00 & - & .00 & .08 & -- & \\
\hline $02 \ldots$ & .04 & -- & .30 & -6 & .00 & -- & .00 & .08 & $-\infty$ & \\
\hline
\end{tabular}

280238082340901 - ROCKY CREEK LF 114 (LAT 280238 LONG 0823409.01 )

JAN 1974

$29 .$.

.47

.62

.00

$\ldots 00$

.09 
TABLE 3. CHEMICAL AND BACTERIOLOGICAL ANALYSES FOR GROUND- AND SURFACE-WATER SAMPLES FROM THE ROCKY CREEK LANDFILL - CONTINUED

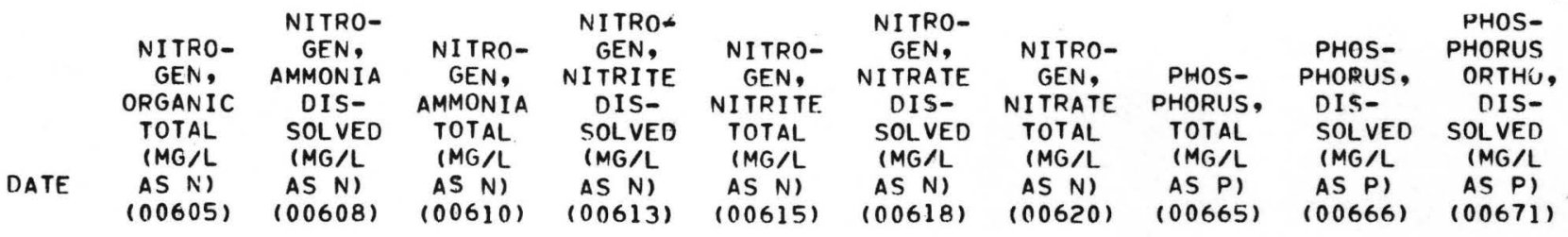

280238082342602 - ROCKY CREEK LF 118 (LAT 280238 LONG 0823426.02 )

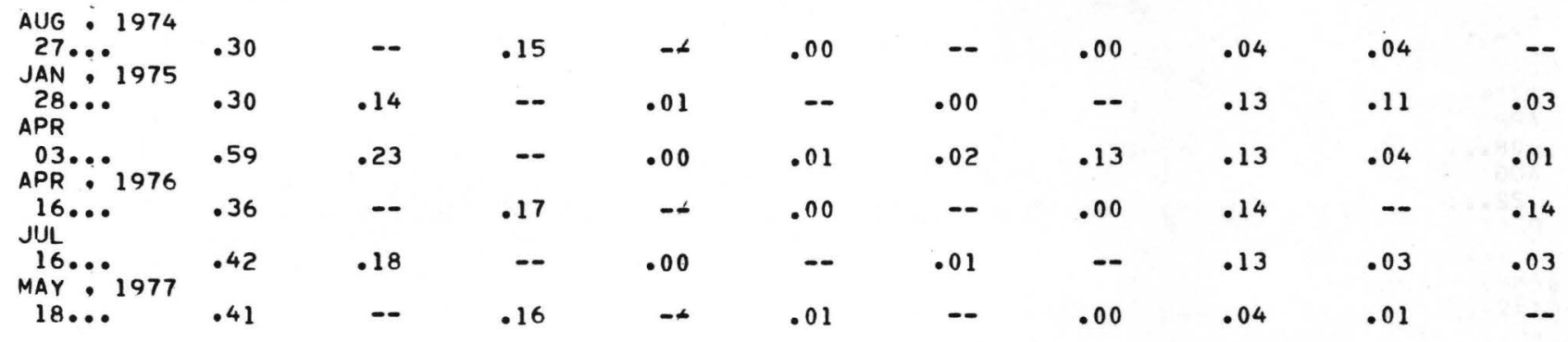

280238082342601 - ROCKY CREEK LF 119 (LAT 280238 LONG 0823426.01 )

\begin{tabular}{|c|c|c|c|c|c|c|c|c|c|c|}
\hline APR 1975 & 1.6 & -- & .44 & $-\infty$ & .00 & -- & .01 & .17 & .00 & -- \\
\hline $09 \ldots$ & .52 & .34 & - & .00 & -- & .01 & -- & .57 & .02 & .00 \\
\hline
\end{tabular}


TABLE 3. CHEMICAL AND BACTERIOLOGICAL ANALYSES FOR GROUND- AND SURFACE-WATER SAMPLES FROM THE ROCKY CREEK LANDFILL - CONTINUED

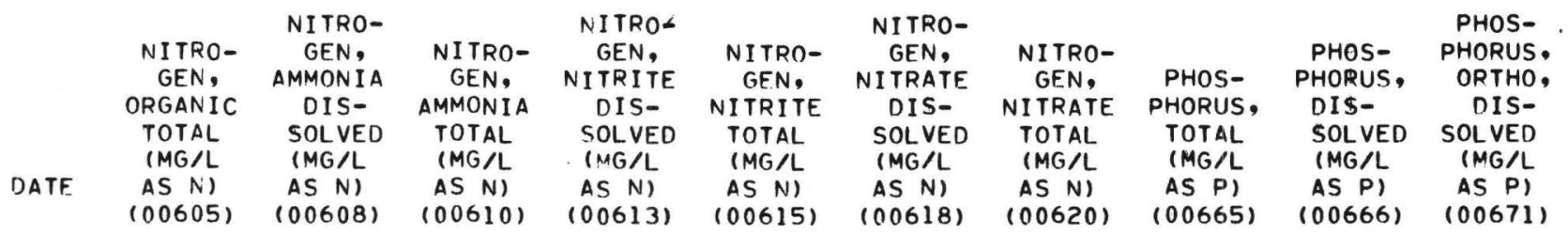

280238082335701 - ROCKY CREEK LF 120 (LAT 280238 LONG 0823357.01 )

\begin{tabular}{|c|c|c|c|c|c|c|c|c|c|}
\hline $\begin{array}{l}\text { AUG } 1974 \\
30 \cdots \cdots \\
\text { JAN } 1975\end{array}$ & .26 & -- & .32 & $-\infty$ & .00 & $-\infty$ & .00 & .12 & .10 \\
\hline$\underset{A P R}{27} \cdots$ & .10 & -- & .34 & $-\infty$ & .00 & -- & .02 & .17 & $\cdots$ \\
\hline $\begin{array}{l}22 \ldots \cdots \\
D E C\end{array}$ & .10 & -- & .53 & $-\infty$ & .00 & -- & .01 & .08 & -- \\
\hline $\begin{array}{l}14 \ldots \bullet \\
\text { MAY } 1977\end{array}$ & .12 & -- & .29 & $-\infty$ & .00 & -- & .00 & .04 & -- \\
\hline $02 \ldots$ & .04 & -- & .00 & -4 & .00 & -- & .00 & .16 & -- \\
\hline
\end{tabular}

280240082340601 - ROCKY CREEK LF 127 (LAT 280240 LONG 0823406.01 )

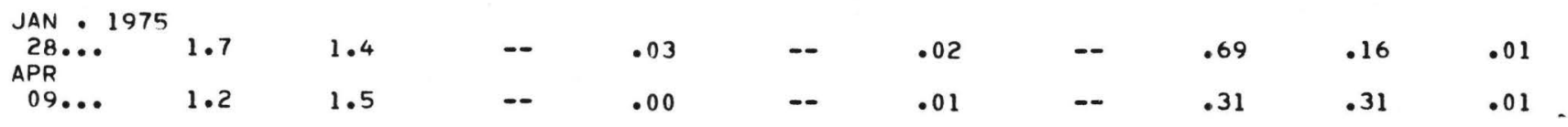

280240082341201 - ROCKY CREEK LF 130 (LAT 280240 LONG 0823412.01 ) 
TABLE 3. CHEMICAL AND BACTERIOLOGICAL ANALYSES FOR GROUND- AND SURFACE-WATER SAMPLES FROM THE ROCKY CREEK LANDFILL - CONTINUED

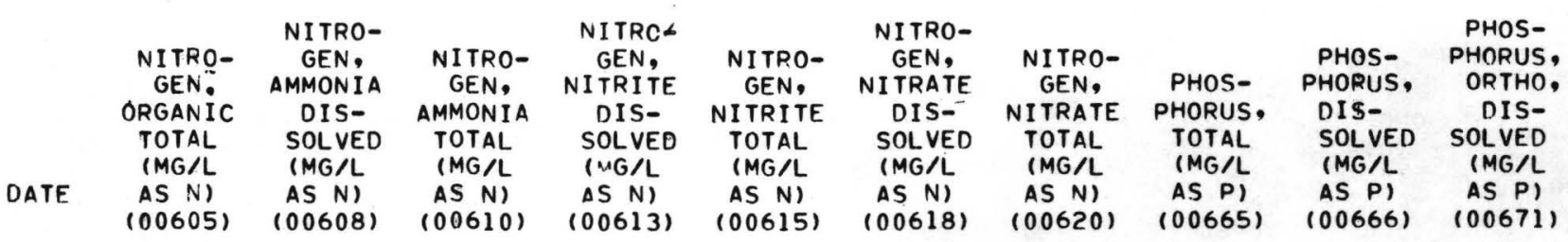

280242082343502 - ROCKY CREEK LF 143 (LAT 280242 LONG 0823435.02 )

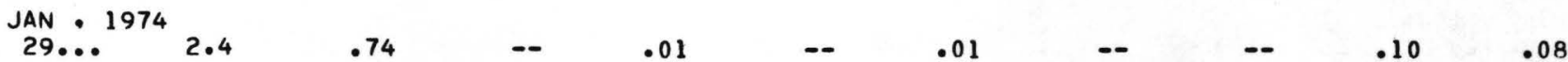

280242082343501 - ROCKY CREEK LF 144 (LAT 280242 LONG 0823435.01 )

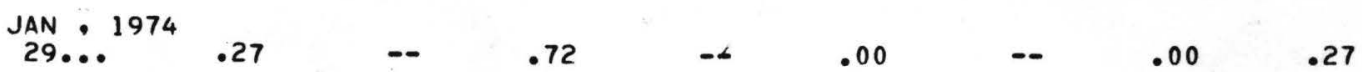

280227082341700 - ROCKY CREEK LF SE PERIMETER DITCH (LAT 280227 LONG 0823417 )

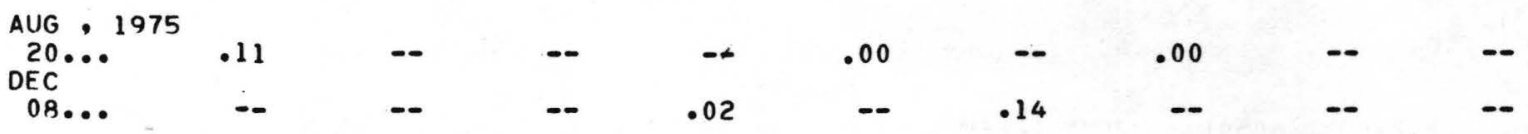
280235082342500 - ROCKY CREEK LF OXIDATION POND (LAT 280235 LONG 0823425 )

DEC , 1975

08 .... 
TABLE 3. CHEMICAL AND BACTERIOLOGICAL ANALYSES FOR GROUND- AND SURFACE-WATER SAMPLES FROM THE ROCKY CREEK LANDFILL - CONTINUED

$\begin{array}{ccccccc}\text { OXYGEN } & \text { OXYGEN } & \text { OXYGEN } & \text { COLI- } & & & \text { COLI- } \\ \text { DEMAND, } & \text { DEMAND, } & \text { DEMAND, } & \text { FORM, } & & \text { COLI- } & \text { FORM, } \\ \text { BIO- } & \text { CHEM- } & \text { CHEM- } & \text { TOTAL, } & \text { COLI- } & \text { FORM, } & \text { FECAL, } \\ \text { CHFM- } & \text { ICAL } & \text { ICAL } & \text { IMMED. } & \text { FORM, } & \text { FECAL, } & 0.45 \\ \text { ICAL, } & \text { (LOW } & \text { (HIGH } & \text { (COLS. } & \text { CON- } & \text { EC } & \text { UM-MF } \\ 5 \text { DAY } & \text { LEVEL) } & \text { LEVEL) } & \text { PER } & \text { FIRMED } & \text { BROTH } & \text { (COLS. } \\ (M G / L) & (M G / L) & (M G / L) & 100 M L) & (M P N) & \text { (MPN) } & 100 M L) \\ (00310) & (00335) & (00340) & (31501) & (31505) & (31615) & (31616)\end{array}$

280221082342901 - ROCKY CREEK LF 53 (LAT 280221 LONG 08234.29 .01 )

\begin{tabular}{|c|c|c|c|c|c|c|c|}
\hline $\begin{array}{l}29 \\
\text { AUG }\end{array}$ & -- & -- & -- & $<1$ & -- & -- & $<1$ \\
\hline $28 \ldots$ & .5 & 7 & -- & $<1$ & -- & -- & $<1$ \\
\hline $\begin{array}{l}\text { JAN } 1975 \\
27 \cdots \cdots \\
A P R\end{array}$ & 1.3 & 1 & - & $<1$ & -- & -- & $<1$ \\
\hline $\begin{array}{l}07 \cdots \\
\text { AUG }\end{array}$ & . 8 & 7 & -- & $<1$ & -- & -- & $<1$ \\
\hline $\begin{array}{l}20 \cdots \\
D E C\end{array}$ & 1.1 & 7 & - & $<1$ & -- & -- & $<1$ \\
\hline $\begin{array}{l}09 \cdots \cdots 1976 \\
\text { APR } 1970\end{array}$ & .9 & 12 & -- & $B 16$ & -- & -- & $<1$ \\
\hline $\begin{array}{l}14 \cdots \\
\text { JUL }\end{array}$ & .7 & 7 & - & B57 & -- & -- & $<1$ \\
\hline $\begin{array}{l}14 \cdots \\
\text { MAY }, 1977\end{array}$ & .7 & 9 & -- & $<1$ & -- & -- & $<1$ \\
\hline $02 \ldots$ & .6 & 5 & -- & -- & $<3$ & $<3$ & $-\infty$ \\
\hline
\end{tabular}

280226082342101 - ROCKY CREEK LF 65 (LAT 280226 LONG 0823421.01 )

\begin{tabular}{|c|c|c|c|c|c|c|c|}
\hline $\begin{array}{l}\text { AUG }, 1975 \\
22 . \cdots \\
\text { DEC }\end{array}$ & 2.0 & 39 & -- & -- & 43 & 4 & -- \\
\hline 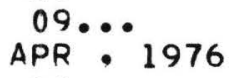 & 1.3 & 8 & -- & -- & 150 & 4 & -- \\
\hline $\begin{array}{l}14 \cdots \cdots \\
\text { JUL }\end{array}$ & - 8 & -- & 15 & -- & 15000 & 93 & \\
\hline $\begin{array}{l}14 \cdots \bullet \\
\text { MAY }, 1977\end{array}$ & 2.2 & -- & 35 & -- & 93 & $<3$ & \\
\hline $05 \ldots$ & 1.9 & 53 & -- & -- & $<3$ & $<3$ & \\
\hline
\end{tabular}


TABLE 3. CHEMICAL AND BACTERIOLOGICAL ANALYSES FOR GROUND- AND SURFACE-WATER SAMPLES FROM THE ROCKY CREEK LANDFILL - CONTINUED

$\begin{array}{cccccccc} & \text { OXYGEN } & \text { OXYGEN } & \text { OXYGEN } & \text { COLI- } & & & \text { COLI- } \\ \text { DEMAND, } & \text { DEMAND, } & \text { DEMAND, } & \text { FORM, } & & \text { COLI- } & \text { FORM, } \\ & \text { BIO- } & \text { CHEM- } & \text { CHEM- } & \text { TOTAL, } & \text { COLI- } & \text { FORM, } & \text { FECAL, } \\ & \text { CHEM- } & \text { ICAL } & \text { ICAL } & \text { IMMED. } & \text { FORM, } & \text { FECAL, } & 0.45 \\ & \text { ICAL, } & \text { (LOW } & \text { (HIGH } & \text { (COLS. } & \text { CON- } & \text { EC } & \text { UM-MF } \\ & \text { 5 DAY } & \text { LEVEL) } & \text { LEVEL) } & \text { PER } & \text { FIRMED } & \text { RROTH } & (\text { COLS. } \\ \text { DATE } & (M G / L) & (M G / L) & (M G / L) & 100 M L) & (M P N) & (M P N) & 100 M L) \\ & (00310) & (00335) & (00340) & (31501) & (31505) & (31615) & (31616)\end{array}$

280226082342502 - ROCKY CREEK LF 66 (LAT 280226 LONG 0823425.02 )

\begin{tabular}{|c|c|c|c|c|c|c|c|}
\hline $28 \cdots$ & .8 & 27 & -- & 21 & -- & -- & $<1$ \\
\hline $27 \ldots$ & .9 & 31 & -- & -- & $<3$ & $<3$ & -- \\
\hline $\begin{array}{l}03 \cdots \\
\text { AUG }\end{array}$ & .2 & -- & -- & -- & $<3$ & $<3$ & - \\
\hline $\begin{array}{l}20 \cdots \\
D E C\end{array}$ & 1.4 & 43 & -- & -- & $<3$ & $<3$ & -- \\
\hline $\begin{array}{l}\text { 08... } \\
\text { APR } 1976\end{array}$ & . 8 & 45 & -- & -- & $<3$ & $<3$ & - \\
\hline $\begin{array}{l}16 \cdots \\
\text { JUL }\end{array}$ & .7 & 42 & -- & -- & 1100 & 240 & \\
\hline $\begin{array}{l}15 \cdots \\
\text { MAY }: 1977\end{array}$ & 1.2 & -- & 28 & -- & $<3$ & $<3$ & \\
\hline $05 \ldots$ & 1.5 & 40 & -- & -- & $<3$ & $<3$ & \\
\hline
\end{tabular}

280226082342501 - ROCKY CREEK LF 67 (LAT 280226 LONG 0823425.01 )

$\begin{array}{lllllrrr}\text { APR }, 1976 & & & & & & \\ 16 . \therefore & 1.3 & 11 & -- & -- & 2400 & 2400 & - \\ \text { MAY } 1977 & & 14 & -- & -- & 240 & 9 & -\infty \\ 05 . . . & 4.1 & 14 & \end{array}$

280226082341202 - ROCKY CREEK LF 69 (LAT $2802 \quad 26$ LONG 0823412.02 )
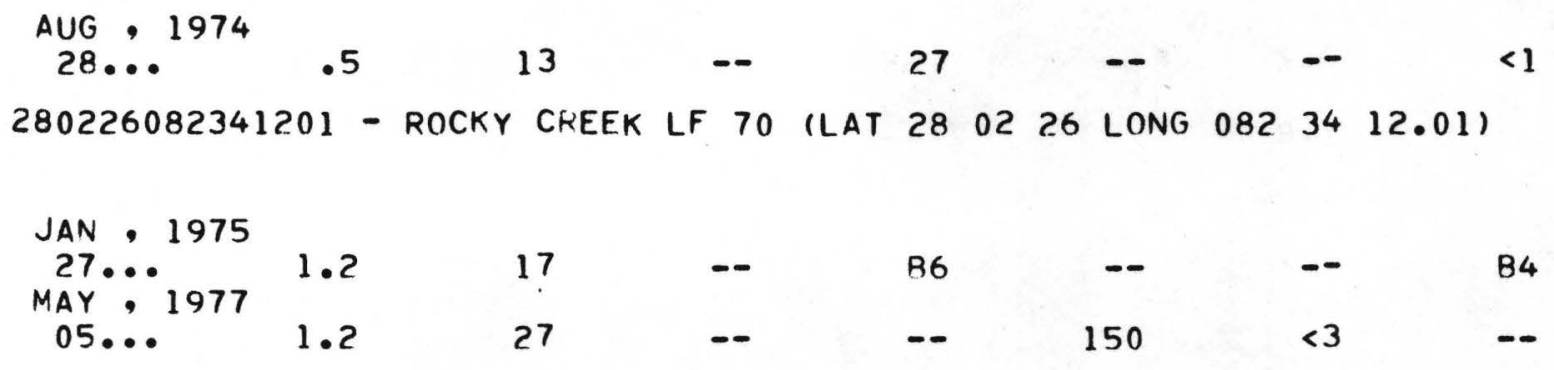

280228082335901 - ROCKY CREEK LF 73 (LAT 280228 LONG 0823359.01 )

JUL , 1976

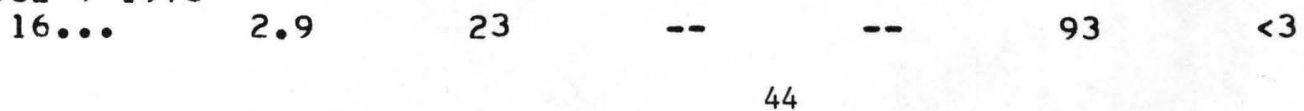


TABLE 3. CHEMICAL AND BACTERIOLOGICAL ANALYSES FOR GROUND- AND SURFACE-WATER SAMPLES FROM THE ROCKY CREEK LANDF ILL - CONTINUED

$\begin{array}{cccccccc} & \text { OXYGEN } & \text { OXYGEN } & \text { OXYGEN } & \text { COLI- } & & & \text { COLI- } \\ \text { DEMAND, } & \text { DEMAND, } & \text { DEMAND, } & \text { FORM, } & & \text { COLI- } & \text { FORM, } \\ & \text { BIO- } & \text { CHEM- } & \text { CHEM- } & \text { TOTAL, } & \text { COLI- } & \text { FORM, } & \text { FECAL, } \\ & \text { CHEM- } & \text { ICAL } & \text { ICAL } & \text { IMMED. } & \text { FORM, } & \text { FECAL, } & 0.45 \\ & \text { ICAL, } & \text { (LOW } & \text { (HIGH } & (\text { COLS. } & \text { CON- } & \text { EC } & \text { UM-MF } \\ & 5 \text { DAY } & \text { LEVEL) } & \text { LEVEL) } & \text { PER } & \text { FIRMED } & \text { BROTH } & (\text { COLS.) } \\ \text { DATE } & (M G / L) & (M G / L) & (M G / L) & 100 M L) & (M P N) & \text { (MPN) } & 100 M L) \\ & (00310) & (00335) & (00340) & (31501) & (31505) & (31615) & (31616)\end{array}$

280228082335902. - ROCKY CREEK LF 74 (LAT 280228 LONG 0823359.02 )

\begin{tabular}{|c|c|c|c|c|c|c|}
\hline AUG & 1.8 & -- & 150 & -- & 23 & $<3$ \\
\hline $\begin{array}{l}22 \cdots \cdots \\
\text { DEC }\end{array}$ & 2.2 & 33 & -- & -- & $<3$ & $<3$ \\
\hline $\begin{array}{l}10 \cdots 1976 \\
\text { APR }, 1976\end{array}$ & .9 & 16 & -- & B10 & -- & -- \\
\hline $\mathrm{JUL}^{14 \ldots}$ & 1.1 & - & 15 & -- & 23 & 4 \\
\hline $\begin{array}{l}15 \cdots \cdots \\
\text { MAY } 1977\end{array}$ & 1.3 & 19 & -- & -- & $<3$ & $<3$ \\
\hline $18 \ldots$ & 6.0 & -- & 35 & -- & 93 & $<3$ \\
\hline
\end{tabular}

280231082343603 - ROCKY CREEK LF 83 (LAT 280231 LONG 0823436.03 )

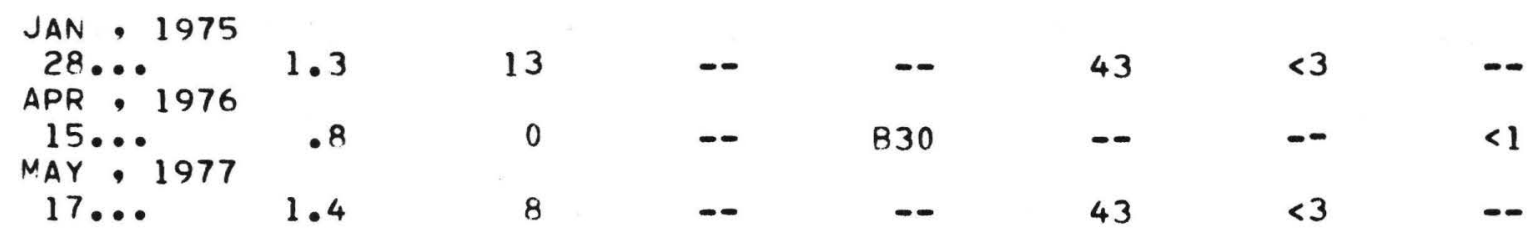

280231082343602 - ROCKY CREEK LF 84 (LAT 280231 LONG 0823436.02 )

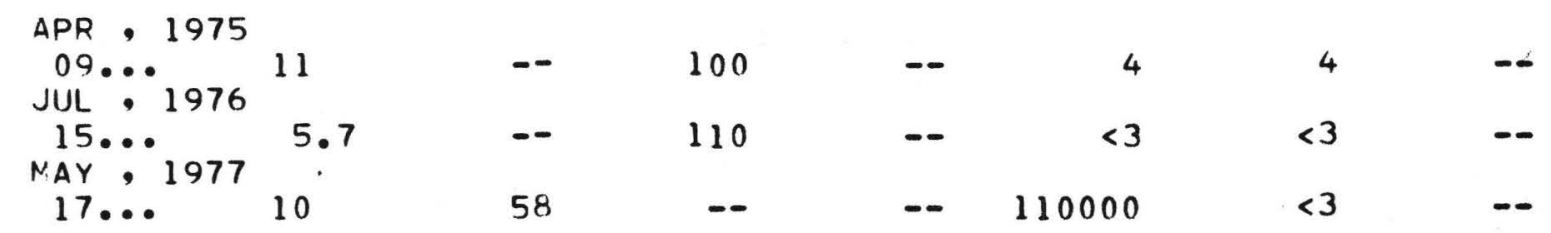

280233082340701 - ROCKY CREEK LF 89 (LAT 280233 LONG 0823407.01 )

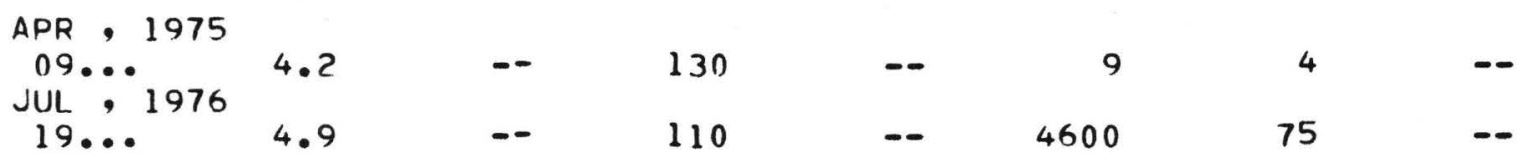


TABLE 3. CHEMICAL AND BACTERIOLIOGICAL ANALYSES FOR GROUND- AND SURFACE-WATER SAMPLES FROM THE ROCKY CREEK LANDFILL - CONTINUED

$\begin{array}{ccccccc}\text { OXYGEN } & \text { OXYGEN } & \text { OXYGEN } & \text { COLI- } & & & \text { COLI- } \\ \text { DEMAND, } & \text { DEMAND, } & \text { DEMAND, } & \text { FORM, } & & \text { COLI- } & \text { FORM, } \\ \text { BIO- } & \text { CHEM- } & \text { CHEM- } & \text { TOTAL, } & \text { COLI- } & \text { FORM, } & \text { FECAL, } \\ \text { CHEM- } & \text { ICAL } & \text { ICAL } & \text { IMMED. } & \text { FORM, } & \text { FECAL, } & 0.45 \\ \text { ICAL, } & \text { (LOW } & \text { (HIGH } & \text { (COLS. } & \text { CON- } & \text { EC } & \text { UM-MF } \\ 5 \text { DAY } & \text { LEVEL) } & \text { LEVEL) } & \text { PER } & \text { FIRMFD } & \text { BROTH } & (\text { COLS.) } \\ (M G / L) & (M G / L) & (M G / L) & 100 M L) & (M P N) & \text { (MPN) } & 100 M L) \\ (00310) & (00335) & (00340) & (31501) & (31505) & (31615) & (31616)\end{array}$

280235082335801 - ROCKY CREEK LF 98 (LAT 280235 LONG 0823358.01 )

\begin{tabular}{|c|c|c|c|c|c|c|c|}
\hline 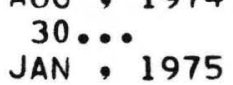 & -- & 8 & -- & -- & -- & -- & -- \\
\hline $\begin{array}{l}27 \cdots \\
A P R\end{array}$ & .6 & 2 & -- & -- & $<3$ & $<3$ & -- \\
\hline $\begin{array}{l}07 \\
\text { AUG }\end{array}$ & .7 & $\cdots$ & -- & $<1$ & -- & -- & $<1$ \\
\hline $\begin{array}{l}20 \cdots \cdots \\
\text { DEC }\end{array}$ & .5 & 10 & -- & -- & 4 & 3 & \\
\hline $\begin{array}{l}09 \cdots \\
A P R\end{array} 1976$ & .4 & 22 & -- & -- & $<3$ & $<3$ & \\
\hline $\begin{array}{l}14 \\
\text { JUL }\end{array}$ & 6.0 & 9 & -- & 810 & -- & -- & \\
\hline $\begin{array}{l}14 \cdots \\
\text { MAY } 1977\end{array}$ & .6 & -- & 7 & $<1$ & -- & -- & \\
\hline $02 \ldots$ & .8 & 8 & -- & -- & $<3$ & $<3$ & \\
\hline
\end{tabular}

280238082340901 - ROCKY CREEK LF 114 (LAT $28 \quad 0238$ LONG 0823409.01 ) JAN, 1974

29.
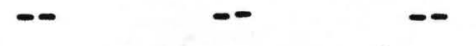

0

280238082342602 - ROCKY CREEK LF 118 (LAT $2802 \quad 38$ LONG 0823426.02 )

\begin{tabular}{|c|c|c|c|c|c|c|c|}
\hline $27 \ldots$ & 13 & 24 & -- & $B 8100$ & - & -- & $<1$ \\
\hline $\begin{array}{l}\text { JAN , } 1975 \\
28 \ldots \ldots \\
\text { APR }\end{array}$ & 4.1 & 28 & -- & -- & $<3$ & $<3$ & -- \\
\hline $\begin{array}{l}03 \cdots 1976 \\
A P R, 19\end{array}$ & 1.6 & -- & -- & -- & $<3$ & $<3$ & - \\
\hline $\begin{array}{l}16 \ldots \\
\text { JUL }\end{array}$ & $>6.3$ & 43 & -- & -- & 4600 & $<3$ & \\
\hline MAY 16.1977 & 4.4 & -- & 38 & -- & 43 & 43 & \\
\hline $18 \ldots$ & 1.2 & 44 & -- & -- & 15 & $<3$ & \\
\hline
\end{tabular}


TABLE 3. CHEMICAL AND BACTERIOLOGICAL ANALYSES FOR GROUND- AND SURFACE-WATER SAMPLES FROM THE ROCKY CREEK LANDF ILL - CONTINUED

$\begin{array}{lllllll}\text { OXYGEN } & \text { OXYGEN } & \text { OXYGEN } & \text { COLI- } & & & \text { COLI- } \\ \text { DEMAND, } & \text { DEMAND, } & \text { DEMAND, } & \text { FORM, } & & \text { COLI- } & \text { FORM, } \\ \text { BIO- } & \text { CHEM- } & \text { CHEM- } & \text { TOTAL, } & \text { COLI- } & \text { FORM, } & \text { FECAL, } \\ \text { CHEM- } & \text { ICAL } & \text { ICAL } & \text { IMMED. } & \text { FORM, } & \text { FECAL, } & 0.45 \\ \text { ICAL, } & \text { (LOW } & \text { (HIGH } & \text { (COLS. } & \text { CON- } & \text { EC } & \text { UM-MF } \\ 5 \text { DAY } & \text { LEVEL) } & \text { LEVEL) } & \text { PER } & \text { FIRMED } & \text { RROTH } & \text { (COLS.) } \\ (M G / L) & (M G / L) & (M G / L) & 100 M L) & (M P N) & (M P N) & 100 M L) \\ (00310) & (00335) & (00340) & (31501) & (31505) & (31615) & (31616)\end{array}$

280238082342601 - ROCKY CKEEK LF 119 (LAT 280238 LONG 0823426.01 )

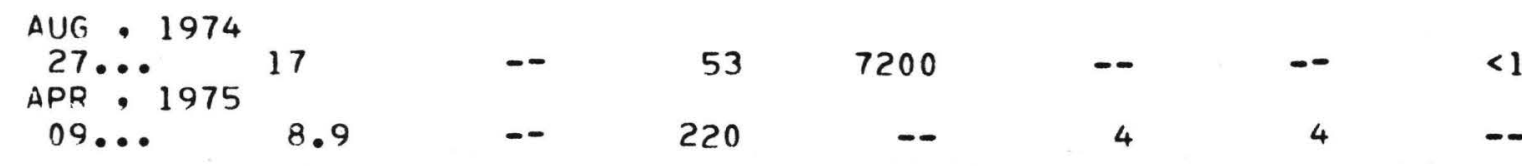

280238082335701 - ROCKY CREEK LF 120 (LAT 280238 LONG 0823357.01 )

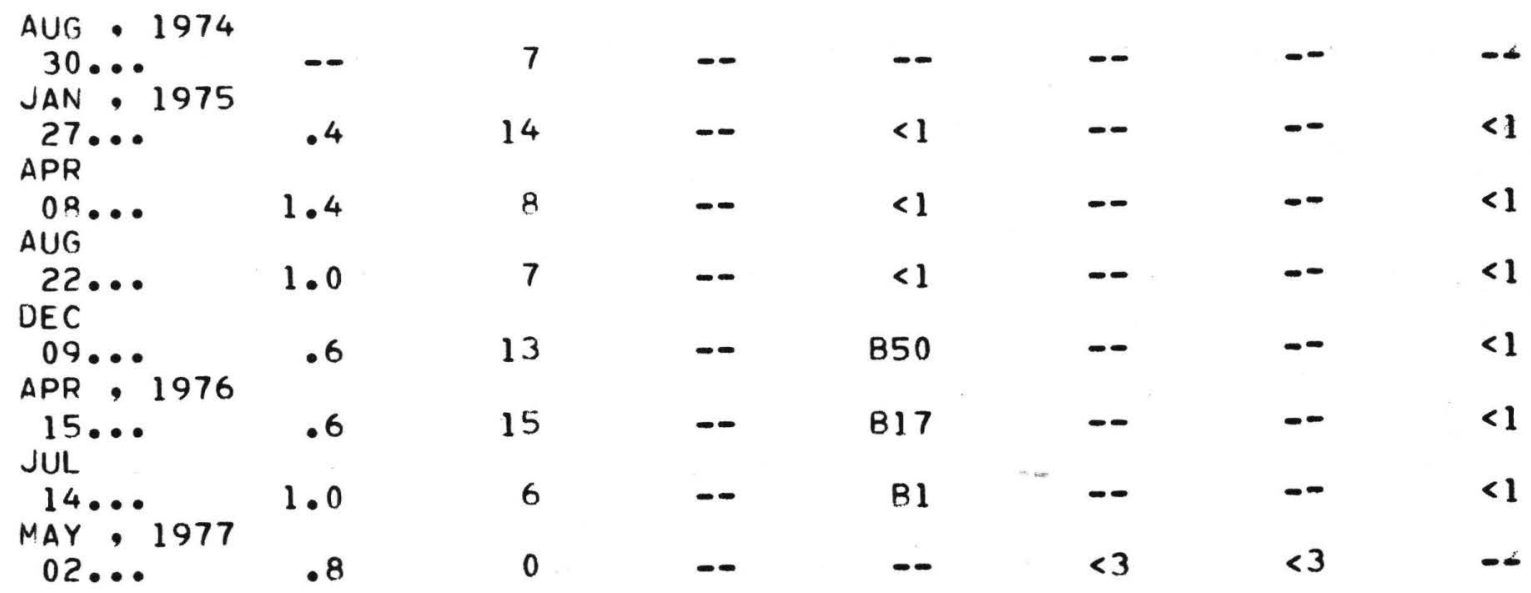

280240082340601 - ROCKY CREEK LF 127 (LAT 280240 LONG 0823406.01 )

\begin{tabular}{|c|c|c|c|c|c|c|}
\hline $\begin{array}{l}28 \ldots \\
A P R\end{array}$ & 2.2 & - & 87 & -- & 460 & $<3$ \\
\hline $09 \ldots$ & $<3.5$ & -- & 140 & -- & 2400 & $<3$ \\
\hline
\end{tabular}

280240082341201 - ROCKY CREEK LF 130 (LAT 280240 LONG 0823412.01 )

$\begin{array}{cccccccc}\text { AUG }, 1974 & & & & & & & \end{array}$ 
TABLE 3. CHEMICAL AND BACTERIOLOGICAL ANALYSES FOR GROUND- AND SURFACE-WATER SAMPLES FROM THE ROCKY CREEK LANDFILL - CONTINUED

$\begin{array}{ccccccc}\text { OXYGEN } & \text { OXYGEN } & \text { OXYGEN } & \text { COLI- } & & & \text { COLI- } \\ \text { DEMAND, } & \text { DEMAND, } & \text { DEMAND, } & \text { FORM, } & & \text { COLI- } & \text { FORM, } \\ \text { BIO- } & \text { CHEM- } & \text { CHEM- } & \text { TOTAL, } & \text { COLI- } & \text { FORM, } & \text { FECAL, } \\ \text { CHEM- } & \text { ICAL } & \text { ICAL } & \text { IMMED. } & \text { FORM, } & \text { FECAL, } & 0.45 \\ \text { ICAL, } & \text { (LOW } & \text { (HIGH } & (\text { COLS. } & \text { CON- } & \text { EC } & \text { UM-MF } \\ 5 \text { DAY } & \text { LEVEL) } & \text { LEVEL) } & \text { PER } & \text { FIRMED } & \text { BROTH } & (C O L S . / \\ (M G / L) & (M G / L) & (M G / L) & 100 M L) & (M P N) & (M P N) & 100 M L) \\ (00310) & (00335) & (00340) & (31501) & (31505) & (31615) & (31616)\end{array}$

280240082335901 - ROCKY CREEK LF 132 (LAT 280240 LONG 0823359.01 )

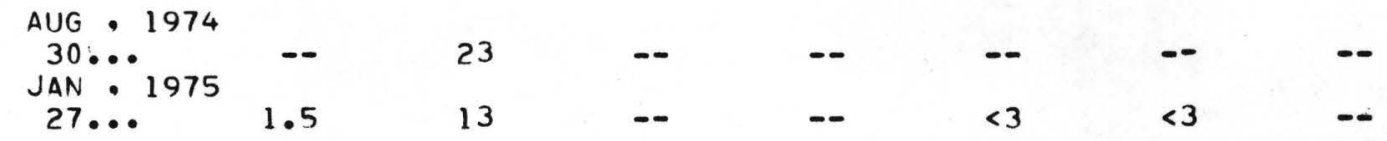

280242082343502 - ROCKY CREEK LF 143 (LAT 280242 LONG 0823435.02 )

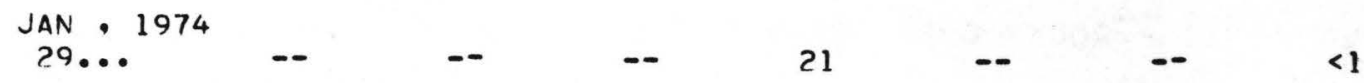

280242082343501 - ROCKY CREEK LF 144 (LAT 280242 LONG 0823435.01 )

JAN, 1974

29...

280227082341700 - ROCKY CREEK LF SE PERIMETER DITCH (LAT 280227 LONG 0823417 )

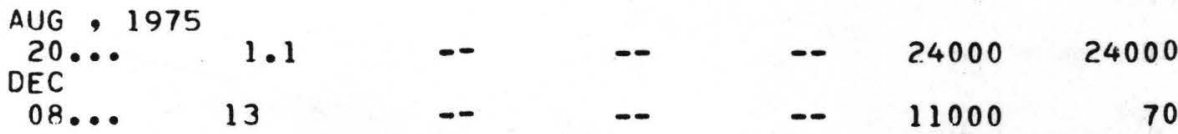

280235082342500 - ROCKY CREEK LF OXIDATION POND (LAT 280235 LONG 0823425 )

DEC, 1975

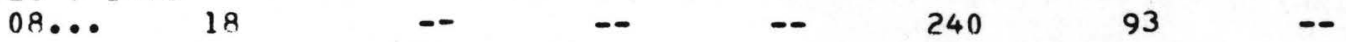


TABLE 3. CHEMICAL AND BACTERIOLOGICAL ANALYSES FOR GROUND- AND SURFACE-WATER SAMPLES FROM THE ROCKY CREEK LANDFILL - CONTINUED

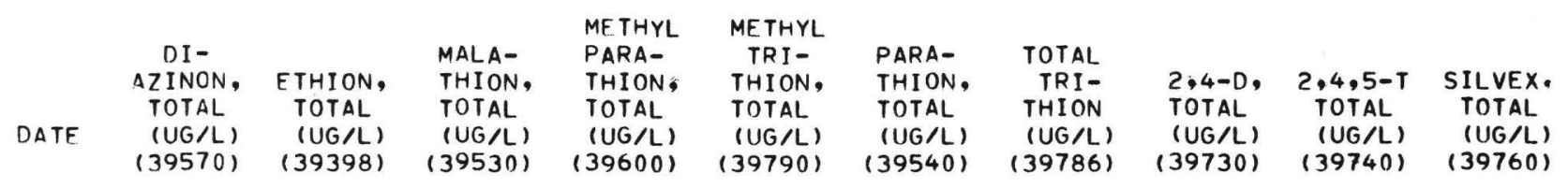

280226082342502 - ROCKY CREEK LF 66 (LAT $2802 \quad 26$ LONG 0823425.02 )

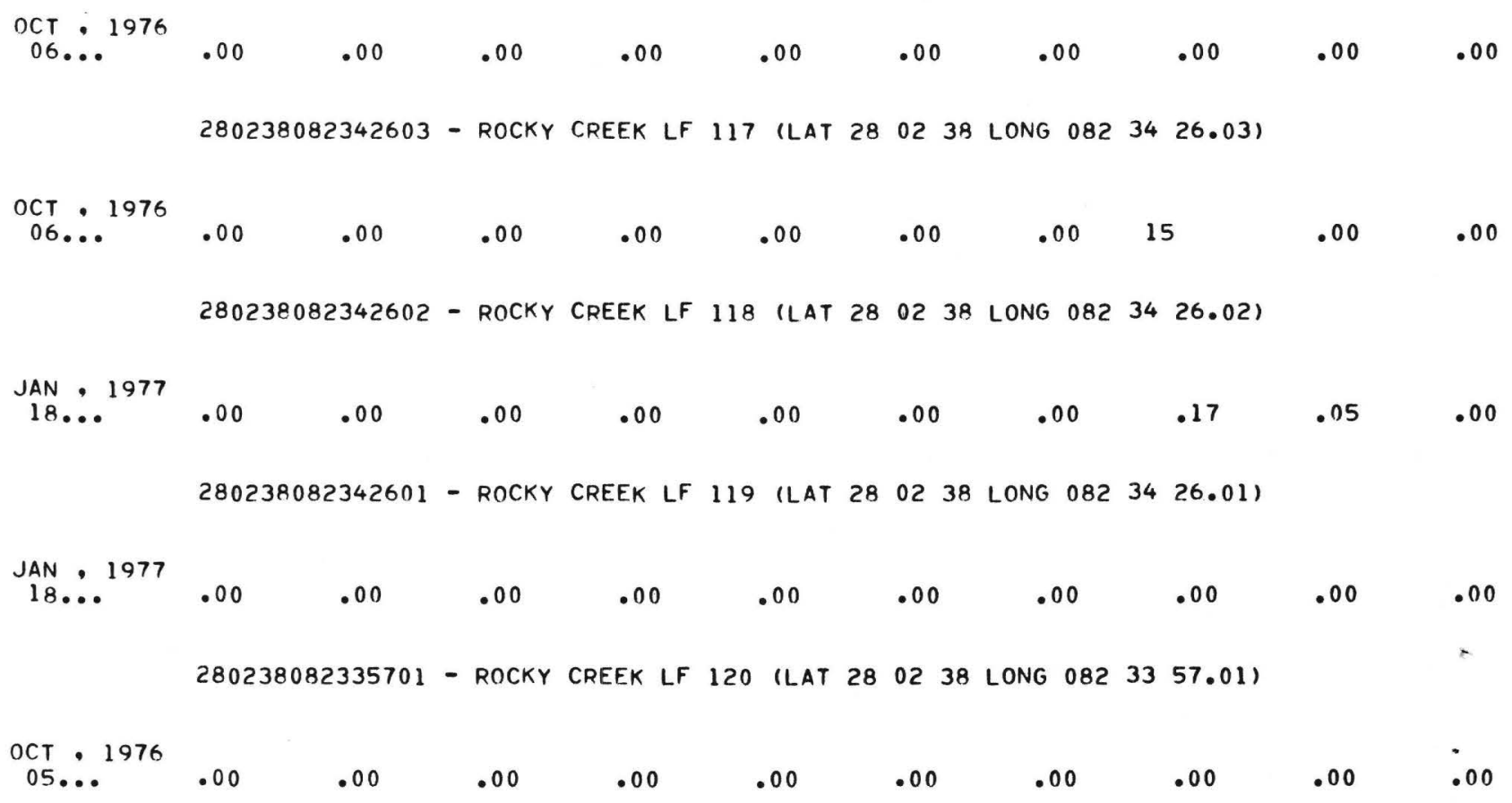


TABLE 3. CHEMICAL AND BACTERIOLOGICAL ANALYSES FOR GROUND- AND SURFACE-WATER SAMPLES FROM THE ROCKY CREEK LANOFILL - CONTINUED

\begin{tabular}{|c|c|c|c|c|c|c|c|c|c|c|c|c|}
\hline DATE & $\begin{array}{l}\text { ALDRIN, } \\
\text { TOTAL } \\
\text { (UG/L) } \\
(39330)\end{array}$ & $\begin{array}{l}\text { CHLCR- } \\
\text { DANE, } \\
\text { TOTAL } \\
\text { (UG/L) } \\
(39350)\end{array}$ & $\begin{array}{c}\text { DDD, } \\
\text { TOTAL } \\
\text { (UG/L) } \\
(39360)\end{array}$ & $\begin{array}{c}\text { DDE, } \\
\text { TOTAL } \\
\text { (UG/L) } \\
(39365)\end{array}$ & $\begin{array}{c}\text { DDT, } \\
\text { TOTAL } \\
\text { (UG/L) } \\
(39370)\end{array}$ & $\begin{array}{l}\text { DI- } \\
\text { ELDRIN } \\
\text { TOTAL } \\
\text { (UG/L) } \\
(39380)\end{array}$ & $\begin{array}{l}\text { ENORIN, } \\
\text { TOTAL } \\
\text { (UG/L) } \\
(39390)\end{array}$ & $\begin{array}{l}\text { HEPTA- } \\
\text { CHLOR, } \\
\text { TOTAL } \\
\text { (UG/L) } \\
(39410)\end{array}$ & $\begin{array}{l}\text { HEPTA- } \\
\text { CHLOR } \\
\text { EPOXIDE } \\
\text { TOTAL } \\
(U G / L) \\
(39420)\end{array}$ & $\begin{array}{l}\text { LINDANE } \\
\text { TOTAL } \\
\text { (UG/L) } \\
(39340)\end{array}$ & $\begin{array}{l}\text { TOX- } \\
\text { APHENE, } \\
\text { TOTAL } \\
\text { (UG/L) } \\
(39400)\end{array}$ & $\begin{array}{c}\text { PCB, } \\
\text { TOTAL } \\
\text { (UG/L) } \\
(39516)\end{array}$ \\
\hline
\end{tabular}

280226082342502 - ROCKY CREEK LF 66 (LAT 280226 LONG 0823425.02 )

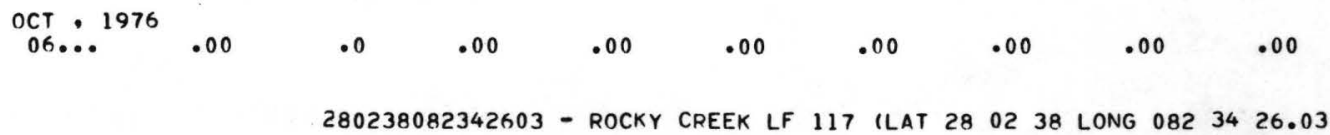

OCT 1976

$06 \ldots 1976.00$

280238082342603 - ROCKY CREEK LF 117 (LAT 280238 LONG 0823426.03 )

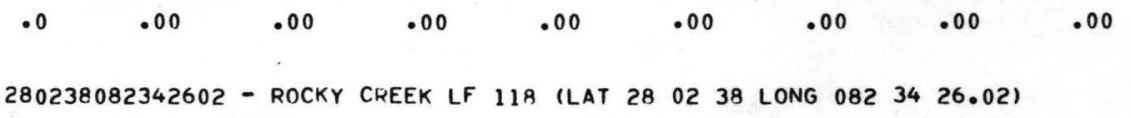

JAN 1977.0
$18 .$.

$.0 \quad .00$

.00

$.00 \quad .00 \quad .00$

.00

.00

0

280238082342601 - ROCKY CREEK LF 119 (LAT 280238 LONG 0823426.01 )

JAN 1977

$18 \ldots$

$.0-000$

.00

$.00 \quad .00$

.00

.00

.00

280238082335701 - ROCKY CREEK LF 120 (LAT 280238 LONG 0823357.01 )

OCT, 1976

$05 . .00$

$.0 \quad .00$

.00

.00

.00

.00

.00

.00

.00

o

.0 
TABLE 4. CHEMICAL AND BACTERIOLOGICAL ANALYSES FOR GROUND- AND SURFACE-WATER SAMPLES FROM THE EUREKA SPRINGS LANDFILL

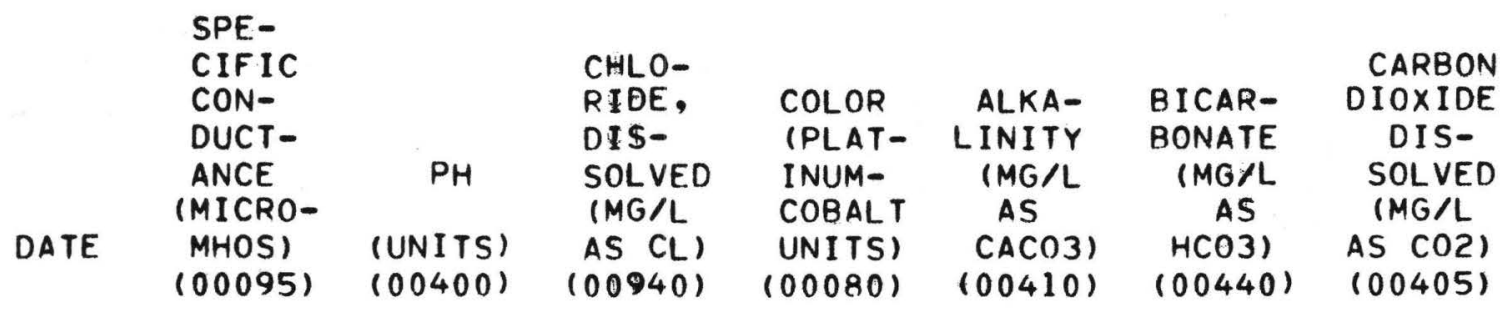

280056082192501 - EUREKA SPRINGS LF 1 (LAT 280056 LONG 0821925.01 )

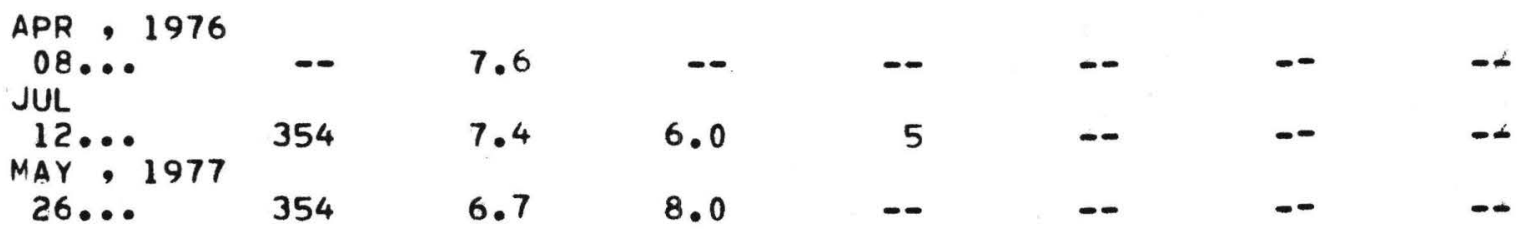

280101082192801 - EUREKA SPRINGS LF 6 (LAT 280101 LONG 0821928.01 )

\begin{tabular}{|c|c|c|c|c|c|c|c|}
\hline $\begin{array}{l}\text { AUG } \\
19 \ldots 1 .\end{array}$ & 56 & 5.4 & 11 & -- & -- & -- & $-d$ \\
\hline MAY $\because 1977$ & 341 & 6.7 & 14 & 140 & -- & -- & \\
\hline $26 \ldots$ & 308 & 6.2 & 10 & -- & -- & - & \\
\hline
\end{tabular}

280104082193001 - EUREKA SPRINGS LF 7 ILAT 280104 LONG 0821930.011

\begin{tabular}{|c|c|c|c|c|c|c|c|}
\hline $\begin{array}{l}\text { AUG } 1975 \\
19 . \cdots \\
\text { DEC }\end{array}$ & 118 & 5.4 & 9.0 & -- & -- & -- & $\cdots$ \\
\hline $\begin{array}{l}02 \cdots \cdots \\
\text { APR } \because 1976\end{array}$ & 130 & 5.4 & 9.8 & -- & -- & -- & $-\infty$ \\
\hline MAY & -- & 6.4 & 11 & -- & -- & -- & $\infty$ \\
\hline $\begin{array}{l}08 \cdots \\
\text { MAY }\end{array}$ & 110 & -- & 9.8 & 400 & - & -- & \\
\hline $31 \ldots$ & 120 & 5.8 & 10 & -- & - & -- & \\
\hline
\end{tabular}


TABLE 4. CHEMICAL AND BACTERIOLOGICAL ANALYSES FOR GROUND- AND SURFACE-WATER SAMPLES FROM THE EUREKA SPRINGS LANDFILL - CONTINUED

\begin{tabular}{|c|c|c|c|c|c|c|c|}
\hline & $\begin{array}{l}\text { SPE- } \\
\text { CIF IC } \\
\text { CON- } \\
\text { DUCT- } \\
\text { ANCE } \\
\text { IMICRO- }\end{array}$ & PH & $\begin{array}{l}\text { CHLO- } \\
\text { RIDE, } \\
\text { DIS- } \\
\text { SOLVED } \\
\text { (MG/L. }\end{array}$ & $\begin{array}{l}\text { COLOR } \\
\text { IPLAT- } \\
\text { INUM- } \\
\text { COBALT }\end{array}$ & $\begin{array}{l}\text { ALKA- } \\
\text { LINITY } \\
\text { IMG/L } \\
\text { AS }\end{array}$ & $\begin{array}{c}\text { BICAR- } \\
\text { BONATE } \\
\text { IMGYL } \\
\text { AS }\end{array}$ & $\begin{array}{c}\text { CARBON } \\
\text { DIOXIDE } \\
\text { DIS- } \\
\text { SOLVED } \\
\text { (MG/L }\end{array}$ \\
\hline$\Delta T$ & $\begin{array}{l}\text { MHOS) } \\
(00095)\end{array}$ & $\begin{array}{l}\text { (UNITS) } \\
(00400)\end{array}$ & $\begin{array}{l}\text { AS CL) } \\
(00940)\end{array}$ & $\begin{array}{l}\text { UNITS) } \\
(00080)\end{array}$ & $\begin{array}{r}\text { CAC03) } \\
(00410)\end{array}$ & $\begin{array}{l}\mathrm{HCO} 3) \\
(00440)\end{array}$ & $\begin{array}{l}\text { AS C02) } \\
(00405)\end{array}$ \\
\hline
\end{tabular}

280103082193401 - EUREKA SPRINGS LF 8 (LAT 280103 LONG 0821934.01 )

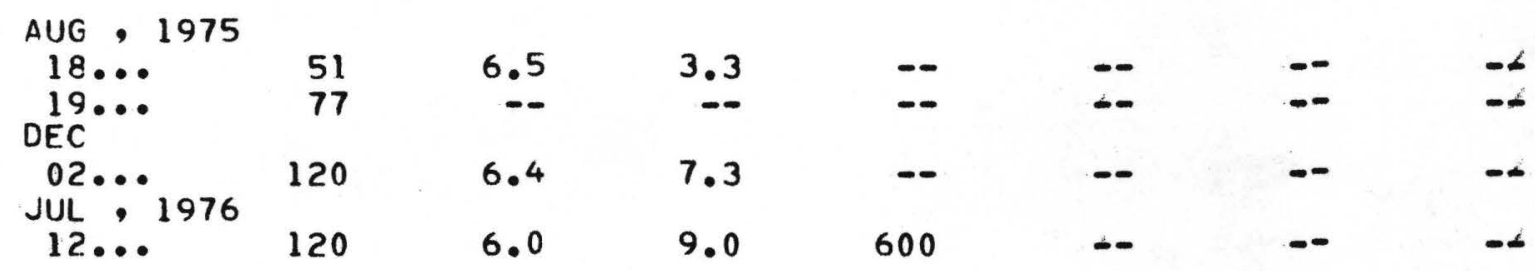

280109082192401 - EUREKA SPRINGS LF 21 BASS (LAT 280109 LONG 0821924.01 )

\begin{tabular}{|c|c|c|c|c|c|c|c|}
\hline$\underset{\text { SEP }}{09}$ & 367 & -- & 9.5 & $-\infty$ & -- & - & -- \\
\hline $\begin{array}{l}03 \cdots \\
\text { JAN, } 1975\end{array}$ & 369 & 7.6 & 9.6 & - & -- & -- & -4 \\
\hline MAR & 354 & 7.8 & 9.5 & - & $-\infty$ & -- & -4 \\
\hline $28 \ldots$ & 369 & 7.6 & 9.1 & -- & -- & -- & $-\infty$ \\
\hline AUG & & & & & & & \\
\hline & 362 & 7.6 & 1.8 & -- & -- & -- & -- \\
\hline $\begin{array}{l}01 \cdots \cdots \\
\text { APR } 1976\end{array}$ & 360 & 7.6 & 10 & $\cdots$ & -- & -- & $-\infty$ \\
\hline $\begin{array}{l}05 \\
\text { JUL }\end{array}$ & 362 & 7.2 & 11 & 2 & -- & -- & $-\infty$ \\
\hline MAY $\because 1977$ & 345 & 7.8 & 10 & 3 & -- & -- & -4 \\
\hline $26 \ldots$ & 341 & 7.0 & 10 & -- & -- & -- & \\
\hline
\end{tabular}


TABLE 4. CHEMICAL AND BACTERIOLOGICAL ANALYSES FOR GROUND- AND SURFACE-WATER SAMPLES FROM THE EUREKA SPRINGS LANDFILL - CONTINUED

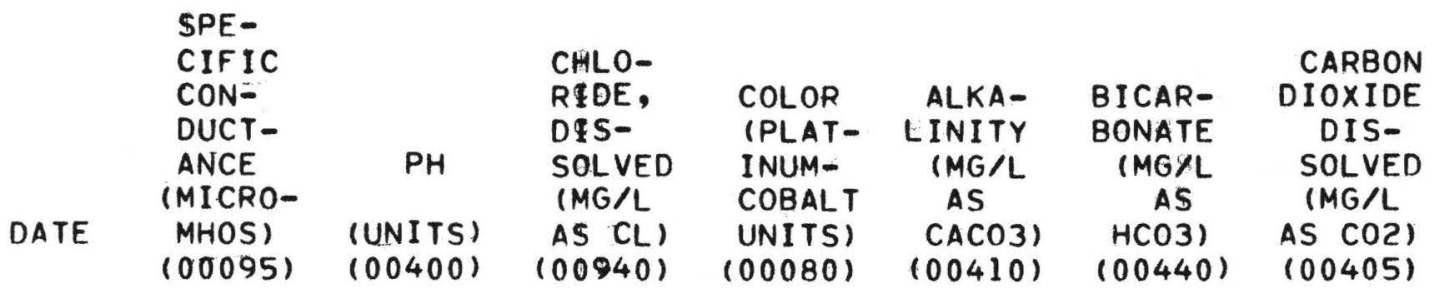

280117082193201 - EUREKA SPRINGS LF 24 GREY (LAT 280117 LONG 0821932.01 )

\begin{tabular}{|c|c|c|c|c|c|c|c|}
\hline $\begin{array}{l}\text { FEB }, 1974 \\
25 \ldots . \\
\text { MAY }\end{array}$ & 333 & -- & 8.9 & - & -- & -- & -- \\
\hline $\begin{array}{l}\text { O9... } \\
\text { AUG } 1975\end{array}$ & 331 & - & 8.7 & -- & - & -- & -6 \\
\hline $\begin{array}{l}18 \cdots 1976 \\
A P R\end{array}$ & 329 & 7.8 & .6 & -- & - & -- & -6 \\
\hline $\begin{array}{l}13 \cdots \\
\text { JUL }\end{array}$ & 326 & 7.2 & 11 & 2 & -- & -- & $-\infty$ \\
\hline $\begin{array}{l}08 \cdots \\
\text { MAY }: 1977\end{array}$ & 330 & 7.8 & 9.0 & 3 & -- & -- & -- \\
\hline $25 \ldots$ & 345 & 7.1 & 8.5 & -- & -- & - & -6 \\
\hline
\end{tabular}

280044082202501 - EUREKA SPRINGS LF 68 (LAT 280044 LONG 0822025.01 )

APR , 1975

$02 \ldots \quad 372$

280051082202901 - EUREKA SPRINGS LF 72 (LAT 280051 LONG 0822029.01 )

\begin{tabular}{|c|c|c|c|}
\hline $\begin{array}{l}\text { SEP , } 1974 \\
04 \ldots .\end{array}$ & 374 & 7.7 & 8.5 \\
\hline $\begin{array}{l}\text { JAN }, 1975 \\
24 \ldots\end{array}$ & 347 & 7.9 & 8.5 \\
\hline $\begin{array}{l}\text { AUG } \\
18 \cdots \cdots \\
\text { DEC }\end{array}$ & 373 & 7.6 & 11 \\
\hline $\begin{array}{l}03 \cdots \cdots \\
\text { APR } 1976\end{array}$ & 370 & 7.8 & 9.8 \\
\hline $\begin{array}{l}05 \ldots \\
\text { JUL }\end{array}$ & 375 & 7.1 & 10 \\
\hline $\begin{array}{l}09 \cdots \\
\text { MAY }, 1977\end{array}$ & 385 & 7.5 & 10 \\
\hline $\begin{array}{l}25 \\
A \cup G\end{array}$ & 0 & 7.2 & 10 \\
\hline
\end{tabular}

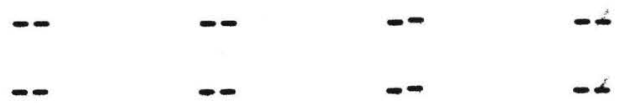

280052082202701 - EUREKA SPRINGS LF 79 (LAT 280052 LONG 0822027.01 )

APR , 1975

$02 \ldots \quad 382 \quad 7.7 \quad 9.0$ 
TABLE 4. CHEMICAL AND BACTERIOLOGICAL ANALYSES FOR GROUND- AND SURFACE-WATER SAMPLES FROM THE EUREKA SPRINGS LANDFILL - CONTINUED

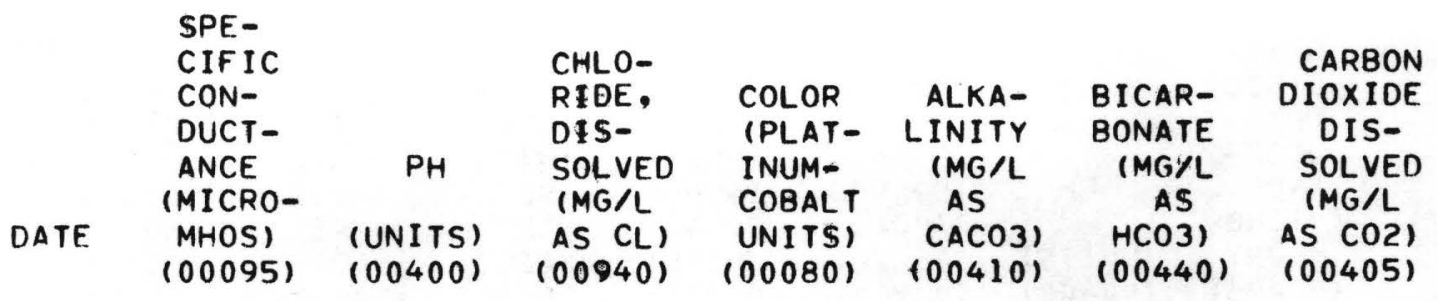

280112082193101 - EUREKA SPRINGS EF 22 CATON (LAT 280112 LONG 0821931.01 )

\begin{tabular}{|c|c|c|c|c|c|c|c|}
\hline $\begin{array}{l}\text { FEB } \quad 1974 \\
25 \ldots . .\end{array}$ & 371 & -- & 9.2 & - & -- & -- & -- \\
\hline MAY & & & & & & & \\
\hline & 356 & -- & 10 & -- & -- & -- & -6 \\
\hline $\begin{array}{l}\text { O3... } \\
\text { JAN } 1975\end{array}$ & 352 & 7.6 & 10 & -- & -- & - & -6 \\
\hline $16 \cdots$ & 342 & 7.8 & 11 & -- & -- & -- & $-\infty$ \\
\hline $28 \ldots$ & 358 & 7.7 & 9.9 & -- & -- & -- & -6 \\
\hline AUG & & & & & & & \\
\hline $\begin{array}{l}18 \ldots \\
O E C\end{array}$ & 358 & 7.6 & 13 & -- & -- & - & $-\infty$ \\
\hline $\begin{array}{l}01 \ldots \\
\text { APR }, 1976\end{array}$ & 348 & 7.6 & 12 & -- & -- & -- & $-\infty$ \\
\hline $\begin{array}{l}05 \cdots \\
\text { JUL }\end{array}$ & 362 & 7.3 & 9.8 & 10 & -- & -- & $-\infty$ \\
\hline $\begin{array}{l}08 \cdots \\
\text { MAY } \because 1977\end{array}$ & 340 & 7.9 & 11 & 2 & -- & -- & -4 \\
\hline $25 \ldots$ & 380 & 7.1 & 10 & - & -- & -- & \\
\hline
\end{tabular}

280116082193601 - EUREKA SPRINGS LF 23 GREEN (LAT 280116 LONG 0821936.01 )

FEB, 1974

\begin{tabular}{|c|c|c|c|c|c|}
\hline MAY & 326 & -- & 7.7 & - & $\cdots$ \\
\hline $\begin{array}{l}07 \ldots \\
\text { SEP }\end{array}$ & 322 & 7.6 & 8.8 & -- & 136 \\
\hline $\begin{array}{l}03 \ldots \\
\text { JAN } 1975\end{array}$ & 321 & 7.8 & 7.8 & - & - \\
\hline $16 \cdots$ & 312 & 7.7 & 8.5 & - & - \\
\hline $\begin{array}{l}28 \ldots \\
\text { AUG }\end{array}$ & 329 & 7.6 & 6.5 & -- & -- \\
\hline $18 \ldots$ & 323 & 7.7 & 3.4 & - & -- \\
\hline $\begin{array}{l}01 \cdots 1 \\
\text { APR } 1976\end{array}$ & 320 & 7.6 & 10 & 3 & -- \\
\hline $\begin{array}{l}05 \cdots \cdots \\
J U L\end{array}$ & 333 & 7.2 & 10 & - & - \\
\hline $\begin{array}{l}08 \cdots \\
\text { MAY } 1977\end{array}$ & 326 & 7.7 & 8.8 & 4 & - \\
\hline $25 \ldots$ & 340 & 7.1 & 8.5 & -- & - \\
\hline
\end{tabular}


TABLE 4. CHEMICAL AND BACTERIOLOGICAL ANALYSES FOR GROUND- AND SURFACE-WATER SAMPLES FROM THE EUREKA SPRINGS LANDFILL - CONTINUED

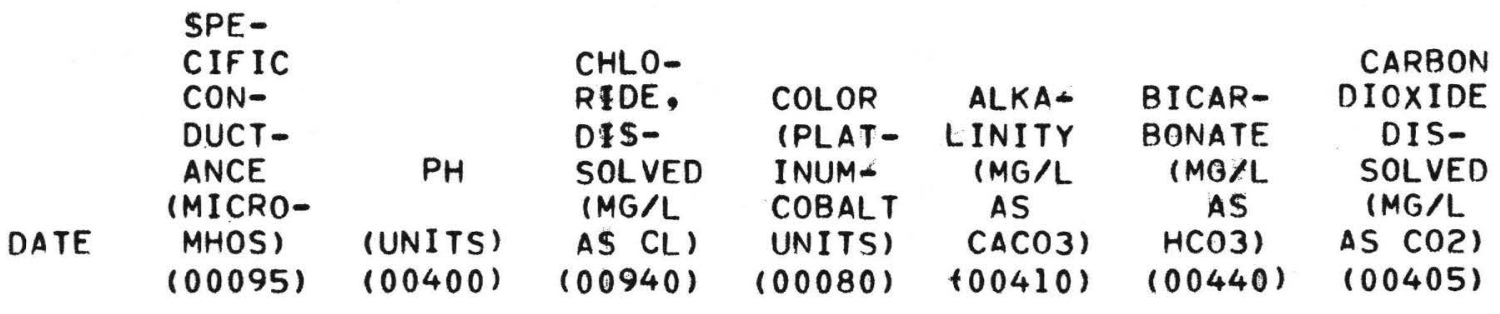

280052082202901 - EUREKA SPRINGS LF 80 (LAT 280052 LONG 0822029.01 )

\begin{tabular}{|c|c|c|c|c|c|c|c|}
\hline $\begin{array}{l}\text { FEE }, 1974 \\
22 \ldots \cdots \\
\text { MAY }\end{array}$ & 364 & -- & 8.0 & -- & - & -- & $-\infty$ \\
\hline$\underset{\text { SEP }}{08 \cdots}$ & 412 & - & 16. & $-\infty$ & - & -- & $-\infty$ \\
\hline JAN $\because 1975$ & 359 & 7.8 & 7.5 & - & -- & -- & $-d$ \\
\hline $\begin{array}{l}24 \\
\text { APR }\end{array}$ & 361 & 7.8 & 8.8 & -- & - & -- & $-\alpha$ \\
\hline $\begin{array}{l}02 \ldots \\
\text { DEC }\end{array}$ & 377 & -- & -- & -- & - & -- & -- \\
\hline $\begin{array}{l}05 \cdots 1976 \\
\text { APR } 1976\end{array}$ & 369 & 7.6 & 8.0 & -- & - & -- & $\cdots$ \\
\hline MAY $07 \cdots$ & -- & 6.8 & 11 & - & - & -- & -- \\
\hline $\begin{array}{l}07 \ldots \\
\text { MAY }, 1977\end{array}$ & 368 & - & 8.8 & 6 & - & -- & -- \\
\hline $31 \ldots$ & 420 & 6.3 & 58 & $\cdots$ & - & -- & -- \\
\hline
\end{tabular}

280052082202902 - EUREKA SPRINGS LF 81 (LAT 280052 LONG 0822029.02 )

\begin{tabular}{|c|c|c|c|c|c|c|c|}
\hline $\begin{array}{l}\text { FEB , } 1974 \\
22 \ldots \ldots \\
\text { MAY }\end{array}$ & 571 & -- & 45 & -- & -- & -- & - \\
\hline $\begin{array}{l}\text { 08.. } \\
\text { JAN } 1975\end{array}$ & 544 & -- & 40 & -- & -- & -- & - \\
\hline $\begin{array}{l}24 \cdots \cdots \\
\text { APR }\end{array}$ & 494 & 7.9 & 40 & $\cdots$ & -- & -- & -- \\
\hline $\begin{array}{l}02 \cdots \\
\text { DEC }\end{array}$ & 525 & -- & -- & -- & -- & -- & - \\
\hline $\begin{array}{l}03 \cdots \cdots \\
\text { APR }, 1976\end{array}$ & 460 & 7.7 & 40 & - & -- & -- & $-\infty$ \\
\hline $\begin{array}{l}07 \cdots \\
\text { MAY }\end{array}$ & - & -- & 45 & -- & -- & -- & - \\
\hline $\begin{array}{l}07 \ldots \\
\text { JUL }\end{array}$ & 530 & -- & 46 & 17 & -- & -- & \\
\hline $09 \ldots$ & 800 & 7.4 & 60 & 3 & -- & -- & \\
\hline
\end{tabular}


TABLE 4. CHEMICAL AND BACTERIOLIOGICAL ANALYSES FOR GROUND- AND SURFACE-WATER SAMPLES FROM THE EUREKA SPRINGS LANDFILL - CONTINUED

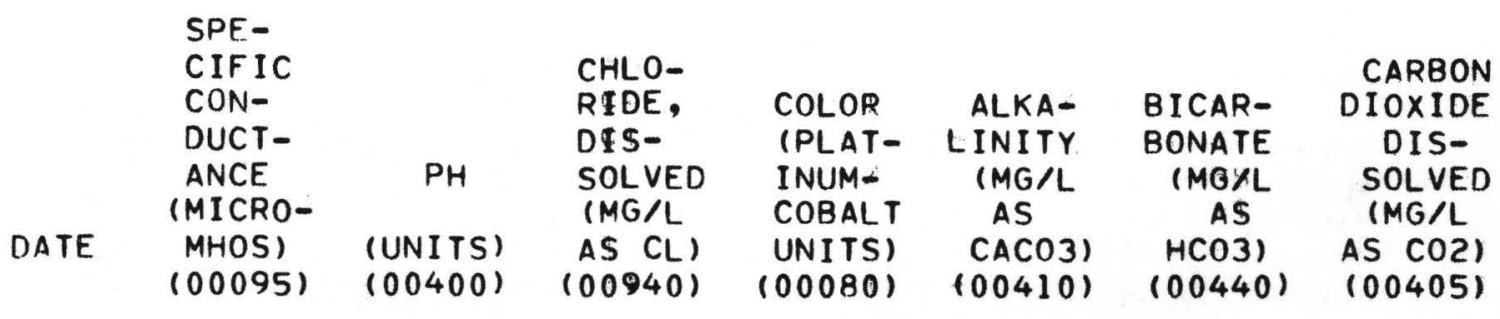

280057082203903 - EUREKA SPRINGS LF 96 (LAT 280057 LONG 0822039.03 )

FEB $\cdot 1974$

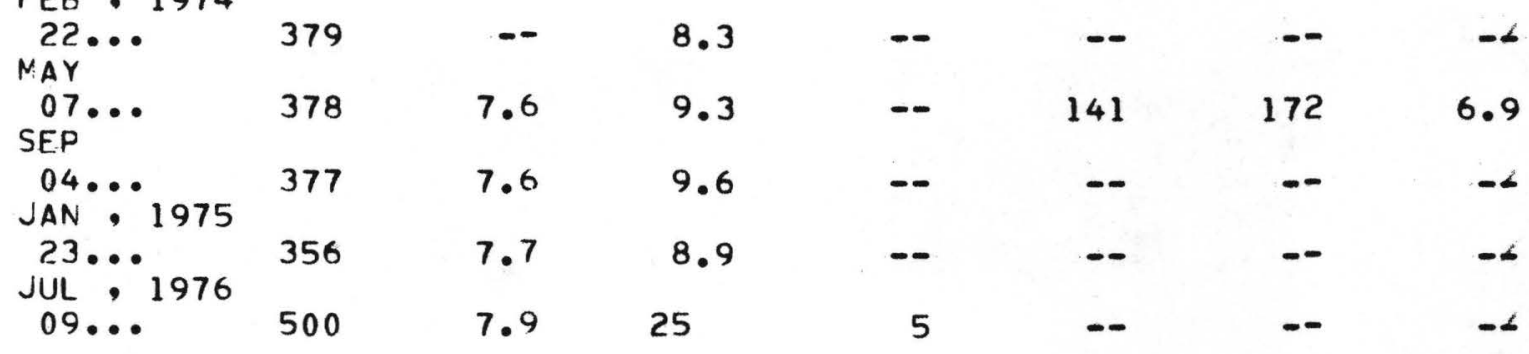

280057082203901 - EUREKA SPRINGS LF 98 (LAT 280057 LONG 0822039.01 )

FEB , 1974

$\begin{array}{llll}22 \ldots & 507 & -- & 29 \\ \text { MAY } & & & \\ 08 \ldots & 460 & -- & 19 \\ \text { APR } 1976 & & & \\ \text { O7... } & -- & -- & 23 \\ \text { MAY } & & & \\ 07 \ldots & 500 & -- & 22\end{array}$

9

19

23

22

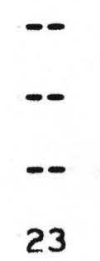

23

280059082201201 - EUREKA SPRINGS LF 104 (LAT 280059 LONG 0822012.01 )

SEP , 1974

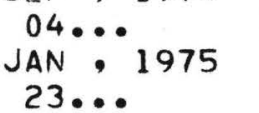

DEC

$03 \ldots . .350$

APR , 1976

MAY

$07 \ldots$
7.6

7.7

7.7

7.8

$--$

$$
\begin{aligned}
& 7.2 \\
& 7.6 \\
& 7.2 \\
& 9.4 \\
& 8.4
\end{aligned}
$$

18

280059082202201 - EUREKA SPRINGS LF 107 (LAT 280059 LONG 0822022.01 )

$A P R, 1975$

$01 \ldots \quad 389 \quad 7.5 \quad 14$ 
TABLE 4. CHEMICAL AND BACTERIOLOGICAL ANALYSES FOR GROUND- AND SURFACE-WATER SAMPLES FROM THE EUREKA SPRINGS LANDFILL - CONTINUED

\begin{tabular}{|c|c|c|c|c|c|c|c|}
\hline & $\begin{array}{l}\text { SPE- } \\
\text { CIF IC } \\
\text { CON- } \\
\text { DUCT- } \\
\text { ANCE } \\
\text { (MICRO- }\end{array}$ & $\mathrm{PH}$ & $\begin{array}{l}\text { CHLO- } \\
\text { RIOE, } \\
\text { DES- } \\
\text { SOLVEO } \\
\text { (MG/L }\end{array}$ & $\begin{array}{l}\text { COLOR } \\
\text { IPLAT- } \\
\text { INUM- } \\
\text { COBALT }\end{array}$ & $\begin{array}{l}\text { ALKA- } \\
\text { LINITY } \\
\text { IMG/L } \\
\text { AS }\end{array}$ & $\begin{array}{c}\text { BICAR- } \\
\text { BONATE } \\
\text { IMGYL } \\
\text { AS }\end{array}$ & $\begin{array}{c}\text { CARBON } \\
\text { DIOXIDE } \\
\text { DIS- } \\
\text { SOLVED } \\
\text { IMG/L }\end{array}$ \\
\hline DATE & $\begin{array}{l}\text { MHOS }) \\
(00095)\end{array}$ & $\begin{array}{l}\text { (UNITS) } \\
(00400)\end{array}$ & $\begin{array}{l}\text { AS CL) } \\
(00940)\end{array}$ & $\begin{array}{l}\text { UNITS) } \\
(00080)\end{array}$ & $\begin{array}{r}\text { (ACO3) } \\
(00410)\end{array}$ & $\begin{array}{l}\mathrm{HC03}) \\
(00440)\end{array}$ & $\begin{array}{l}A S C 02) \\
(00405)\end{array}$ \\
\hline
\end{tabular}

280116082193502 - EUREKA SPRINGS LF 149 (LAT 280116 LONG 0821935.02 )

FEB , 1974

$\begin{array}{llll}25 \ldots & 832 & -- & 97 \\ \text { MAY } & & & \\ \text { O9. } 1975 & 424 & -- & 37 \\ \text { JAN, } 1975 & & & \\ \text { MAR } \cdots & 650 & 6.5 & 65 \\ \text { 28... } & 563 & 6.6 & 43\end{array}$

DEC

$\begin{array}{crrr}\text { 02... } & 1290 & 6.0 & 140 \\ \text { JUL } 1976 & & & \\ 09 . . . & 2250 & 6.4 & 180\end{array}$

37


TABLE 4. CHEMICAL AND BACTERIOLOGICAL ANALYSES FOR GROUND- AND SURFACE-WATER SAMPLES FROM THE EUREKA SPRINGS LANDFILL - CONTINUED

\begin{tabular}{|c|c|c|c|c|c|c|c|}
\hline & $\begin{array}{l}\text { SPE- } \\
\text { CIFIC } \\
\text { CON- } \\
\text { DUCT- } \\
\text { ANCE } \\
\text { (MICRO- }\end{array}$ & PH & $\begin{array}{l}\text { CHLO- } \\
\text { RIDE, } \\
\text { DIS- } \\
\text { SOLVED } \\
\text { (MG/L }\end{array}$ & $\begin{array}{l}\text { COLOR } \\
\text { IPLAT- } \\
\text { INUM- } \\
\text { COBAL T }\end{array}$ & $\begin{array}{l}\text { ALKA- } \\
\text { LINITY } \\
\text { (MG/L }\end{array}$ & $\begin{array}{c}\text { BICAR - } \\
\text { BONATE } \\
\text { IMGYL }\end{array}$ & $\begin{array}{c}\text { CARBON } \\
\text { DIOXIDE } \\
\text { DIS- } \\
\text { SOLVED } \\
\text { IMGI }\end{array}$ \\
\hline$\triangle T E$ & $\begin{array}{l}\text { MHOS } \\
(00095)\end{array}$ & $\begin{array}{l}\text { (UNITS) } \\
(00400)\end{array}$ & $\begin{array}{l}\text { AS CL) } \\
(00940)\end{array}$ & $\begin{array}{l}\text { UNITS) } \\
(00080)\end{array}$ & $\begin{array}{r}\text { (AC03) } \\
(00410)\end{array}$ & $\begin{array}{c}\mathrm{HCO3)} \\
(00440)\end{array}$ & $\begin{array}{l}\text { AS C02) } \\
(00405)\end{array}$ \\
\hline
\end{tabular}

280058082202400 - EUREKA SPRINGS LF SW PERIMETER OITCH (LAT 280058 LONG 0822024 )

NOV, 1975

$26 \ldots 1210 \quad 0 \quad 49$

280102082202000 - EUREKA SPRINGS LF OXIDATION POND (LAT 280102 LONG 0822020$)$

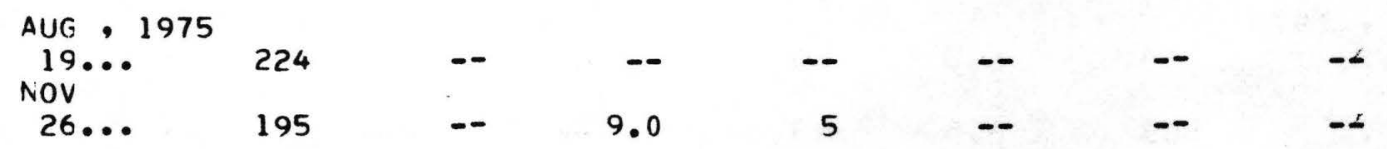


TABLE 4. CHEMICAL AND BACTERIOLOGICAL ANALYSES FOR GROUND- AND SURFACE-WATER SAMPLES FROM THE EUREKA SPRINGS LANDFILL - CONTINUED

$\begin{array}{cccccccc} & & \text { MAGNE- } & & \text { POTAS- } & \text { SODIUM } & & \text { HARD- } \\ & \text { CALCIUM } & \text { SIUM, } & \text { SODIUM, } & \text { SIUM, } & \text { AD- } & \text { HARD- } & \text { NESS, } \\ & \text { DIS- } & \text { DIS- } & \text { DIS- } & \text { DIS- } & \text { SORP- } & \text { NESS } & \text { NONCAR- } \\ & \text { SOLVED } & \text { SOLVED } & \text { SOLVED } & \text { SOLVED } & \text { TION } & \text { (MG/L } & \text { BONATE } \\ & (M G / L & (M G / L & (M G / L & (M G / L & \text { RATIO } & \text { AS } & \text { (MG/L } \\ \text { DATE } & \text { AS CA } & \text { AS MG) } & \text { AS NA) } & \text { AS K) } & & \text { CACO3) } & \text { CACO3) } \\ & (00915) & (00925) & (00930) & (00935) & (00931) & (00900) & (00902)\end{array}$

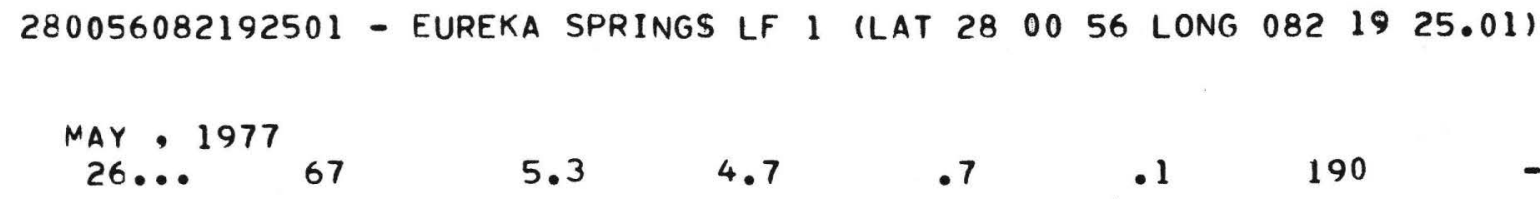

2.7

3.8

6.5

1.7

.6

22

280103082193401 - EUREKA SPRINGS LF 8 (LAT 280103 LONG 0821934.01 )

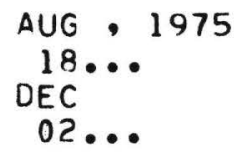

$\begin{array}{ll}5.5 & 1.2 \\ 9.7 & 2.0\end{array}$

4.9

$1 \cdot 1$

.5

19

6.8

1.5

.5

32 
TABLE 4. CHEMICAL AND BACTERIOLOGICAL ANALYSES FOR GROUND- AND SURFACE-WATER SAMPLES FROM THE EUREKA SPRINGS LANDFILL - CONTINUED

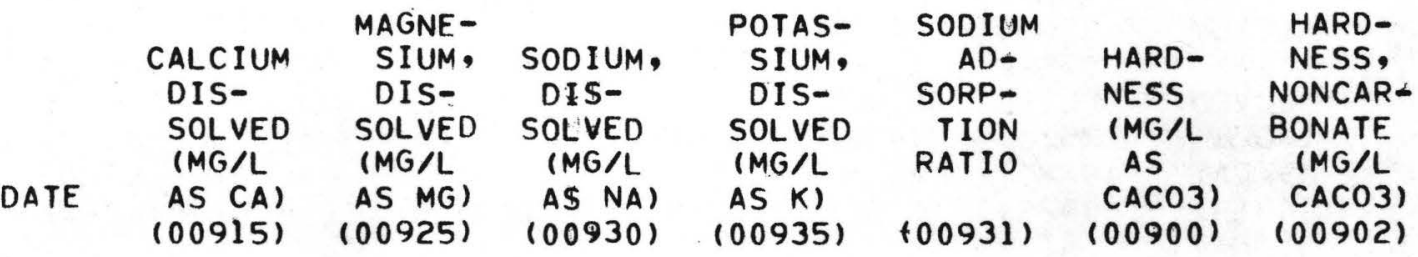

280109082192401 - EUREKA SPRINGS LF 21 BASS (LAT 280109 LONG 0821924.01 )

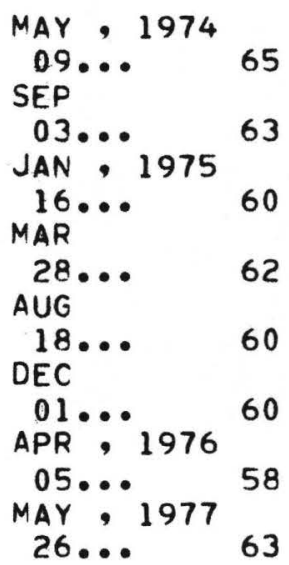

$\begin{array}{lllll}6.3 & 5.6 & .5 & .2 & 190 \\ 6.1 & 5.7 & .4 & .2 & 180 \\ 5.7 & 5.6 & .4 & .2 & 170 \\ 5.8 & 5.6 & .4 & .2 & 180 \\ 5.7 & 6.2 & .6 & .2 & 170 \\ 6.1 & 6.3 & .5 & .2 & 180 \\ 5.8 & 5.9 & .5 & .2 & 170 \\ 6.9 & 5.9 & .5 & .2 & 190\end{array}$

280112082193101 - EUREKA SPRINGS LF 22 CATON (LAT 280112 LONG 0821931.01 )

\begin{tabular}{|c|c|c|c|c|c|c|c|}
\hline $\begin{array}{l}25 \cdots \\
25 \cdots \cdots\end{array}$ & $\begin{array}{l}59 \\
58\end{array}$ & $\begin{array}{l}6.1 \\
3.9\end{array}$ & $\begin{array}{l}5.9 \\
6.2\end{array}$ & $\begin{array}{l}.6 \\
.8\end{array}$ & .2 & $\begin{array}{l}170 \\
160\end{array}$ & $-\infty$ \\
\hline$\underset{\text { SEP }}{09} \cdots$ & 63 & 4.0 & 6.3 & .6 & .2 & 170 & $\infty$ \\
\hline $\begin{array}{l}03 \cdots \\
\text { JAN } 1975\end{array}$ & 64 & 4.0 & 6.2 & .5 & .2 & 180 & - \\
\hline MAR & 61 & 3.8 & 6.1 & .5 & .2 & 170 & $-\infty$ \\
\hline $\begin{array}{l}28 \ldots \\
A \cup G\end{array}$ & 64 & 4.2 & 6.1 & .5 & .2 & 180 & - \\
\hline $\begin{array}{l}18 \cdots \\
\text { DEC }\end{array}$ & 63 & 3.6 & 5.9 & .5 & .2 & 170 & -- \\
\hline $\begin{array}{ll}01 \cdots 1976 \\
A P R\end{array}$ & 59 & 3.9 & 6.3 & .6 & .2 & 160 & $-\infty$ \\
\hline MAY, 1977 & 57 & 3.7 & 6.3 & .6 & .2 & 160 & -- \\
\hline $25 \ldots$ & 63 & 4.4 & 6.0 & .6 & .2 & 180 & - \\
\hline
\end{tabular}


TABLE 4. CHEMICAL AND BACTERIOLOGICAL ANALYSES FOR GROUND- AND SURFACE-WATER SAMPLES FROM THE EUREKA SPRINGS LANDFILL - CONTINUED

\begin{tabular}{|c|c|c|c|c|c|c|c|}
\hline & $\begin{array}{l}\text { SPE- } \\
\text { CIFIC } \\
\text { CON- } \\
\text { DUCT- } \\
\text { ANCE } \\
\text { IMICRO- }\end{array}$ & $\mathrm{PH}$ & $\begin{array}{l}\text { CHLO- } \\
\text { RIDE, } \\
\text { DIS- } \\
\text { SOLVED } \\
\text { (MG/L }\end{array}$ & $\begin{array}{l}\text { COLOR } \\
\text { IPLAT- } \\
\text { INUM- } \\
\text { COBALT }\end{array}$ & $\begin{array}{l}\text { ALKA- } \\
\text { LINITY } \\
\text { IMG/L } \\
\text { AS }\end{array}$ & $\begin{array}{c}\text { BICAR- } \\
\text { BONATE } \\
\text { IMOYL } \\
\text { AS }\end{array}$ & $\begin{array}{c}\text { CARBON } \\
\text { DIOXIDE } \\
\text { DIS- } \\
\text { SOLVED } \\
\text { IMG/L }\end{array}$ \\
\hline$\triangle \mathrm{ATE}$ & $\begin{array}{l}\text { MHOS) } \\
(00095)\end{array}$ & $\begin{array}{l}\text { (UNITS) } \\
(00400)\end{array}$ & $\begin{array}{l}\text { AS CL) } \\
(00940)\end{array}$ & $\begin{array}{l}\text { UNITS) } \\
(00080)\end{array}$ & $\begin{array}{r}\text { CACO3) } \\
(00410)\end{array}$ & $\begin{array}{l}\mathrm{HCO} 3) \\
(00440)\end{array}$ & $\begin{array}{l}\text { AS C02) } \\
(00405)\end{array}$ \\
\hline
\end{tabular}

280059082202202 - EUREKA SPRINGS LF 108 (LAT 280059 LONG 0822022.02 )

$\begin{array}{llcc}\text { SEP , } 1974 & & & \\ 04 \ldots \cdots & 371 & 7.6 & 7.6 \\ \text { JAN } 1975 & & 7.8 & 8.7 \\ \text { 23... } & 358 & 7.8 \\ \begin{array}{l}\text { APR } \\ 01\end{array} & 830 & 7.8 & 150\end{array}$

280103082202802 - EUREKA SPRINGS LF 129 (LAT 280103 LONG 0822028.02 )

JUL, 1976

$\begin{array}{lllll}12 \ldots & 200 & 7.4 & 8.8 & 100\end{array}$

280103082202801 - EUREKA SPRINGS LF 130 (LAT 280103 LONG 0822028.01 )

APR , 1976

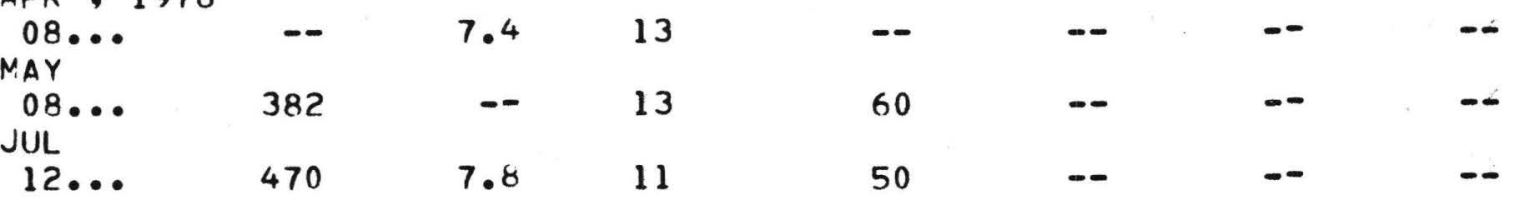

280108082194201 - EUREKA SPRINGS LF 148 (LAT 280108 LONG 0821942.01 )

FEB , 1974

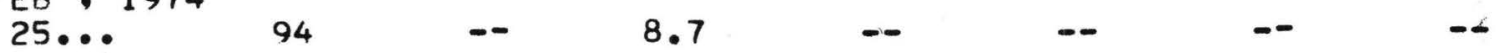

SEP

03... $\quad 44 \quad 6.0 \quad 7.4$

80209082193901 - EUREKA SPRINGS LF 148 A (LAT 280209 LONG 0821939.01 )

JAN, .1975

$16 \ldots 120$

DEC

03... 110

APR , 1976

$13 \ldots 150$

$6.6 \quad 11$

$6.6 \quad 8.1$

$6.8 \quad 9.9$

460 
.E 4. CHEMICAL AND BACTERIOLOGICAL ANALYSES FOR GROUND- AND SURFACE-WATER SAMPLES FROM THE EUREKA SPRINGS LANDF ILL - CONTINUED

\begin{tabular}{|c|c|c|c|c|c|c|c|}
\hline & $\begin{array}{l}\text { CALCIUM } \\
\text { DIS- } \\
\text { SOLVED } \\
\text { (MG/L }\end{array}$ & $\begin{array}{l}\text { MAGNE- } \\
\text { SIUM, } \\
\text { DIS- } \\
\text { SOLVED } \\
\text { (MG/L }\end{array}$ & $\begin{array}{l}\text { SODIUM, } \\
\text { DIS- } \\
\text { SOLVED } \\
\text { (MG/L }\end{array}$ & $\begin{array}{l}\text { POTAS- } \\
\text { SIUM, } \\
\text { DIS- } \\
\text { SOLVED } \\
\text { IMG } / L\end{array}$ & $\begin{array}{l}\text { SODIUM } \\
\text { AD - } \\
\text { SORP- } \\
\text { TION } \\
\text { RATIO }\end{array}$ & $\begin{array}{l}\text { HARD - } \\
\text { NESS } \\
\text { (MG/L } \\
\text { AS }\end{array}$ & $\begin{array}{l}\text { HARD- } \\
\text { NESS, } \\
\text { NONCAR- } \\
\text { BONATE } \\
\text { (MG/L }\end{array}$ \\
\hline 1 & $\begin{array}{l}\text { AS CA) } \\
(00915)\end{array}$ & $\begin{array}{l}\text { AS MG) } \\
(00925)\end{array}$ & $\begin{array}{l}\text { AS NA) } \\
(00930)\end{array}$ & $\begin{array}{l}\text { AS K) } \\
(00935)\end{array}$ & (00931) & $\begin{array}{l}\text { (ACO3) } \\
(00900)\end{array}$ & $\begin{array}{l}\text { CACO3) } \\
(00902)\end{array}$ \\
\hline
\end{tabular}

182193601 - EUREKA SPRINGS LF 23 GREEN (LAT 280116 LONG 0821936.01 )

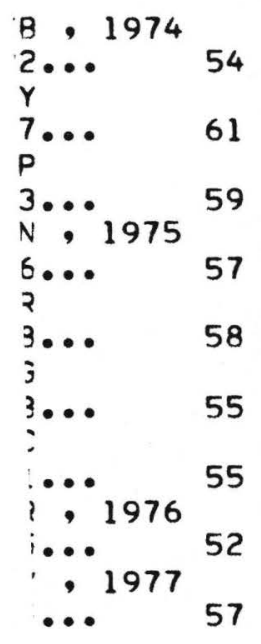

$\begin{array}{llllll}4.0 & 4.9 & .5 & .2 & 150 & - \\ 3.9 & 4.9 & .5 & .2 & 170 & 32 \\ 3.8 & 4.9 & .5 & .2 & 160 & - \\ 3.8 & 5.7 & .5 & .2 & 160 & - \\ 4.0 & 4.7 & .5 & .2 & 160 & - \\ 3.7 & 5.0 & .5 & .2 & 150 & - \\ 4.0 & 5.4 & .5 & .2 & 150 & - \\ 3.8 & 6.3 & .5 & .2 & 150 & - \\ 4.6 & 4.8 & .5 & .2 & 160 & -\end{array}$

2193201 - EUREKA SPRINGS LF 24 GREY (LAT 280117 LONG 0821932.01 )

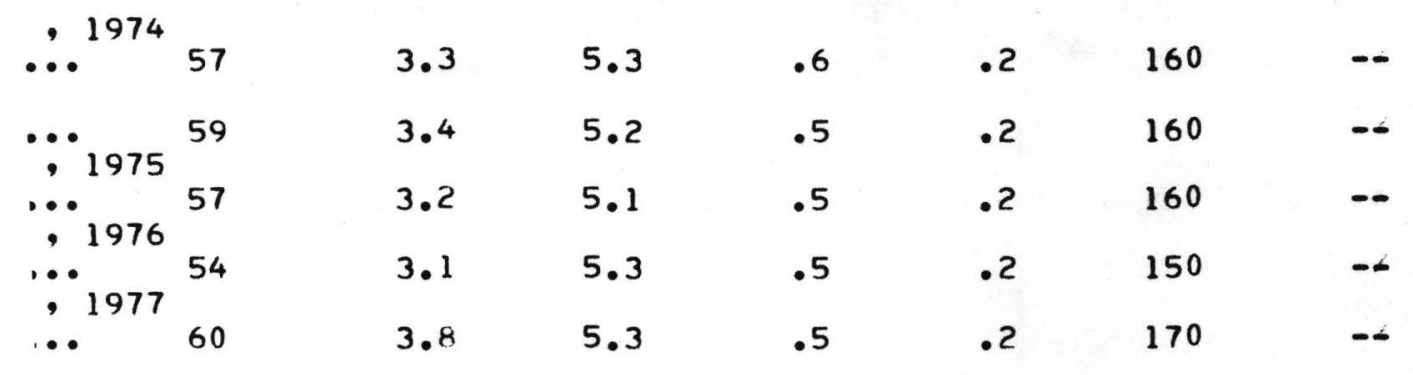


TABLE 4. CHEMICAL AND BACTERIOLOGICAL ANALYSES FOR GROUND- AND SURFACE-WATER SAMPLES FROM THE EUREKA SPRINGS LANDFILL - CONTINUED

$\begin{array}{cccccccc} & & & & \text { POTAS- } & \text { SODIUM } & & \text { HARD- } \\ & \text { CALCIUM } & \text { SIUM, } & \text { SODIUM, } & \text { SIUM, } & \text { AD- } & \text { HARD- } & \text { NESS, } \\ & \text { DIS- } & \text { DIS- } & \text { DIS- } & \text { DIS- } & \text { SORP- } & \text { NESS } & \text { NONCAR- } \\ & \text { SOLVED } & \text { SOLVED } & \text { SOLVED } & \text { SOLVED } & \text { TION } & (M G / L & \text { BONATE } \\ & (M G / L & (M G / L & (M G / L & (M G / L & \text { RATIO } & \text { AS } & \text { (MG/L } \\ \text { DATE } & \text { ASCA) } & \text { AS MG) } & \text { AS NA) } & \text { AS K } & & \text { CACO3) } & \text { CACO3) } \\ & (00915) & (00925) & (00930) & (00935) & (00931) & (00900) & (00902)\end{array}$

280051082202901 - EUREKA SPRINGS LF 72 (LAT 280051 LONG 0822029.01 )

\begin{tabular}{|c|c|c|c|c|c|c|}
\hline $\begin{array}{l}\text { SEP } 1974 \\
04 \ldots . .\end{array}$ & 64 & 6.4 & 5.7 & .4 & .2 & 190 \\
\hline $\begin{array}{l}\text { JAN } 1975 \\
24 \ldots .\end{array}$ & 61 & 6.3 & 5.5 & .4 & .2 & 180 \\
\hline $\begin{array}{l}\text { AUG } \\
18 \cdots \cdots \\
\text { DEC }\end{array}$ & 64 & 5.9 & 5.5 & .5 & .2 & 180 \\
\hline $03 \ldots$ & 62 & 6.4 & 6.7 & .5 & .2 & 180 \\
\hline $\begin{array}{l}\text { APR }, 1976 \\
\text { O5. . } \\
\text { MAY } 1977\end{array}$ & 57 & 5.9 & 5.8 & .5 & .2 & 170 \\
\hline $25 \ldots$ & 66 & 6.8 & 5.5 & .5 & .2 & 190 \\
\hline
\end{tabular}

280052082202701 - EUREKA SPRINGS LF 79 (LAT 280052 LONG 0822027.01 )
APR, 1975
$02 \ldots 65$
$6.7 \quad 5.4$
.7
.2
190

280052082202901 - EUREKA SPRINGS LF 80 (LAT 280052 LONG 0822029.01 )

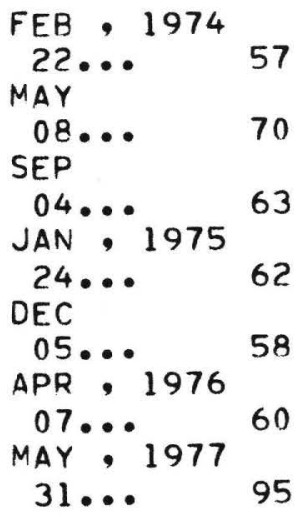

$\begin{array}{lrrrrr}6.8 & 5.6 & 1.0 & .2 & 170 & \ldots \\ 7.8 & 6.2 & .6 & .2 & 210 & \ldots \\ 6.4 & 5.4 & .5 & .2 & 180 & \ldots \\ 6.7 & 5.9 & .9 & .2 & 180 & \ldots \\ 6.4 & 6.5 & .8 & .2 & 170 & - \\ 6.2 & 6.1 & .8 & .2 & 180 & \ldots \\ 20 & 13 & .3 & .3 & 320 & \ldots\end{array}$


TABLE 4. CHEMICAL AND BACTERIOLOGICAL ANALYSES FOR GROUND- AND SURFACE-WATER SAMPLES FROM THE EUREKA SPRINGS LANDFILL - CONTINUED

\begin{tabular}{|c|c|c|c|c|c|c|}
\hline $\begin{array}{l}\text { CALCIUM } \\
\text { DIS- } \\
\text { SOLVED } \\
\text { (MG/L }\end{array}$ & $\begin{array}{l}\text { MAGNE- } \\
\text { SIUM, } \\
\text { DIS- } \\
\text { SOLVED } \\
\text { IMG/L }\end{array}$ & $\begin{array}{l}\text { SODIUM, } \\
\text { DIS- } \\
\text { SOLVED } \\
\text { (MG/L }\end{array}$ & $\begin{array}{l}\text { POTAS- } \\
\text { SIUM, } \\
\text { DIS- } \\
\text { SOLVED } \\
\text { IMG }\end{array}$ & $\begin{array}{l}\text { SODIUM } \\
\text { AD- } \\
\text { SORP- } \\
\text { TION } \\
\text { RATIO }\end{array}$ & $\begin{array}{l}\text { HARD - } \\
\text { NESS } \\
\text { IMG/L } \\
\text { AS }\end{array}$ & $\begin{array}{l}\text { HARD- } \\
\text { NESS, } \\
\text { NONCAR- } \\
\text { BONATE } \\
\text { (MG/L }\end{array}$ \\
\hline $\begin{array}{l}\text { AS CA) } \\
(00915)\end{array}$ & $\begin{array}{l}\text { AS MG }) \\
(00925)\end{array}$ & $\begin{array}{l}\text { AS NA) } \\
(00930)\end{array}$ & $\begin{array}{l}\text { AS K) } \\
(00935)\end{array}$ & $(00931)$ & $\begin{array}{r}\text { CAC03) } \\
(00900)\end{array}$ & $\begin{array}{r}\text { CACO3) } \\
(00902)\end{array}$ \\
\hline
\end{tabular}

280052082202902 - EUREKA SPRINGS LF 81 (LAT 280052 LONG 0822029.02 )

\begin{tabular}{|c|c|c|c|c|c|c|}
\hline $\begin{array}{l}\text { FEB , } 1974 \\
22 . . \cdots \\
\text { MAY }\end{array}$ & 81 & 15 & 9.9 & 1.1 & $\cdot 3$ & 260 \\
\hline JAN $\because 1975$ & 86 & 14 & 8.1 & .4 & .2 & 270 \\
\hline $\begin{array}{l}24 \\
\text { DEC }\end{array}$ & 79 & 13 & 9.2 & .3 & .3 & 25 \\
\hline $\begin{array}{l}03 \cdots \cdots \\
\text { APR } 1976\end{array}$ & 60 & 12 & 9.4 & 1.5 & .3 & 200 \\
\hline $07 \ldots$ & 78 & 13 & 9.3 & .3 & .3 & 250 \\
\hline
\end{tabular}

280057082203903 - EUREKA SPRINGS LF 96 (LAT 280057 LONG $082 \quad 2039.03$ )

FEB, 1974

\begin{tabular}{|c|c|c|c|c|c|c|}
\hline $\begin{array}{l}22 \\
\text { MAY } \cdots\end{array}$ & 61 & 6.4 & 5.7 & .6 & .2 & 180 \\
\hline $\begin{array}{l}07 \ldots \\
\text { SEP }\end{array}$ & 66 & 7.0 & 5.5 & .5 & $\cdot 2$ & 190 \\
\hline $\begin{array}{l}04 \cdots \\
\text { JAN } 1975\end{array}$ & 63 & 7.9 & 5.5 & .5 & .2 & 190 \\
\hline $23 \ldots$ & 63 & 6.4 & 5.6 & .4 & .2 & 180 \\
\hline
\end{tabular}

280057082203901 - EUREKA SPRINGS LF 98 (LAT 280057 LONG 0822039.01 )

\begin{tabular}{|c|c|c|c|c|c|c|}
\hline $\begin{array}{l}\text { FEB, } 1974 \\
22 \ldots \ldots \\
\text { MAY }\end{array}$ & 78 & 14 & 5.7 & .8 & .2 & 250 \\
\hline $\begin{array}{l}08 \cdots \cdots \\
\text { APR } 1976\end{array}$ & 75 & 11 & 5.6 & .5 & .2 & 230 \\
\hline $07 \ldots$ & 80 & 12 & 10 & .5 & .3 & 250 \\
\hline
\end{tabular}


TABLE 4. CHEMICAL AND BACTERIOLOGICAL ANALYSES FOR GROUND- AND SURFACE-WATER SAMPLES FROM THE EUREKA SPRINGS LANDFILL - CONTINUED

$\begin{array}{ccccccc} & \text { MAGNE- } & & \text { POTAS- } & \text { SODIUM } & & \text { HARD- } \\ \text { CALCIUM } & \text { SIUM, } & \text { SODIUM, } & \text { SIUM, } & \text { AD- } & \text { HARD- } & \text { NESS, } \\ \text { DIS- } & \text { DIS- } & \text { DIS- } & \text { DIS- } & \text { SORP- } & \text { NESS } & \text { NONCAR- } \\ \text { SOLVED } & \text { SOLVED } & \text { SOLVED } & \text { SOLVED } & \text { TION } & \text { (MG/L } & \text { BONATE } \\ (M G / L & (M G / L & \text { (MG/L } & (M G / L & \text { RATIO } & \text { AS } & \text { (MG/L } \\ \text { ASCA) } & \text { AS MG) } & \text { AS NA) } & \text { AS K }) & & \text { CACO3) } & \text { CACO3) } \\ (00915) & (00925) & (00930) & (00935) & (00931) & (00900) & (00902)\end{array}$

280059082201201 - EUREKA SPRINGS LF 104 (LAT 280059 LONG 0822012.01 )

\begin{tabular}{|c|c|c|c|c|c|c|}
\hline JAN, 1975 & 60 & 6.1 & 5.3 & .5 & .2 & 180 \\
\hline $\begin{array}{l}23 \cdots \cdots \\
D E C\end{array}$ & 57 & 6.4 & 5.7 & .8 & .2 & 170 \\
\hline 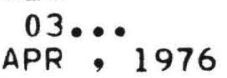 & 56 & 6.2 & 7.0 & .7 & $\cdot 2$ & 170 \\
\hline $07 \ldots$ & 49 & 5.8 & 6.6 & .8 & .2 & 150 \\
\hline
\end{tabular}

280059082202201 - EUREKA SPRINGS LF 107 (LAT 280059 LONG 0822022.01 )
$A P R, 1975$
$01 \ldots 63$
7.6
7.2
.6
.2
190

280059082202202 - EUREKA SPRINGS LF 108 (LAT 280059 LONG 0822022.02 )

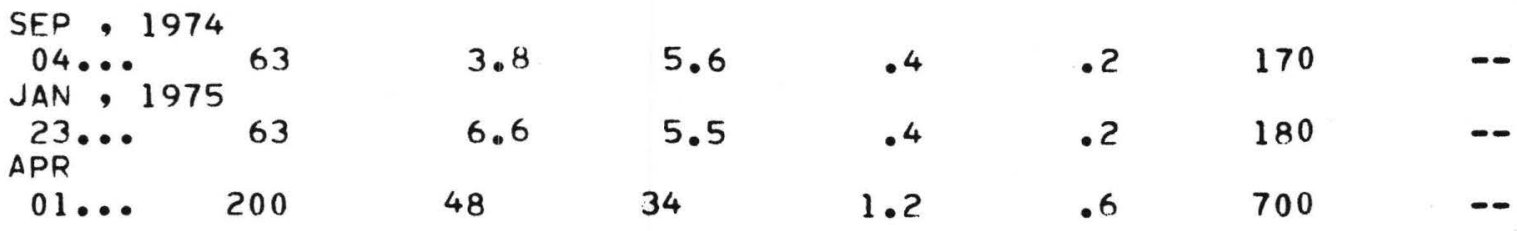

280103082202801 - EUREKA SPRINGS LF 130 (LAT 280103 LONG 0822028.01 )
APR , 1976
$08 \ldots 56$
$5.7 \quad 6.8$
5.5
.2
160

280108082194201 - EUREKA SPRINGS LF 148 (LAT 280108 LONG 0821942.01 )

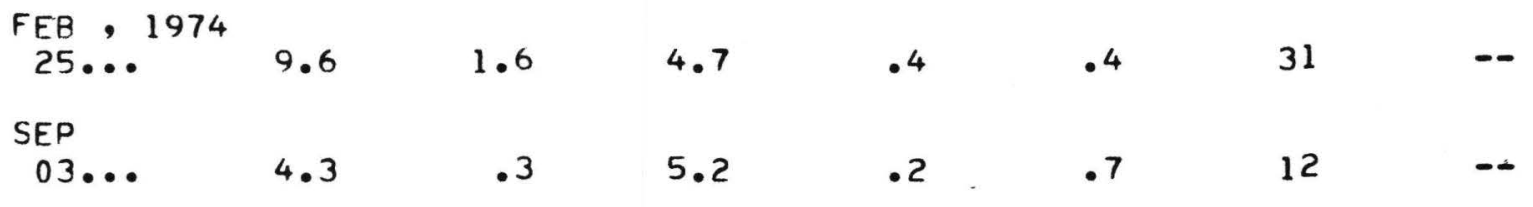


TABLE 4. CHEMICAL AND BACTERIOLOGICAL ANALYSES FOR GROUND- AND SURFACE-WATER SAMPLES FROM THE EUREKA SPRINGS LANDFILL - CONTINUED

\begin{tabular}{|c|c|c|c|c|c|c|c|}
\hline & $\begin{array}{l}\text { CALCIUM } \\
\text { DIS- } \\
\text { SOLVED } \\
\text { (MG/L }\end{array}$ & $\begin{array}{l}\text { MAGNE- } \\
\text { SIUM, } \\
\text { DIS- } \\
\text { SOLVED } \\
\text { (MG/L }\end{array}$ & $\begin{array}{l}\text { SODIUM, } \\
\text { DIS- } \\
\text { SOLVED } \\
\text { (MG/L }\end{array}$ & $\begin{array}{l}\text { POTAS- } \\
\text { SIUM, } \\
\text { DIS- } \\
\text { SOLVED } \\
\text { IMG/L }\end{array}$ & $\begin{array}{l}\text { SODIUM } \\
\text { AD- } \\
\text { SORP- } \\
\text { TION } \\
\text { RATIO }\end{array}$ & $\begin{array}{l}\text { HARD - } \\
\text { NESS } \\
\text { IMG/L } \\
\text { AS }\end{array}$ & $\begin{array}{l}\text { HARD- } \\
\text { NESS, } \\
\text { NONCAR- } \\
\text { BONATE } \\
\text { (MG/L }\end{array}$ \\
\hline & $\begin{array}{l}\text { AS CA) } \\
(00915)\end{array}$ & $\begin{array}{l}\text { AS MG) } \\
(00925)\end{array}$ & $\begin{array}{l}\text { AS NA) } \\
(00930)\end{array}$ & $\begin{array}{l}\text { AS K) } \\
(00935)\end{array}$ & $(00931)$ & $\begin{array}{r}\text { (ACO3) } \\
(00900)\end{array}$ & $\begin{array}{l}\text { (ACO3) } \\
(00902)\end{array}$ \\
\hline
\end{tabular}

280209082193901 - EUREKA SPRINGS LF 148 A ILAT 280209 LONG 0821939.01 )

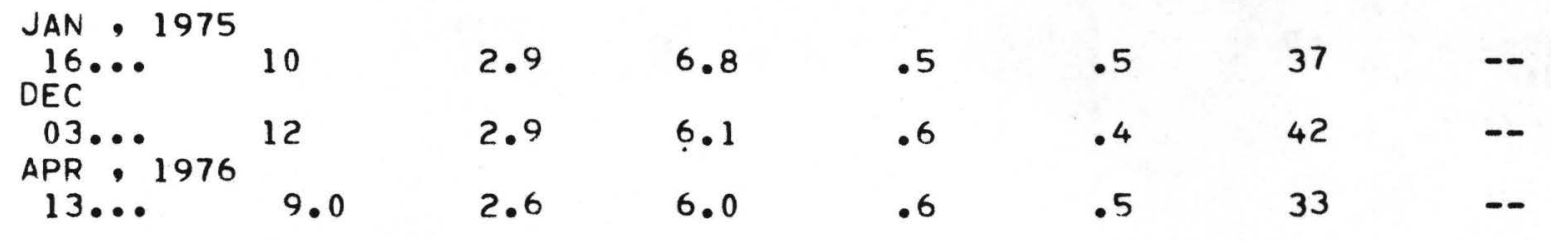

280116082193502 - EUREKA SPRINGS LF 149 (LAT $2801 \quad 16$ LONG $082 \quad 1935.02$ )

\begin{tabular}{|c|c|c|c|c|c|c|}
\hline $\begin{array}{l}\text { FEB , } 1974 \\
25 \ldots .\end{array}$ & 85 & 13 & 43 & 6.6 & 1.1 & 270 \\
\hline $\begin{array}{l}\text { MAY } \\
0.9 \ldots\end{array}$ & 49 & 6.0 & 12 & 1.6 & .4 & 150 \\
\hline $\begin{array}{l}\text { JAN , } 1975 \\
\text { I6... } \\
\text { MAR }\end{array}$ & 64 & 11 & 38 & 7.8 & 1.2 & 210 \\
\hline $28 \ldots$ & 59 & 9.2 & 29 & 4.9 & .9 & 190 \\
\hline
\end{tabular}

280116082193501 - EUREKA SPRINGS LF 150 (LAT $2801 \quad 16$ LONG 0821935.01 )

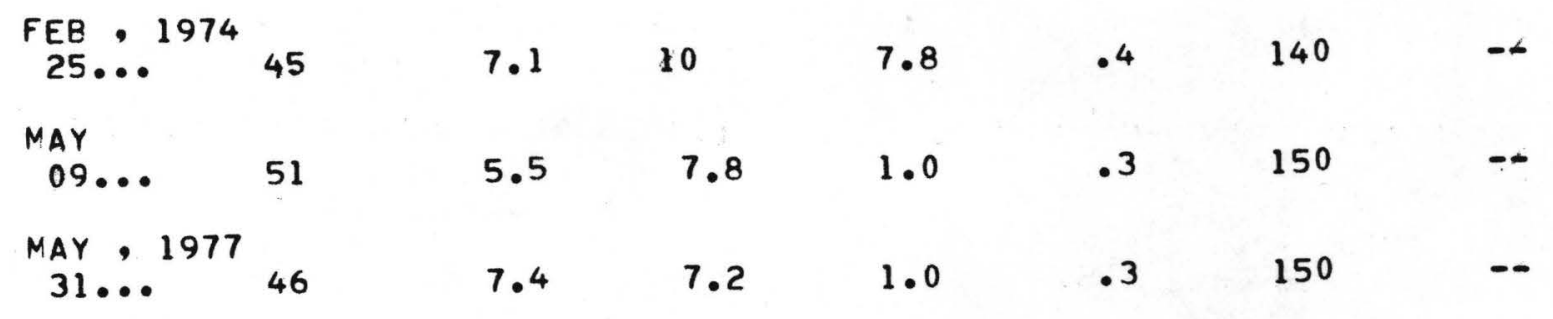


TABLE 4. CHEMICAL AND BACTERIOLOGICAL ANALYSES FOR GROUND- AND SURFACE-WATER SAMPLES FROM THE EUREKA SPRINGS LANDFILL - CONTINUED

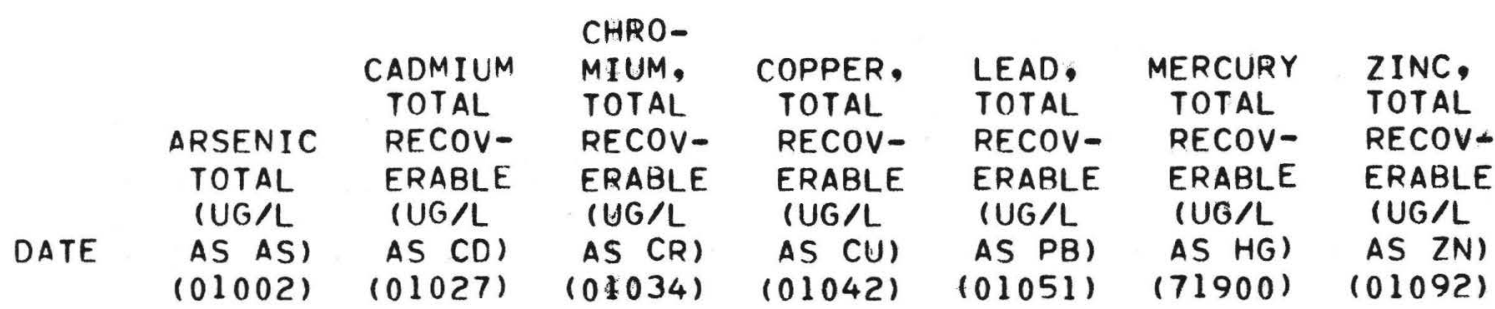

280056082192501 - EUREKA SPRINGS LF 1 (LAT 280056 LONG 082.1925 .01 )

\begin{tabular}{|c|c|c|c|c|c|c|c|}
\hline $08 \ldots$ & ? & 1 & 30 & 3 & 18 & .3 & 50 \\
\hline JUL & & & & & & & \\
\hline $\begin{array}{l}12 \ldots \cdots \\
\text { MAY } 1977\end{array}$ & 2 & 2 & 20 & 8 & 26 & .6 & 50 \\
\hline $26 \ldots$ & 1 & 0 & 40 & 7 & 14 & .0 & 80 \\
\hline
\end{tabular}

280101082192801 - EUREKA SPRINGS LF 6 (LAT 280101 LONG 0821928.01 )

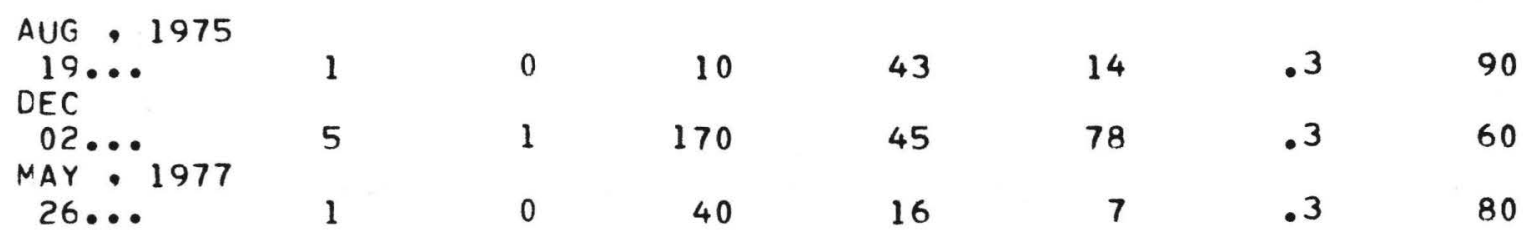

280104082193001 - EUREKA SPRINGS LF 7 (LAT 280104 LONG 0821930.01 )

\begin{tabular}{|c|c|c|c|c|c|c|c|}
\hline DEC & 3 & 0 & 20 & 72 & 27 & .6 & 100 \\
\hline $\begin{array}{l}02 \cdots 1976 \\
\text { APR } \because 1970\end{array}$ & 1 & 0 & $<10$ & 34 & 17 & .0 & 10 \\
\hline MAY $\because 1977$ & 1 & 1 & 50 & 22 & 20 & .3 & 90 \\
\hline $31 \ldots$ & 3 & 0 & 20 & 0 & 9 & .0 & 30 \\
\hline
\end{tabular}

280103082193401 - EUREKA SPRINGS LF 8 (LAT 280103 LONG 0821934.01 )

\begin{tabular}{|c|c|c|c|c|c|c|c|}
\hline DEC $18 \cdots$ & 23 & 1 & 300 & 110 & 270 & .5 & 100 \\
\hline $\begin{array}{l}02 \cdots \\
\text { JUL }: 1976\end{array}$ & 2 & 0 & $<10$ & 30 & 20 & .0 & 20 \\
\hline $12 \ldots$ & 1 & 1 & 30 & 8 & 17 & ? & 50 \\
\hline
\end{tabular}


TABLE 4. CHEMICAL AND BACTERIOLOGICAL ANALYSES FOR GROUND- AND SURFACE-WATER SAMPLES FROM THE EUREKA SPRINGS LANDFILL - CONTINUED

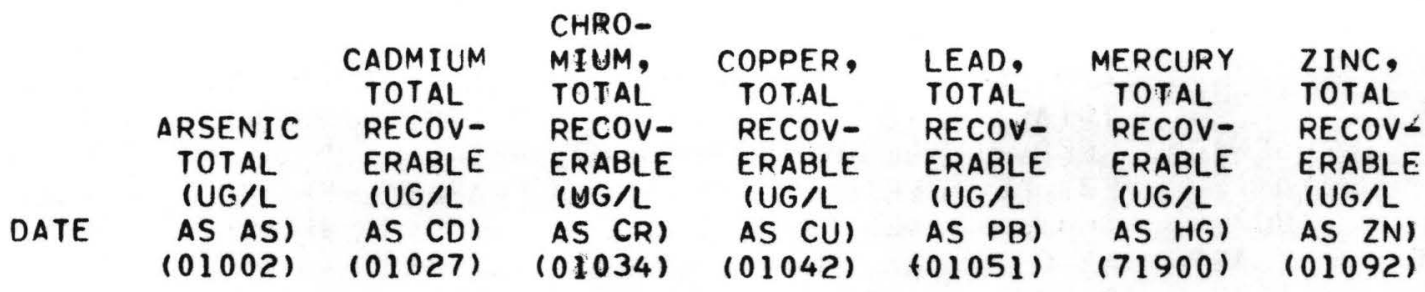

280109082192401 - EUREKA SPRINGS LF ?1 BASS (LAT 280109 LONG 0821924.01 )

\begin{tabular}{|c|c|c|c|c|c|c|c|}
\hline $\begin{array}{l}\text { SEP , } 1974 \\
\text { O3.@ }\end{array}$ & 2 & 0 & $<10$ & 6 & 7 & .1 & 0 \\
\hline $\begin{array}{l}16 \ldots \\
\text { MAR }\end{array}$ & 4 & 1 & 20 & 9 & 3 & .3 & 60 \\
\hline $\begin{array}{l}28 \ldots \\
\text { AUG }\end{array}$ & 2 & 1 & $<10$ & 9 & 18 & .0 & 70 \\
\hline $\begin{array}{l}18 \cdots \\
\text { DEC }\end{array}$ & 2 & 1 & $<10$ & 22 & 2 & .3 & 40 \\
\hline $\begin{array}{l}01 \cdots \\
\text { APR } 1976\end{array}$ & 3 & 0 & $<10$ & 19 & 8 & .0 & 20 \\
\hline $\begin{array}{l}\text { O5 } \cdots \\
\text { JUL }\end{array}$ & 3 & 0 & 20 & 10 & 0 & .1 & 20 \\
\hline MAY $\because 1977$ & 3 & 0 & 50 & 2 & 2 & .9 & 30 \\
\hline $26 \ldots$ & 1 & 0 & 60 & 2 & 13 & .0 & 40 \\
\hline
\end{tabular}

280112082193101 - EUREKA SPRINGS UF 22 CATON (LAT 280112 LONG 0821931.01 )

\begin{tabular}{|c|c|c|c|c|c|c|c|}
\hline $\begin{array}{l}\text { SEP } 1974 \\
03 \ldots \cdots\end{array}$ & 2 & 1 & $<10$ & 58 & 26 & .9 & 150 \\
\hline MAR & 1 & 1 & $<10$ & 83 & 13 & .0 & 440 \\
\hline $\begin{array}{l}28 \\
\text { AUG }\end{array}$ & 0 & 0 & $<10$ & 90 & 6 & .0 & 580 \\
\hline $\operatorname{DEC}^{18 \ldots}$ & 0 & 0 & $<10$ & 90 & 2 & .5 & 620 \\
\hline $\begin{array}{l}01 \cdots 1976 \\
\text { APR }, 1976\end{array}$ & 1 & 0 & $<10$ & 80 & 7 & .1 & 310 \\
\hline JUL & 1 & 1 & 10 & 78 & 0 & .0 & 450 \\
\hline $\begin{array}{l}08 \cdots \\
\text { MAY }: 1977\end{array}$ & 0 & 0 & 20 & 55 & 1 & .7 & 370 \\
\hline $25 \ldots$ & 1 & 0 & 10 & 54 & 7 & .0 & 410 \\
\hline
\end{tabular}


TABLE 4. CHEMICAL AND BACTERIOLOGICAL ANALYSES FOR GROUND- AND SURFACE-WATER SAMPLES FROM THE EUREKA SPRINGS LANDFILL - CONTINUED

\begin{tabular}{|c|c|c|c|c|c|c|c|}
\hline & $\begin{array}{l}\text { ARSENIC } \\
\text { TOTAL } \\
\text { (UG/L }\end{array}$ & $\begin{array}{l}\text { CADMIUM } \\
\text { TOTAL } \\
\text { RECOV- } \\
\text { ERABLE } \\
\text { IUG/L }\end{array}$ & $\begin{array}{l}\text { CHRO- } \\
\text { MYUM, } \\
\text { TOTAL } \\
\text { RECOV- } \\
\text { ERABLE } \\
\text { IUG/L }\end{array}$ & $\begin{array}{l}\text { COPPER, } \\
\text { TOTAL } \\
\text { RECOV- } \\
\text { ERABLE } \\
\text { (UG/L }\end{array}$ & $\begin{array}{l}\text { LEAD, } \\
\text { TOTAL } \\
\text { RECOV- } \\
\text { ERABLE } \\
\text { (UG/L }\end{array}$ & $\begin{array}{l}\text { MERCURY } \\
\text { TOPAL } \\
\text { RECOV- } \\
\text { ERABLE } \\
\text { IUG/L }\end{array}$ & $\begin{array}{l}\text { ZINC, } \\
\text { TOTAL } \\
\text { RECOV- } \\
\text { ERABLE } \\
\text { IUG/L }\end{array}$ \\
\hline & $\begin{array}{l}\text { AS AS) } \\
(01002)\end{array}$ & $\begin{array}{r}\text { AS CD }) \\
(01027)\end{array}$ & $\begin{array}{l}\text { AS CR) } \\
(01034)\end{array}$ & $\begin{array}{l}\text { AS CU) } \\
(01042 .)\end{array}$ & $\begin{array}{r}\text { AS PB) } \\
(01051)\end{array}$ & $\begin{array}{l}\text { AS HG) } \\
(71900)\end{array}$ & $\begin{array}{l}\text { AS ZN) } \\
(01092)\end{array}$ \\
\hline
\end{tabular}

280116082193601 - EUREKA SPRINGS LF 23 GREEN (LAT 280116 LONG 0821936.01 )

\begin{tabular}{|c|c|c|c|c|c|c|c|}
\hline $03 . \cdots$ & 0 & 1 & $<10$ & 9 & 17 & .2 & 150 \\
\hline MAR & 0 & 2 & $<10$ & 7 & 21 & .0 & 440 \\
\hline$\underset{A U G}{28} \cdots$ & 0 & 0 & $<10$ & 9 & 11 & .0 & 32 \\
\hline $\begin{array}{l}18 \ldots . . \\
D E C\end{array}$ & 0 & 1 & $<10$ & 10 & 2 & .4 & $50 c$ \\
\hline $\begin{array}{l}01 \cdots \cdots \\
\text { APR } \because 1976\end{array}$ & 0 & 0 & $<10$ & 4 & 5 & .0 & 340 \\
\hline $\begin{array}{l}05 \ldots \\
\text { JUL }\end{array}$ & 1 & 0 & 20 & 2 & 0 & .3 & 300 \\
\hline $\begin{array}{l}08 \cdots \\
\text { MAY }, 1977\end{array}$ & 0 & 0 & 20 & 0 & 2 & .6 & 260 \\
\hline $25 \ldots$ & 1 & 0 & 10 & 2 & 5 & .0 & 230 \\
\hline
\end{tabular}

280117082193201 - EUREKA SPRINGS LF 24 GREY (LAT 280117 LONG 0821932.01 )

\begin{tabular}{|c|c|c|c|c|c|c|c|}
\hline APR: 1976 & 0 & 0 & $<10$ & 5 & 3 & .4 & 340 \\
\hline MAY $13 . \cdots 1977$ & 0 & 0 & 20 & 2 & 9 & .2 & 400 \\
\hline $25 \ldots$ & 1 & 0 & 10 & 2 & 8 & .0 & 460 \\
\hline
\end{tabular}

280051082202901 - EUREKA SPRINGS LF 72 (LAT 280051 LONG 0822029.01 )

\begin{tabular}{|c|c|c|c|c|c|c|c|}
\hline $\begin{array}{l}\text { SEP } 1974 \\
\text { O4. } 1975 \\
\text { JAN } 197\end{array}$ & 1 & 0 & $<10$ & 4 & 4 & .2 & 30 \\
\hline $\begin{array}{l}24 \\
A \cup G\end{array}$ & 1 & 0 & 10 & 9 & 12 & .1 & 40 \\
\hline $18 \cdots$ & 0 & 0 & $<10$ & 6 & 3 & .2 & 160 \\
\hline $\begin{array}{l}03 \cdots \cdots 1976 \\
A P R: 197\end{array}$ & 1 & 0 & $<10$ & 1 & 0 & 1.1 & 400 \\
\hline $\begin{array}{l}05 \ldots \\
\text { JUL }\end{array}$ & 1 & 0 & 20 & 1 & 0 & .2 & 70 \\
\hline $\begin{array}{l}09 \ldots \\
\text { MAY } 1977\end{array}$ & 0 & 0 & 10 & 0 & 2 & 1.1 & 130 \\
\hline $25 \ldots$ & 2 & 0 & 10 & 0 & 8 & -- & 320 \\
\hline
\end{tabular}


TABLE 4. CHEMICAL AND BACTERIOLOGICAL ANALYSES FOR GROUND- AND SURFACE-WATER SAMPLES FROM THE EUREKA SPRINGS LANDFILL - CONTINUED

\begin{tabular}{|c|c|c|c|c|c|c|c|}
\hline & $\begin{array}{l}\text { ARSENIC } \\
\text { TOTAL } \\
\text { IUG/L }\end{array}$ & $\begin{array}{l}\text { CADMIUM } \\
\text { TOTAL } \\
\text { RECOV- } \\
\text { ERABLE } \\
\text { (UG/L }\end{array}$ & $\begin{array}{l}\text { CHRO- } \\
\text { MIUM, } \\
\text { TOTAL } \\
\text { RECOV- } \\
\text { ERABLE } \\
\text { (UG/L }\end{array}$ & $\begin{array}{l}\text { COPPER, } \\
\text { TOTAL } \\
\text { RECOV- } \\
\text { ERABLE } \\
\text { (UG/L }\end{array}$ & $\begin{array}{l}\text { LEAD, } \\
\text { TOTAL } \\
\text { RECOV- } \\
\text { ERABLE } \\
\text { IUG/L }\end{array}$ & $\begin{array}{l}\text { MERCURY } \\
\text { TOTAL } \\
\text { RECOV- } \\
\text { ERABLE } \\
\text { IUG/L }\end{array}$ & $\begin{array}{l}\text { ZINC, } \\
\text { TOTAL } \\
\text { RECOV- } \\
\text { ERABLE } \\
\text { IUG/L }\end{array}$ \\
\hline DATE & $\begin{array}{l}\text { AS AS) } \\
\left(\begin{array}{lll}0 & 1002\end{array}\right)\end{array}$ & $\begin{array}{l}\text { AS CD }) \\
(01027)\end{array}$ & $\begin{array}{l}\text { AS CR) } \\
(01034)\end{array}$ & $\begin{array}{l}\text { AS CU) } \\
(01042)\end{array}$ & $\begin{array}{r}A S P B) \\
(010511\end{array}$ & $\begin{array}{l}\text { AS HG) } \\
(71900)\end{array}$ & $\begin{array}{l}\text { AS ZN) } \\
(01092)\end{array}$ \\
\hline
\end{tabular}

280052082202701 - EUREKA SPRINGS LF 79 (LAT 280052 LONG 0822027.01 )

APR, 1975

$\begin{array}{llllllll}02 \ldots & 1 & 1 & 10 & 37 & 16 & .1 & 70\end{array}$

280052082202901 - EUREKA SPRINGS LF 80 (LAT 280052 LONG 0822029.01 )

SEP , 1974

JAN: 1975

$24 \ldots . . .4$

DEC

05...

APR, 1976

MAY $: 1977$

$31 \ldots 3$

1

$1<10$

5

27

.1

60

$0 \quad 40 \quad 13$

10

.5

40

$0<10 \quad 22$

24

1.4

20

5

5

60

19

24

.2

80

3

9

10

47

150

.420000

280052082202902 - EUREKA SPRINGS LF 81 (LAT 280052 LONG 08220.29 .02 )

JAN, 1975

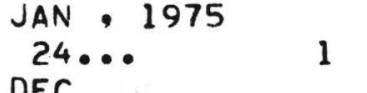

DEC

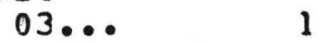

APR , 1976

$07 \ldots 1$

JUL

3

0
2
1

10
$<10$
30

34

50

.1

1900

09...

3

1

20

18

38

.3

6600

280057082203903 - EUREKA SPRINGS LF 96 (LAT 280057 LONG 0822039.03 )

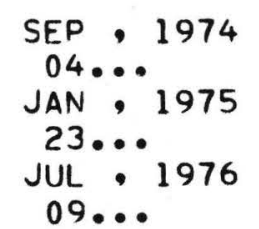

1
1
4

1

$<10$
20

22

24

.2

2100

38

18

.3

3800

$09 . .$.

4

5

10

4
7

0
13

.1

160

.420

$\begin{array}{llll}41 & 120 & .5 & 3300\end{array}$ 
TABLE 4. CHEMICAL AND BACTERIOLOGICAL ANALYSES FOR GROUND- AND SURFACE-WATER SAMPLES FROM THE EUREKA SPRINGS LANDFILL - CONTINUED

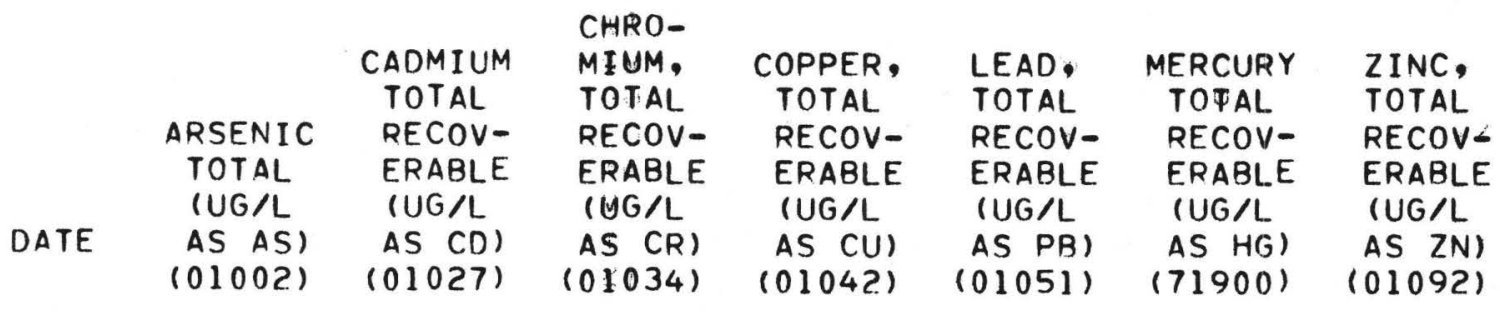

280057082203901 - EUREKA SPRINGS LF 98 (LAT 280057 LONG 0822039.01 )

APR , 1976

$\begin{array}{llllllll}07 \ldots & 2 & 1 & 20 & 7 & 16 & .4 & 1800\end{array}$

280059082201201 - EUREKA SPRINGS LF 104 (LAT 280059 LONG 0822012.01 )

\begin{tabular}{|c|c|c|c|c|c|c|c|}
\hline $\begin{array}{l}\text { SEP }, 1974 \\
04 \ldots \cdots\end{array}$ & 3 & 1 & $<10$ & 5 & 28 & .1 & 9 \\
\hline DEC $23 \cdots$ & 4 & 1 & 60 & 22 & 17 & .7 & 140 \\
\hline $\begin{array}{l}03 \cdots \\
\text { APR }, 1976\end{array}$ & 4 & 0 & $<10$ & 4 & 0 & .7 & 80 \\
\hline $07 \ldots$ & 3 & 0 & 30 & 4 & 0 & , & 140 \\
\hline
\end{tabular}

280059082202201 - EUREKA SPRINGS LF 107 (LAT 280059 LONG 0822022.01 )

APR , 1975

$\begin{array}{llllllll}01 \ldots & 3 & 1 & <10 & 11 & 44 & .1 & 70\end{array}$

280059082202202 - EUREKA SPRINGS LF 108 (LAT 280059 LONG 0822022.02 )

\begin{tabular}{|c|c|c|c|c|c|c|c|}
\hline $\begin{array}{l}\text { SEP , } 1974 \\
04 \ldots .\end{array}$ & 1 & 2 & $<10$ & 4 & 24 & .2 & 0 \\
\hline $\begin{array}{l}\text { JAN, } 1975 \\
23 \ldots . . \\
\text { APR }\end{array}$ & 1 & 0 & 10 & 8 & 4 & .1 & 10 \\
\hline $01 \ldots$ & 3 & 0 & 20 & 56 & 39 & .3 & 250 \\
\hline
\end{tabular}

280103082202802 - EUREKA SPRINGS LF 129 (LAT 280103 LONG 0822028.02 )

$\begin{array}{cccccccc}\text { JUL } & 1976 & 11 & 1 & 20 & 5 & 10 & 1.2\end{array}$


TABLE 4. CHEMICAL AND BACTERIOLIOGICAL ANALYSES FOR GROUND- AND SURFACE-WATER SAMPLES FROM THE EUREKA SPRINGS LANDF ILL - CONTINUED

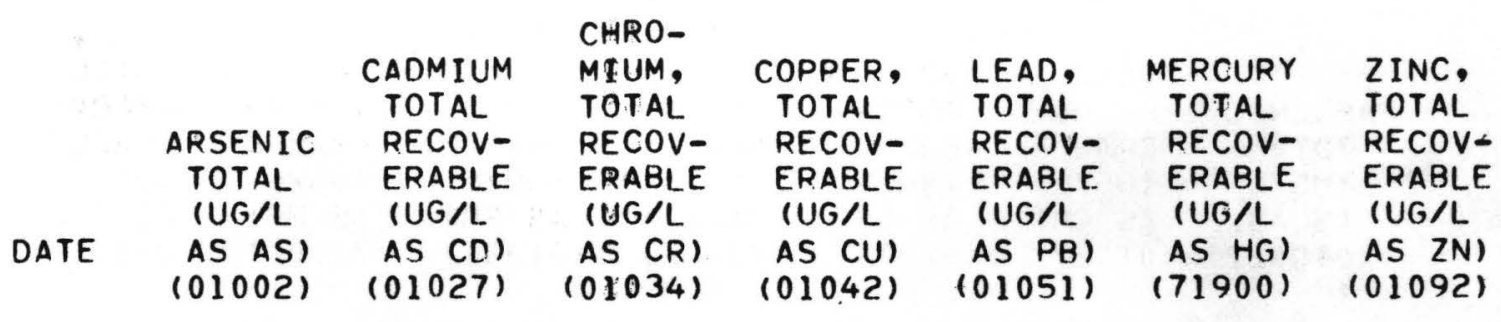

280103082202801 - EUREKA SPRINGS LF 130 (LAT 280103 LONG 0822028.01 )

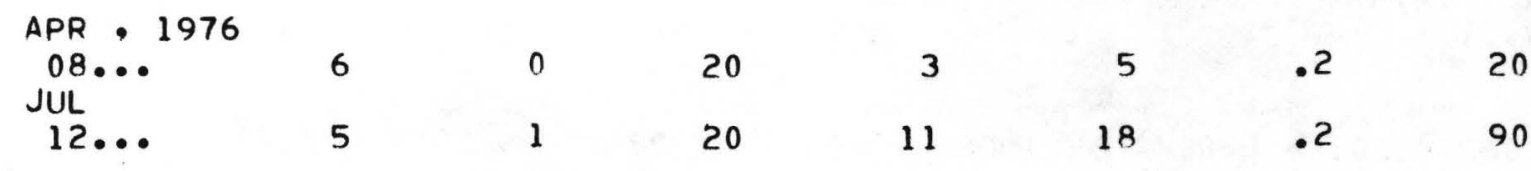

280108082194201 - EUREKA SPRINGS LF 148 (LAT 280108 LONG 0821942.01 )

SEP 1974

$\begin{array}{llllllll}03 . . & 2 & 11 & <10 & 5 & 120 & .2 & 80\end{array}$

280209082193901 - EUREKA SPRINGS LF 148 A (LAT 280209 LONG 0821939.01$)$

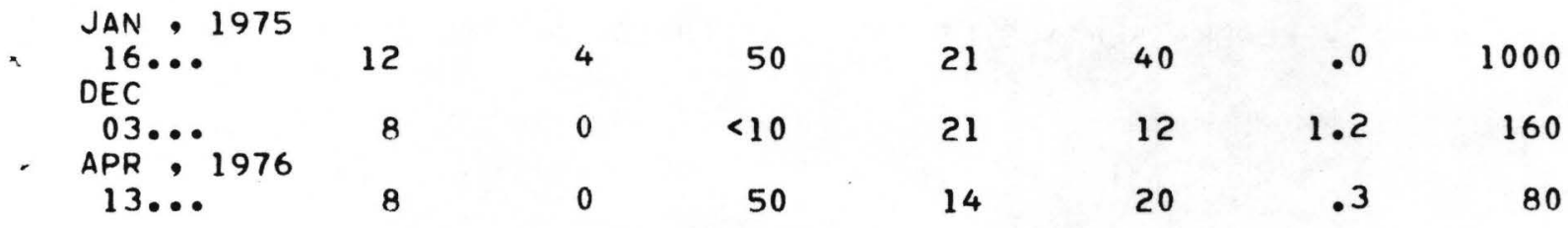

280116082193502 - EUREKA SPRINGS LF 149 (LAT 280116 LONG 0821935.02 )

\begin{tabular}{|c|c|c|c|c|c|c|c|}
\hline $\begin{array}{l}\text { JAN }, 1975 \\
\text { I6... } \\
\text { MAR }\end{array}$ & 0 & 6 & 20 & 19 & 33 & .0 & 18000 \\
\hline $\begin{array}{l}28 \ldots \\
\text { JUL }: 1976\end{array}$ & 0 & 10 & $<10$ & 8 & 46 & .1 & 4700 \\
\hline $09 \ldots$ & 0 & 4 & 20 & 12 & 64 & .6 & 13000 \\
\hline
\end{tabular}

280116082193501 - EUREKA SPRINGS LF 150 (LAT 280116 LONG 0821935.01 )

JUL , 1976

\begin{tabular}{|c|c|c|c|c|c|c|c|}
\hline MAY $: 1977$ & 0 & 0 & 20 & 0 & 4 & .2 & 60 \\
\hline $31 \ldots$ & 3 & 22 & 170 & 22 & 64 & .6 & 230 \\
\hline
\end{tabular}


TABLE 4. CHEMICAL AND BACTERIOLOGICAL ANALYSES FOR GROUND- AND SURFACE-WATER SAMPLES FROM THE EUREKA SPRINGS LANDF ILL - CONTINUED

\begin{tabular}{|c|c|c|c|c|c|c|c|c|c|c|}
\hline & $\begin{array}{l}\text { NITRO- } \\
\text { GEN: } \\
\text { ORGANIC } \\
\text { TOTAL } \\
\text { IMG/L }\end{array}$ & $\begin{array}{l}\text { NITRO- } \\
\text { GEN, } \\
\text { AMMONIA } \\
\text { DIS- } \\
\text { SOLVED } \\
\text { IMG/L }\end{array}$ & $\begin{array}{l}\text { NITRO- } \\
\text { GEN, } \\
\text { AMMONIA } \\
\text { TOTAL } \\
\text { IMG/L }\end{array}$ & $\begin{array}{l}\text { NITRO- } \\
\text { GEN, } \\
\text { NITRITE } \\
\text { DIS- } \\
\text { SOLVED } \\
\text { IMG/L }\end{array}$ & $\begin{array}{l}\text { NITRO- } \\
\text { GEN, } \\
\text { NITRI TE } \\
\text { TOTAL } \\
\text { IMG/L }\end{array}$ & $\begin{array}{c}\text { NITRO- } \\
\text { GEN, } \\
\text { NITRATE } \\
\text { DIS- } \\
\text { SOLVED } \\
\text { IMG LL }\end{array}$ & $\begin{array}{l}\text { NITRO- } \\
\text { GEN, } \\
\text { NITRATE } \\
\text { TOTAL } \\
\text { IMG/L }\end{array}$ & $\begin{array}{l}\text { PHOS- } \\
\text { PHORUS, } \\
\text { TOTAL } \\
\text { (MG/L }\end{array}$ & $\begin{array}{l}\text { PHOS- } \\
\text { PHORUS, } \\
\text { DIS- } \\
\text { SOLVED } \\
\text { IMG/L }\end{array}$ & $\begin{array}{l}\text { PHOS- } \\
\text { PHORUS, } \\
\text { ORTHO } \\
\text { DIS- } \\
\text { SOLVED } \\
\text { IMG/L }\end{array}$ \\
\hline DATE & $\begin{array}{l}\text { AS N) } \\
(00605)\end{array}$ & $\begin{array}{l}\text { AS N) } \\
(00608)\end{array}$ & $\begin{array}{l}\text { AS N) } \\
(00610)\end{array}$ & $\begin{array}{l}\text { AS N) } \\
(00613)\end{array}$ & $\begin{array}{l}\text { AS N) } \\
(00615)\end{array}$ & $\begin{array}{l}\text { AS N) } \\
(00618)\end{array}$ & $\begin{array}{c}\text { AS N) } \\
(00620)\end{array}$ & $\begin{array}{c}\text { AS P) } \\
(00665)\end{array}$ & $\begin{array}{l}\text { AS P) } \\
(00666)\end{array}$ & $\begin{array}{c}\text { AS P) } \\
(00671)\end{array}$ \\
\hline
\end{tabular}

280056082192501 - EUREKA SPRINGS LF 1 (LAT 280056 LONG 0821925.01 )

\begin{tabular}{|c|c|c|c|c|c|c|c|c|c|c|}
\hline MAY 1977 & . 39 & $\cdots$ & .09 & $-\infty$ & .00 & -- & .02 & .13 & -- & $-\infty$ \\
\hline $26 \ldots$ & .07 & .47 & - & .02 & -- & .03 & - & .49 & .01 & .00 \\
\hline
\end{tabular}

280101082192801 - EUREKA SPRINGS LF 6 (LAT 280101 LONG 0821928.01 )

\begin{tabular}{|c|c|c|c|c|c|c|c|c|c|c|}
\hline $\begin{array}{l}\text { AUG } 1975 \\
19 . . .\end{array}$ & $4 \cdot 2$ & .59 & -- & .00 & -- & .04 & -- & .26 & .07 & .00 \\
\hline 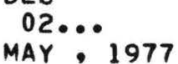 & 1.8 & 2.6 & -- & .00 & $\cdots$ & .02 & -- & 1.8 & .08 & .13 \\
\hline $26 \ldots$ & 1.7 & 1.7 & $-\infty$ & .00 & $-\infty$ & .04 & -- & 4.0 & .20 & .03 \\
\hline
\end{tabular}

280104082193001 - EUREKA SPRINGS LF 7 (LAT 280104 LONG 0821930.01 )

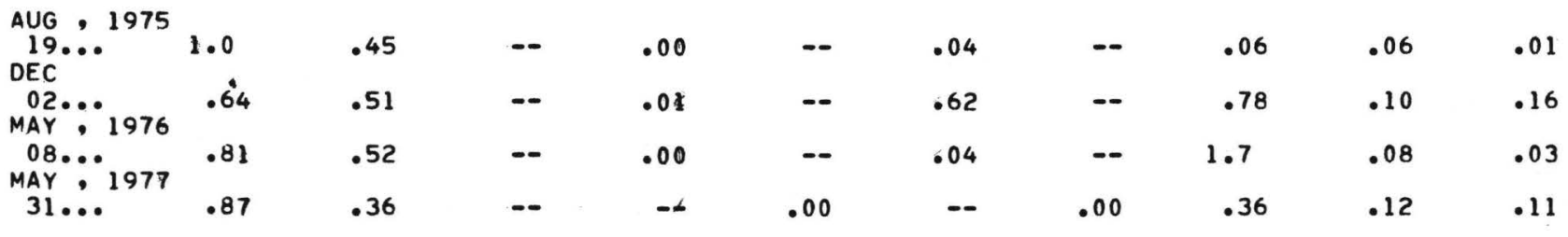

280103082193401 - EUREKA SPRINGS LF \& (LAT 280103 LONG 0821934.01 )

\begin{tabular}{|c|c|c|c|c|c|c|c|c|c|c|}
\hline DEC & .18 & & -- & & -- & & -- & 1.6 & .04 & .00 \\
\hline $\begin{array}{l}02 \ldots 1976 \\
\text { JUL } 1976\end{array}$ & .47 & .26 & -- & .02 & - & .00 & -- & 1.3 & .19 & .07 \\
\hline $12 \ldots$ & .93 & 1.9 & - & .00 & $-\infty$ & .07 & - & 4.0 & .11 & .06 \\
\hline
\end{tabular}


TABLE 4. CHEMICAL AND BACTERIOLOGICAL ANALYSES FOR GROUND- AND SURFACE-WATER SAMPLES FROM THE EUREKA SPRINGS LANDFILL - CONTINUED

\begin{tabular}{|c|c|c|c|c|c|c|c|c|c|c|}
\hline & $\begin{array}{l}\text { NITRO- } \\
\text { GEN, } \\
\text { ORGAN IC } \\
\text { TOTAL } \\
\text { (MGAL }\end{array}$ & $\begin{array}{l}\text { NITRO- } \\
\text { GEN, } \\
\text { AMMONIA } \\
\text { DIS- } \\
\text { SOLVED } \\
\text { IMG/L }\end{array}$ & $\begin{array}{l}\text { NITRO- } \\
\text { GEN, } \\
\text { AMMONIA } \\
\text { TOTAL } \\
\text { IMG/L }\end{array}$ & $\begin{array}{c}\text { NITROL } \\
\text { GEN, } \\
\text { NITRITE } \\
\text { DIS- } \\
\text { SOLVED } \\
\text { (MG/L }\end{array}$ & $\begin{array}{l}\text { NITRO- } \\
\text { GEN, } \\
\text { NITRITE } \\
\text { TOTAL } \\
\text { (MG/L }\end{array}$ & $\begin{array}{l}\text { NITRO- } \\
\text { GEN, } \\
\text { NITRATE } \\
\text { DIS- } \\
\text { SOLVED } \\
\text { (MG/L }\end{array}$ & $\begin{array}{l}\text { NITRO- } \\
\text { GEN, } \\
\text { NITRATE } \\
\text { TOTAL } \\
\text { (MG/L }\end{array}$ & $\begin{array}{l}\text { PHOS- } \\
\text { PHORUS, } \\
\text { TOTAL } \\
\text { (MG/L }\end{array}$ & $\begin{array}{l}\text { PHOS- } \\
\text { PHORUS, } \\
\text { DI\$- } \\
\text { SOLVED } \\
\text { IMG/L }\end{array}$ & $\begin{array}{l}\text { PHOS- } \\
\text { PHORUS, } \\
\text { ORTHO, } \\
\text { DIS- } \\
\text { SOLVED } \\
\text { (MG/L }\end{array}$ \\
\hline & $\begin{array}{l}\text { AS N) } \\
(00605)\end{array}$ & $\begin{array}{l}\text { AS N) } \\
(00608)\end{array}$ & $\begin{array}{l}\text { AS N) } \\
(00610)\end{array}$ & $\begin{array}{l}\text { AS N) } \\
(00613)\end{array}$ & $\begin{array}{l}\text { AS N) } \\
(00615)\end{array}$ & $\begin{array}{l}\text { AS N) } \\
(00618)\end{array}$ & $\begin{array}{c}\text { AS N) } \\
(00620)\end{array}$ & $\begin{array}{l}\text { AS P) } \\
(00665)\end{array}$ & $\begin{array}{l}\text { AS P) } \\
(00666)\end{array}$ & $\begin{array}{l}\text { AS P) } \\
(00671)\end{array}$ \\
\hline
\end{tabular}

280109082192401 - EUREKA SPRINGS LF 21 BASS (LAT 280109 LONG 0821924.01 )

\begin{tabular}{|c|c|c|c|c|c|c|c|c|c|}
\hline $\begin{array}{l}\text { SEP } 1974 \\
\text { O3... } \\
\text { JAN } 1975\end{array}$ & .00 & .04 & $-\infty$ & .00 & -- & .00 & -- & .12 & .09 \\
\hline MAR & .04 & .07 & -- & .00 & - & .00 & - & .05 & .05 \\
\hline$\stackrel{28}{28} \cdots$ & .04 & - & .06 & -6 & .00 & -- & .01 & .10 & $\cdots$ \\
\hline $\begin{array}{l}18 \ldots \\
D E C\end{array}$ & .00 & -- & .05 & - & .00 & - & .00 & .09 & -- \\
\hline $\begin{array}{l}01 \cdots 1976 \\
\text { APR }, 19\end{array}$ & .18 & - & .05 & -6 & .00 & -- & .00 & .08 & -- \\
\hline $\begin{array}{l}05 \ldots \\
\text { JUL }\end{array}$ & .18 & -- & .04 & $-\alpha$ & .00 & -- & .00 & .08 & -- \\
\hline $\begin{array}{l}08 \cdots \\
\text { MAY } 1977\end{array}$ & .18 & -- & .04 & -6 & .00 & - & .00 & .07 & \\
\hline $26 \ldots$ & .00 & -- & .03 & -6 & .00 & -- & .00 & .07 & - \\
\hline
\end{tabular}

280112082193101 - EUREKA SPRINGS LF 22 CATON (LAT 280112 LONG 0821931.01 )

\begin{tabular}{|c|c|c|c|c|c|c|c|c|}
\hline $\begin{array}{l}\text { FEB } 1974 \\
19 . \cdots \\
\text { SEP }\end{array}$ & .05 & -- & .04 & -6 & .00 & - & .00 & $-\infty$ \\
\hline $\begin{array}{l}03 \cdots 1975 \\
\text { JAN } 1970\end{array}$ & .03 & .01 & - & .04 & - & 1.3 & - & .08 \\
\hline $\begin{array}{l}16 \cdots \cdots \\
\text { MAR }\end{array}$ & .08 & .00 & - & .07 & -- & 1.5 & -- & .04 \\
\hline $\begin{array}{l}28 \bullet \cdots \\
\text {-AUG }\end{array}$ & .04 & - & .01 & -6 & .14 & - & 1.4 & .06 \\
\hline${ }_{D E C}^{18 \cdots}$ & .02 & -- & .00 & -6 & .12 & $-\infty$ & 1.4 & .04 \\
\hline $\begin{array}{l}01 \cdots 1976 \\
\text { APR } 197\end{array}$ & .12 & -- & .00 & -6 & .07 & $-\infty$ & 1.8 & .03 \\
\hline $\begin{array}{l}05 \cdots \cdots \\
\text { JUL }\end{array}$ & .48 & -- & .01 & -6 & .13 & -- & 1.3 & .04 \\
\hline MAY $\because 1977$ & $\cdot 24$ & -- & .00 & -6 & .07 & $\cdots$ & 1.7 & .03 \\
\hline $25 \ldots$ & .00 & -- & .00 & -6 & .10 & -- & 1.5 & .02 \\
\hline
\end{tabular}


TABLE 4. CHEMICAL AND BACTERIOUOGICAL ANALYSES FOR GROUND- AND SURFACE-WATER SAMPLES FROM THE EUREKA SPRINGS LANDFILL - CONTINUED

\begin{tabular}{|c|c|c|c|c|c|c|c|c|c|c|}
\hline & $\begin{array}{l}\text { NITRO- } \\
\text { GEN, } \\
\text { ORGANIC } \\
\text { TOTAL } \\
\text { IMG/L }\end{array}$ & $\begin{array}{l}\text { NITRO- } \\
\text { GEN, } \\
\text { AMMONIA } \\
\text { DIS- } \\
\text { SOLVED } \\
\text { IMG/L }\end{array}$ & $\begin{array}{l}\text { NI TRO- } \\
\text { GEN, } \\
\text { AMMONIA } \\
\text { TOTAL } \\
\text { IMG/L }\end{array}$ & $\begin{array}{l}\text { NITRO' } \\
\text { GEN, } \\
\text { NITRITE } \\
\text { DIS- } \\
\text { SOLVED } \\
\text { IMG/L }\end{array}$ & $\begin{array}{l}\text { NITRO- } \\
\text { GEN, } \\
\text { NITRITE } \\
\text { TOTAL } \\
\text { IMG/L }\end{array}$ & $\begin{array}{l}\text { NITRO- } \\
\text { GEN, } \\
\text { NITRATE } \\
\text { DIS- } \\
\text { SOLVED } \\
\text { IMGXL }\end{array}$ & $\begin{array}{l}\text { NITRO- } \\
\text { GEN, } \\
\text { NITRATE } \\
\text { TOTAL } \\
\text { IMG/L }\end{array}$ & $\begin{array}{l}\text { PHOS- } \\
\text { PHORUS, } \\
\text { TOTAL } \\
\text { IMG/L }\end{array}$ & $\begin{array}{l}\text { PHOS- } \\
\text { PHORUS, } \\
\text { DIS- } \\
\text { SOLVED } \\
\text { IMG }\end{array}$ & $\begin{array}{l}\text { PHOS- } \\
\text { PHORUS, } \\
\text { ORTHO, } \\
\text { DIS- } \\
\text { SOLVED } \\
\text { IMG }\end{array}$ \\
\hline ATE & $\begin{array}{l}\text { AS N) } \\
(00605)\end{array}$ & $\begin{array}{l}\text { AS N) } \\
(00608)\end{array}$ & $\begin{array}{l}\text { AS N) } \\
(00610)\end{array}$ & $\begin{array}{l}\text { AS N) } \\
(00613)\end{array}$ & $\begin{array}{l}\text { AS NI } \\
(00615)\end{array}$ & $\begin{array}{l}\text { AS N) } \\
(00618)\end{array}$ & $\begin{array}{l}\text { AS N) } \\
(00620)\end{array}$ & $\begin{array}{l}\text { AS P) } \\
(00665)\end{array}$ & $\begin{array}{l}\text { AS P) } \\
(00666)\end{array}$ & $\begin{array}{l}\text { AS P) } \\
(00671)\end{array}$ \\
\hline
\end{tabular}

280116082193601 - EUREKA SPRINGS LF 23 GREEN (LAT 280116 LONG 0821936.01 )

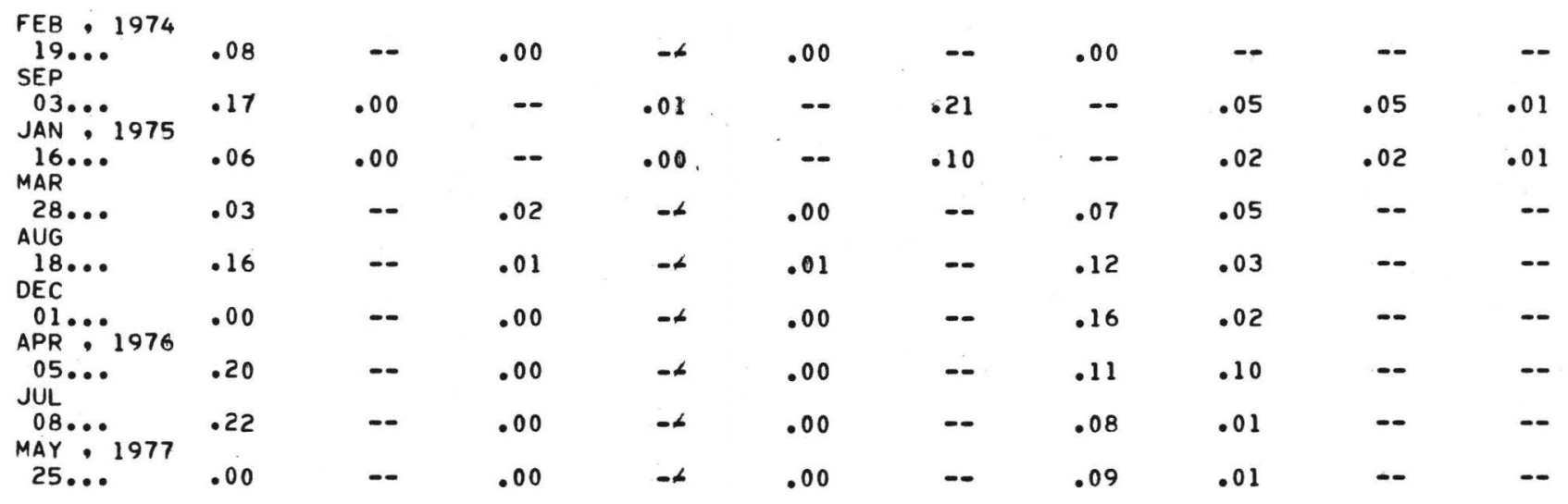

280127082193201 - EUREKA SPRINGS LF 24 GREY (LAT 280117 LONG 0821932.01 )

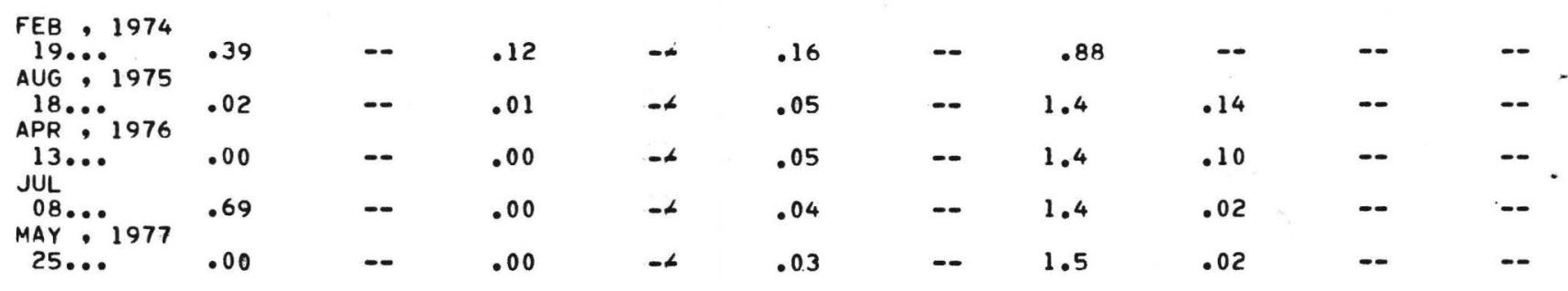

280044082202501 - EUREKA SPRINGS LF 68 (LAT 280044 LONG 0822025.01 )

APR, 1975

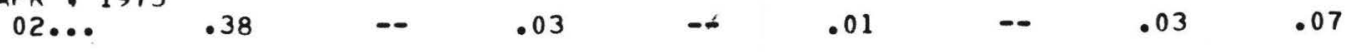


TABLE 4. CHEMICAL AND BACTERIOLOGICAL ANALYSES FOR GROUND- AND SURFACE-WATER SAMPLES FROM THE EUREKA SPRINGS LANDFILL - CONTINUED

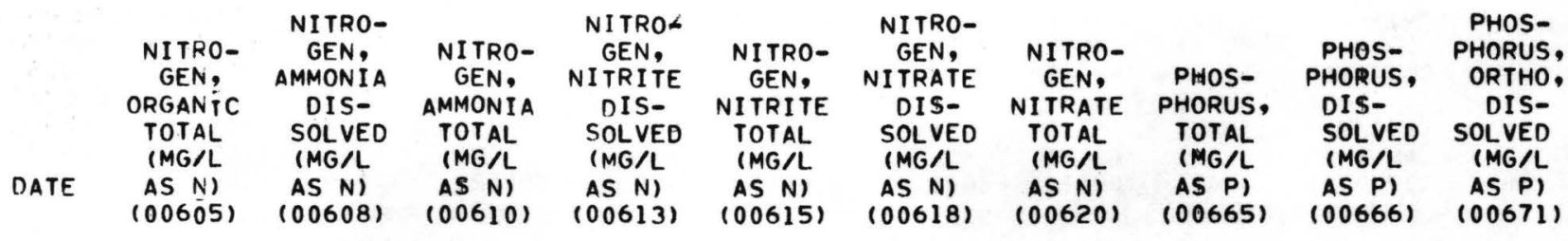

280051082202901 - EUREKA SPRINGS LF 72 (LAT 280051 LONG 0822029.01 )

\begin{tabular}{|c|c|c|c|c|c|c|c|c|c|c|}
\hline SEP $\cdot 1974$ & .15 & .02 & -- & .01 & -- & .07 & -- & .07 & .06 & .03 \\
\hline $\begin{array}{l}24 \ldots \\
\text { AUG }\end{array}$ & .00 & -- & .01 & -6 & .01 & -- & .00 & .06 & -- & -- \\
\hline $\begin{array}{l}18 \\
D E C\end{array}$ & .00 & -- & .01 & -6 & .02 & -- & .15 & .04 & -- & -- \\
\hline${ }_{\triangle P R}^{03 \cdots}{ }_{1976}$ & .14 & -- & .02 & -6 & .02 & -- & .18 & .05 & -- & $\cdots$ \\
\hline $\begin{array}{l}05 \ldots \\
\text { JUL }\end{array}$ & .08 & -- & .00 & - & .00 & -- & .00 & .05 & -- & -- \\
\hline MAY $\because 1977$ & .16 & -- & .00 & -6 & .01 & -- & .23 & .04 & -- & -- \\
\hline $25 \ldots$ & .00 & -- & .00 & - & .00 & -- & .02 & .03 & -- & -- \\
\hline
\end{tabular}


TABLE 4. CHEMICAL AND BACTERIOLOGICAL ANALYSES FOR GROUND- AND SURFACE-WATER SAMPLES FROM THE EUREKA SPRINGS LANDFILL - CONTINUED

\begin{tabular}{|c|c|c|c|c|c|c|c|c|c|c|}
\hline & $\begin{array}{l}\text { NITRO- } \\
\text { GEN: } \\
\text { ORGANIC } \\
\text { TOTAL }\end{array}$ & $\begin{array}{l}\text { NITRO- } \\
\text { GEN, } \\
\text { AMMONIA } \\
\text { DIS- } \\
\text { SOLVED }\end{array}$ & $\begin{array}{l}\text { NITRO- } \\
\text { GEN, } \\
\text { AMMONIA } \\
\text { TOTAL }\end{array}$ & $\begin{array}{l}\text { NI TRO- } \\
\text { GEN, } \\
\text { NI TRITE } \\
\text { DIS- } \\
\text { SOLVEO }\end{array}$ & $\begin{array}{l}\text { NITRO- } \\
\text { GEN, } \\
\text { NITRITE } \\
\text { TOTAL }\end{array}$ & $\begin{array}{c}\text { NITRO- } \\
\text { GEN, } \\
\text { NITRATE } \\
\text { DIS- } \\
\text { SOLVED }\end{array}$ & $\begin{array}{l}\text { NITRO- } \\
\text { GEN, } \\
\text { NITRATE } \\
\text { TOTAL }\end{array}$ & $\begin{array}{l}\text { PHOS- } \\
\text { PHORUS, } \\
\text { TOTAL }\end{array}$ & $\begin{array}{l}\text { PHOS- } \\
\text { PHORUS, } \\
\text { DIS- } \\
\text { SOLVED }\end{array}$ & $\begin{array}{l}\text { PHOS- } \\
\text { PHORUS, } \\
\text { ORTHO, } \\
\text { DIS- } \\
\text { SOLVED }\end{array}$ \\
\hline DATE & $\begin{array}{l}\text { AS N) } \\
(00605)\end{array}$ & $\begin{array}{l}\text { AS N) } \\
(00608)\end{array}$ & $\begin{array}{l}A S N) \\
(00610)\end{array}$ & $\begin{array}{l}\text { AS N) } \\
(00613)\end{array}$ & $\begin{array}{l}\text { AS N) } \\
(00615)\end{array}$ & $\begin{array}{l}\text { AS N) } \\
(00618)\end{array}$ & $\begin{array}{l}\text { AS N) } \\
(00620)\end{array}$ & $\begin{array}{l}\text { AS P) } \\
(00665)\end{array}$ & $\begin{array}{l}\text { AS P) } \\
(00666)\end{array}$ & $\begin{array}{l}\text { AS P) } \\
(00671)\end{array}$ \\
\hline
\end{tabular}

280052082202901 - EUREKA SPRINGS LF 80 (LAT 280052 LONG 0822029.01 )

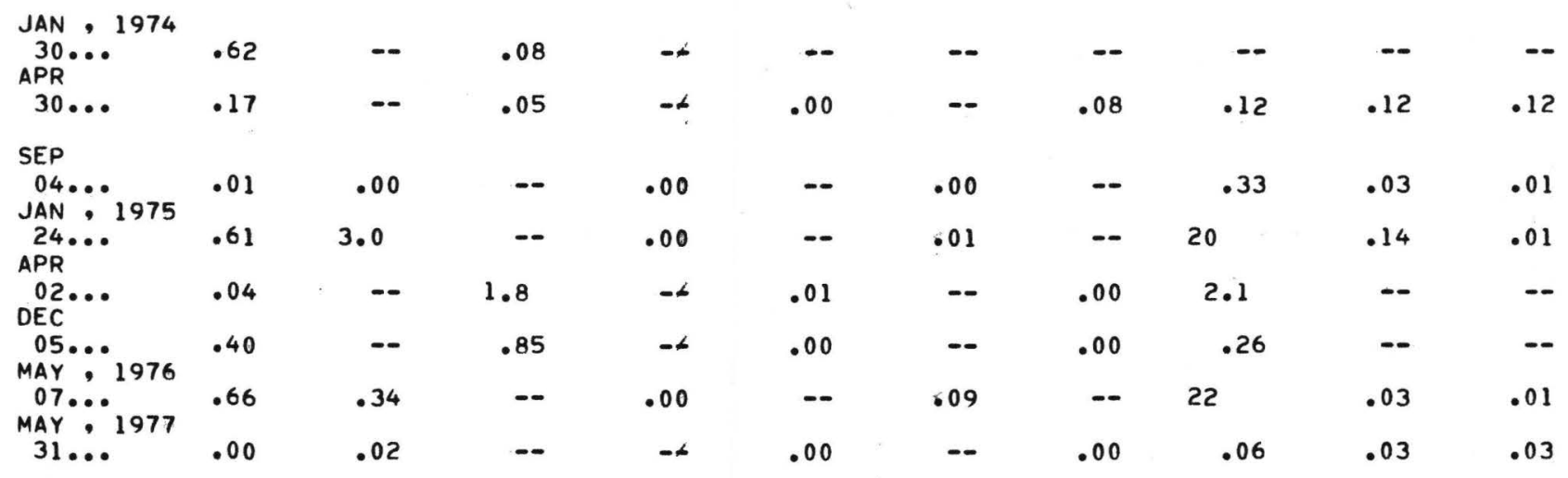

280052082202902 - EUREKA SPRINGS LF 81 (LAT 280052 LONG 0822029.02 )

\begin{tabular}{|c|c|c|c|c|c|c|c|c|c|c|}
\hline $30 \ldots$ & .60 & -- & .11 & -6 & .00 & $-\infty$ & .06 & $-\infty$ & .04 & .04 \\
\hline APR & & & & & & & & & & \\
\hline $30 \ldots$ & .54 & -- & .15 & $-\infty$ & .00 & -- & .35 & .04 & .04 & .04 \\
\hline JAN, 1975 & & & & & & & & & & \\
\hline $\begin{array}{l}24 \ldots \cdots \\
\text { APR }\end{array}$ & 3.6 & .04 & - & .00 & -- & .00 & -- & .17 & .05 & .01 \\
\hline $\begin{array}{l}02 \ldots . . \\
\text { DEC }\end{array}$ & .34 & -- & .21 & $-\infty$ & .00 & -- & .01 & .22 & -- & -- \\
\hline MAY $\because 1976$ & $1 \cdot 2$ & -- & 2.6 & $-\infty$ & .01 & -- & .03 & .30 & -- & -- \\
\hline $\begin{array}{l}07 \cdots \cdots \\
J U L\end{array}$ & $1 \cdot 3$ & .23 & - & .00 & -- & .08 & -- & .31 & .03 & .02 \\
\hline $09 \ldots$ & .52 & $-\infty$ & .32 & -6 & .00 & -- & .02 & .08 & -- & -- \\
\hline
\end{tabular}


TABLE 4. CHEMICAL AND BACTERIOLOGICAL ANALYSES FOR GROUND- AND SURFACE-WATER SAMPLES FROM THE EUREKA SPRINGS LANDFILL - CONTINUED

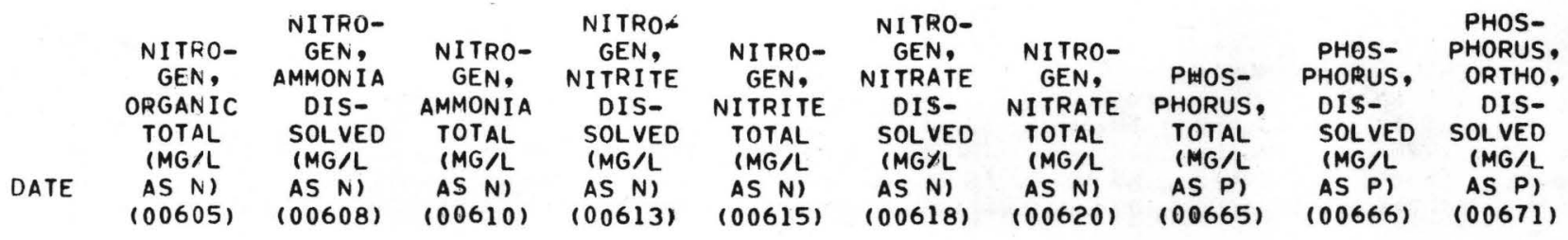

280057082203903 - EUREKA SPRINGS LF 96 (LAT 2800.57 LONG 0822039.03 )

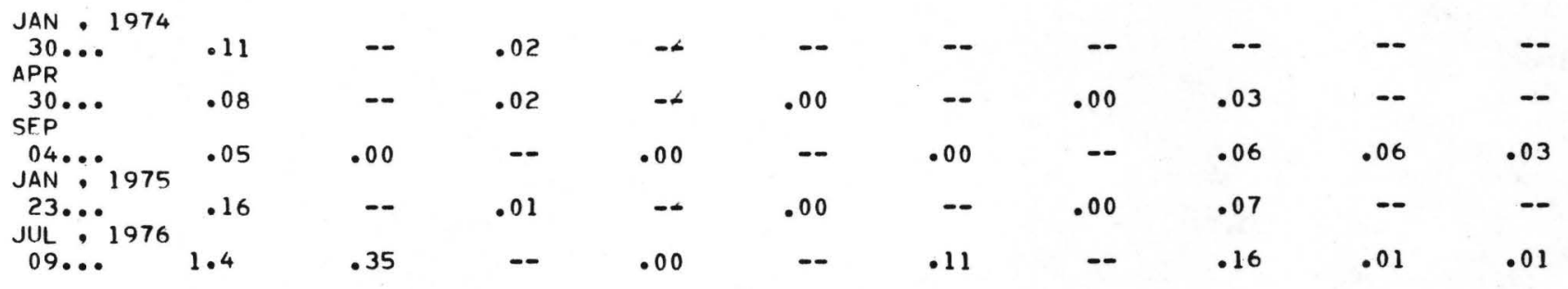

280057082203901 - EUREKA SPRINGS LF 98 (LAT 280057 LONG 0822039.01 )

\begin{tabular}{|c|c|c|c|c|c|c|c|c|c|c|}
\hline \multicolumn{11}{|l|}{ APR } \\
\hline $30 \ldots$ & .17 & -- & .20 & $-\infty$ & .00 & -- & .03 & .03 & .03 & .03 \\
\hline MAY, 1976 & & & & & & & & & & \\
\hline $07 \ldots$ & .05 & -- & .12 & $-\alpha$ & .00 & - & .02 & .08 & -- & -- \\
\hline
\end{tabular}

280059082201201 - EUREKA SPRINGS LF 104 (LAT 28 00 59 LONG 082 20 12.01)

SEP $: 1974$

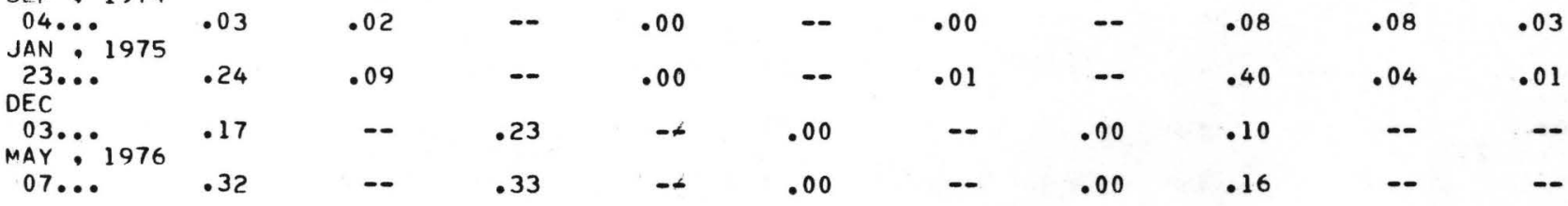

280059082202201 - EUREKA SPRINGS LF 107 (LAT 280059 LONG 0822022.01 )

APR, 1975

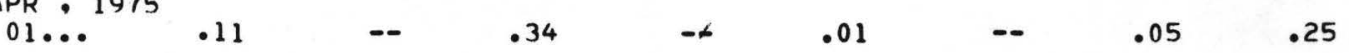


TABLE 4. CHEMICAL AND BACTERIOLOGICAL ANALYSES FOR GROUND- AND SURFACE-WATER SAMPLES FROM THE EUREKA SPRINGS LANDFILL - CONTINUED

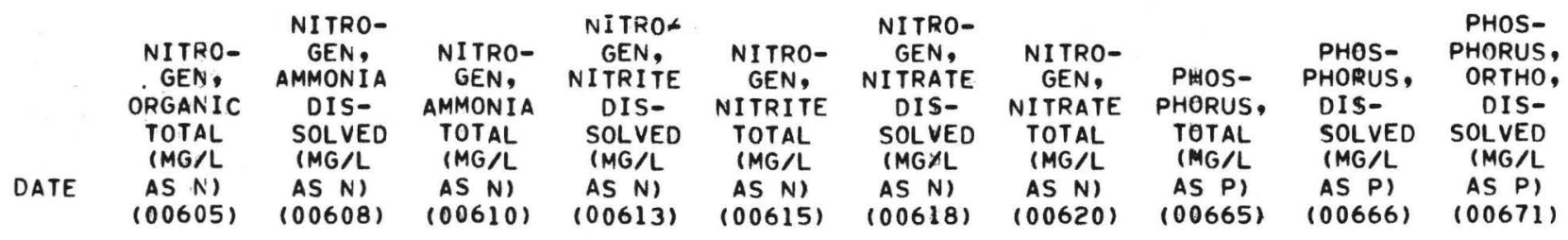

280059082202202 - EUREKA SPRINGS LF 108 (LAT 280059 LONG 0822022.02 )

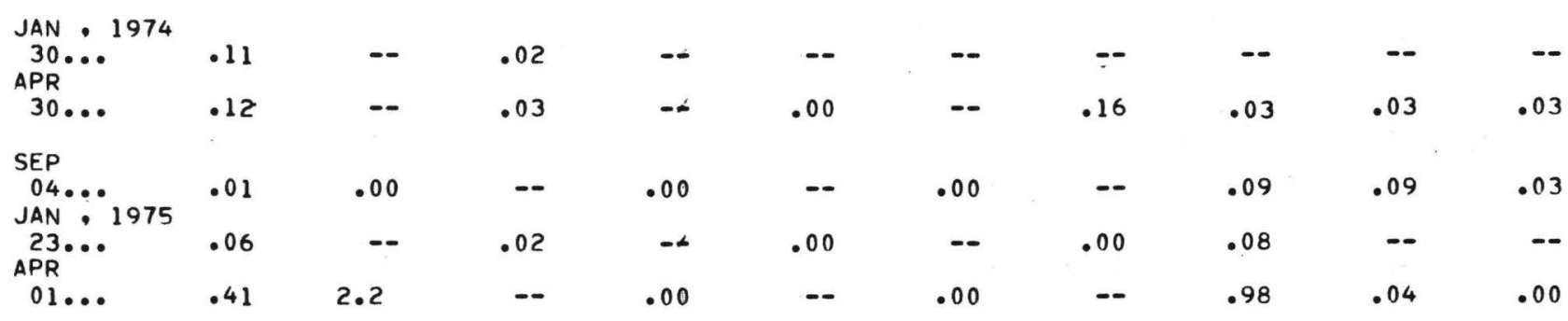

280103082202802 - EUREKA SPRINGS LF 129 (LAT 280103 LONG 0822028.02 )

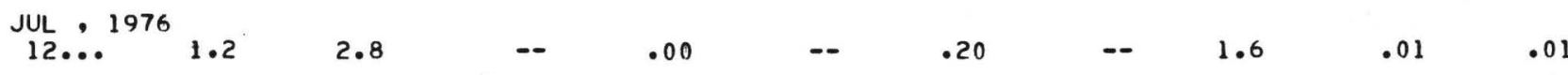

280103082202801 - EUREKA SPRINGS LF 130 (LAT 280103 LONG 0822028.01 )

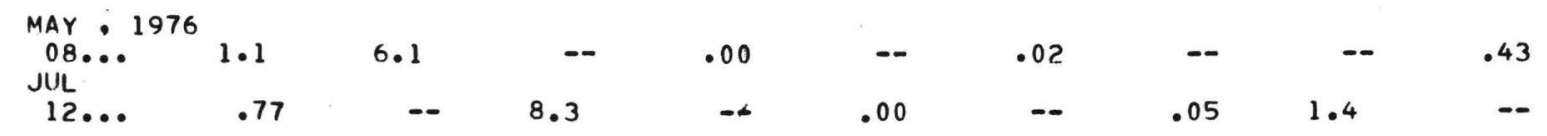

280108082194201 - EUREKA SPRINGS LF 148 (LAT 280108 LONG 0821942.01 )

FEB , 1974

\begin{tabular}{|c|c|c|c|c|c|c|c|c|c|c|}
\hline SEP $20 \cdots$ & .23 & .60 & -- & .00 & -- & .12 & -- & -- & - & .02 \\
\hline
\end{tabular}

28020908219390.1 - EUREKA SPRINGS LF 148 A (LAT 280209 LONG 0821939.01 )

DEC , 1975

\begin{tabular}{|c|c|c|c|c|c|c|c|c|c|c|}
\hline $\begin{array}{l}03 \cdots 1976 \\
A P R\end{array}$ & 1.2 & .70 & -- & .04 & - & .00 & -- & 2.0 & .74 & \\
\hline $13 \ldots$ & .64 & .96 & -- & .08 & - & .00 & -- & 2.8 & 1.8 & 1.3 \\
\hline
\end{tabular}




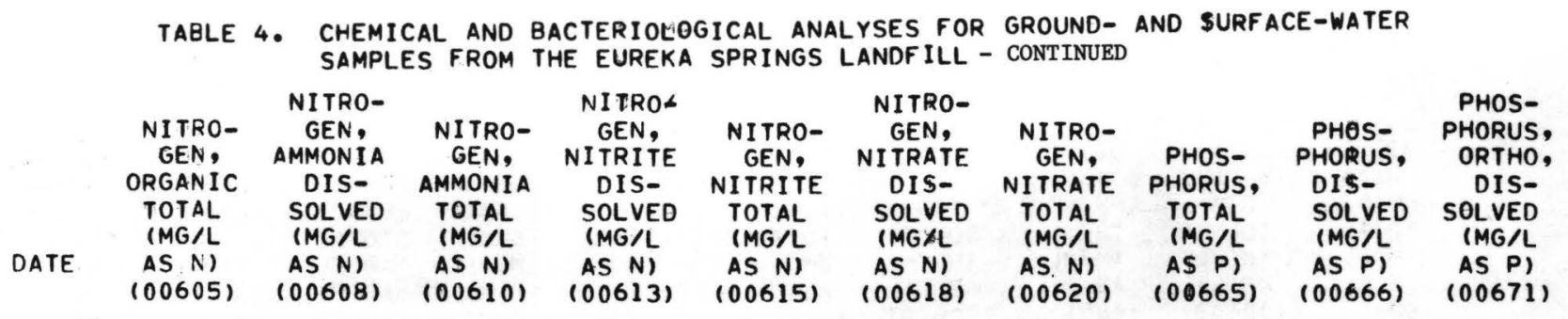

280116082193502 - EUREKA SPRINGS LF 149 (LAT 280116 LONG 0821935.02 )

\begin{tabular}{|c|c|c|c|c|c|c|c|c|c|c|}
\hline $\begin{array}{l}\text { JAN }, 1975 \\
\text { I6... } \\
\text { MAR }\end{array}$ & .80 & .13 & -- & .11 & $\cdots$ & .75 & - & .01 & .01 & .01 \\
\hline${ }_{D E C}^{28} \cdots$ & .71 & - & .10 & -6 & .05 & -- & 6.0 & .06 & $-\infty$ & -- \\
\hline $09 \ldots$ & .09 & $-\infty$ & .74 & $-\infty$ & .26 & -- & 140 & .04 & $-\infty$ & - \\
\hline
\end{tabular}

280116082193501 - EUREKA SPRINGS LF 150 (LAT 280116 LONG 0821935.01 )

FEB, 1974

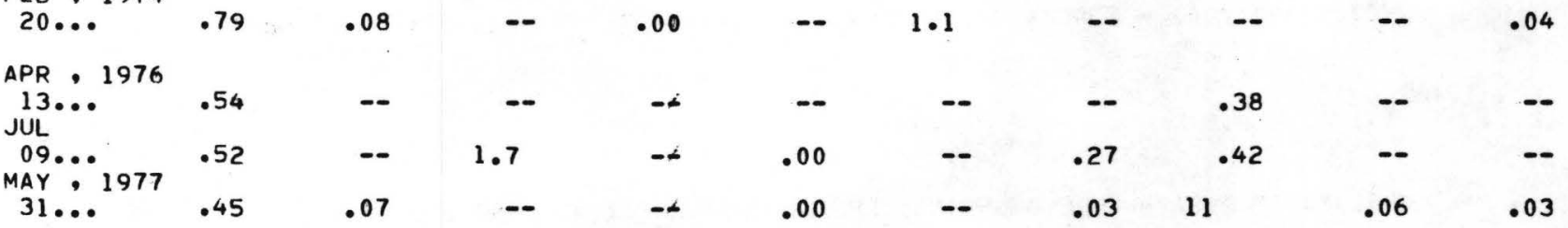

280102082202000 - EUREKA SPRINGS LF OXIDATION POND (LAT 280102 LONG 0822020 )

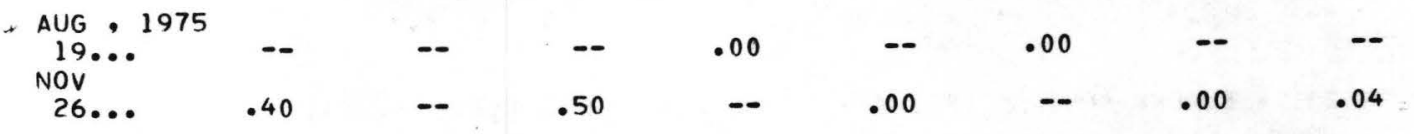

280058082202400 - EUREKA SPRINGS LF SW PERIMETER DITCH (LAT 280058 LONG 0822024 )

NOV 1975

$\begin{array}{lllllllllllllll}26.0 & 1.2 & -0 & .17 & -4 & .00 & 00 & .00 & 06\end{array}$ 
TABLE 4. CHEMICAL AND BACTERIOLOGICAL ANALYSES FOR GROUND- AND SURFACE-WATER SAMPLES FROM THE EUREKA SPRINGS LANDFILL - CONTINUED

\begin{tabular}{|c|c|c|c|c|c|c|c|}
\hline & $\begin{array}{l}\text { UXYGEN } \\
\text { DEMAND, } \\
\text { BIO- } \\
\text { CHEM- } \\
\text { ICAL, } \\
5 \text { DAY }\end{array}$ & $\begin{array}{l}\text { OXYGEN } \\
\text { DEMAND, } \\
\text { CHEM- } \\
\text { ICAL } \\
\text { (LOW } \\
\text { LEVEL.) }\end{array}$ & $\begin{array}{l}\text { OX } \$ G E N \\
\text { DEMAND, } \\
\text { CHEM- } \\
\text { ICAL } \\
\text { (HIGH } \\
\text { LEVEL) }\end{array}$ & $\begin{array}{l}\text { COLI- } \\
\text { FORM, } \\
\text { TOTAL, } \\
\text { IMMED. } \\
\text { ICOLS. } \\
\text { PER }\end{array}$ & $\begin{array}{l}\text { COLI- } \\
\text { FORM, } \\
\text { CON- } \\
\text { FIRMED }\end{array}$ & $\begin{array}{l}\text { COLI- } \\
\text { FORM, } \\
\text { FECAL, } \\
\text { EC } \\
\text { BROTH }\end{array}$ & $\begin{array}{l}\text { COLI- } \\
\text { FORM, } \\
\text { FECAL, } \\
0.45 \\
\text { UM-MF } \\
\text { (COLS. }\end{array}$ \\
\hline & $\begin{array}{l}(M G / L) \\
(00310)\end{array}$ & $\begin{array}{l}(M G / L) \\
(00335)\end{array}$ & $\begin{array}{l}(M G / L) \\
(00340)\end{array}$ & $\begin{array}{l}100 \mathrm{ML}) \\
(31501)\end{array}$ & $\begin{array}{c}\text { (MPN) } \\
(31505)\end{array}$ & $\begin{array}{l}\text { (MPN) } \\
(31615)\end{array}$ & $100 \mathrm{ML}$ \\
\hline
\end{tabular}

280056082192501 - EUREKA SPRINGS LF 1 (LAT 280056 LONG 082.19 25.01)

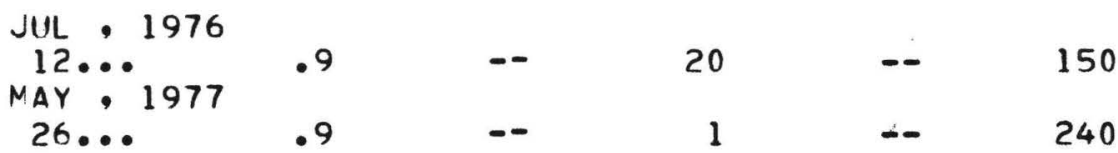

280101082192801 - EUREKA SPRINGS LF 6 (LAT 280101 LONG 0821928.01 )

\begin{tabular}{|c|c|c|c|c|c|c|c|}
\hline $\begin{array}{l}19 \ldots \\
\text { DEC }\end{array}$ & $4 \cdot 3$ & -- & 380 & -- & $<3$ & $<3$ & -4 \\
\hline $02 \ldots$ & 4.1 & -- & 25 & - & -- & - & -6 \\
\hline $\begin{array}{l}\text { NAY } 1977 \\
26 \ldots . .\end{array}$ & 3.2 & -- & 100 & - & 75 & 240 & \\
\hline
\end{tabular}

280104082193001 - EUREKA SPRINGS LF 7 (LAT 280104 LONG 0821930.01 )

\begin{tabular}{|c|c|c|c|c|c|c|c|}
\hline $\begin{array}{l}\text { AUE, } 1975 \\
19 . \cdots \\
\text { DEC }\end{array}$ & 2.0 & -- & 91 & -- & $<3$ & $<3$ & -- \\
\hline $\begin{array}{l}02 \ldots \cdots \\
\text { MAY }, 1976\end{array}$ & 1.3 & -- & 130 & -- & -- & -- & $-\infty$ \\
\hline $\begin{array}{l}08 \ldots \\
\text { MAY }, 1977\end{array}$ & 1.3 & -- & 95 & - & 4600 & 240 & \\
\hline $31 \ldots$ & $1 \cdot 2$ & -- & 13 & -- & 200 & 93 & \\
\hline
\end{tabular}

280103082193401 - EUREKA SPRINGS LF 8 (LAT 280103 LONG 0821934.01 )

\begin{tabular}{|c|c|c|c|c|c|c|c|}
\hline $\begin{array}{l}19 \ldots \\
\text { DEC }\end{array}$ & .4 & 7 & -- & - & $<3$ & $<3$ & -6 \\
\hline $02 \ldots$ & 1.6 & -- & 53 & -- & -- & -- & $-\infty$ \\
\hline $12 \ldots$ & 4.2 & -- & 210 & -- & 750 & 43 & \\
\hline
\end{tabular}


TABLE 4. CHEMICAL AND BACTERIOLOGICAL ANALYSES FOR GROUND- AND SURFACE-WATER SAMPLES FROM THE EUREKA SPRINGS LANDFILL - CONTINUED

\begin{tabular}{|c|c|c|c|c|c|c|c|}
\hline & $\begin{array}{l}\text { OXYGEN } \\
\text { DEMAND, } \\
\text { BIO- } \\
\text { CHEM- } \\
\text { ICAL, } \\
5 \text { DAY }\end{array}$ & $\begin{array}{l}\text { OXYGEN } \\
\text { DEMAND, } \\
\text { CHEM- } \\
\text { ICAL } \\
\text { (LOW } \\
\text { LEVEL) }\end{array}$ & $\begin{array}{l}\text { OX*GEN } \\
\text { DEMAND, } \\
\text { CHEM- } \\
\text { ICAL } \\
\text { (HIGH } \\
\text { LEVEL) }\end{array}$ & $\begin{array}{l}\text { COL I- } \\
\text { FORM, } \\
\text { TOTAL, } \\
\text { IMMED. } \\
\text { ICOLS• } \\
\text { PER }\end{array}$ & $\begin{array}{l}\text { COLI - } \\
\text { FORM, } \\
\text { CON- } \\
\text { FIRMED }\end{array}$ & $\begin{array}{l}\text { COL I- } \\
\text { FORM, } \\
\text { FECAL, } \\
\text { EC } \\
\text { BROTH }\end{array}$ & $\begin{array}{l}\text { COLI - } \\
\text { FORM, } \\
\text { FECAL, } \\
0.45 \\
\text { UM-MF } \\
\text { (COLS. }\end{array}$ \\
\hline IL & $\begin{array}{l}(M G / L) \\
(00310)\end{array}$ & $\begin{array}{l}\text { (MG/L) } \\
(00335)\end{array}$ & $\begin{array}{l}\text { (MGXL) } \\
(00340)\end{array}$ & $\begin{array}{l}100 \mathrm{ML}) \\
(31501)\end{array}$ & $\begin{array}{l}\text { (MPN) } \\
\text { (31505) }\end{array}$ & $\begin{array}{l}\text { (MPN) } \\
(31615)\end{array}$ & $\begin{array}{l}100 \mathrm{ML}) \\
(31616)\end{array}$ \\
\hline
\end{tabular}

280109082192401 - E.UREKA SPRINGS LF 21 BASS (LAT 280109 LONG 0821924.01 )
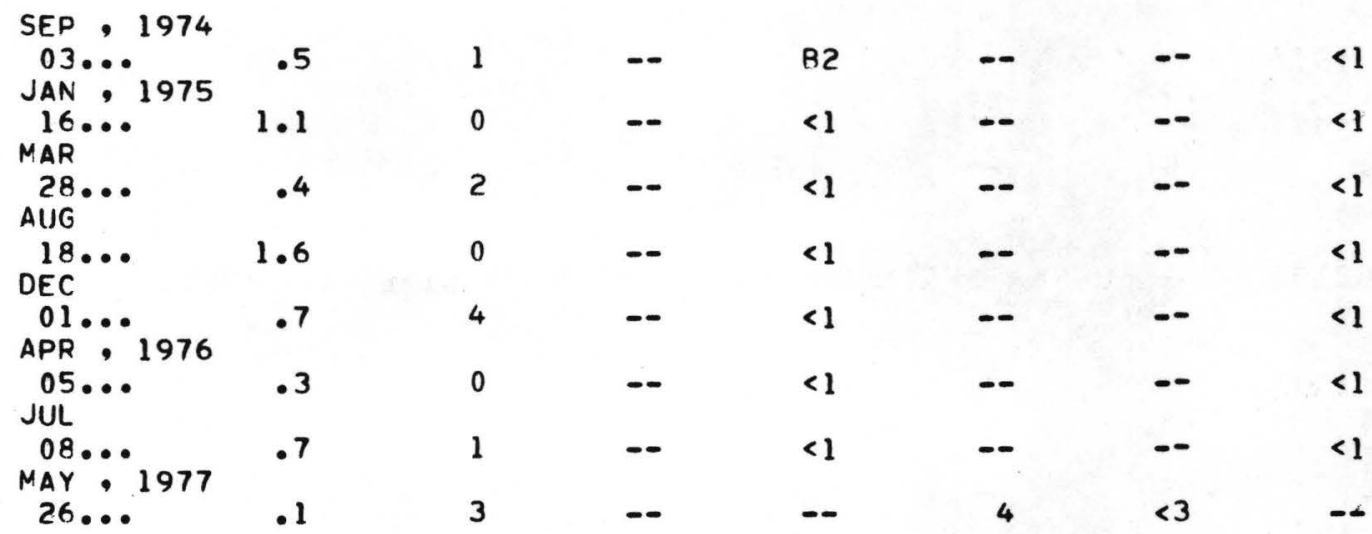

280112082193101 - EUREKA SPRINGS LF 22 CATON (LAT 280112 LONG 0821931.01 )

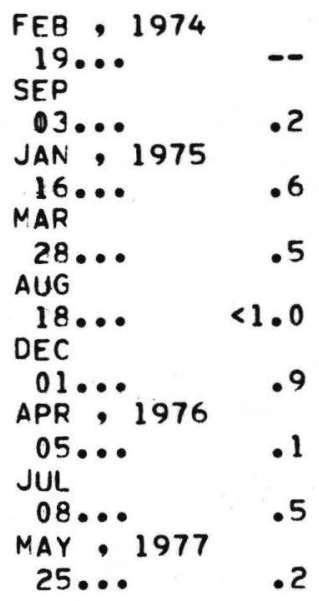

$\begin{array}{lrlll}-- & B 8 & - & -- & B 2 \\ -- & B 15 & -- & -- & <1 \\ -- & <1 & - & -- & <1 \\ -- & <1 & - & -- & <1 \\ -- & <1 & -- & -- & <1 \\ -- & <1 & - & -- & <1 \\ -- & <1 & -- & -- & <1 \\ -- & <1 & -- & -- & <1 \\ -- & <1 & -- & -- & <1\end{array}$


TABLE 4. CHEMICAL AND BACTERIOLOGICAL ANALYSES FOR GROUND- AND SURFACE-WATER SAMPLES FROM THE EUREKA SPRINGS LANDFILL - CONTINUED

\begin{tabular}{|c|c|c|c|c|c|c|c|}
\hline & $\begin{array}{l}\text { OXYGEN } \\
\text { DEMAND, } \\
\text { BIO- } \\
\text { CHEM- } \\
\text { ICAL, } \\
5 \text { DAY }\end{array}$ & $\begin{array}{l}\text { OXYGEN } \\
\text { DEMAND, } \\
\text { CHEM- } \\
\text { ICAL } \\
\text { (LOW } \\
\text { LEVEL) }\end{array}$ & $\begin{array}{l}\text { OXXGEN } \\
\text { DEMAND, } \\
\text { CHEM- } \\
\text { ICAL } \\
\text { (HIGH } \\
\text { LEVEL) }\end{array}$ & $\begin{array}{l}\text { COLI - } \\
\text { FORM, } \\
\text { TOTAL, } \\
\text { IMMED. } \\
\text { ICOLS. } \\
\text { PER }\end{array}$ & $\begin{array}{l}\text { COLI- } \\
\text { FORM, } \\
\text { CON- } \\
\text { F IRMED }\end{array}$ & $\begin{array}{l}\text { COLI - } \\
\text { FORM, } \\
\text { FECAL, } \\
\text { EC } \\
\text { BROTH }\end{array}$ & $\begin{array}{l}\text { COLI - } \\
\text { FORM, } \\
\text { FECAL, } \\
0.45 \\
\text { UM-MF } \\
\text { ICOLS.A }\end{array}$ \\
\hline & $\begin{array}{l}(M G / L) \\
(00310)\end{array}$ & $\begin{array}{l}(M G / L) \\
(00335)\end{array}$ & $\begin{array}{l}(M G / L) \\
(00340)\end{array}$ & $\begin{array}{l}100 \mathrm{ML}) \\
(31501)\end{array}$ & $\begin{array}{c}\text { (MPN) } \\
(31505)\end{array}$ & $\begin{array}{c}\text { (MPN) } \\
(31615)\end{array}$ & $\begin{array}{l}100 \mathrm{ML}) \\
(31616)\end{array}$ \\
\hline
\end{tabular}

280116082193601 - EUREKA SPRINGS LF 23 GREEN (LAT 280116 LONG 0821936.01 )

\begin{tabular}{|c|c|c|c|c|c|c|c|}
\hline FEB , 1974 & - & -- & -- & 19 & -- & -- & 0 \\
\hline JAN $\because 1975$ & .5 & 0 & -- & $B 13$ & - & -- & 1 \\
\hline${ }_{\text {MAR }} 16 \ldots$ & .6 & 2 & -- & 1900 & -- & -- & $<1$ \\
\hline $\begin{array}{l}28 \cdots \\
\text { AUG }\end{array}$ & .3 & 0 & -- & $<1$ & -- & -- & $<1$ \\
\hline $18 \ldots$ & 1.3 & 0 & -- & $<1$ & -- & -- & $<1$ \\
\hline APR $\because 1976$ & 1.0 & 3 & -- & $<1$ & -- & -- & $<1$ \\
\hline $\begin{array}{l}05 \cdots \cdots \\
\text { JUL }\end{array}$ & .1 & 0 & -- & $<1$ & -- & -- & $<1$ \\
\hline $\begin{array}{l}\text { O8... } \\
\text { MAY } 1977\end{array}$ & .9 & 0 & -- & $<1$ & -- & -- & $<1$ \\
\hline $25 \ldots$ & .2 & 0 & -- & $<1$ & -- & -- & $<1$ \\
\hline
\end{tabular}

280117082193201 - EUREKA SPRINGS LF 24 GREY (LAT $2801 \quad 17$ LONG 0821932.01 )

\begin{tabular}{|c|c|c|c|c|c|c|c|}
\hline FEB 1974 & -- & -- & -- & 320 & -- & -- & 0 \\
\hline $\begin{array}{l}\text { AUE } 1975 \\
\text { 18... } \\
\text { APR } 1976\end{array}$ & 1.2 & 0 & -- & $<1$ & -- & -- & $<1$ \\
\hline $13 \ldots \cdots$ & .6 & 0 & -- & B1 & -- & -- & $<1$ \\
\hline MAY $\because 1977$ & .3 & 0 & -- & $<1$ & -- & -- & $<1$ \\
\hline $25 \ldots$ & .2 & 0 & -- & B1 & $\cdots$ & -- & $<1$ \\
\hline
\end{tabular}


TABLE 4. CHEMICAL AND BACTERIOLOGICAL ANALYSES FOR GROUND- AND SURFACE-WATER SAMPLES FROM THE EUREKA SPRINGS LANDFILL - CONTINUED

\begin{tabular}{|c|c|c|c|c|c|c|c|}
\hline & $\begin{array}{l}\text { OXYGEN } \\
\text { DEMAND, } \\
\text { BIO- } \\
\text { CHEM- } \\
\text { ICAL, } \\
5 \text { DAY }\end{array}$ & $\begin{array}{l}\text { OXYGEN } \\
\text { DEMAND, } \\
\text { CHEM- } \\
\text { ICAL } \\
\text { (LOW } \\
\text { LEVEL) }\end{array}$ & $\begin{array}{l}\text { OXYGEN } \\
\text { DEMAND, } \\
\text { CHEM- } \\
\text { ICAL } \\
\text { (HIGH } \\
\text { LEVEL) }\end{array}$ & $\begin{array}{l}\text { COLI- } \\
\text { FORM, } \\
\text { TOTAL, } \\
\text { IMMED. } \\
\text { ICOLS. } \\
\text { PER }\end{array}$ & $\begin{array}{l}\text { COL I - } \\
\text { FORM, } \\
\text { CON- } \\
\text { F IRMED }\end{array}$ & $\begin{array}{l}\text { COLI- } \\
\text { FORM, } \\
\text { FECAL, } \\
\text { EC } \\
\text { RROTH }\end{array}$ & $\begin{array}{l}\text { COLI - } \\
\text { FORM, } \\
\text { FECAL, } \\
0.45 \\
\text { UM-MF } \\
\text { (COLS.) }\end{array}$ \\
\hline & $\begin{array}{l}(M G / L) \\
(00310)\end{array}$ & $\begin{array}{l}(M G / L) \\
(00335)\end{array}$ & $\begin{array}{l}(M G \times L) \\
(00340)\end{array}$ & $\begin{array}{l}100 \mathrm{ML}) \\
(31501)\end{array}$ & $\begin{array}{c}(M P N) \\
+31505)\end{array}$ & $\begin{array}{c}\text { (MPN) } \\
(31615)\end{array}$ & $\begin{array}{l}100 \mathrm{ML}) \\
(31616)\end{array}$ \\
\hline
\end{tabular}

280044082202501 - EUREKA SPRINGS LF 68 (LAT 280044 LONG 0822025.01 )

APR , 1975

$02 \ldots . \quad-1$
$5 \quad 19$

$--\quad<1$

280051082202901 - EUREKA SPRINGS LF 72 (LAT 280051 LONG 0822029.01 )

SEP , 1974

\begin{tabular}{|c|c|c|c|c|c|c|c|}
\hline $\begin{array}{l}04 \cdots \cdots \\
\text { JAN, } 1975\end{array}$ & .1 & 13 & -- & B3 & -- & -- & $<1$ \\
\hline $\begin{array}{l}24 \ldots \\
\text { AUG }\end{array}$ & .7 & 1 & -- & $B 1$ & -- & -- & $<1$ \\
\hline $18 \cdots$ & 1.2 & 1 & - & $<1$ & -- & -- & $<1$ \\
\hline $\begin{array}{l}03 \cdots \cdots 1976 \\
\text { APR } \because 1976\end{array}$ & .4 & 0 & -- & -- & -- & -- & -1 \\
\hline $\begin{array}{l}05 \cdots \cdots \\
\text { JUL }\end{array}$ & .1 & 1 & $-\infty$ & $<1$ & -- & -- & $<1$ \\
\hline $\begin{array}{l}09 \cdots \cdots \\
\text { MAY }: 1977\end{array}$ & .8 & 0 & -- & $<1$ & -- & -- & $<1$ \\
\hline $25 \ldots$ & E. 0 & 0 & $\ldots$ & $<1$ & -- & - & \\
\hline
\end{tabular}

280052082202901 - EUREKA SPRINGS LF 80 (LAT 280052 LONG 0822029.01 )

JAN, 1974
$\begin{aligned} & 30 \ldots \\ & \text { APR }\end{aligned}$
$30 \ldots$
$30 \ldots$


TABLE 4. CHEMICAL AND BACTERIOLOGICAL ANALYSES FOR GROUND- AND SURFACE-WATER SAMPLES FROM THE EUREKA SPRINGS LANDFILL - CONTINUED

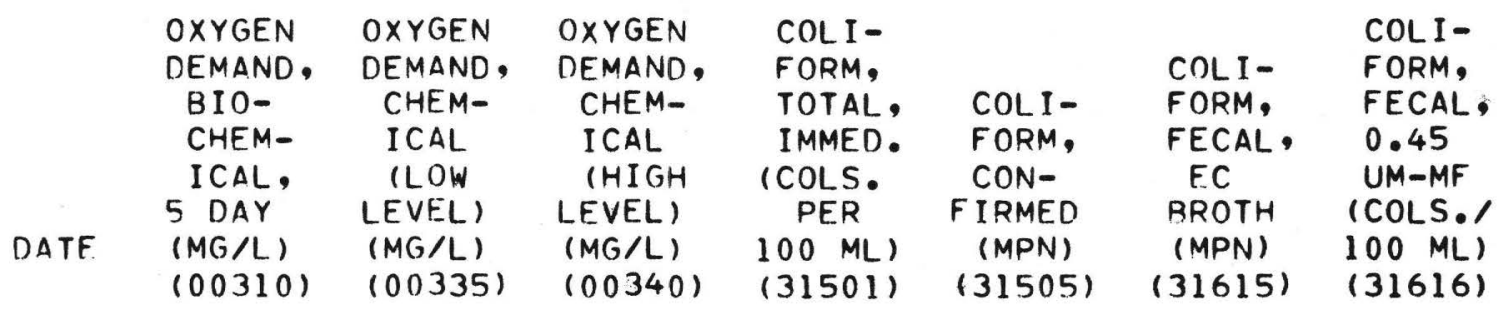

280052082202902 - EUREKA SPRINGS LF 81 (LAT 280052 LONG 0822029.02 )

\begin{tabular}{|c|c|c|c|c|c|c|c|}
\hline $\begin{array}{l}\text { JAN }, 1974 \\
30 \ldots .\end{array}$ & -- & -- & - & $>2700$ & -- & -- & $>200$ \\
\hline APR & & & & & & & \\
\hline JAN 30.1975 & -- & -- & -- & 210 & -- & -- & $<1$ \\
\hline$\underset{A P R}{24} \cdots$ & 1.0 & 4 & -- & 220 & -- & -- & $<1$ \\
\hline $\begin{array}{l}02 \ldots \\
\text { DEC }\end{array}$ & 3.6 & 41 & -- & -- & 3 & $<3$ & $-\infty$ \\
\hline $\begin{array}{l}03 \cdots \cdots \\
\text { NAY, } 1976\end{array}$ & 7.6 & 43 & -- & -- & -- & -- & - \\
\hline $\begin{array}{l}\text { NAY, } 1976 \\
\text { O7... } \\
\text { JUL }\end{array}$ & 2.6 & 20 & -- & -- & 240 & 93 & -- \\
\hline $09 \ldots$ & 2.8 & 11 & -- & -- & 15 & 9 & - \\
\hline
\end{tabular}


TABLE 4. CHEMICAL AND BACTERIOLOGICAL ANALYSES FOR GROUND- AND SURFACE-WATER SAMPLES FROM THE EUREKA SPRINGS LANDFILL - CONTINUED

$\begin{array}{ccccccc}\text { OXYGEN } & \text { OXYGEN } & \text { OXYGEN } & \text { COLI- } & & & \text { COLI- } \\ \text { DEMAND, } & \text { DEMAND, } & \text { DEMAND, } & \text { FORM, } & & \text { COLI- } & \text { FORM, } \\ \text { BIO- } & \text { CHEM- } & \text { CHEM- } & \text { TOTAL, } & \text { COLI- } & \text { FORM, } & \text { FECAL, } \\ \text { CHEM- } & \text { ICAL } & \text { ICAL } & \text { IMMED. } & \text { FORM, } & \text { FECAL, } & 0.45 \\ \text { ICAL, } & \text { (LOW } & \text { (HIGH } & \text { (COLS. } & \text { CON- } & \text { EC } & \text { UM-MF } \\ 5 \text { DAY } & \text { LEVEL) } & \text { LEVEL) } & \text { PER } & \text { FIRMED } & \text { BROTH } & \text { (COLS.) } \\ (M G / L) & (M G / L) & (M G / L) & 100 M L) & (M P N) & \text { (MPN) } & 100 \text { ML) } \\ (00310) & (00335) & (00340) & (31501) & (31505) & (31615) & (31616)\end{array}$

280057082203903 - E.UREKA SPRINGS LF 96 (LAT 280057 LONG 0822039.03 )

\begin{tabular}{|c|c|c|c|c|c|c|}
\hline $\begin{array}{l}30 \cdots \cdots \\
A P R\end{array}$ & -- & -- & -- & $<1$ & -- & -- \\
\hline $\begin{array}{l}30 \cdots \\
\text { SEP }\end{array}$ & -- & -- & -- & $<1$ & -- & -- \\
\hline $\begin{array}{l}04 \cdots \cdots \\
\text { JAN }: 1975\end{array}$ & .2 & 9 & -- & 41 & -- & -- \\
\hline $\begin{array}{l}23 \cdots \cdots \\
\text { JUL }, 1976\end{array}$ & - 8 & 2 & -- & $<1$ & -- & -- \\
\hline $09 \ldots$ & 4.9 & 27 & -- & - & 11000 & 460 \\
\hline
\end{tabular}

280057082203901 - EUREKA SPRINGS LF 98 (LAT 280057 LONG 0822039.01 )

- JAN , 1974

\begin{tabular}{|c|c|c|c|c|c|c|c|}
\hline$\underset{A P R}{30} \cdots$ & - & -- & -- & B35 & - & -- & 0 \\
\hline $\begin{array}{l}30 \cdots \\
\text { MAY } \because 1976\end{array}$ & & -- & - & $<1$ & - & - & $<1$ \\
\hline $07 \ldots$ & .5 & 9 & -- & -- & 4 & $<3$ & \\
\hline
\end{tabular}

280059082201201 - EUREKA SPRINGS LF 104 (LAT 2800 59 LONG 0822012.01 ;

SEP 1974

\begin{tabular}{|c|c|c|c|c|c|c|}
\hline $\begin{array}{l}04 \cdots \cdots \\
\text { JAN } 1975\end{array}$ & $\cdot 0$ & 0 & -- & 53 & -- & -- \\
\hline DEC & 1.2 & 8 & -- & - & 240 & 40 \\
\hline MAY $\because 1976$ & .2 & 2 & -- & -- & -- & -- \\
\hline $07 \ldots$ & .5 & 1 & -- & - & 14 & $<3$ \\
\hline
\end{tabular}

280059082202201 - EUREKA SPRINGS LF 107 (LAT 280059 LONG 0822022.01 )

APR , 1975

$01 \ldots$

$\cdot 3$

7 
TABLE 4. CHEMICAL AND BACTERIOLOGICAL ANALYSES FOR GROUND- AND SURFACE-WATER SAMPLES FROM THE EUREKA SPRINGS LANDFILL - CONTINUED

\begin{tabular}{|c|c|c|c|c|c|c|}
\hline OXYGEN & OXYGEN & OXYGEN & $\mathrm{COLI}=$ & & & COLI - \\
\hline DEMAND. & DEMAND, & DEMAND, & FORM, & & $\mathrm{COLI}$ - & FORM, \\
\hline BI0- & CHEM- & CHEM- & TOTAL, & COLI - & FORM, & FECAL \\
\hline CHEM - & ICAL & ICAL & IMMED. & FORM, & FECAL, & 0.45 \\
\hline ICAL, & (LOW & (HIGH & ICOLS. & CON- & EC & $U M-M F$ \\
\hline 5 DAY & LEVEL) & LEVEL) & PER & FIRMED & BROTH & $1 \mathrm{COLS}$ \\
\hline$(M G / L)$ & $(M G / L)$ & $(M G \times L)$ & $100 \mathrm{ML})$ & (MPN) & (MPN) & $100 \mathrm{ML})$ \\
\hline$(00310)$ & $(00335)$ & $(00340)$ & $(31501)$ & $(31505)$ & $(31615)$ & $(31616)$ \\
\hline
\end{tabular}

280116082193502 - EUREKA SPRINGS LF 149 (LAT 280116 LONG 0821935.02 )

280116082193501 - EUREKA SPRINGS LF 150 (LAT 280116 LONG 0821935.01 )

\begin{tabular}{|c|c|c|c|c|c|c|c|}
\hline $\begin{array}{l}\text { FEB } 1974 \\
20 \ldots 11976 \\
\text { APR } 1976\end{array}$ & -- & -- & -- & 2300 & - & -- & $>400$ \\
\hline JUL $13 \ldots$ & 1.3 & -- & -- & -- & -- & -- & - \\
\hline MAY $\because 1977$ & 1.9 & 10 & -- & 2000 & -- & -- & 370 \\
\hline $31 \ldots$ & . 9 & 0 & - & - & 4 & $<3$ & $-\alpha$ \\
\hline
\end{tabular}

280102082202000 - EUREKA SPRINGS LF OXIDATION POND (LAT 280102 LONG 0822020 )

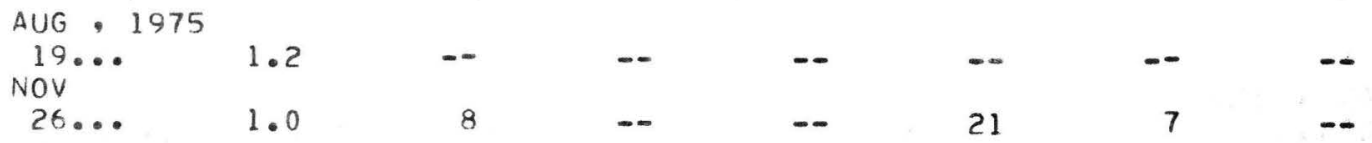

280058082202400 - EUREKA SPRINGS LF SW PERIMETER DITCH (LAT 280058 LONG 0822024 )

Nov, 1975

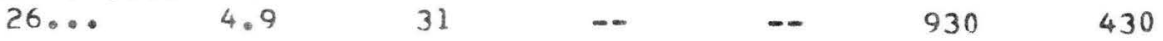


TABLE 4. CHEMICAL AND BACTERIOLOGICAL ANALYSES FOR GROUND- AND SURFACE-WATER SAMPLES FROM THE EUREKA SPRINGS LANDFILL - CONTINUED

\begin{tabular}{|c|c|c|c|c|c|c|}
\hline $\begin{array}{l}\text { OXYGEN } \\
\text { DEMAND, } \\
\text { BIO- } \\
\text { CHEM- } \\
\text { ICAL, } \\
5 \text { DAY }\end{array}$ & $\begin{array}{l}\text { OXYGEN } \\
\text { DEMAND, } \\
\text { CHEM- } \\
\text { ICAL } \\
\text { (LOW } \\
\text { LEVEL) }\end{array}$ & $\begin{array}{l}\text { OX } ¥ G E N \\
\text { DEMAND, } \\
\text { CHEM- } \\
\text { ICAL } \\
\text { (HIGH } \\
\text { LEVEL) }\end{array}$ & $\begin{array}{l}\text { COLI- } \\
\text { FORM, } \\
\text { TOTAL, } \\
\text { IMMED. } \\
\text { ICOLS. } \\
\text { PER }\end{array}$ & $\begin{array}{l}\text { COL I- } \\
\text { FORM, } \\
\text { CON- } \\
\text { F IRMED }\end{array}$ & $\begin{array}{l}\text { COLI - } \\
\text { FORM, } \\
\text { FECAL, } \\
\text { EC } \\
\text { BROTH }\end{array}$ & $\begin{array}{l}\text { COL I - } \\
\text { FORM, } \\
\text { FECAL, } \\
0.45 \\
\text { UM-MF } \\
\text { ICOLS. }\end{array}$ \\
\hline $\begin{array}{l}(M G / L) \\
(00310)\end{array}$ & $\begin{array}{l}(M G / L) \\
(00335)\end{array}$ & $\begin{array}{l}(M G / L) \\
(00340)\end{array}$ & $\begin{array}{l}100 \mathrm{ML}) \\
(31501)\end{array}$ & $\begin{array}{c}\text { (MPN) } \\
(31505)\end{array}$ & $\begin{array}{c}(M P N) \\
(31615)\end{array}$ & $\begin{array}{l}100 \mathrm{ML}) \\
(31616)\end{array}$ \\
\hline
\end{tabular}

280059082202202 - EUREKA SPRINGS LF 108 (LAT 280059 LONG 0822022.02 )

\begin{tabular}{|c|c|c|c|c|c|c|}
\hline $\begin{array}{l}30 \\
A P R\end{array}$ & -- & -- & -- & -- & -- & -- \\
\hline$\underset{\text { SEP }}{30} \cdots$ & -- & -- & -- & B20 & -- & -- \\
\hline $\begin{array}{l}04 \cdots \cdots \\
\text { JAN } \because 1975\end{array}$ & 5.1 & 0 & -- & B53 & -- & -- \\
\hline$\underset{A P R}{23} \cdots$ & .6 & 8 & -- & Bl & -- & -- \\
\hline $01 \ldots$ & 1.5 & 38 & - & - & - & -- \\
\hline
\end{tabular}

280103082202802 - EUREKA SPRINGS LF 129 (LAT 280103 LONG 08220 28.02)

JUL, 1976

$\begin{array}{lllllll}12 \ldots & 1.7 & - & & 4 & 4 & 4600\end{array}$

280103082202801 - EUREKA SPRINGS LF 130 (LAT 280103 LONG 0822028.01 )

$\begin{array}{lllllrrr}\text { MAY }, 1976 & & & & & \\ \text { O8... } & 2.9 & -- & 3 & -- & 150000 & 1100 & - \\ \text { JUL } & & & & & & \end{array}$

280108082194201 - EUREKA SPRINGS LF 148 (LAT 280108 LONG 0821942.01 )

SEP, 1974

03...

280209082193901 - EUREKA SPRINGS LF 148 A (LAT 280209 LONG 0821939.01 )

DEC, 1975

APR 1976

$1.2 \quad 28$

$13 \ldots .7$

31

3900

3900 
TABLE 4. CHEMICAL AND BACTERIOLOGICAL ANALYSES FOR GROUND- AND SURFACE-WATER SAMPLES FROM THE EUREKA SPRINGS LANDFILL - CONTINUED

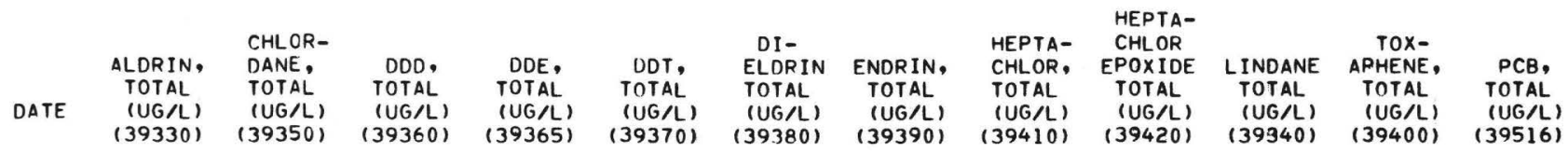

280116082193601 - EUREKA SPRINGS LF 23 GREEN (LAT 280116 LONG 0821936.01 )

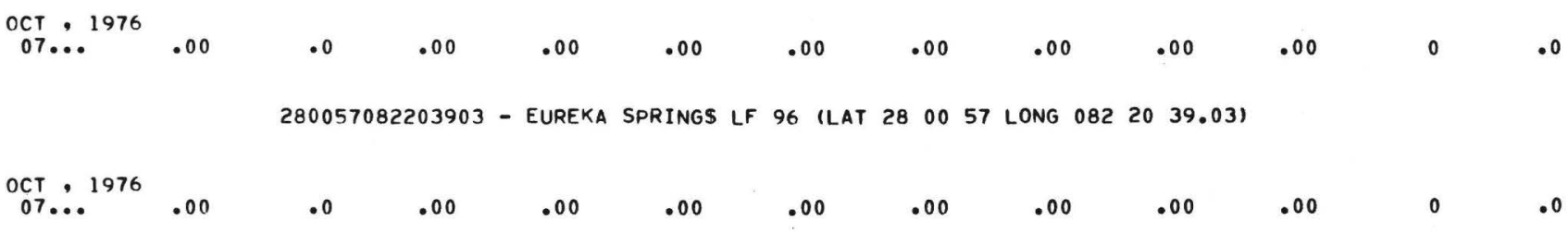

\begin{tabular}{|c|c|c|c|c|c|c|c|c|c|c|}
\hline DATE & $\begin{array}{c}\text { DI- } \\
\text { AZINON, } \\
\text { TOTAL } \\
(U G / L) \\
(39570)\end{array}$ & $\begin{array}{l}\text { ETHION, } \\
\text { TOTAL } \\
\text { (UG/L) } \\
(39398)\end{array}$ & $\begin{array}{l}\text { MALA- } \\
\text { THION, } \\
\text { TOTAL } \\
\text { (UG/L) } \\
(39530)\end{array}$ & $\begin{array}{l}\text { METHYL } \\
\text { PARA- } \\
\text { THIONG } \\
\text { TOTAL } \\
(\text { UG/L) } \\
(39600)\end{array}$ & $\begin{array}{c}\text { METHYL } \\
\text { TRI - } \\
\text { THION, } \\
\text { TOTAL } \\
(\text { UG/L) } \\
(39790)\end{array}$ & $\begin{array}{l}\text { PARA- } \\
\text { THION, } \\
\text { TOTAL } \\
\text { (UG/L) } \\
(39540)\end{array}$ & $\begin{array}{c}\text { TOTAL } \\
\text { TRI- } \\
\text { THION } \\
\text { (UG/L) } \\
(39786)\end{array}$ & $\begin{array}{l}2,4-D, \\
\text { TOTAL } \\
(\text { UG/L) } \\
(39730)\end{array}$ & $\begin{array}{c}2 \% 4,5-T \\
\text { TOTAL } \\
\text { (UG/L) } \\
(39740)\end{array}$ & $\begin{array}{l}\text { SILVEX, } \\
\text { TOTAL } \\
\text { (UG/L) } \\
(39760)\end{array}$ \\
\hline
\end{tabular}

280116082193601 - EUREKA SPRINGS LF 23 GREEN (LAT 280116 LONG 0821936.01 )

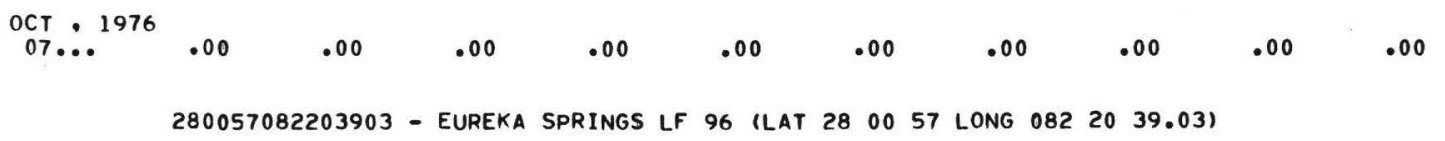

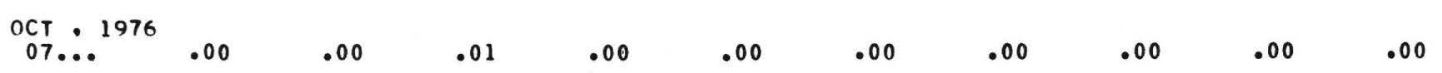


TABLE 5. CHEMICAL AND BACTERIOLOGICAL ANALYSES FOR GROUND- AND SURFACE-WATER SAMPLES FROM THE GIBSONTON LANDF ILL

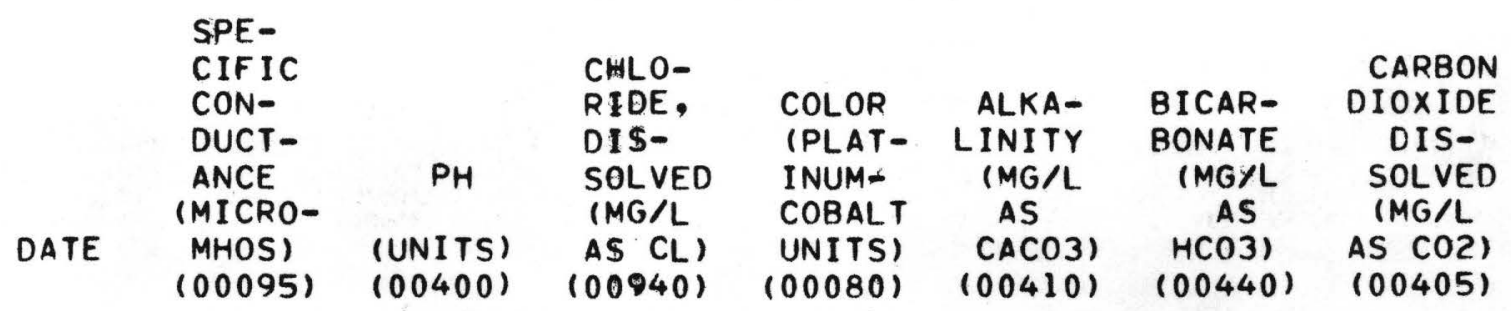

274952082231201 - GIBSONTON LEF 223 (LAT 274952 LONG 0822312.01 )

JUL, 1976

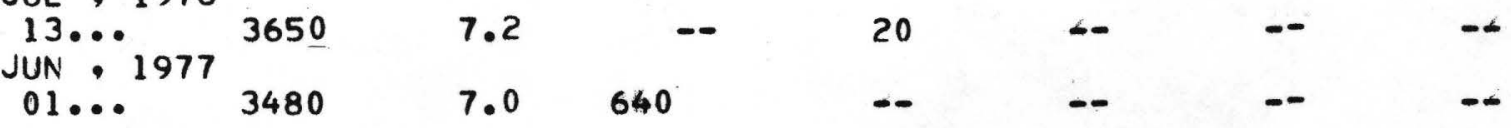

274952082231202 - GIBSONTON LF 223A (LAT 274952 LONG 0822312.02 )

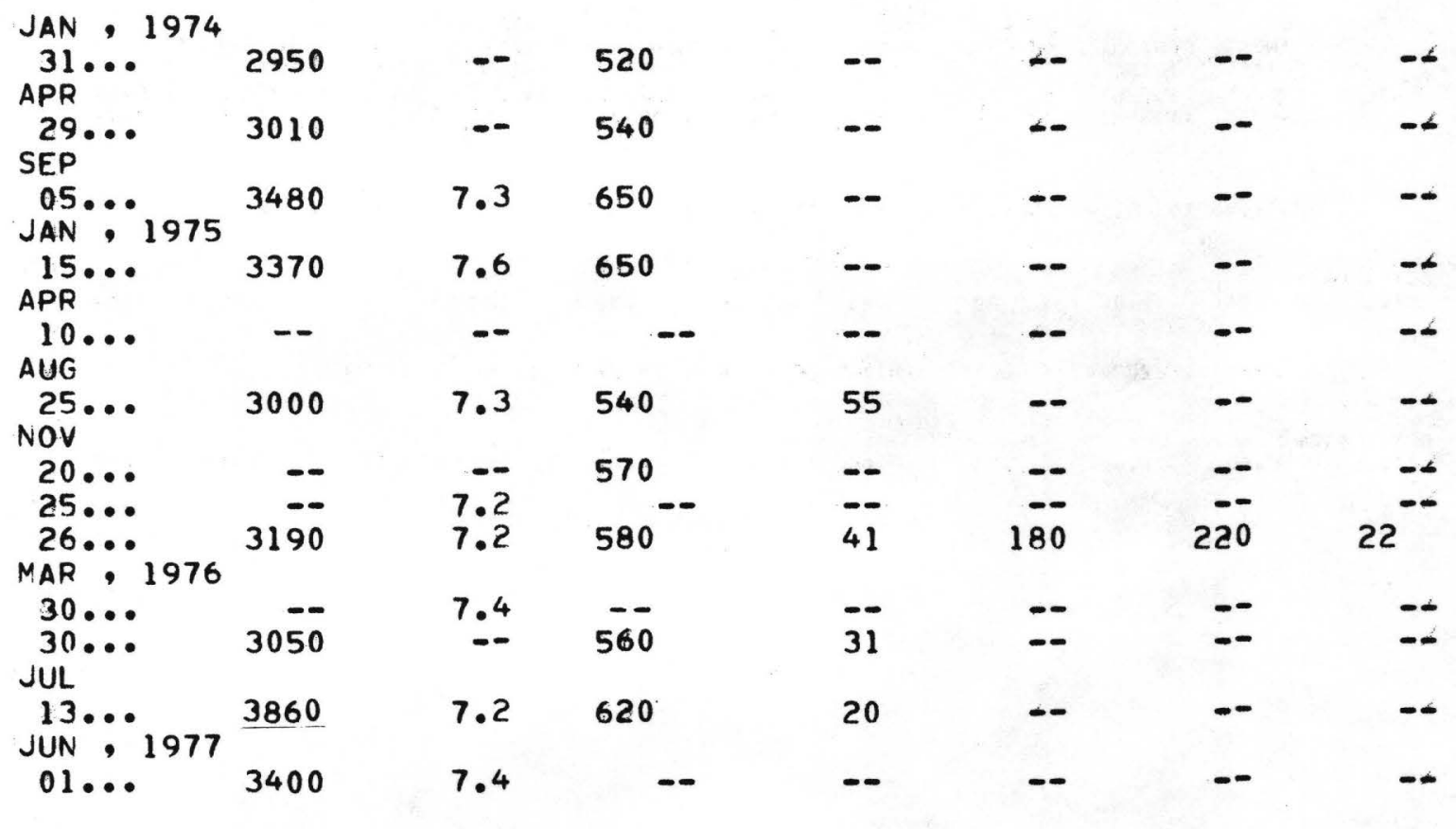

274934082231101 - GIBSONTON LF 241 (LAT 274934 LONG 0822311.01 )

\begin{tabular}{|c|c|c|c|}
\hline $\begin{array}{l}31 \ldots \\
A P R\end{array}$ & 33000 & - & 12000 \\
\hline $\begin{array}{l}29 . . \\
\text { SE.P }\end{array}$ & 34100 & -- & 13000 \\
\hline $\begin{array}{c}05 \ldots \\
\text { JAN } \\
15 \ldots\end{array}$ & $\begin{array}{l}31000 \\
26200\end{array}$ & 7.1 & 11000 \\
\hline
\end{tabular}


TABLE 5. CHEMICAL AND BACTERIOLOGICAL ANALYSES FOR GROUND- AND SURFACE-WATER SAMPLES FROM THE GIBSONTON LANDF ILL - CONTINUED

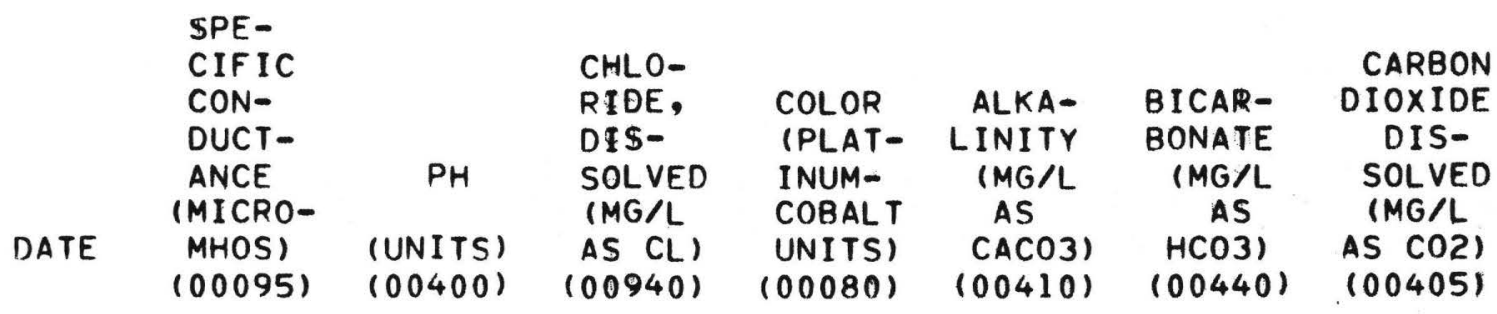

274940082231001 - GIBSONTON LF 243 (LAT 274940 LONG 0822310.01 )

$\begin{array}{lllr}\text { JAN, } 1974 & & & \\ \text { 31... } & 4250 & -- & 940 \\ \text { APR } & & & \\ \text { 29... } & 4450 & -- & 260 \\ \text { SEP } & & & \\ \text { 05... } & 4720 & 7.1 & 1100 \\ \text { JAN, 1975 } & & & \\ \text { 15... } & 4260 & 7.1 & 850 \\ \text { APR } & & & \\ 11 \ldots & 4150 & -- & \end{array}$

274935082230401 - GIBSONTON LF 244 WARD (LAT 274935 LONG 0822304.01 )

\begin{tabular}{|c|c|c|c|c|c|c|c|}
\hline APR & 7000 & -- & 1900 & -- & - & -- & - \\
\hline$\underset{\text { SEP }}{29} \cdots$ & 8520 & -- & 2400 & -- & -- & -- & -6 \\
\hline $\begin{array}{l}05 \cdots \cdots \\
\text { JAN } 1975\end{array}$ & 7750 & 7.4 & 2400 & -- & -- & -- & -6 \\
\hline $\begin{array}{l}15 \cdots \cdots \\
A P R\end{array}$ & 7930 & 7.4 & 2100 & -- & -- & -- & $-\infty$ \\
\hline $\begin{array}{l}10 \cdots \\
A U G\end{array}$ & 9100 & -- & - & -- & -- & -- & $-\infty$ \\
\hline $\begin{array}{l}25 \cdots \\
\text { NOV }\end{array}$ & 7800 & 7.3 & 2300 & 19 & -- & -- & -6 \\
\hline $\begin{array}{l}25 \cdots \cdots \\
\text { MAR } 1976\end{array}$ & 6900 & 7.1 & 1900 & 32 & 164 & 200 & 25 \\
\hline $30 \ldots$ & -- & 7.1 & -- & - & -- & -- & -6 \\
\hline JUN $\because 1977$ & 8800 & -- & 2600 & 15 & -- & -- & - \\
\hline $01 \ldots$ & 9000 & 7.2 & 2600 & -- & -- & -- & \\
\hline
\end{tabular}

274945082231500 - GIBSONTON LF PERIMETER DITCH (LAT 274945 LONG 0822315$)$

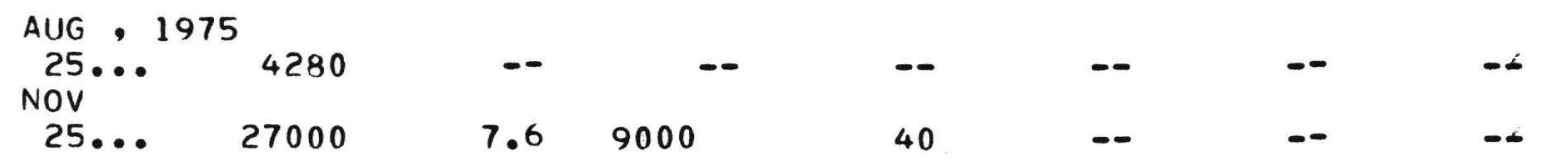


TABLE 5. CHEMICAL AND BACTERIOLOGICAL ANALYSES FOR GROUND- AND SURFACE-WATER SAMPLES FROM THE GIBSONTON LANDF ILL - CONTINUED

SPE-

\begin{tabular}{|c|c|c|c|c|c|c|}
\hline $\begin{array}{l}\text { CIFIC } \\
\text { CON- } \\
\text { DUCT- } \\
\text { ANCE } \\
\text { MICRO- }\end{array}$ & $\mathrm{PH}$ & $\begin{array}{l}\text { CHLO- } \\
\text { RIDE, } \\
\text { DIS- } \\
\text { SOLVED } \\
\text { IMG/I }\end{array}$ & $\begin{array}{l}\text { COLOR } \\
\text { IPLAT- } \\
\text { INUM- } \\
\text { COBAL T }\end{array}$ & $\begin{array}{c}\text { ALKA- } \\
\text { LINITY } \\
\text { IMG/L } \\
\text { AS }\end{array}$ & $\begin{array}{c}\text { BICAR- } \\
\text { BONATE } \\
\text { IMG/L } \\
\text { AS }\end{array}$ & $\begin{array}{r}\text { CAF } \\
\text { DIO } \\
\text { D } \\
\text { SOL } \\
\text { IMC }\end{array}$ \\
\hline $\begin{array}{l}\text { HOS1 } \\
0095 \text { ) }\end{array}$ & & $\begin{array}{l}\text { AS CL) } \\
(00940)\end{array}$ & $\begin{array}{l}\text { UNITS) } \\
(00080)\end{array}$ & $\begin{array}{r}(A C 03) \\
(00410)\end{array}$ & $\begin{array}{c}\mathrm{HCO} 3) \\
(00440)\end{array}$ & $\begin{array}{l}\text { AS C02) } \\
(00405)\end{array}$ \\
\hline
\end{tabular}

274955082231400 - GIBSONTON LF OXIDATION POND (LAT 274955 LONG 08223 14)

\begin{tabular}{|c|c|c|c|c|c|c|c|}
\hline $\begin{array}{l}25 \ldots \\
\text { NOV }\end{array}$ & 18800 & & - & 34 & -- & - & -- \\
\hline $25 \ldots$ & 12500 & 8.2 & 3900 & 100 & - & -- & -- \\
\hline
\end{tabular}


TABLE 5. CHEMICAL AND BACTERIOLOGICAL ANALYSES FOR GROUND- AND SURFACE-WATER SAMPLES FROM THE GIBSONTON LANDF ILL - CONTINUED

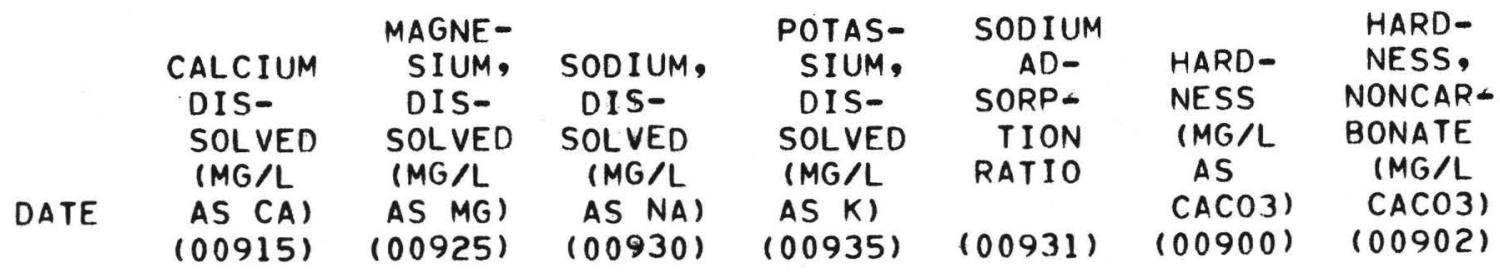

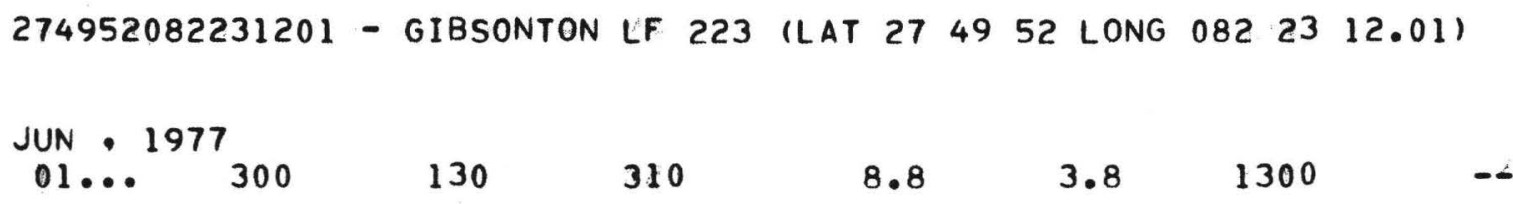

274952082231202 - GIBSONTON LF 223A (LAT 274952 LONG 0822312.02 )

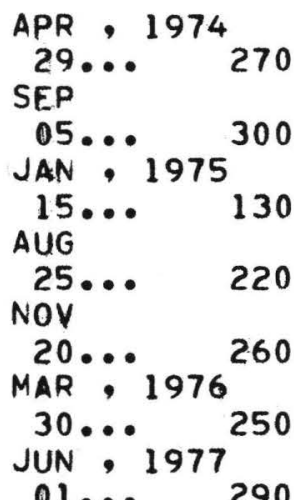

$01 \ldots 290$

$\begin{array}{rrrrrr}110 & 260 & 9.3 & 3.4 & 1100 & \ldots \\ 110 & 300 & 12 & 3.8 & 1200 & \ldots \\ 120 & 310 & 10 & 4.7 & 820 & \ldots \\ 94 & 300 & 8.3 & 4.3 & 940 & \ldots \\ 110 & 290 & 8.3 & 3.8 & 1100 & \ldots \\ 100 & 270 & 7.8 & 3.7 & 1000 & \ldots \\ 110 & 290 & 9.4 & 3.7 & 1200 & \ldots\end{array}$


TAELE 5. CHEMICAL AND BACTERIOLOGICAL ANALYSES FOR GROUND- AND SURFACE-WATER SAMPLES FROM THE GIBSONTON LANDF ILL - CONTINUED

$\begin{array}{cccccccc} & & \text { MAGNE- } & \text { POTAS- } & \text { SODIUM } & \text { HARD- } \\ & \text { CALCIUM } & \text { SIUM, } & \text { SODIUM, } & \text { SIUM, } & \text { AD- } & \text { HARD- } & \text { NESS, } \\ & \text { DIS- } & \text { DIS- } & \text { DIS- } & \text { DIS- } & \text { SORP- } & \text { NESS } & \text { NONCARA } \\ & \text { SOLVED } & \text { SOLVED } & \text { SOLVED } & \text { SOLVED } & \text { TION } & (M G / L & \text { BONATE } \\ & (M G / L & (M G / L & (M G / L & (M G / L & R A T I O & \text { AS } & (M G / L \\ \text { DATE } & \text { AS CA) } & \text { AS MG) } & \text { AS NA) } & \text { AS K) } & & \text { CACO3) } & \text { CACO3) } \\ & (00915) & (00925) & (00930) & (00935) & +00931) & (00900) & (00902)\end{array}$

274934082231101 - GIBSONTON LF 241 (LAT 274934 LONG 0822311.01 )

\begin{tabular}{|c|c|c|c|c|c|c|}
\hline$\underset{\text { SEP }}{29 . \cdots}$ & 350 & 740 & 7000 & 62 & 49 & 3900 \\
\hline $\begin{array}{l}05 \ldots \\
\text { JAN }\end{array}$ & 270 & 660 & 6000 & 220 & 45 & 3400 \\
\hline $15 \ldots$ & 200 & 460 & 5400 & 200 & 48 & 2400 \\
\hline
\end{tabular}

274940082231001 - GIBSONTON LF 243 (LAT 274940 LONG 0822310.01 )

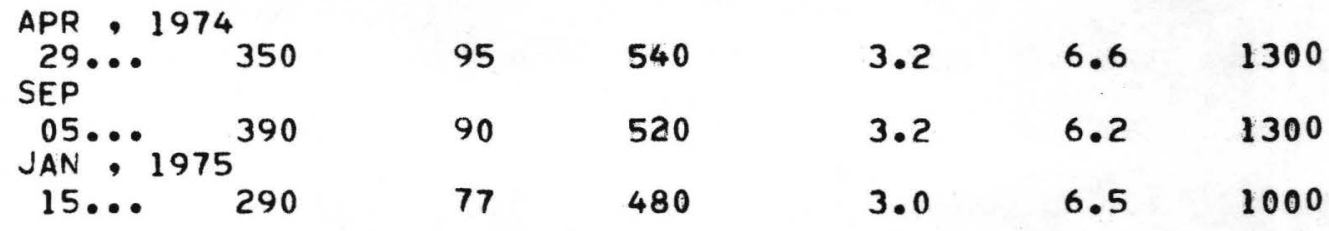

274935082230401 - GIBSONTON LF 244 WARD (LAT 274935 LONG 0822304.01 )

\begin{tabular}{|c|c|c|c|c|c|c|c|}
\hline $\begin{array}{l}\text { APR } \\
29 \cdots \\
\text { SEP }\end{array}$ & $\underbrace{1974} 460$ & 250 & 1000 & 25 & 9.3 & 2200 & -6 \\
\hline $\begin{array}{l}05 \cdots \\
\text { JAN } \bullet\end{array}$ & $1975^{420}$ & 220 & 970 & 16 & 9.5 & 2000 & $-\infty$ \\
\hline $\begin{array}{l}15 \\
\text { AUG }\end{array}$ & - $\quad 360$ & 180 & 1000 & 20 & 11 & 1600 & \\
\hline $\begin{array}{l}25 \cdots \\
\text { NOV }\end{array}$ & 430 & 210 & 970 & 20 & 9.6 & 1900 & \\
\hline 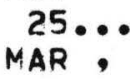 & $1976^{410}$ & 190 & 840 & 18 & 8.6 & 1800 & 1600 \\
\hline $\begin{array}{l}30 \cdots \\
\text { JUN }\end{array}$ & $1977^{450}$ & 230 & 1400 & 23 & 13 & 2100 & \\
\hline $01 \ldots$ & - $\quad 480$ & 240 & 1200 & 24 & 11 & 2200 & \\
\hline
\end{tabular}


TABLE 5. CHEMICAL AND BACTERIOLOGICAL ANALYSES FOR GROUND- AND SURFACE-WATER SAMPLES FROM THE GIBSONTON LANDF ILL - CONTINUED

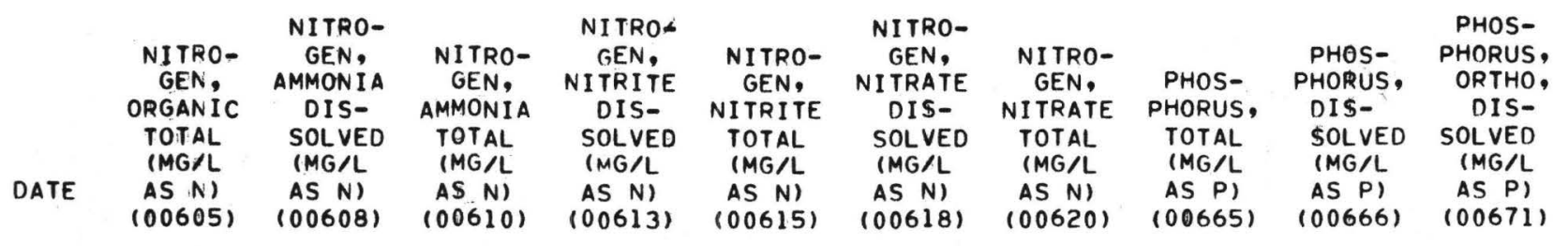

274952082231201 - GIBSONTON LF 223 (LAT 274952 LONG 0822312.01 )

\begin{tabular}{|c|c|c|c|c|c|c|c|c|c|c|}
\hline $01 \ldots$ & .52 & .79 & -- & .00 & -- & $1 \cdot 2$ & -- & $2 \cdot 2$ & .02 & .01 \\
\hline
\end{tabular}

274952082231202 - GIBSONTON LF 223A (LAT 274952 LONG 0822312.02 )

SEP, 1974

JAN 1975

15

.65

421.0

$1.0 \quad-0 \quad .00$

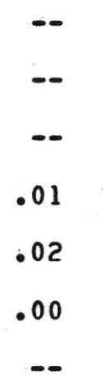

.00
.00
.03
--
--
--

$\begin{array}{cccc}-- & .18 & .04 & .02 \\ -- & .43 & .02 & .02 \\ -- & 1.8 & 1.2 & 1.2 \\ .00 & .26 & -. & -. \\ .03 & .12 & -. & -- \\ .00 & .42 & -. & -- \\ -- & .73 & .04 & .03\end{array}$

274934082231101 - GIBSONTON LF 241 (LAT 274934 LONG 0822311.01 )

SEP 1974

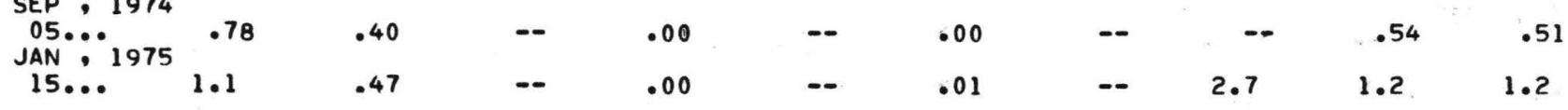

274940082231001 - GIBSONTON LF 243 (LAT 274940 LONG 0822310.01 )

SEP • 1974

JAN? 1975

$15 \ldots . .53$

APR

$11 \ldots$

.49
.53
.83

$\begin{array}{lll}.80 & -- & .00 \\ .69 & -- & .00 \\ .45 & -- & .00\end{array}$

$\begin{array}{ll}-. & .00 \\ - & .00 \\ -- & .02\end{array}$

$\begin{array}{cc}-- & .51 \\ -- & .76 \\ -- & 2.6\end{array}$

.03
.00
.02

.00

.00

.01 
TABLE 5. CHEMICAL AND BACTERIOLOGICAL ANALYSES FOR GROUND- AND SURFACE-WATER SAMPLES FROM THE GIBSONTON LANDFILL - CONTINUED

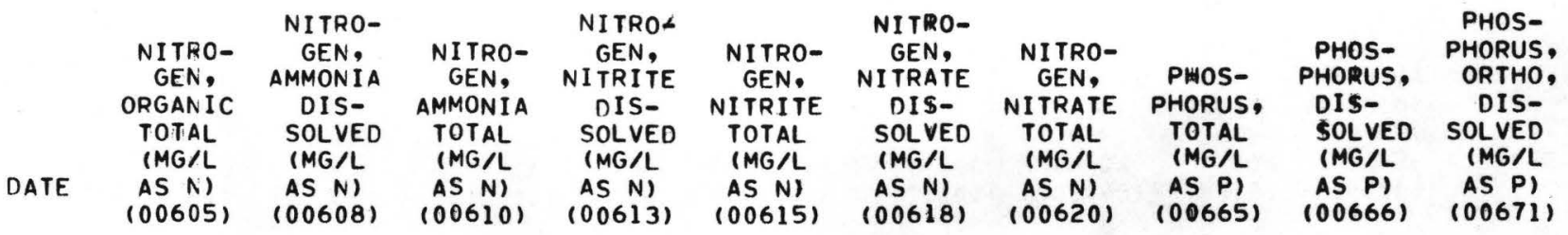

274935082230401 - GIBSONTON LF 244 WARD (LAT 274935 LONG 0822304.01 )

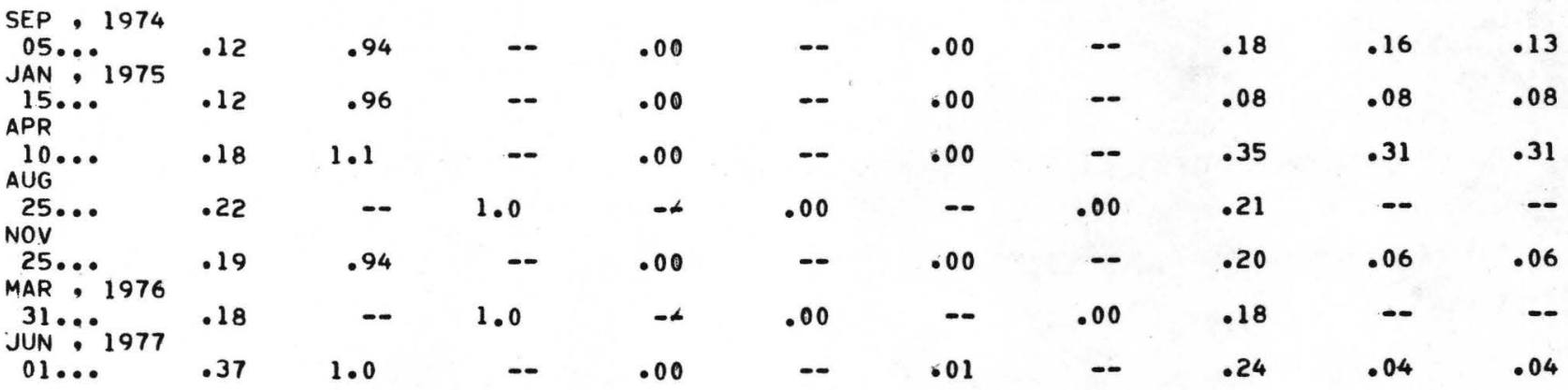

274945082231500 - GIBSONTON LF PERIMETER DITCH (LAT 274945 LONG 0822315$)$

\begin{tabular}{|c|c|c|c|c|c|c|c|c|c|c|}
\hline $25 \ldots$ & 1.2 & 3.0 & -- & .02 & - & .04 & -- & 1.4 & 1.2 & 1.4 \\
\hline
\end{tabular}
274955082231400 - GIBSONTON LF OXIDATION POND (LAT 274955 LONG $08223 \quad 14$ )

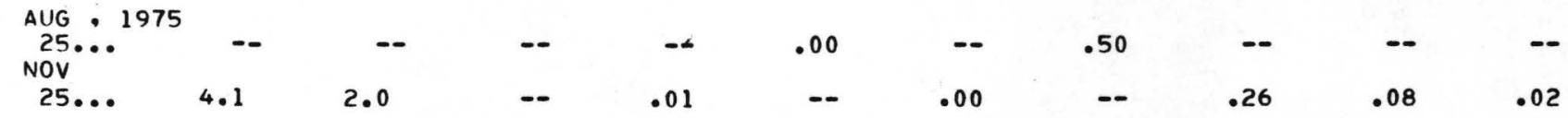


TABLE 5. CHEMICAL AND BACTERIOLOGICAL ANALYSES FOR GROUND- AND SURFACE-WATER SAMPLES FROM THE GIBSONTON LANDF ILL - CONTINUED

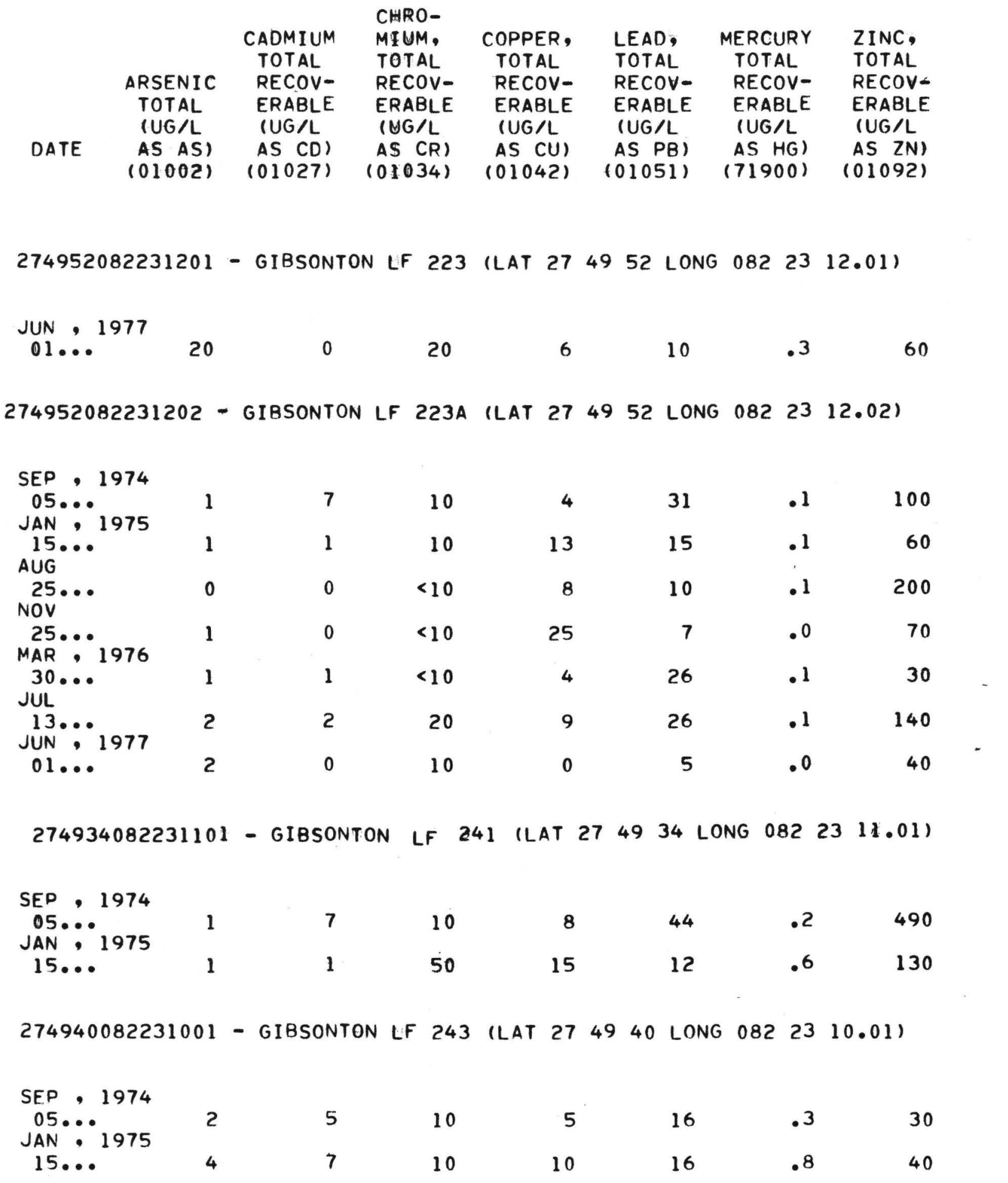


TABLE 5. CHEMICAL AND BACTERIOLOGICAL ANALYSES FOR GROUND- AND SURFACE-WATER SAMPLES FROM THE GIBSONTON LANDFILL - CONTINUED

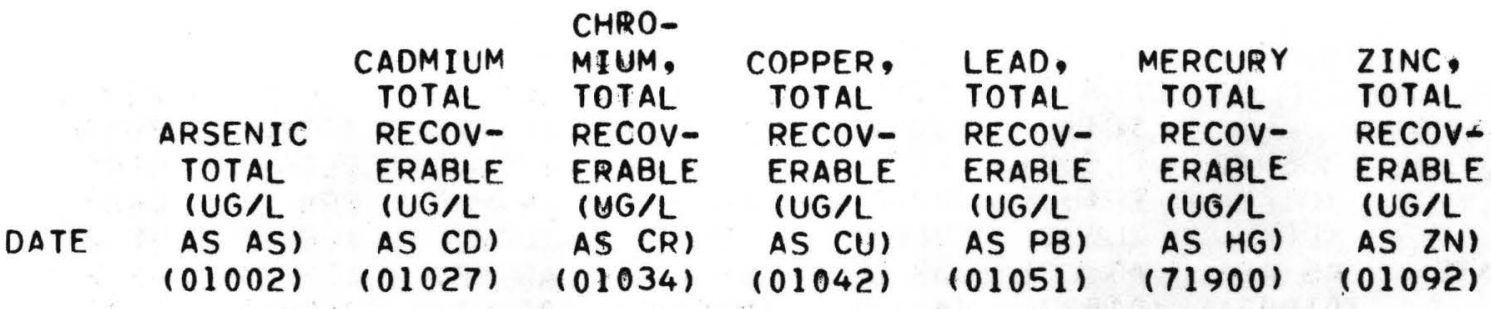

274935082230401 - GIBSONTON LF 244 WARD (LAT 274935 LONG 0822304.01 )

\begin{tabular}{|c|c|c|c|c|c|c|}
\hline JAN: 1975 & 1 & 1 & 10 & 6 & 22 & .1 \\
\hline $\begin{array}{l}15 \ldots \\
\text { AUG }\end{array}$ & 0 & 1 & 10 & 11 & 18 & .1 \\
\hline $\begin{array}{l}25 \cdots \cdots \\
\text { NOV }\end{array}$ & 0 & 0 & $<10$ & 8 & 5 & .1 \\
\hline $\begin{array}{l}25 \cdots \cdots \\
\text { MAR }: 1976\end{array}$ & 0 & 0 & $<10$ & 74 & 13 & .2 \\
\hline $\begin{array}{l}30 \cdots \\
\text { JUN }: 1977\end{array}$ & 0 & 0 & 10 & 20 & 12 & .0 \\
\hline $01 \ldots$ & 2 & 0 & 20 & 6 & 24 & .4 \\
\hline
\end{tabular}


TABLE 5. CHEMICAL AND BACTERIOLOGICAL ANALYSES FOR GROUND- AND SURFACE-WATER SAMPLES FROM THE GIBSONTON LANDF ILL - CONTINUED

$\begin{array}{ccccccc}\text { OXYGEN } & \text { OXYGEN } & \text { OXYGEN } & \text { COLI- } & & & \text { COLI- } \\ \text { DEMAND, } & \text { DEMAND, } & \text { DEMAND, } & \text { FORM, } & & \text { COLI- } & \text { FORM, } \\ \text { BIO- } & \text { CHEM- } & \text { CHEM- } & \text { TOTAL, } & \text { COLI- } & \text { FORM, } & \text { FECAL, } \\ \text { CHEM- } & \text { ICAL } & \text { ICAL } & \text { IMMED. } & \text { FORM, } & \text { FECAL, } & \text { O.45 } \\ \text { ICAL, } & \text { (LOW } & \text { (HIGH } & \text { (COLS. } & \text { CON- } & \text { EC } & \text { UM-MF } \\ 5 \text { DAY } & \text { LEVEL) } & \text { LEVEL) } & \text { PER } & \text { FIRMED } & \text { BROTH } & (\text { COLS.) } \\ (M G / L) & (M G / L) & (M G A L) & 100 M L) & \text { (MPN) } & \text { (MPN) } & 100 M L) \\ (00310) & (00335) & (00340) & (3.1501) & (31505) & (31615) & (31616)\end{array}$

$$
\begin{aligned}
& 274952082231201 \text { - GIBSONTON LF } 223 \text { (LAT } 274952 \text { LONG } 0822312.01 \text { ) }
\end{aligned}
$$

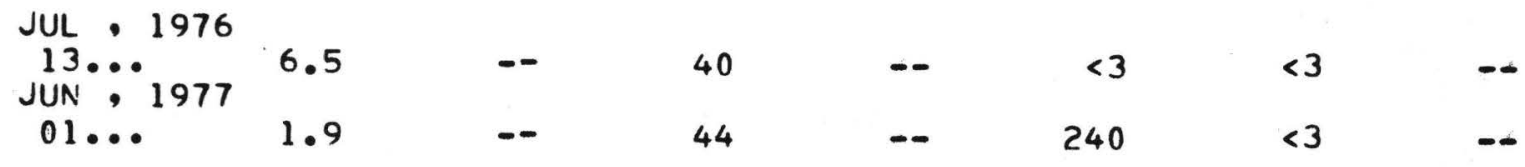

274952082231202 - GIBSONTON LF 223A (LAT 274952 LONG 0822312.02 )

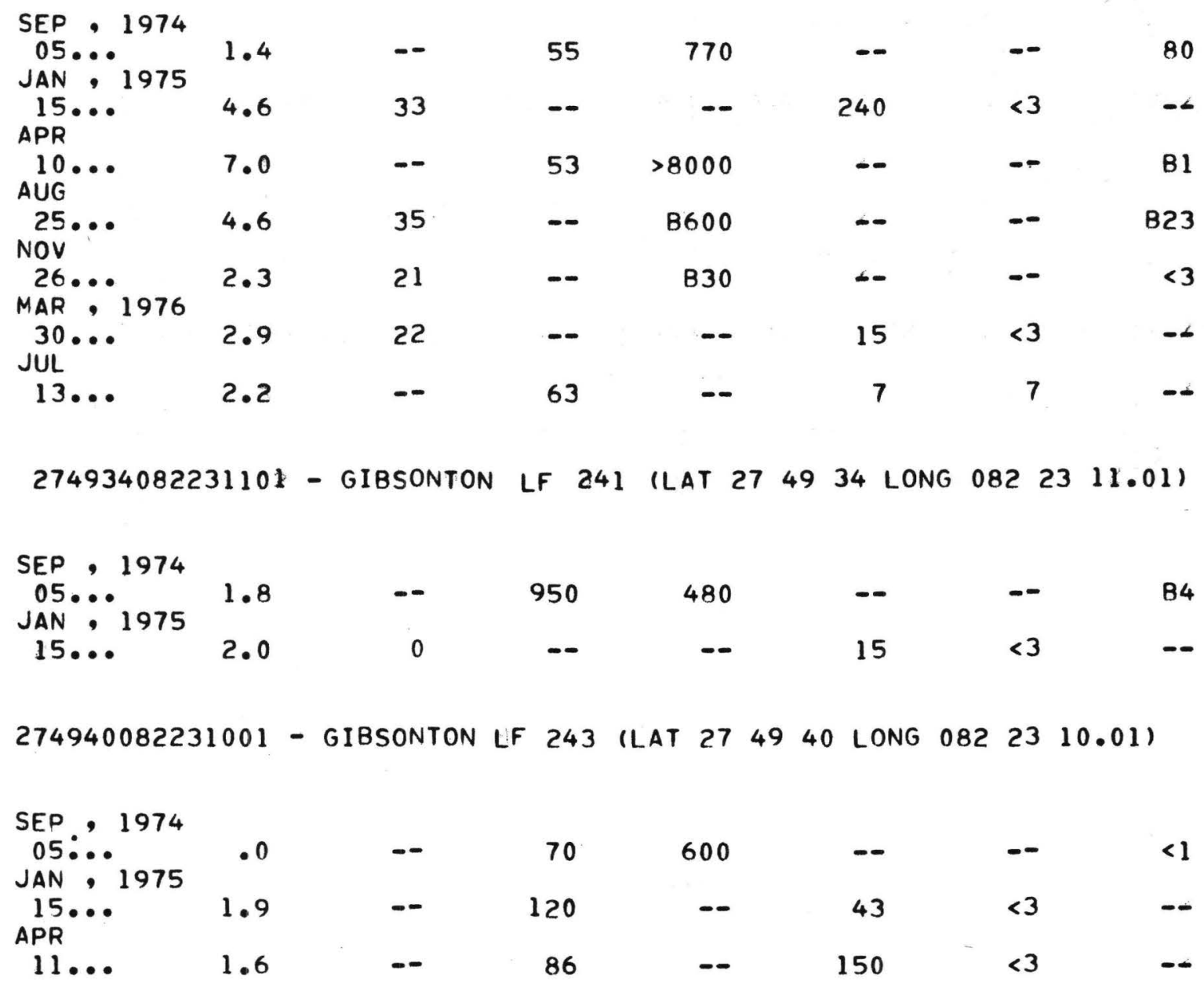


TABLE 5. CHEMICAL AND BACTERIOLOGICAL ANALYSES FOR GROUND- AND SURFACE-WATER SAMPLES FROM THE GIBSONTON LANDFILL - CONTINUED

\begin{tabular}{|c|c|c|c|c|c|c|c|}
\hline & $\begin{array}{l}\text { OXYGEN } \\
\text { DEMAND, } \\
\text { BIO- } \\
\text { CHEM- } \\
\text { ICAL, } \\
5 \text { DAY }\end{array}$ & $\begin{array}{l}\text { OXYGEN } \\
\text { DEMAND, } \\
\text { CHEM- } \\
\text { ICAL } \\
\text { (LOW } \\
\text { LEVEL) }\end{array}$ & $\begin{array}{l}\text { OXYGEN } \\
\text { DEMAND, } \\
\text { CHEM- } \\
\text { ICAL } \\
\text { (HIGH } \\
\text { LEVEL) }\end{array}$ & $\begin{array}{l}\text { COL I- } \\
\text { FORM, } \\
\text { TOTAL, } \\
\text { IMMED. } \\
\text { ICOLS. } \\
\text { PER }\end{array}$ & $\begin{array}{l}\text { COL I- } \\
\text { FORM, } \\
\text { CON- } \\
\text { F IRMED }\end{array}$ & $\begin{array}{l}\text { COLI- } \\
\text { FORM, } \\
\text { FECAL, } \\
\text { EC } \\
\text { BROTH }\end{array}$ & $\begin{array}{l}\text { COLI- } \\
\text { FORM, } \\
\text { FECAL } \\
0.45 \\
\text { UM-MF } \\
\text { (COLS. }\end{array}$ \\
\hline & $\begin{array}{l}(M G / L) \\
(00310)\end{array}$ & $\begin{array}{l}(M G / L) \\
(00335)\end{array}$ & $\begin{array}{l}(M G / L) \\
(00340)\end{array}$ & $\begin{array}{l}100 \mathrm{ML}) \\
(31501)\end{array}$ & $\begin{array}{c}(M P N) \\
(31505)\end{array}$ & $\begin{array}{c}\text { (MPN) } \\
(31615)\end{array}$ & $\begin{array}{l}100 \mathrm{ML}) \\
(31616)\end{array}$ \\
\hline
\end{tabular}

274935082230401 - GIBSONTON LF 244 WARD (LAT 274935 LONG 0822304.01 )

SEP , 1974

JAN 051975

$15 \ldots$

APR

$10 \ldots$

AUG

$25 . .$.

NOV

MAR: 1976

$31 \cdots 1977$

$01 \ldots$

$2.4 \quad--$

87

24

2700

$-$

130

$2.5 \quad 24$

130

--

BI

$.8 \quad-$

130

$-$

$<3$

--

$3.4 \quad 25$

-- 700

--

140

$2.6 \quad--$

67

1000

$--$

B4

1.630

$-11000$

150

3.2 -.

90

- 240

43

274945082231500 - GIBSONTON LF PERIMETER DITCH (LAT 274945 LONG 08223 15)

AUG , 1975

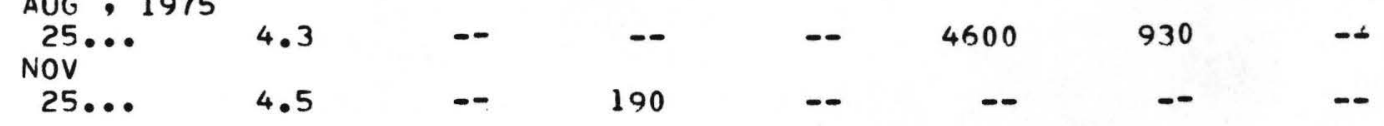

274955082231400 - GIBSONTON LF OXIDATION POND (LAT 274955 LONG 0822314 )

$\begin{array}{llllllll}\text { AUG } \\ 25 . .1975 & 9.0 & -- & -- & -- & 23 & 4 & - \\ \text { NOV } & 9.0 & & & & & & \\ 25 . . & >9.8 & -- & 300 & -- & -- & -- & -\end{array}$


TABLE 5. CHEMICAL AND BACTERIOLOGICAL ANALYSES FOR GROUND- AND SURFACE-WATER SAMPLES FROM THE GIBSONTON LANDF ILL - CONTINUED

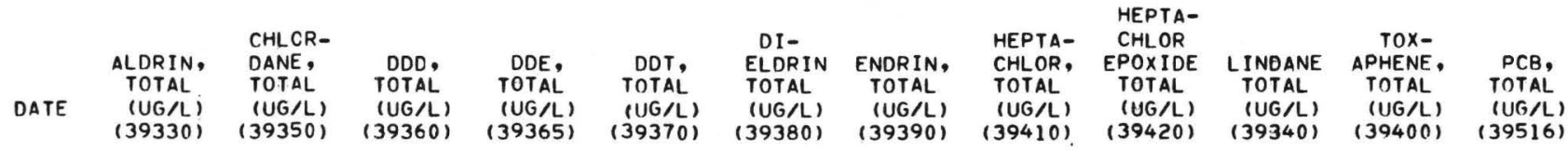

274952082231202 - GIBSONTON LF 223A (LAT 274952 LONG 08223 12.02)

OCT $\cdot 1976$

08 ....

.00

.0

.00

.00

.00

.00

.00

.00

.00

.00

0

.0

\begin{tabular}{|c|c|c|c|c|c|c|c|c|c|c|}
\hline DATE & $\begin{array}{c}\text { DI- } \\
\text { AZINON, } \\
\text { TOTAL } \\
(U G / L) \\
(39570)\end{array}$ & $\begin{array}{l}\text { ETHION, } \\
\text { TOTAL } \\
\text { (UG/L) } \\
(39398)\end{array}$ & $\begin{array}{l}\text { MALA- } \\
\text { THION, } \\
\text { TOTAL } \\
\text { (UG/L) } \\
(39530)\end{array}$ & $\begin{array}{l}\text { METHYL } \\
\text { PARA- } \\
\text { THION } \\
\text { TOTAL } \\
\text { (UG/L) } \\
(39600)\end{array}$ & $\begin{array}{l}\text { METHYL } \\
\text { TRI - } \\
\text { THION, } \\
\text { TOTAL } \\
\text { (UG/L) } \\
(39790)\end{array}$ & $\begin{array}{l}\text { PARA- } \\
\text { THION, } \\
\text { TOTAL } \\
\text { (UGAL) } \\
(39540)\end{array}$ & $\begin{array}{l}\text { TOTAL } \\
\text { TRI- } \\
\text { THION } \\
\text { (UG/L) } \\
(39786)\end{array}$ & $\begin{array}{l}2,4-D, \\
\text { TOTAL } \\
(U G / L) \\
(39730)\end{array}$ & $\begin{array}{c}2,4,5-T \\
\text { TOTAL } \\
\text { (UG/L) } \\
(39740)\end{array}$ & $\begin{array}{l}\text { SILVEX, } \\
\text { TOTAL } \\
\text { (UG/L) } \\
(39760)\end{array}$ \\
\hline
\end{tabular}

274952082231202 - GIBSONTON LF 223A (LAT 274952 LONG 08223 12.02)

OCT : 1976

08 ...

.00

.00

.00

.00

.00

.00

.00

.00

.00

.00 
TABLE 6. CHEMICAL AND BACTERIOLOGICAL ANALYSES FOR GROUND- AND SURFACE-WATER SAMPLES FROM THE RUSKIN LANDFILL

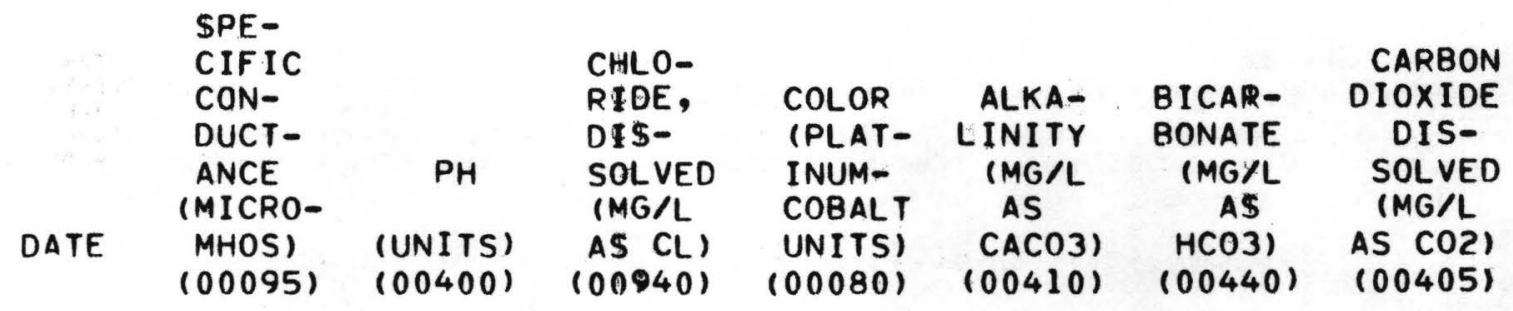

274353082255002 - RUSKIN LF 112 A (LAT 274353 LONG 0822550.02 )

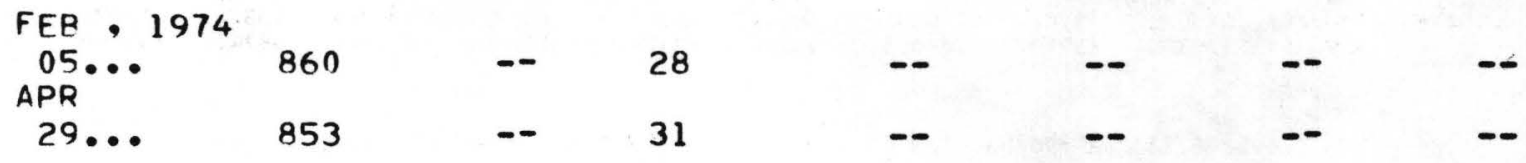

274352082255101 - RUSKIN LF 114 (LAT 274352 LONG 0822551.01 )

$\begin{array}{llll}\text { FER , 1974 } & & & \\ \text { O5... } & 850 & -- & 21 \\ \text { APR } & & & \\ 29 \ldots & 822 & -- & 22\end{array}$

274346082254201 - RUSKIN LF 123 (LAT 274346 LONG 0822542.01 )

\begin{tabular}{|c|c|c|c|c|c|c|c|}
\hline 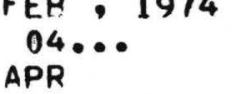 & 1500 & -- & 120 & -- & - & -- & -6 \\
\hline $\begin{array}{l}29 \cdots \cdots \\
\text { AUG } \because 1975\end{array}$ & 1450 & -- & 120 & -- & - & -- & -2 \\
\hline$\underset{O C T}{25}$ & 1380 & 7.4 & 210 & 13 & 295 & 360 & 22 \\
\hline MAR & 1100 & -- & 61 & - & - & -- & \\
\hline $30 \ldots$ & - & 7.5 & $\overline{-10}$ & -- & -- & $-\infty$ & - \\
\hline $\begin{array}{l}31 \bullet \cdots \\
J U N, 1977\end{array}$ & 5200 & -- & 170 & 8 & -- & $-\infty$ & \\
\hline $01 \ldots$ & 1180 & 7.4 & 70 & -- & -- & -- & \\
\hline
\end{tabular}


TABLE 6. CHEMICAL AND BACTERIOLOGICAL ANALYSES FOR GROUND- AND SURFACE-WATER SAMPLES FROM THE RUSKIN LANDFILL - CONTINUED

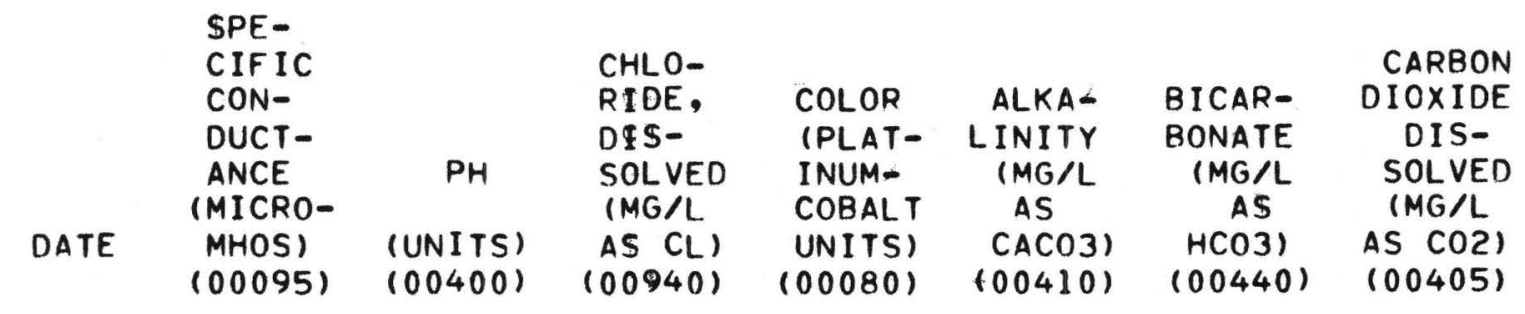

274345082255001 - RUSKIN LF 132 (LAT 274345 LONG 0822550.01 )

\begin{tabular}{|c|c|c|c|c|c|c|c|}
\hline $\begin{array}{l}\text { FEB , } 19.74 \\
\text { 05... } \\
\text { APR }\end{array}$ & 760 & -- & 24 & -- & - & -- & - \\
\hline $\begin{array}{l}29 \cdots \cdots \\
\text { JAN }: 1975\end{array}$ & 756 & -- & 26 & -- & -- & -- & - \\
\hline $\begin{array}{l}14 \\
A P R\end{array}$ & 755 & 7.6 & 27 & -- & -- & -- & $\cdots$ \\
\hline $\begin{array}{l}10 \\
A \cup G\end{array}$ & 700 & 7.7 & 25 & -- & - & -- & - \\
\hline $\begin{array}{l}25 \cdots \cdots \\
\text { OCT }\end{array}$ & 740 & 7.5 & 35 & 100 & 262 & 320 & 15 \\
\hline $\begin{array}{l}08 \cdots \cdots \\
\text { NOV }\end{array}$ & 790 & 7.5 & 29 & 5 & 262 & 320 & 13 \\
\hline 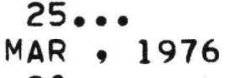 & 760 & 7.5 & 25 & 200 & 246 & 300 & 15 \\
\hline $30 \cdots \cdots$ & - & 7.7 & 21 & -- & -- & -- & $-\infty$ \\
\hline $\begin{array}{l}31 \cdots 1977 \\
\text { JUN } 197\end{array}$ & 680 & -- & 25 & 17 & -- & -- & \\
\hline $01 \ldots$ & 800 & 7.2 & 26 & -- & -- & -- & \\
\hline
\end{tabular}

274345082254001 - RUSKIN LF 141 WILLIS (LAT 274345 LONG 0822545.01 )

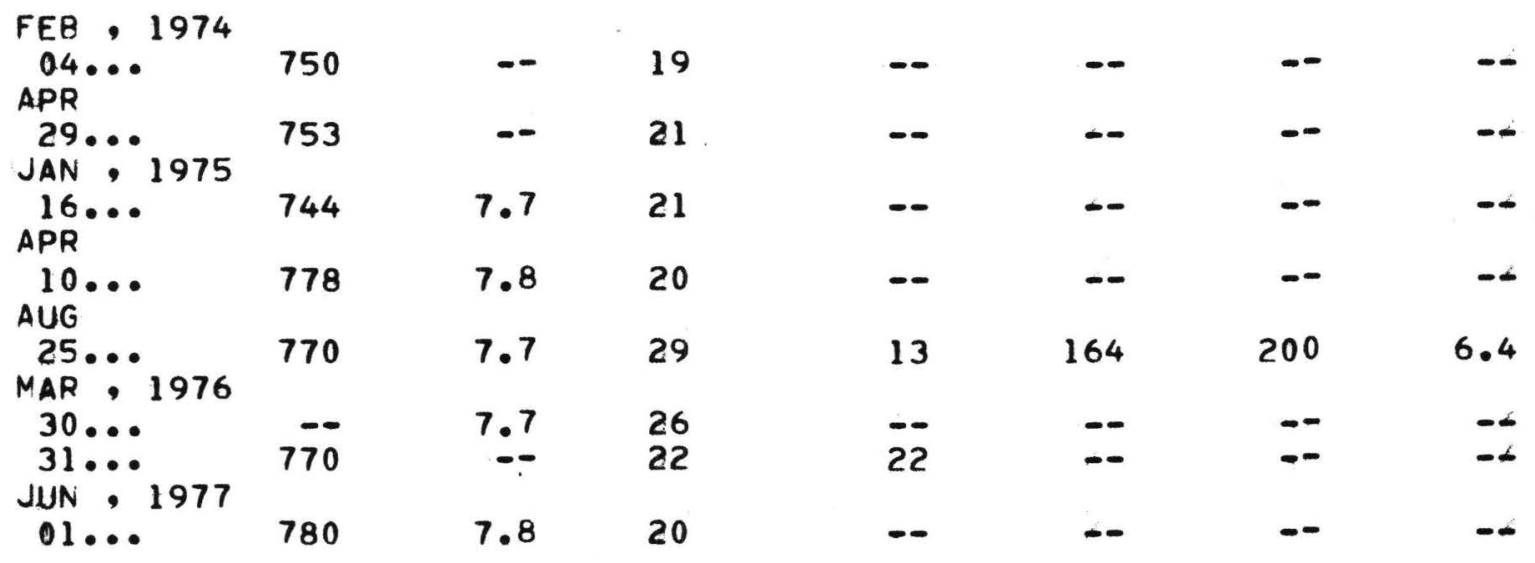


TABLE 6. CHEMICAL AND BACTERIOLOGICAL ANALYSES FOR GROUND- AND SURFACE-WATER SAMPLES FROM THE RUSKIN LANDFILL - CONTINUED

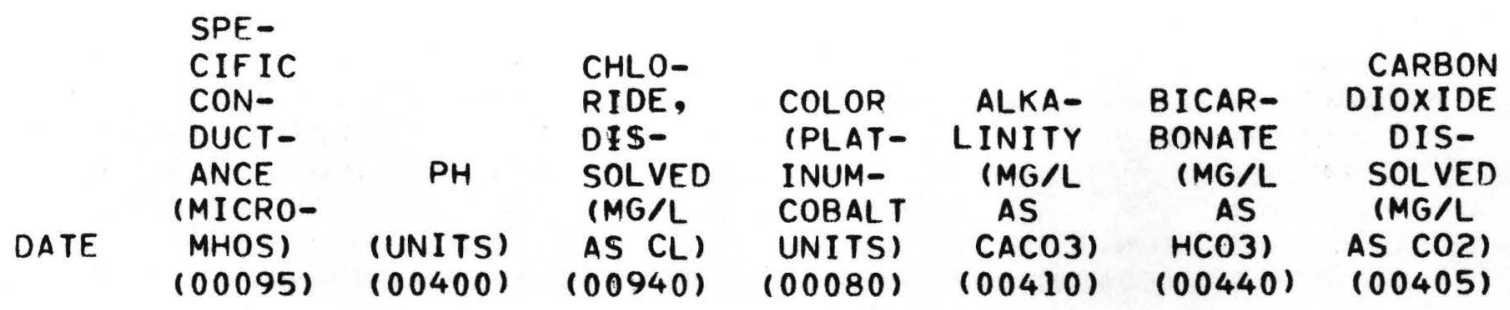

274353082255000 - RUSKIN LF OXIDATION POND (LAT 274353 LONG 0822550 )

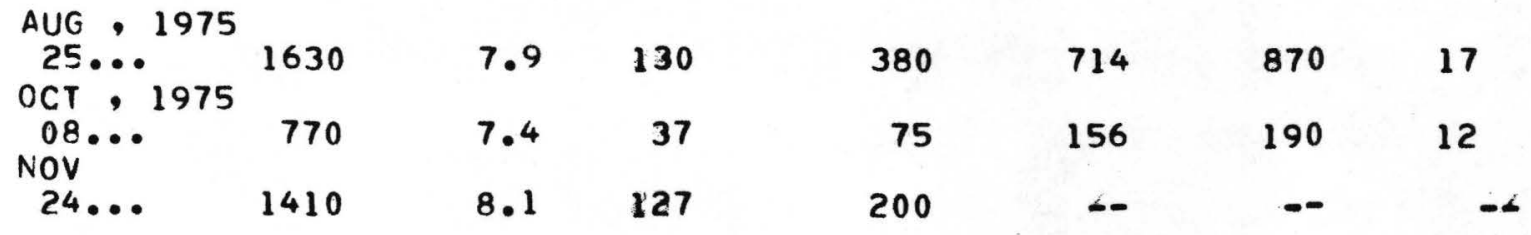


TABLE 6. CHEMICAL AND BACTERIOLOGICAL ANALYSES FOR GROUND- AND SURFACE-WATER SAMPLES FROM THE RUSKIN LANDFILL - CONTINUED

\begin{tabular}{|c|c|c|c|c|c|c|c|}
\hline & $\begin{array}{l}\text { CALCIUM } \\
\text { DIS- } \\
\text { SOLVED } \\
\text { (MG/L }\end{array}$ & $\begin{array}{l}\text { MAGNE- } \\
\text { SIUM, } \\
\text { DIS- } \\
\text { SOLVED } \\
\text { (MG/L }\end{array}$ & $\begin{array}{l}\text { SODIUM, } \\
\text { DIS- } \\
\text { SOLVED } \\
\text { (MG/L }\end{array}$ & $\begin{array}{l}\text { POTAS- } \\
\text { SIUM, } \\
\text { DIS- } \\
\text { SOLVED } \\
\text { IMG/L. }\end{array}$ & $\begin{array}{l}\text { SODIUM } \\
\text { AD- } \\
\text { SORP- } \\
\text { TION } \\
\text { RATIO }\end{array}$ & $\begin{array}{l}\text { HARD - } \\
\text { NESS } \\
\text { (MG/L } \\
\text { AS }\end{array}$ & $\begin{array}{l}\text { HARD- } \\
\text { NESS, } \\
\text { NONCAR- } \\
\text { BONATE } \\
\text { (MG/L }\end{array}$ \\
\hline & $\begin{array}{l}\text { AS CA) } \\
(00915)\end{array}$ & $\begin{array}{l}\text { AS MG) } \\
(00925)\end{array}$ & $\begin{array}{l}\text { AS NA) } \\
(00930)\end{array}$ & $\begin{array}{l}\text { AS K) } \\
(00935)\end{array}$ & $(00931)$ & $\begin{array}{r}\text { (ACO3) } \\
(00900)\end{array}$ & $\begin{array}{l}\text { (AC03) } \\
(00902)\end{array}$ \\
\hline
\end{tabular}

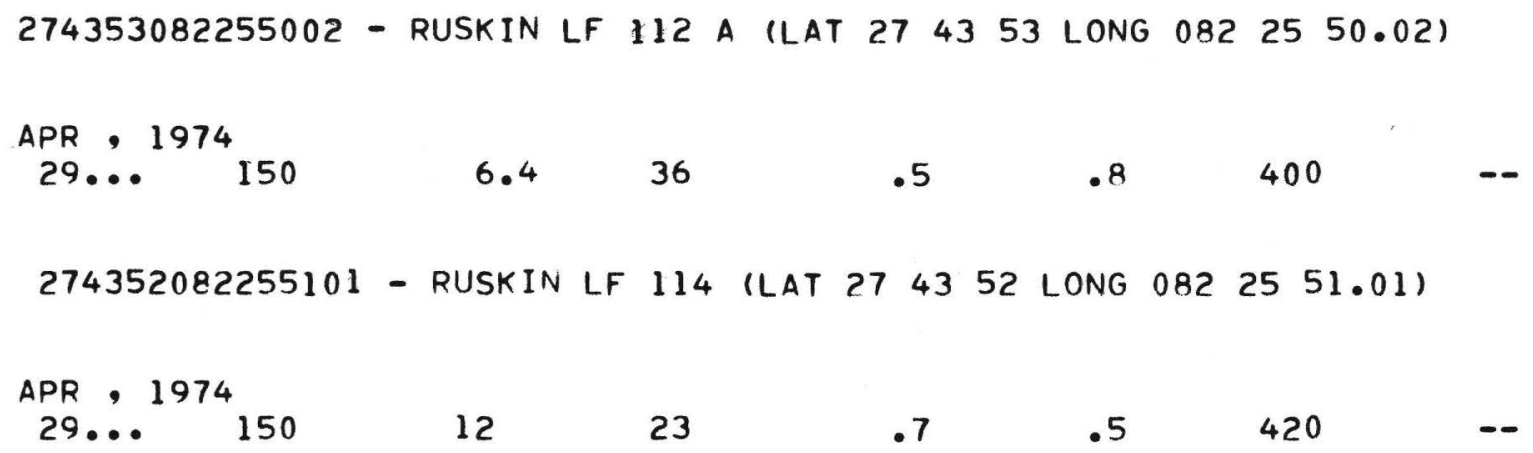

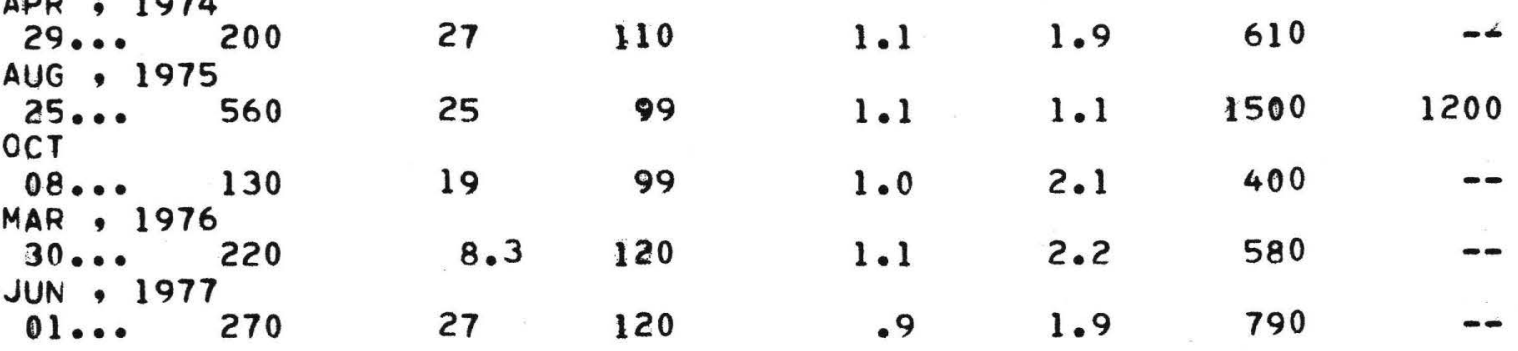


TABLE 6. CHEMICAL AND BACTERIOLOGICAL ANALYSES FOR GROUND- AND SURFACE-WATER SAMPLES FROM THE RUSKIN LANDFILL - CONTINUED

\begin{tabular}{|c|c|c|c|c|c|c|c|}
\hline & $\begin{array}{l}\text { CALCIUM } \\
\text { DIS- } \\
\text { SOLVED } \\
\text { (MG/L }\end{array}$ & $\begin{array}{l}\text { MAGNE- } \\
\text { SIUM, } \\
\text { DIS- } \\
\text { SOLVED } \\
\text { (MG/L }\end{array}$ & $\begin{array}{l}\text { SOOIUM, } \\
\text { DIS- } \\
\text { SOLVED } \\
\text { (MG/L }\end{array}$ & $\begin{array}{l}\text { POTAS- } \\
\text { SIUM, } \\
\text { DIS- } \\
\text { SOLVED } \\
\text { (MG/L }\end{array}$ & $\begin{array}{l}\text { SODIUM } \\
\text { AD- } \\
\text { SORP } \\
\text { TION } \\
\text { RATIO }\end{array}$ & $\begin{array}{l}\text { HARD - } \\
\text { NESS } \\
\text { IMG/L } \\
\text { AS }\end{array}$ & $\begin{array}{l}\text { HARD- } \\
\text { NESS, } \\
\text { NONCAR } \\
\text { BONATE } \\
\text { (MG/L }\end{array}$ \\
\hline & $\begin{array}{l}\text { AS CA) } \\
(00915)\end{array}$ & $\begin{array}{r}\text { AS MG }) \\
(00925)\end{array}$ & $\begin{array}{l}\text { AS NA) } \\
(00930)\end{array}$ & $\begin{array}{c}\text { AS K) } \\
(00935)\end{array}$ & $(00931)$ & $\begin{array}{r}(A C 03) \\
(00900)\end{array}$ & $\begin{array}{r}\text { (ACO3) } \\
(00902)\end{array}$ \\
\hline
\end{tabular}

274345082255001 - RUSKIN LF 132 (LAT 274345 LONG 0822550.01 )

\begin{tabular}{|c|c|c|c|c|c|c|c|}
\hline $\begin{array}{l}29 . \\
\text { JAN }\end{array}$ & 120 & 27 & 26 & .6 & .6 & 410 & -- \\
\hline$\underset{A P R}{14}$ & 110 & 20 & 28 & .5 & .6 & 360 & -- \\
\hline$\underset{A \cup G}{10} \bullet$ & 110 & 25 & 27 & .4 & .6 & 380 & \\
\hline $\begin{array}{l}25 \\
\text { OCT }\end{array}$ & 100 & 22 & 26 & .6 & .6 & 340 & 77 \\
\hline $\begin{array}{l}\text { O8.. } \\
\text { NOV }\end{array}$ & 110 & 22 & 28 & .7 & $\cdot 6$ & 370 & 110 \\
\hline $\begin{array}{l}25 . . \\
\text { MAR }\end{array}$ & 110 & 23 & 26 & .7 & .6 & 370 & 120 \\
\hline $\begin{array}{l}30 \ldots \\
\text { JUN }\end{array}$ & 110 & 24 & 28 & .5 & 1.1 & 130 & \\
\hline $01 \ldots$ & 110 & 25 & 28 & .5 & .6 & 380 & \\
\hline
\end{tabular}

. 274345082254001 - RUSKIN LF 141 WILLIS (LAT 274345 LONG 082 25*45.01)

\begin{tabular}{|c|c|c|c|c|c|c|}
\hline $\begin{array}{l}A P R \cdot 1974 \\
29 \ldots \ldots \\
\end{array}$ & 90 & 43 & 16 & 2.5 & .3 & 400 \\
\hline $16 \ldots$ & 87 & 35 & 15 & 2.3 & .3 & 360 \\
\hline $\begin{array}{l}10 \\
\text { AUG }\end{array}$ & 88 & 41 & 15 & 2.2 & $\cdot 3$ & 390 \\
\hline $\begin{array}{l}25 \cdots \cdots \\
\text { MAR } 1976\end{array}$ & 90 & 43 & 15 & $2 \cdot 2$ & .3 & 400 \\
\hline $\begin{array}{l}30 \cdots \\
\text { JUN }: 1977\end{array}$ & 90 & 42 & 16 & 2.2 & .3 & 400 \\
\hline $01 \ldots$ & 97 & 43 & 15 & 2.3 & .3 & 420 \\
\hline
\end{tabular}

274353082255000 - RUSKIN LF OXIDATION POND (LAT 274353 LONG 0822550 )

$$
\text { AUG, } 1975
$$

$25 \ldots 180$

29

80

67

1.5

570 
TABLE 6. CHEMICAL AND BACTERIOLOGICAL ANALYSES FOR GROUND- AND SURFACE-WATER SAMPLES, FROM THE RUSK\$N LANDFILL - CONTINUED

\begin{tabular}{|c|c|c|c|c|c|c|c|c|c|c|}
\hline & $\begin{array}{l}\text { NITRO- } \\
\text { GEN } \\
\text { ORGANIC } \\
\text { TOTAL } \\
\text { IMGAL }\end{array}$ & $\begin{array}{l}\text { NITRO- } \\
\text { GEN, } \\
\text { AMMONIA } \\
\text { DIS- } \\
\text { SOLVEO } \\
\text { IMG/L }\end{array}$ & $\begin{array}{l}\text { NITRO- } \\
\text { GEN, } \\
\text { AMMONIA } \\
\text { TOTAL } \\
\text { (MG/L }\end{array}$ & $\begin{array}{l}\text { NITRO- } \\
\text { GEN, } \\
\text { NITRITE } \\
\text { DIS- } \\
\text { SOLVED } \\
\text { (MG/L }\end{array}$ & $\begin{array}{l}\text { NITRO- } \\
\text { GEN, } \\
\text { NITRITE } \\
\text { TOTAL } \\
\text { IMG/L }\end{array}$ & $\begin{array}{l}\text { NITRO- } \\
\text { GEN, } \\
\text { NITRATE } \\
\text { DIS- } \\
\text { SOLVED } \\
\text { IMGKL }\end{array}$ & $\begin{array}{l}\text { NITRO- } \\
\text { GEN, } \\
\text { NITRATE } \\
\text { TOTAL } \\
\text { IMG/L }\end{array}$ & $\begin{array}{l}\text { PHOS- } \\
\text { PHORUS, } \\
\text { TOTAL } \\
\text { IMG/L }\end{array}$ & $\begin{array}{l}\text { PHOS- } \\
\text { PHORUS, } \\
\text { DIS- } \\
\text { SOLVED } \\
\text { IMG/L }\end{array}$ & $\begin{array}{l}\text { PHOS- } \\
\text { PHORUS, } \\
\text { ORTHO, } \\
\text { DIS- } \\
\text { SOLVED } \\
\text { IMG/L }\end{array}$ \\
\hline & $\begin{array}{c}\text { AS N) } \\
(00605)\end{array}$ & $\begin{array}{l}\text { AS N) } \\
(00608)\end{array}$ & $\begin{array}{l}\text { AS N) } \\
(00610)\end{array}$ & $\begin{array}{l}\text { AS N) } \\
(00613)\end{array}$ & $\begin{array}{l}\text { AS N) } \\
(00615)\end{array}$ & $\begin{array}{l}\text { AS N) } \\
(00618)\end{array}$ & $\begin{array}{c}\text { AS N) } \\
(00620)\end{array}$ & $\begin{array}{c}\text { AS P) } \\
(00665)\end{array}$ & $\begin{array}{l}\text { AS P) } \\
(00666)\end{array}$ & $\begin{array}{c}\text { AS P) } \\
(00671)\end{array}$ \\
\hline
\end{tabular}

274346082254201 - RUSKIN LF 123 (LAT 274346 LONG 0822542.01 )

AUG , 1975

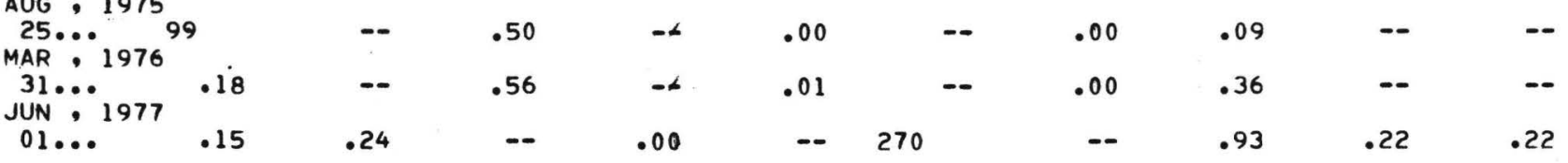

274345082255001 - RUSKIN LF 132 (LAT 274345 LONG 0822550.01 )

\begin{tabular}{|c|c|c|c|c|c|c|c|c|c|c|}
\hline $\begin{array}{l}\text { JAN } 1974 \\
14 \ldots . \cdots \\
\end{array}$ & .30 & .09 & -- & .00 & -- & .00 & -- & .05 & .00 & .00 \\
\hline AUG $10 . .$. & .24 & .33 & -- & .01 & -- & .00 & -- & .48 & .13 & .13 \\
\hline OCT & .40 & -- & .25 & -6 & .01 & -- & .00 & .34 & -- & -- \\
\hline $\begin{array}{l}08 . . . \\
\text { NOV }\end{array}$ & -- & -- & -- & -6 & .01 & $\cdots$ & .00 & -- & -- & -- \\
\hline MAR $25 . \cdots 1976$ & .40 & .10 & -- & .00 & -- & .03 & -- & .87 & .03 & .01 \\
\hline JUN 1977 & .78 & -- & .08 & -6 & .00 & -- & .00 & .08 & -- & -- \\
\hline $01 \ldots$ & .36 & .03 & -- & .00 & $-\infty$ & 220 & - & .37 & .34 & . 34 \\
\hline
\end{tabular}


TABLE 6. CHEMICAL AND BACTERIOLOGICAL ANALYSES FOR GROUND- AND SURFACE-WATER SAMPLES FROM THE RUSKIN LANDFILL - CONTINUED

\begin{tabular}{|c|c|c|c|c|c|c|c|c|c|c|}
\hline & $\begin{array}{l}\text { NITRO- } \\
\text { GEN, } \\
\text { ORGANIC } \\
\text { TOTAL } \\
\text { (MG/L }\end{array}$ & $\begin{array}{l}\text { NITRO- } \\
\text { GEN, } \\
\text { AMMONIA } \\
\text { OIS- } \\
\text { SOLVED } \\
\text { IMG/L }\end{array}$ & $\begin{array}{l}\text { NITRO- } \\
\text { GEN, } \\
\text { AMMONIA } \\
\text { TOTAL } \\
\text { (MG/L }\end{array}$ & $\begin{array}{l}\text { NITROL } \\
\text { GEN, } \\
\text { NI TRITE } \\
\text { DIS- } \\
\text { SOLVEO } \\
\text { (MG/L }\end{array}$ & $\begin{array}{l}\text { NITRO- } \\
\text { GEN, } \\
\text { NITRI TE } \\
\text { TOTAL } \\
\text { (MG/L }\end{array}$ & $\begin{array}{l}\text { NITRO- } \\
\text { GEN, } \\
\text { NITRATE } \\
\text { DIS- } \\
\text { SOLVED } \\
\text { (MG/L }\end{array}$ & $\begin{array}{l}\text { NITRO- } \\
\text { GEN, } \\
\text { NITRATE } \\
\text { TOTAL } \\
\text { (MG/L }\end{array}$ & $\begin{array}{l}\text { PHOS- } \\
\text { PHORUS, } \\
\text { TOTAL } \\
\text { (MG/L }\end{array}$ & $\begin{array}{l}\text { PHOS- } \\
\text { PHORUS, } \\
\text { DIS- } \\
\text { SOLVED } \\
\text { (MG/L }\end{array}$ & $\begin{array}{l}\text { PHOS- } \\
\text { PHORUS, } \\
\text { ORTHO, } \\
\text { DIS- } \\
\text { SOLVED } \\
\text { IMG/L }\end{array}$ \\
\hline & $\begin{array}{c}\text { AS N) } \\
(00605)\end{array}$ & $\begin{array}{l}\text { AS N) } \\
(00608)\end{array}$ & $\begin{array}{l}\text { AS N) } \\
(00610)\end{array}$ & $\begin{array}{l}\text { AS N) } \\
(00613)\end{array}$ & $\begin{array}{l}\text { AS N) } \\
(00615)\end{array}$ & $\begin{array}{l}\text { AS N) } \\
(00618)\end{array}$ & $\begin{array}{l}\text { AS N) } \\
(00620)\end{array}$ & $\begin{array}{c}\text { AS P) } \\
(00665)\end{array}$ & $\begin{array}{l}\text { AS P) } \\
(00666)\end{array}$ & $\begin{array}{c}\text { AS P) } \\
(00671)\end{array}$ \\
\hline
\end{tabular}

274345082254001 - RUSKIN LF 141 WILLIS (LAT 274345 LONG 0822545.01 )

\begin{tabular}{|c|c|c|c|c|c|c|c|c|c|c|}
\hline $14 \ldots \ldots$ & .14 & .34 & -- & .00 & -- & .00 & -- & .00 & .00 & .00 \\
\hline $10 \ldots$ & .14 & .32 & -- & .00 & -- & .00 & - & .02 & .01 & .00 \\
\hline 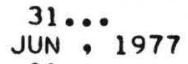 & .13 & -- & .33 & -6 & .00 & $-\infty$ & .00 & .02 & - & -- \\
\hline $01 \ldots$ & .00 & -- & .26 & $-\alpha$ & .00 & - & .00 & .01 & $-\infty$ & -- \\
\hline
\end{tabular}

274353082255000 - RUSKIN LF OXIDATION POND (LAT 274353 LONG 0822550 )

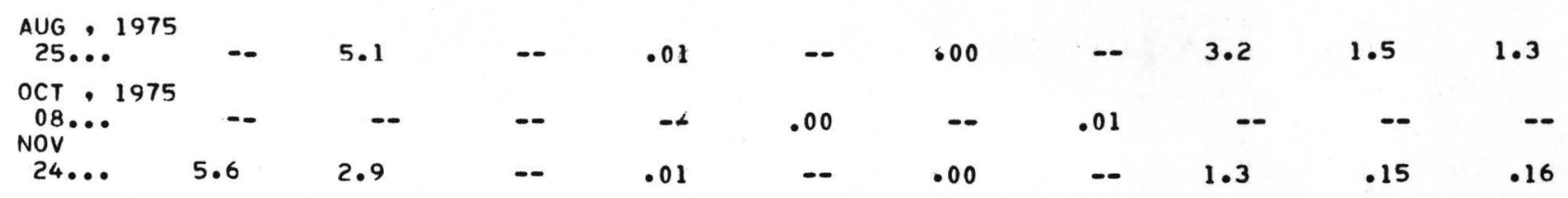


TABLE 6. CHEMICAL AND BACTERIOLOGICAL ANALYSES FOR GROUND- AND SURFACE-WATER SAMPLES FROM THE RUSKIN LANDF ILL - CONTINUED

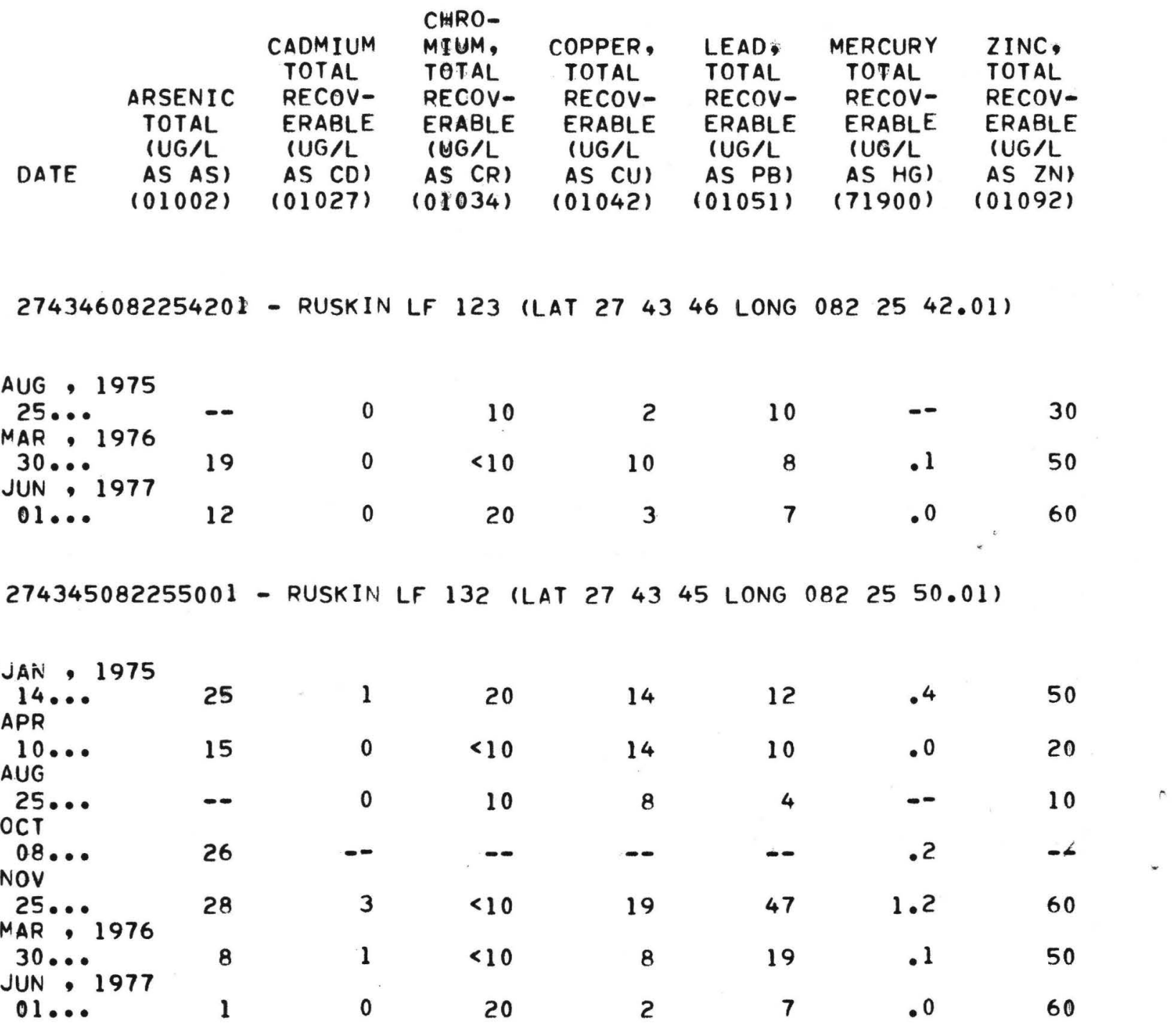


TABLE 6. CHEMICAL AND BACTERIOLOGICAL ANALYSES FOR GROUND- AND SURFACE-WATER SAMPLES FROM THE RUSKIN LANDFILL - CONTINUED

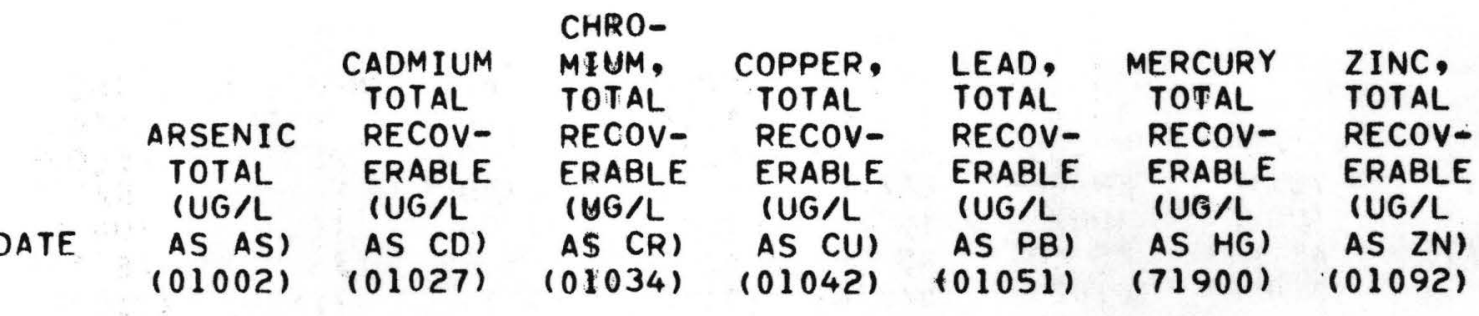

274345082254001 - RUSKIN LF 141 WILLIS (LAT 274345 LONG 0822545.01 )

\begin{tabular}{|c|c|c|c|c|c|c|c|}
\hline $16 \ldots$ & 0 & 0 & $<10$ & 7 & 0 & .0 & 380 \\
\hline $\begin{array}{l}10 \\
A \cup G\end{array}$ & $\begin{array}{r}0 \\
+\quad\end{array}$ & 0 & $<10$ & 18 & 8 & .0 & 330 \\
\hline $\begin{array}{l}25 \cdots \cdots \\
\text { MAR } 1976\end{array}$ & -- & 0 & $<10$ & 1300 & 3 & -- & 240 \\
\hline $\begin{array}{l}30 \cdots \cdots \\
\text { JUN } 1977\end{array}$ & 1 & 0 & $<10$ & 250 & 4 & $\cdot 1$ & 250 \\
\hline $01 \ldots$ & 32 & 0 & 10 & 4 & 10 & .0 & 260 \\
\hline
\end{tabular}

274353082255000 - RUSKIN LF OXIDATION POND (LAT 274353 LONG 0822550 )

AUG, 1975

25...

$\begin{array}{ccccccc}\text { OCT, } 1975 & & & & & \\ 08 . . . & 8 & - & - & - & - & 0\end{array}$ 
TABLE 6. CHEMICAL AND BACTERIOUOGICAL ANALYSES FOR GROUND- AND SURFACE-WATER SAMPLES FROM THE RUSKIN LANDFILL - CONTINUED

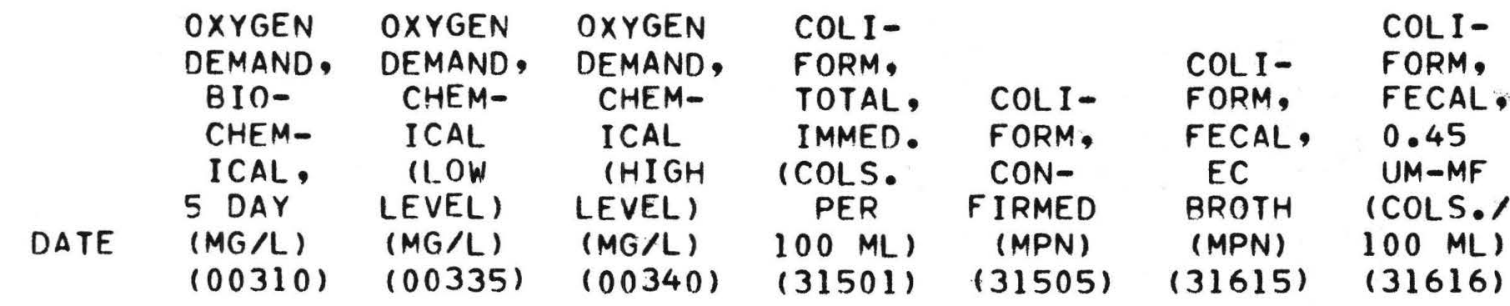

274346082254201 - RUSKIN LF 123 (LAT 274346 LONG 0822542.01 )

\begin{tabular}{|c|c|c|c|c|c|c|}
\hline $\begin{array}{l}25 \cdots 1976 \\
\text { MAR }, 1970\end{array}$ & .9 & 13 & -- & $<1$ & -- & -- \\
\hline $\begin{array}{l}31 \cdots \\
\text { JUN }, 1977\end{array}$ & .6 & 19 & -- & -- & 460 & $<3$ \\
\hline $01 \ldots$ & .9 & -- & 24 & -- & 9 & $<3$ \\
\hline
\end{tabular}

274345082255001 - RUSKIN LF 132 (LAT 274345 LONG 0822550.01 )

\begin{tabular}{|c|c|c|c|c|c|c|c|}
\hline $\begin{array}{l}14 \cdots \cdots 1975 \\
\text { APR } 1970\end{array}$ & 1.3 & 18 & -- & B16 & - & -- & $<1$ \\
\hline$\underset{A \cup G}{10} \ldots$ & 1.1 & -- & 18 & -- & 390 & $<3$ & - \\
\hline${ }_{\text {CCT }}^{25} \cdots$ & .8 & 11 & -- & $<1$ & -- & -- & $<1$ \\
\hline $\begin{array}{l}08 \cdots \cdots \\
\text { NOV }\end{array}$ & - 9 & -- & -- & - & 93 & 23 & -- \\
\hline 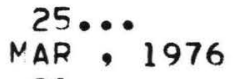 & 2.8 & -- & 22 & -- & 23 & 23 & -- \\
\hline $\begin{array}{l}31 \cdots \cdots \\
\text { JUN } 1977\end{array}$ & .5 & 9 & $-\infty$ & -- & 240 & $<3$ & $-\alpha$ \\
\hline $01 \ldots$ & .5 & 7 & -- & -- & 43 & $<3$ & \\
\hline
\end{tabular}


TABLE 6. CHEMICAL AND BACTERIOLOGICAL ANALYSES FOR GROUND- AND SURFACE-WATER SAMPLES FROM THE RUSKIN LANDFILL - CONTINUED

$\begin{array}{ccccccc}\text { OXYGEN } & \text { OXYGEN } & \text { OXYGEN } & \text { COLI- } & & & \text { COLI- } \\ \text { DEMAND, } & \text { DEMAND, } & \text { DEMAND, } & \text { FORM, } & & \text { COLI- } & \text { FORM, } \\ \text { BIO- } & \text { CHEM- } & \text { CHEM- } & \text { TOTAL, } & \text { COLI- } & \text { FORM, } & \text { FECAL, } \\ \text { CHEM- } & \text { ICAL } & \text { ICAL } & \text { IMMED. } & \text { FORM, } & \text { FECAL, } & 0.45 \\ \text { ICAL, } & \text { (LOW } & \text { (HIGH } & \text { (COLS. } & \text { CON- } & \text { EC } & \text { UM-MF } \\ 5 \text { DAY } & \text { LEVEL) } & \text { LEVEL) } & \text { PER } & \text { FIRMED } & \text { BROTH } & (\text { COLS.) } \\ (M G / L) & (M G / L) & (M G / L) & 100 M L) & \text { (MPN) } & \text { (MPN) } & 100 \text { ML) } \\ (00310) & (00335) & (00340) & (31501) & (31505) & (31615) & (31616)\end{array}$

274345082254001 - RUSKIN LF 141 WILLIS (LAT 274345 LONG O82 2545.01 )

\begin{tabular}{|c|c|c|c|c|c|c|}
\hline APR & 2.0 & 9 & -- & $<1$ & -- & -- \\
\hline $\begin{array}{l}10 \cdots \\
A \cup G\end{array}$ & .9 & -- & 21 & 83 & $\cdots$ & -- \\
\hline $\begin{array}{l}25 \cdots 1976 \\
\text { MAR } 1970\end{array}$ & 2.0 & 12 & -- & $<1$ & -- & -- \\
\hline $\begin{array}{l}31 \cdots 1 \\
\text { JUN } 1977\end{array}$ & .6 & 12 & -- & -- & $<3$ & $<3$ \\
\hline
\end{tabular}

274353082255000 - RUSKIN LF OXIDATION POND (LAT 274353 LONG 0822550 )

AUG, 1975

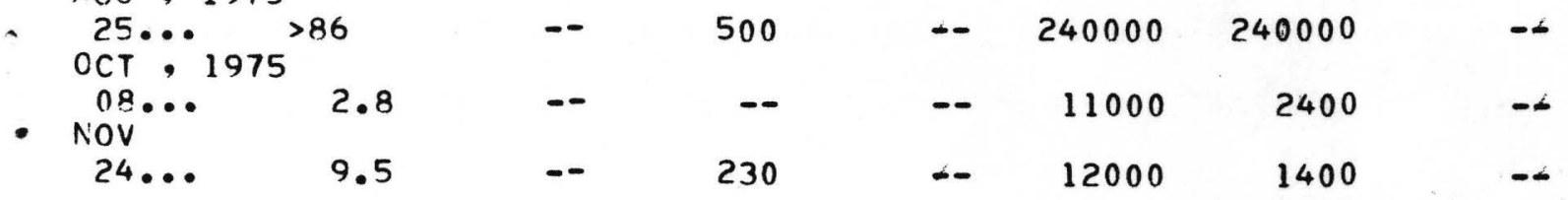

